\title{
LANDSLIDE HAZARD ASSESSMENT
}

\author{
DISSERTATION
}

\author{
Presented in Partial Fulfillment of the Requirements for \\ the Degree Doctor of Philosophy in the Graduate \\ School of The Ohio State University
}

By

M. A. ABDEL-LATIF, B.Sc., M.Sc.

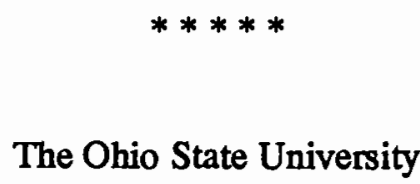

1994

Dissertation Committee:

Approved by

PROF. T. H. Wu

PROF. W. E. Wolfe

PROF. F. C. Hadipriono

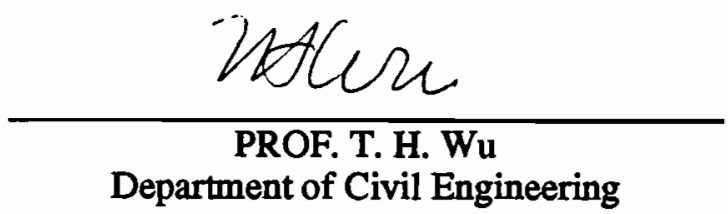




\section{DEDICATION}

To my family. 


\section{ACKNOWLEDGEMENTS}

I would like to thank most my adviser, Professor T. H. Wu, for his support, guidance and many helpful discussions.

Special gratitude and sincere regards are extended to Professor W. E. Wolfe and Professor F. C. Hadipriono for their valuable suggestions and advice.

Finally, greatest sincere, thanks, and appreciation go to my family for their love, support, understanding, and encouragement without which this study would never have been completed. 


\section{VITA}

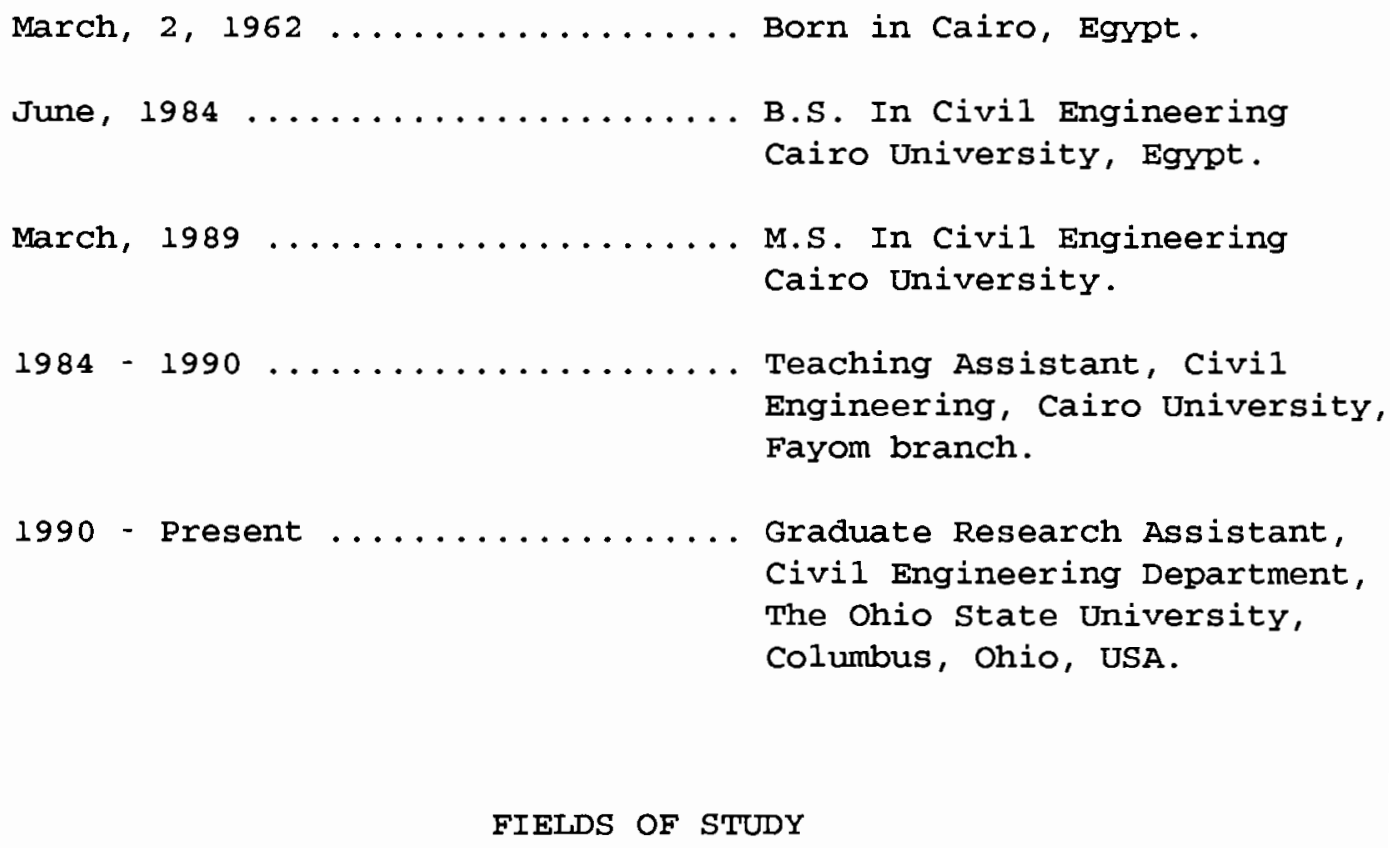

FIELDS OF STUDY

Major Field : Civil Engineering. Geotechnical Engineering ........ Prof. T.H. Wu :Prof. W.E. Wolfe :Prof. C.A. Moore :Prof. R.S. Sandhu

Minor Field : Statistics $\ldots \ldots \ldots \ldots \ldots \ldots$ : Prof. W. Notz :Prof. D. Wolfe 


\section{TABLE OF CONTENTS}

PAGE

DEDICATION $\ldots \ldots \ldots \ldots \ldots \ldots \ldots \ldots \ldots \ldots \ldots$ ii

ACKNOWLEDGEMENTS $\ldots \ldots \ldots \ldots \ldots \ldots \ldots$ iii

VITA $\ldots \ldots \ldots \ldots \ldots \ldots \ldots \ldots \ldots \ldots \ldots \ldots$ iv

LIST OF FIGURES $\ldots \ldots \ldots \ldots \ldots \ldots \ldots$ vii

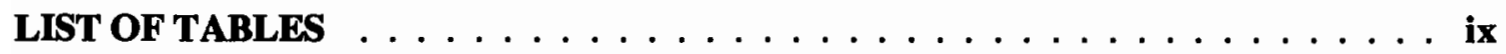

\section{CHAPTER}

I. INTRODUCTION $\ldots \ldots \ldots \ldots \ldots \ldots \ldots \ldots \ldots$

1.1 Objective and Scope $\ldots \ldots \ldots \ldots \ldots \ldots$

II. LITERATURE REVIEW $\ldots \ldots \ldots \ldots \ldots \ldots$

2.1 Groundwater . . . . . . . . . . . . . . 5

2.1.1 Solutions of Groundwater Flow Through Soil . . . . . . 5

2.1.1.1 General . . . . . . . . . . . . . . 5 5

2.1.1.2 Numerical Solutions . . . . . . . . . . . 6

2.1.1.3 Simplified Solutions . . . . . . . . . . 7

2.1.2 Pervious Inclusions $\ldots \ldots \ldots \ldots \ldots$

2.1 .3 Fracture Flow . . . . . . . . . . . . 11

2.2 Stability Analyses of Slopes $\ldots \ldots \ldots \ldots \ldots \ldots$

2.3 Uncertainties . . . . . . . . . . . . . . . . . . 19

2.3.1 Types of Uncertainties . . . . . . . . . . . . . . . . . 19

2.3.1.1 Systematic Uncertainty . . . . . . . . . . . . 19

2.3.1.2 Spatial Variability . . . . . . . . . . 20 
2.3.2 Analyses of Uncertainty . . . . . . . . . . . . . 23

2.3.2.1 Introduction . . . . . . . . . . . 23

2.3.2.2 Probabilistic Analysis of groundwater . . . . . . . 25

2.3.2.3 Probabilistic Analysis of slope stability . . . . . . 26 26

2.3.3 Model parameters . . . . . . . . . . . . . . . . . 29

2.3.3.1 Groundwater parameters . . . . . . . . . . . . . 29

2.3.3.2 Shear Strength parameters . . . . . . . . . . 30 30

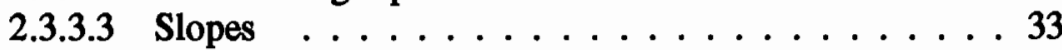

2.4 Bayesian Updating $\ldots \ldots \ldots \ldots \ldots \ldots$

III. MODEL OF SITE CONDITIONS $\ldots \ldots \ldots \ldots \ldots \ldots$

3.1 Sources of Information $\ldots \ldots \ldots \ldots \ldots \ldots$

3.2 Site Conditions . . . . . . . . . . . . . . 46

3.2.1 Regional Site Conditions . . . . . . . . . . . . 46

3.2.2 Local Conditions . . . . . . . . . . . . . 47

3.2.3 Geologic Anomalies . . . . . . . . . . . . . . . 47

3.3 Uncertainty About Soil Properties . . . . . . . . . . . . . . 48

3.3.1 Systematic Uncertainty . . . . . . . . . . . 48

3.3.2 Random Variations . . . . . . . . . . . . . . . . 49

3.3.3 Occurrence Uncertainty . . . . . . . . . . . . . 50

3.4 Uncertainty About Slope . . . . . . . . . . . . . . 51

IV. RAINSTORM AND SNOWMELT MODELS $\ldots \ldots \ldots \ldots$

4.1 Introduction . . . . . . . . . . . . . 62

4.2 Storm Precipitation . . . . . . . . . . . . . .64

4.3 Storm Duration . . . . . . . . . . . . . . .66

4.4 Sequence of Storms . . . . . . . . . . . . . . . 66 66

4.4.1 Sequence of Long Continuous Storms . . . . . . . . . 66

4.4.2 Sequence of Small Rain Events . . . . . . . . . . . 68

4.5 Model of Snowmelt . . . . . . . . . . . . . . . 70

4.6 Infiltration . . . . . . . . . . . . . . 72

4.7 Distribution of Extreme Infiltration $\ldots \ldots \ldots \ldots$. . . . 75

V. GROUNDWATER MODEL $\ldots \ldots \ldots \ldots \ldots \ldots$

5.1 Introduction . . . . . . . . . . . . . . 80

5.2 Sensitivity Analysis of Groundwater . . . . . . . . . . 81

5.3 Variation of Groundwater Within a Catchment . . . . . . 82

5.4 Flow Through Fractures in Bedrock . . . . . . . . . . 87

5.5 Flow Through Pervious Inclusions . . . . . . . . . . . . 94

5.6 Groundwater Mapping $\ldots \ldots \ldots \ldots$. . . . . . . 98 
6.1 Introduction . . . . . . . . . . . . . . . . . 106

6.2 Uncertainty Due to Storm Characteristics . . . . . . . . . . . . 107

6.2.1 Storm Infiltration and Duration . . . . . . . . . . . . . 107

6.2.2 Antecedent Moisture . . . . . . . . . . . . . . . . 108

6.2.2.1 Number of Storms . . . . . . . . . . . . . . 108

6.2.2.2 Interval Between Storms . . . . . . . . . . . . . 109

6.3 Uncertainty About Soil Properties . . . . . . . . . . . . . 116

6.3.1 Systematic Uncertainty . . . . . . . . . . . . . 116

6.3.2 Random Variations . . . . . . . . . . . . . . . . 117

6.3.3 Occurrence Uncertainty . . . . . . . . . . . . . . . . 123

6.4 Uncertainty Due to Geologic Anomalies . . . . . . . . . . . . 125

6.5 Summary . . . . . . . . . . . . . . . . . 127

VII. PROBABILISTIC ANALYSIS OF SLOPE STABILITY $\ldots \ldots \ldots$

7.1 Introduction . . . . . . . . . . . . . . 128

7.2 First Order Second Moment of Slope Stability . . . . . . . . . 128

7.3 Slope Stability Hazard Mapping . . . . . . . . . . . . . . 131

7.3.1 Macro-Hazard-Map . . . . . . . . . . . . . . . 131

7.3.2 Micro-Hazard-Map . . . . . . . . . . . . . . . 132

7.3.3 Macro-Hazard-Map at Pixel Level . . . . . . . . . . 134

7.4 Comparison With the Landslide Inventory . . . . . . . . . 135

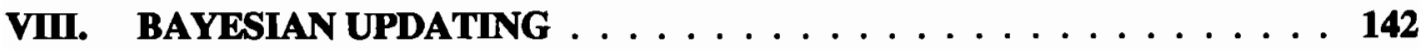

8.1 Introduction . . . . . . . . . . . . . . . 142

8.2 Bayesian updating model $\ldots \ldots \ldots \ldots \ldots$

8.3 Hazard for a Polygon . . . . . . . . . . . . . . . . . 144

8.3.1 Polygon Scale and Uncertainty . . . . . . . . . . . 145

8.3.2 Application . . . . . . . . . . . . . . 147

8.3.3 Interpretation of Probability of Failure . . . . . . . . . 148

8.3.4 Comparison with Monte-Carlo Simulation Technique . . . 150

8.4 Prior model . . . . . . . . . . . . . . . 158

8.5 Observation Model $\ldots \ldots \ldots \ldots \ldots 16 \ldots \ldots$

8.5.1 Landslide Inventory . . . . . . . . . . . . . . . 161

8.5.2 Uncertainty About Observations . . . . . . . . . . 162

8.6 Application of Bayesian model . . . . . . . . . . . . . 167

8.6.1 Case \# 1. . . . . . . . . . . . . . . . . . 167

8.6 .2 Case \# $2 \ldots \ldots \ldots \ldots \ldots$

IX. CONCLUSIONS $\ldots \ldots \ldots \ldots \ldots \ldots \ldots \ldots \ldots$ 


\section{APPENDICES}

A. TWO-DIMENSIONAL FINITE DIFFERENCE MODEL $\ldots \ldots \ldots 172$

B. ONE DIMENSIONAL MASS BALANCE MODEL . . . . . . . . 175

C. DERIVATION OF THE FIRST ORDER SECOND MOMENT $\ldots \ldots 179$

D. BINOMIAL DISTRIBUTION FOR A VARIABLE, P $\ldots \ldots \ldots \ldots$

E. NOTATIONS $\ldots \ldots \ldots \ldots \ldots \ldots \ldots \ldots \ldots \ldots$

BIBLIOGRAPHY $\ldots \ldots \ldots \ldots \ldots \ldots \ldots \ldots \ldots \ldots \ldots$ 


\section{LIST OF FIGURES}

\section{FIGURE}

PAGE

1.1 Components of groundwater flow on soil covered hillslopes. . . . . . . . . 4

2.1 Comparison of predicted water surfaces (Sloan and Moore, 1984). . . . . . 10

2.2 Conceptual model of pipeflow in midslope hollows . . . . . . . . . . 12

$2.3 \quad$ (a) Different types of bedrock pores (Chow, 1964), (b) equivalent coefficient of permeability of a crack of opening, e, (Louis, 1967). . . . . . . 14

2.4 Infinite slope model and the input variables (Hammond et al., 1991). . . . 18

2.5 Random variable model and random field model (Tang et al., 1989). . . . . . 24

2.6 Reliability measures: (a) conventional factor of safety, (b) central factor of safety in supply-demand model, and (c) safety margin and reliability index (Dakhly, 1989). . . . . . . . . . . . . . . . . 28

2.7 Effect of clearcut on root reinforcement (Ziemer, 1981) . . . . . . . . . 34

2.8 Root strength distribution for different morphology types (Tsukamoto and Kusakabe, 1984). . . . . . . . . . . . . . . . . . 36

2.9 (a) Window used for computing derivatives of elevation, (b) modes of elevation errors, (c) precise and smooth representation of the same contour line (Shearer, 1980). . . . . . . . . . . . . . . . . . . 40

3.1 (a) The focus township, (b) the location of the focus township in Lewis county, Washington . . . . . . . . . . . . . . . . 53

3.2 (a) Soil associations for the north part of Glenoma, the hatched area in Fig. 3.1a. For scale illustration, soil series are shown within soil association \#13. (b) Soil series of catchment \#77 shown in Fig. 3.

3.3 Catchments boundaries, and polygons \#1, \#2, and \#3, Glenoma quadrangle.

3.4 (a) Pervious inclusions in the soil layer, profile and section $1-1$, (b) seepage through bedrock fractures (Wu et al., 1993). . . . . . . . . . . . . 56 


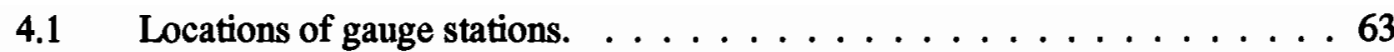

4.2 Scatter graph of storm duration vs. precipitation (Brunengo, 1989). . . . . 65

4.3 Probability function of (a) number of storms per season, (b) duration between storms in a 2-storm season and between the last two storms in a 3 -storm season. . . . . . . . . . . . . . . . . . . 69

4.4 (a) Frequency function of number of days with a given range in precipitation, (b) simulated rain events.

4.5 Probability density function of (a) snowmelt and snow-water

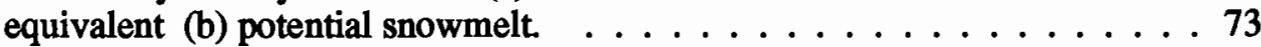

4.6 Probability density function and distribution function of (a) storm precipitation, (b) total amount of water available for infiltration = snowmelt plus precipitation. . . . . . . . . . . 74

4.7 (a) Asymptotic probability distribution functions, and (b) asymptotic probability density functions of rainfall of maximum storm in $\mathbf{n}$ years. . . . 79

$5.1 \quad$ Effect of (a) slope length, $L$, (b) soil depth, $H, \ldots \ldots \ldots 3$

5.2 Effect of (a) permeability, $K$, (b) drainable porosity, . . . . . . . . 84

5.3 Effect of (a) parameter, B, (b) suction at saturation $\ldots \ldots \ldots$. . . . 85

5.4 Effect of (a) precipitation, $R$, (b) storm duration, $D, \ldots \ldots \ldots$

5.5 Different catchment shapes. . . . . . . . . . . . . . 88

5.6 Comparison between groundwater for different catchment shapes. . . . . 89

5.7 Variation of groundwater levels within a catchment. $K=2.8 \mathrm{~cm} / \mathrm{hr}, \mathrm{I}=$ $6.5 \mathrm{in}$, slope angle $=30$, and $\mathrm{L}=300 \mathrm{~m} . \ldots \ldots$. . . . . . . . 90

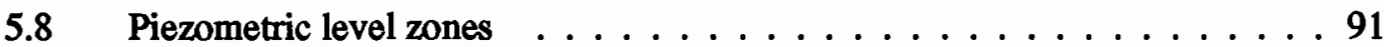

5.9 Model for flow through a fracture or joint, $b f=$ width of joint, $b=$ width of slope. . . . . . . . . . . . . . . . 95

5.10 Groundwater levels within a slope with flow through Fracture, $a=$ $\mathrm{L} / 3, \mathrm{~b}=10 \mathrm{~m} . \ldots \ldots \ldots \ldots \ldots$

5.11 Change of $h w / H$ at exit point with time. . . . . . . . . 97

5.12 Flow through porous inclusion $\ldots \ldots \ldots \ldots \ldots$

5.13 Mean piezometric level for storms of various return periods. . . . . . . 101 
5.14 Catchment boundaries, Glenoma quadrangle, Washington. . . . . . . . . 102

5.15 Catchment boundaries, Mineral quadrangle, Washington. . . . . . . . 103

5.16 Piezometric level map for Glenoma quadrangle, Washington. . . . . . . . 104

5.17 Piezometric level map for Mineral quadrangle, Washington. . . . . . . . 105

6.1 Groundwater for 1 -storm season and 2 -storm season $\ldots \ldots \ldots 11$

6.2 Groundwater for 3 -storm season and 4-storm season . . . . . . . . . 112

6.3 Groundwater response to a sequence of storms. . . . . . . . . . . 113

6.4 (a) Initial moisture conditions for different number of storms, (b) frequency of ho / H for different number of storms. . . . . . . . . . . . 114

6.5 Effect of initial moisture conditions on ground water for 2-storm and 3-storm seasons ........................ 115

6.6 Kennel creek watershed. . . . . . . . . . . . . . . . . 120

$6.7 \quad$ Values of (a) $\mathrm{K}$, (b) $\mathrm{C}$, and (c) $\mathrm{H}$ for Kennel Creek watershed. . . . . . . . 121

6.8 Effect of random variations in $\mathrm{K}, \mathrm{C}$, and $\mathrm{H}$ on groundwater ratio for a plane slope, (a) 3-D view of groundwater, (b), plane view, (c)

frequency of $\mathrm{Nr} \ldots \ldots \ldots 122$

6.9 Effect of using spatial average soil properties, . . . . . . . . . . . . . 124

6.10 Sensitivity of fracture flow to input parameters, . . . . . . . . . 126

7.1 Probability of failure of valley slopes, macro-hazard-map, Glenoma,

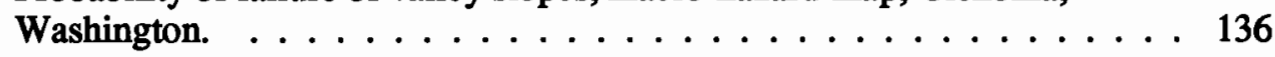

7.2 Map of probability of failure $>0.1$, micro-hazard-map, Glenoma,

Washington. ...................... 137

7.3 Map of probability of failure $>0.1$, macro-hazard-map at pixel level,

Glenoma, Washington. . . . . . . . . . . . . . . 138

7.4 Landslide inventory map for Glenoma, Washington (Brunengo, 1991).

8.1 Ratio between systematic uncertainty and occurrence uncertainty based on random variable model (Tang et al., 1989). . . . . . . . . . . . . 155

8.2 Variations of slope angle over polygons \#1, \#2, and \#3, . . . . . . . 156

$8.3 \quad$ Variations of $\mathrm{p}$ over polygons $\# 1, \# 2$, and $\# 3 . \ldots \ldots 157$ 
8.4 Results of landslide inventory for polygons \#1, \#2, and \#3 (Brunengo, 1991).

A.1 (a) Flowlines in downhill and transverse directions, (b) geometric parameters of two dimensional model (Lee, 1986), (c) specific yield for different soils (Eckis, 1934).

B.1 (a) Idealization of moisture profile in the unsaturated zone, (b) the kinematic storage model (Reddi and $\mathrm{Wu}, 1991) \ldots \ldots \ldots \ldots$ 


\section{LIST OF TABLES}

TABLE

PAGE

2.1 Coefficients of permeability for typical rocks and soils (Hoek and Bray, 1981). . . . . . . . . . . . . . . . . . . . . 15

2.2 Shear strength parameters for different soils (Hammond et al, 1991). . . . . 32

2.3 Measurement of root shear strength per unit area (Hammond et al, 1991). . . . . . . . . . . . . . . . . . . 35

2.4 Values of A and B for high quality contour map (Imhof 1982). . . . . . . . 39

3.1 Sources of information about soil properties. . . . . . . . . . . 57

3.2 Map units and corresponding soil units, models, and averages. . . . . . . . 58

3.3 Systematic uncertainty of soil parameters. . . . . . . . . . . 59

3.4 Random variations of soil parameters. . . . . . . . . . . . 60

3.5 Uncertainty of the parameters of stability model, pixel. . . . . . . . . . 60

3.6 Types of uncertainties and variations of map units. . . . . . . . . 61

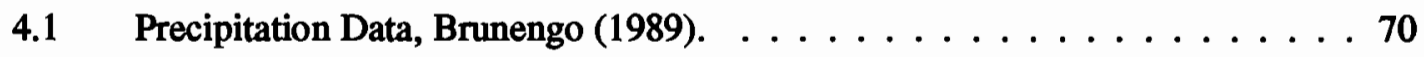

4.2 Means and variances of rainfall and infiltration of maximum storm in $\mathbf{n}$ years. . . . . . . . . . . . . . . . 78

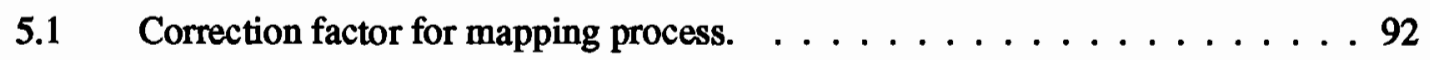

6.1 Parameters used in computations of infiltration and drainage. $\ldots \ldots \ldots 117$

6.2 Soil properties for Kennel Creek watershed (Swanston, 1985). . . . . . . . 119

6.3 Distribution of parameters for jointed rock. . . . . . . . . . . . 125

6.4 Summary of the uncertainties due to input to hydrologic model. . . . . . . 127

7.1 Different procedures used for mapping slope reliability. . . . . . . . 140 
7.2 Calculations of reliability for the macro-hazard-map. . . . . . . . . . 141

7.3 Systematic uncertainty, random variation, and, total uncertainty

matrices for sample pixel. . . . . . . . . . . . . . . . 141

8.1 Systematic and occurrence variances of the parameters of stability

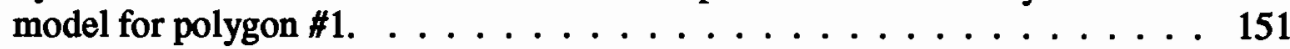

8.2 Comparison between micro-hazard-map and hazard-for-a-polygon. . . . 151

8.3 Uncertainty, polygon $\# 1 . \ldots \ldots \ldots \ldots$

8.4 Uncertainty, polygon $\# 2 \ldots \ldots \ldots \ldots \ldots$

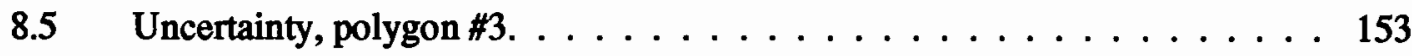

8.6 Relation between $p$ and Pf. $\ldots \ldots \ldots \ldots \ldots$

8.7 Statistics of simulated values, polygon $\# 1 . \ldots \ldots \ldots \ldots$

8.8 Calculation of probability of failure using FOSM and Monte-Carlo simulation. . . . . . . . . . . . . . . . . . . 154

8.9 Prior and posterior matrices for polygon \#1. . . . . . . . . . . . . 159

8.10 Prior and posterior matrices for polygon $\sharp 2 . \ldots \ldots \ldots$

8.11 Prior and posterior matrices for polygon $\# 3 . \ldots \ldots \ldots$

8.12 Information about the landslides in polygons $\# 1, \# 2$, and $\# 3 . \ldots \ldots 6$

8.13 Results of application of the observation model to polygons \#1, \#2, and \#3. . . . . . . . . . . . . . . . . . . . . . 167

8.14 Posterior matrices for Polygon $\# 1$, case $\# 2 . \ldots \ldots$ 


\section{CHAPTER I}

\section{INTRODUCTION}

Rainfall and snowmelt are major causes of mass-wasting in mountainous areas in the form of erosion and landslides. Harr (1975) estimated that $85 \%$ of the landslides that occurred in the western Cascades of Oregon, were associated with snowmelt during rainfall. Snowmelt increases the available surface water that infiltrates the soil. A part of the water that infiltrates the soil is retained in the unsaturated zone. The remainder reaches the saturated zone and causes a rise in groundwater levels, $h_{w}$, shown in Fig. 1.1 In the slope stability problem, a failure occurs when the shear stress due to loads equals or exceeds the shear strength of the soil. The rise in $h_{w}$ reduces the shear strength of soil and increases the seepage force resulting in a reduction of the factor of safety of the slope stability, i.e. increasing the landslide hazard. Thus, prediction of $h_{w}$ is an essential step in evaluation of the landslide hazard.

Prediction of $h_{w}$ is a complex problem that requires evaluation of rainfall, snowmelt, evapotranspiration, runoff, infiltration, and drainage. As shown in Fig. 1.1, part of the water generated by rainfall and/or snowmelt is converted to evapotranspiration and/or surface runoff. The rest infiltrates to the water table or moves beneath the hillslope surface as throughflow, The different groundwater flow mechanisms are vertical unsaturated flow, lateral saturated flow, pipes and macropores flow, and bedrock fracture flow. The dominant flow mechanism may be influenced by the site topography and the presence of bedrock fractures and pervious inclusions. Topography and basin shape play a vital role in developing $h_{w}$. Converging slopes collect more water than plane slopes due to stream convergence, (O'Loughlin, 1986). In a study area in San 
Francisco Bay region, California, the convergent slopes occupy only $26 \%$ of the valley walls but include $74 \%$ of the debris-flow scars, mapped by Alger and Ellen (1987). Fractures and joints in bedrock may change the entire groundwater flow pattern. Also, pervious inclusions, such as pipes, decayed roots, and weathered layers, act as avenues of high seepage velocity and may lead to surface exfilteration in unexpected locations (Beven and Germann, 1982).

Assessment and prediction of the landslide hazard, which is defined as probability of slope failure, require a probabilistic analysis to account for the uncertainties and the variabilities involved in the estimates of soil properties and groundwater levels. Probabilistic analyses have been successfully used for flow in slopes ( Bakr et al., 1978; Lee and Wu, 1987; Reddi and Wu, 1991) and for stability of slopes (Cornell, 1971; Tang et al., 1976; Wu et al., 1986). The estimates of the landslide hazard can be used to produce a landslide hazard map that provides information for use by land managers and foresters who plan and conduct timber harvest and related operations.

The approximate nature of estimates of the landslide hazard can be improved by calibration with field observations. Calibration and updating of probability estimates have been used for management and decision making in design and construction operations such as planning of transportation routes (Einstein, 1988) and offshore construction (Wu et al, 1986). Bayesian updating represents the formal procedure to incorporate the field observation to update and refine the landslide hazard mapping.

\subsection{OBJECTIVE AND SCOPE}

The objective of this research is to develop the methodology for predicting and mapping the groundwater levels and the landslide hazard of hillside slopes. The methodology is rational, with components that account for rainfall, snowmelt, infiltration, drainage, and stability. A focus township that covers areas of Glenoma and Mineral quadrangles in the lower cascade 
mountains of Washington was used as an example of updating the predicted landslide hazard with the observed data.

Prediction of groundwater levels, $h_{w}$, due to infiltration from rain and/or snowmelt, requires a study of the factors that affect the groundwater flow through the soil mass. These factors are the soil properties, the topographic parameters, the storm characteristics, and the geologic anomalies. The soil properties are depth of soil cover, permeability, porosity, and suction. The topographic parameters are slope, length, and shape of the catchment. The storm characteristics are snow accumulation, precipitation, duration, and intervals between a sequence of storms. Geologic anomalies are pipes, macropores, and bedrock fractures. The sensitivity of $h_{w}$ to these factors was studied using Reddi and Wu's lumped model (1991). The finitedifference model of Lee (1986) was used to study the variations in $h_{w}$ within a catchment due to topography. Probability distributions of rainfall, snowmelt, soil properties, and rock fracture were evaluated. Probabilistic analysis of groundwater was used to evaluate the uncertainty about $h_{w}$ as a result of the uncertainties and the variations in the groundwater model parameters.

Prediction of $h_{w}$ was used as input to the slope stability model to estimate the landslide hazard. To account for the uncertainties and the variations in both the strength parameters and all the parameters used in calculating $h_{w}$, reliability analysis was used to estimate the landslide hazard. A map showing the areas of landslide hazard greater than specific value was produced for the focus township. A range in map scales and details, that may meet the needs of land managers and foresters, was considered in this study.

The landslide inventory of the focus township, conducted by Brunengo (1991), was used to update the calculated landslide hazard. A Bayesian updating model was developed to combine the observations from the landslide inventory and the prior calculations of the landslide hazard. 


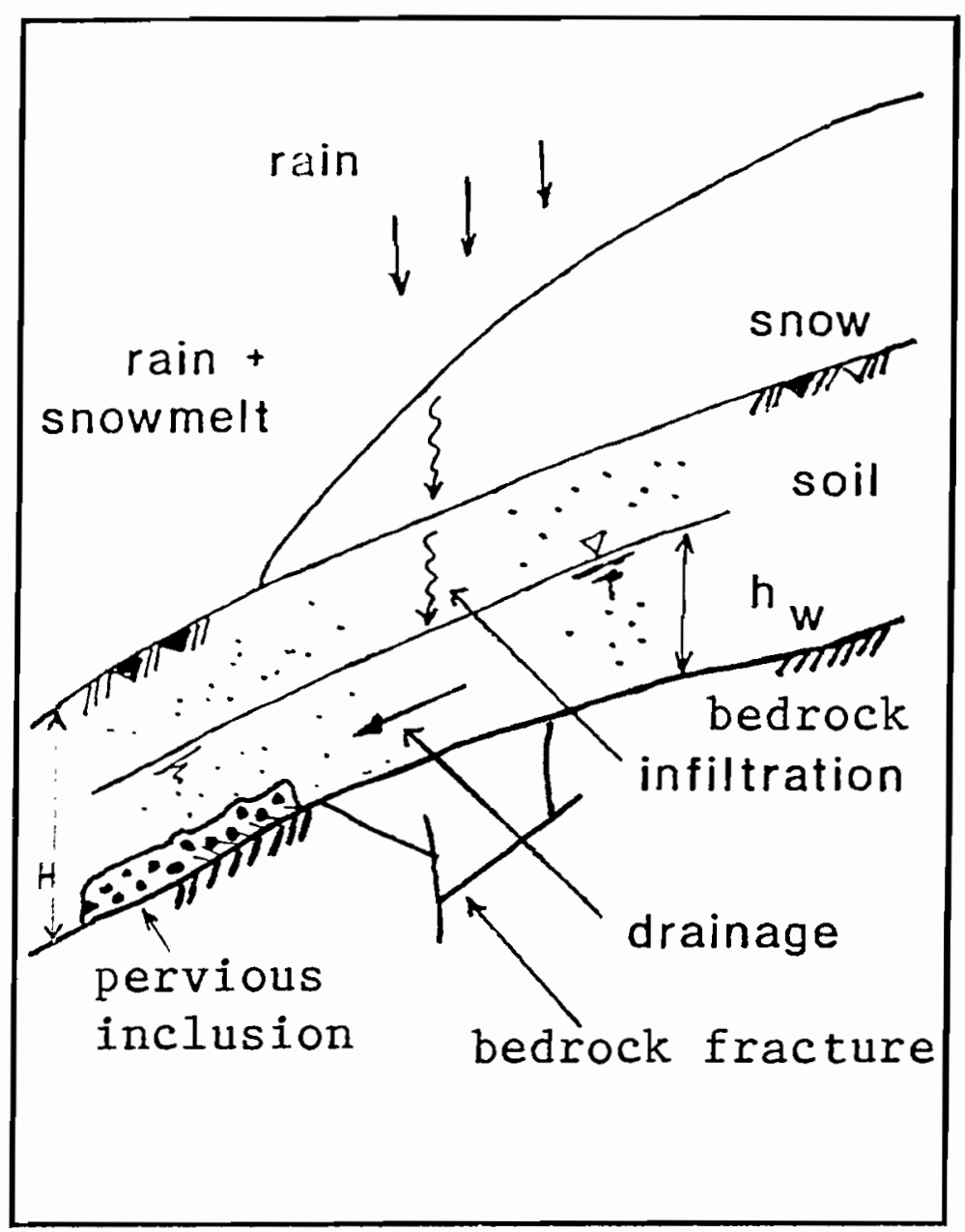

Figure 1.1: Components of groundwater flow on soil covered hillslopes. 


\section{CHAPTER II}

\section{LITERATURE REVIEW}

\subsection{GROUNDWATER}

Rainfall and/or snowmelt constitute a source for infiltration of water into soil which causes a rise in groundwater levels, $h_{w}$, shown in Fig. 1.1 Groundwater drains downslope by gravity and this drainage causes a drop in $h_{w}$. A review of the mathematical solutions of the infiltration and drainage problem is given in Section 2.1.1. The other groundwater flow mechanisms, shown in Fig. 1.1, are flow through pervious inclusions and flow through bedrock fractures. Mechanisms and Mathematical solutions of flow through pervious inclusions and bedrock fractures are reviewed in Sections 2.1.2, and 2.1.3, respectively.

\subsubsection{Solutions of Groundwater Flow Through Soil}

Prediction of changes of $h_{w}$ due to the infiltration and the drainage requires solution of combined unsaturated-saturated flow problem. Many solutions are currently available in literature in various forms: closed form solutions, numerical solutions, and lumped parameter solutions. A brief review of the important features of these solutions is given in the next sections.

\subsubsection{General}

The basic law of flow is Darcy's law and when it is put together with an equation of continuity that describes the conservation of fluid mass during flow through a porous medium, a partial differential equation of flow is the result. The general differential equation for threedimensional transient unsaturated flow through a porous medium can be expressed as (Richards, 
1931)

$$
\frac{\partial}{\partial x}\left(K(\Psi) \frac{\partial \psi}{\partial x}\right)+\frac{\partial}{\partial y}\left(K(\Psi) \frac{\partial \psi}{\partial y}\right)+\frac{\partial}{\partial z}\left(K(\Psi) \frac{\partial \psi}{\partial z}\right)=C(\Psi) \frac{\partial \psi}{\partial t}
$$

in which $\psi=$ pressure head $=h-z, h=$ hydraulic head, $z=$ elevation head, $K(\psi)=$ permeability of soil, and $C(\psi)=$ specific moisture capacity $=\frac{\partial \theta}{\partial \psi}$, and $\theta=$ moisture content. The solution $\psi(x, y, z, t)$ describes the pressure head at any point in a flow field at any time. The solution can easily be converted into a hydraulic head solution, $h(x, y, z, t)$, through the relation $h=\psi+z$. Solutions of Eq. 2.1 are complicated and require knowledge of the characteristic curves $K(\psi)$, and $C(\psi)$. In many cases, however, flow in one or two directions may be neglected and the assumption of one or two dimensional flow may be satisfactory. Philip (1957) considered infiltration into a semi-infinite, homogeneous, one-dimensional soil column of uniform initial moisture content. He used the one-dimensional form of Eq. 2.1 and obtained a closed-form solution for the case where the top of the soil column was maintained at a constant moisture content. Philip (1968) also gave solutions for higher dimensional systems. However, these solutions are applicable only to simple geometry and uniform soil properties. With the advent of digital computers, many complex flow problems can be solved using numerical techniques.

\subsubsection{Numerical Solutions}

Rubin (1968) and Freeze (1971) pioneered the numerical solutions for the flow problems. Rubin, (1968) obtained a finite difference solution for two-dimensional, transient movement of water in an unsaturated soil slab. His two-dimensional flow equation is a special case of Eq. 2.1, where he used Kirchoff's transformation to make the equation quasi-linear and then he solved it using alternating direct implicit scheme.

Freeze (1971) developed the most comprehensive three-dimensional finite difference saturated unsaturated flow model for an entire groundwater basin. He allowed heterogeneity and 
anisotropy of soil properties. He also considered the nonlinear hysteric functional relationship between $\psi$ and $\theta$. An equation of flow similar to Eq. 2.1 was solved by the line successive overrelaxation technique (Freeze, 1971). Other examples of numerical solutions of groundwater flow problem may be found in Nieber and Walter (1981), Beven (1982), and Lee (1986).

\subsubsection{Simplified Solutions}

In a deviation from the previous approach, many models were introduced that simplify the groundwater flow problem. Many of these simplified models computed the flow in the unsaturated and saturated zones separately with the assumption that unsaturated flow is in the vertical direction. In the saturated zone, many simplified assumptions were used such as: the extended Depuit-Forchheimer assumption that the stream lines are parallel to the slope of the bedrock (Childs, 1971; Henderson and Wooding, 1964; Lee, 1986), the Depuit-Forchheimer assumption that the stream lines are horizontal (Lee, 1986), the kinematic assumption that the hydraulic gradient is parallel to the slope of the impervious bed (Beven, 1982), and the Boussinesq assumption that the hydraulic gradient is parallel to the groundwater surface (Sloan et al., 1983).

Beven (1982) used a kinematic wave equation in the form

$$
\theta_{d} \frac{\partial h_{w}}{\partial t}=-K_{s} \sin \alpha \frac{\partial h_{w}}{\partial x}+i
$$

where $\theta_{d}=$ effective porosity, $K_{s}=$ saturated permeability, $\mathrm{i}=$ the rainfall rate, $\alpha=$ slope angle, $h_{w}=$ height of groundwater, $x$ and $t=$ indices for downslope direction and time, respectively. Eq. 2.2 is shown to be a good approximation when

$$
\lambda=4 i \cos \alpha /\left(K_{s} \sin ^{2} \alpha\right)<0.75
$$

The simplifications behind Beven's formulation restricted its application to steep slopes, high saturated hydraulic conductivity, and low rainfall rates as expressed by Eq. 2.3 .

Sangrey (1984) developed a model to predict $h_{w}$ as a function of precipitation. He separated the flow in the unsaturated and the saturated zones. The unsaturated flow was estimated 
empirically. Lee (1986) developed a simplified a 2-D finite difference program to calculate $h_{w}$ as a result of rainfall. He used the extended Depuit-Forchheimer assumption in the down hill direction and the Depuit-Forchheimer assumption in the transverse direction. Details of Lee's model are presented in Appendix A.

Reddi (1988) developed a simplified model for flow on hill slopes based on separation of the saturated and the unsaturated flow. The flow in the unsaturated zone was assumed to be vertically downward. Following Eagleson (1978), the unsaturated zone was divided into three zones: moisture zone, percolation zone, and capillary zone. The kinematic storage model (Sloan et al., 1983) was used to model the saturated flow. The entire hill slope segment was treated as a control volume to compute the saturated flow which is drained by gravity. It was assumed that the water table has a constant slope equal to the bed slope. Details of Reddi's model are given in Appendix B.

To study the suitability of simple models for flow in a shallow soil cover on a sloping bed, Sloan and Moore (1984) compared five models which represented a range of refinement. These models are:

1. a two-dimensional finite element model (Nieber and Walter, 1981) based on Richards two-dimensional equation for both the saturated and the unsaturated flow,

2. a one-dimensional finite element model (Nieber, 1982) based on Richard's onedimensional equation, in which it was assumed that there was no flow normal to the hill slope,

3. a kinematic wave subsurface flow model (Beven, 1981 and 1982) in which it was assumed that the hydraulic gradient equals to the slope of the inclined bedrock, and

4. two simple storage-discharge models; one assumed kinematic wave approximation, and the other used the Boussinesq assumption (Sloan et al., 1983). 
A comparison of the predicted water surface from the above models is shown in Fig.2.1. Sloan and Moore (1984) concluded that the predictions from the simple models are as good as the predictions from the complex models.

\subsubsection{Pervious Inclusions}

Pumice layers, pipes, and macro pores are the common pervious inclusions. Pumice layers are composed of particles of $1-2 \mathrm{~cm}$ in diameter. Pipes are developed as a result of biological processes, root networks, and stress fractures. Biological processes generate organic acids that accelerate the dissolution of primary soil minerals and also disperse secondary minerals (Durgin, 1984). These minerals can be transported through the soil and the soil becomes more porous (Goldsmith and Smith, 1985) McDonnell (1990) reported that pipes occurred at the soilbedrock interface and extended laterally downslope over distances of several tens of meters. The formation of these pipes was illustrated as large roots extend vertically through the shallow mineral soil of average depth $0.6 \mathrm{~m}$ but can not penetrate the underlying bedrock. Roots then extend laterally over the bedrock surface for up to several meters. As a result of root decay and pore enlargement a well connected network has become established. He also reported pipe outlets range from 3 to $100 \mathrm{~mm}$ in diameter based on limited visual observations at a bit faces along first-order stream banks. Fig. 2.2 shows his conceptual model of pipeflow in hillslope. Luxmoore (1981) designated three size classes for pores: macro $>1000 \mathrm{um}$, meso 10-1000 um, and micro $<10$ um where the micropore class corresponds to the soil matrix. The dependence of flow rate on the fourth power of the pore radius means that while the presence of macro pores may make only a very minor contribution to the total soil porosity, nearly all the rapid flow is through these pores (Bouma and Anderson, 1973).

Effect of pervious inclusions on infiltration and drainage has been studied in various forms: Laboratory studies (e.g. Abdul and Gillham, 1984); theoretical studies (e.g. Sklash and Farvolden, 1979, Nitao and Buscheck, 1991, and Khalil and Valliappan, 1992); field studies (e.g. 
(a)

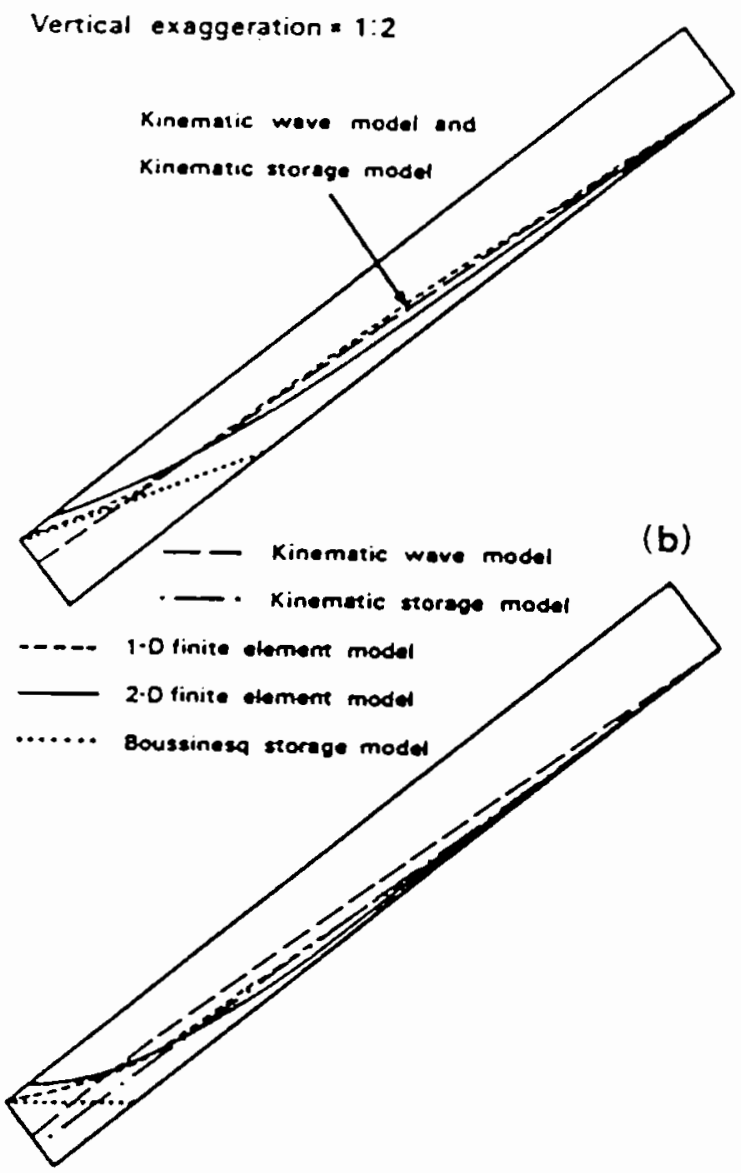

Figure 2.1: $\quad$ Comparison of predicted water surfaces (Sloan and Moore, 1984). 
McDonnell, 1989). Theoretical studies can be divided into two groups. The first group treated the soil as a homogenous porous medium confirming to Darcy's law (see for example, Zaradany, 1978; Bresler et al., 1979). The second group introduced the two-domain concept, where the first domain is the soil matrix and the second domain is the pervious inclusion. The twodomain models considered the nature of flow in the pervious inclusion, the spatial and temporal characteristics of the pervious inclusion, and the interaction between the soil and the pervious inclusion. For review of the two-domain models, refer to the study by Beven and Germann (1988).

\subsubsection{Fracture Flow}

Wilson and Dietrich (1987) reported heterogeneities in bedrock hydraulic conductivity which resulted in unexpected midslope high piezometric levels. Johnson and Sitar (1987) also related some cases of debris flow to the hydraulic conductivity between the soil and the underlying bedrock. They reported that after debris flow, the bedrock was exposed in the scar and copious amounts of water emanated from bedrock fractures, sometimes for days after failure.

Values of porosity and hydraulic conductivity of fractured and cavernous rocks are difficult to determine because they depend upon the nature and the distribution of the fractures, both of which are extremely variable and sporadic in comparison with the relatively orderly distribution of pore spaces in clastic rocks. Fig. 2.3a illustrates different types of rock fractures for different types of bedrock. Metamorphic and igneous crystalline rocks and carbonate rocks are usually dense and nonporous. The storage capacity of these types of rocks is small because the volume of fractures is small, even though they transmit large quantities of water because these fractures act as channels for water flow. Chow (1964) reported several values of the coefficient of transmissibility for different types of rocks. The values range from practically zero in dense, poorly jointed, essentially insoluble carbonates to large values in porous, heavily jointed, and cavernous formations. Typical values of the coefficient of permeability, which is 


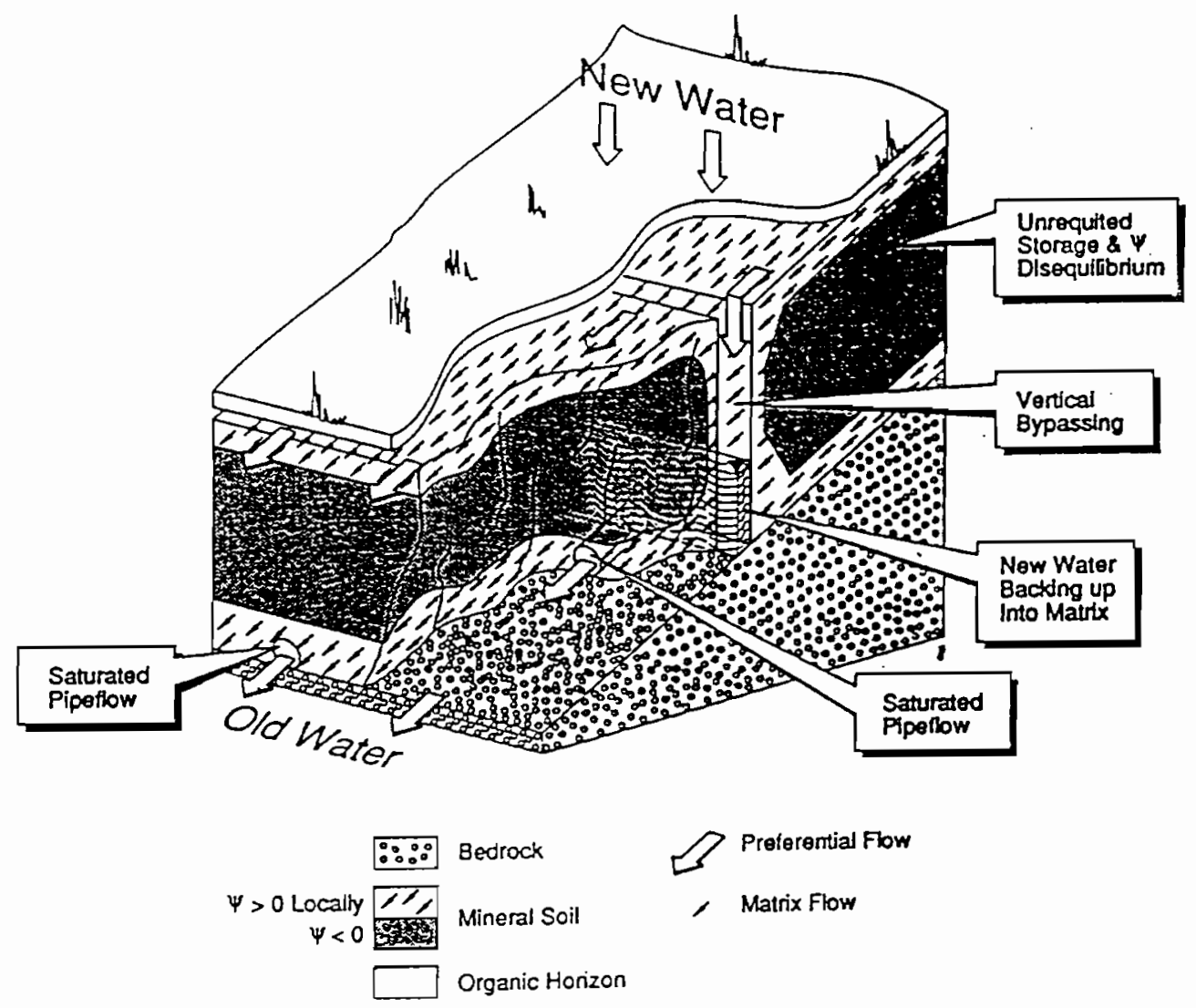

Figure 2.2: $\quad$ Conceptual model of pipeflow in midslope hollows (McDonnell, 1990). 
equal to coefficient of transmissibility divided by aquifer thickness, are listed in Table 2.1 for both intact rock and fractured rock (Hoek and Bary, 1981).

Louis (1967) derived the equivalent permeability, $K_{f}$, of a parallel array of smooth cracks of opening, e, and spacing between cracks, $b$, to be

$$
K_{f}=\frac{g e^{3}}{12 \eta b}
$$

where $\mathrm{g}=$ gravitational acceleration, $\mathrm{e}=$ opening of fracture, $\mathrm{b}=$ joint spacing, and $\eta=$ kinematic viscosity. Fig. $2.3 \mathrm{~b}$ shows values of $K_{f}$ of a parallel array of cracks with different e. Snow (1968) reported tentative dimensions for e. Using Eq. $2.4, K_{f}$ of a crack of e $=0.001 \mathrm{~m}$ and $\mathrm{b}=1.0 \mathrm{~m}$ is $8.1 \times 10^{-2} \mathrm{~m} / \mathrm{hr}$. In the case of an infilled fissure system, the lowest $K_{f}$ is given by

$$
K_{f}=\frac{e}{b} K_{m}+k_{r}
$$

where $K_{m}=$ permeability coefficient of the infilling material and $K_{r}=$ permeability coefficient of intact rock.

Analysis of flow in a fractured rock can be carried out either with continuum approach based on Darcy's law utilizing modified permeability or noncontinuum approach based on the hydraulics of flow in the individual fractures (Freeze and cheery, 1979). The continuum approach involves the replacement of the fracture media by a representative continuum in which spatially defined values of permeability can be assigned. Snow (1968) has shown that many fracture flow problems can be solved using standard porous media techniques utilizing Darcy's law and an anisotropic permeability tensor. If the fracture density is extremely low, it may be necessary to analyze the flow in the individual fractures, i.e. the noncontinuum approach. Wittke (1973) provided an introductory review for the noncontinuum approach. Numerous research is available on modeling flow through fractures (see for example Khalil and valliappan, 1991; Nitao and Buscheck, 1991; Rasmussen, 1991; Durlofsky, 1991). 

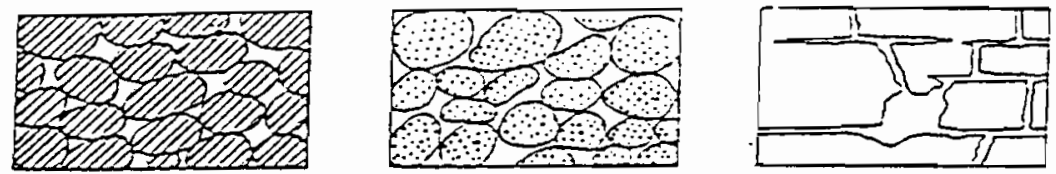

(a)
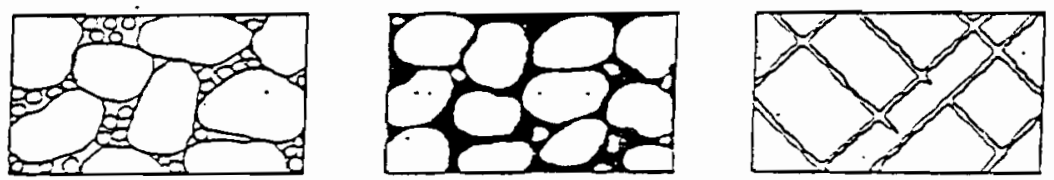

(b)

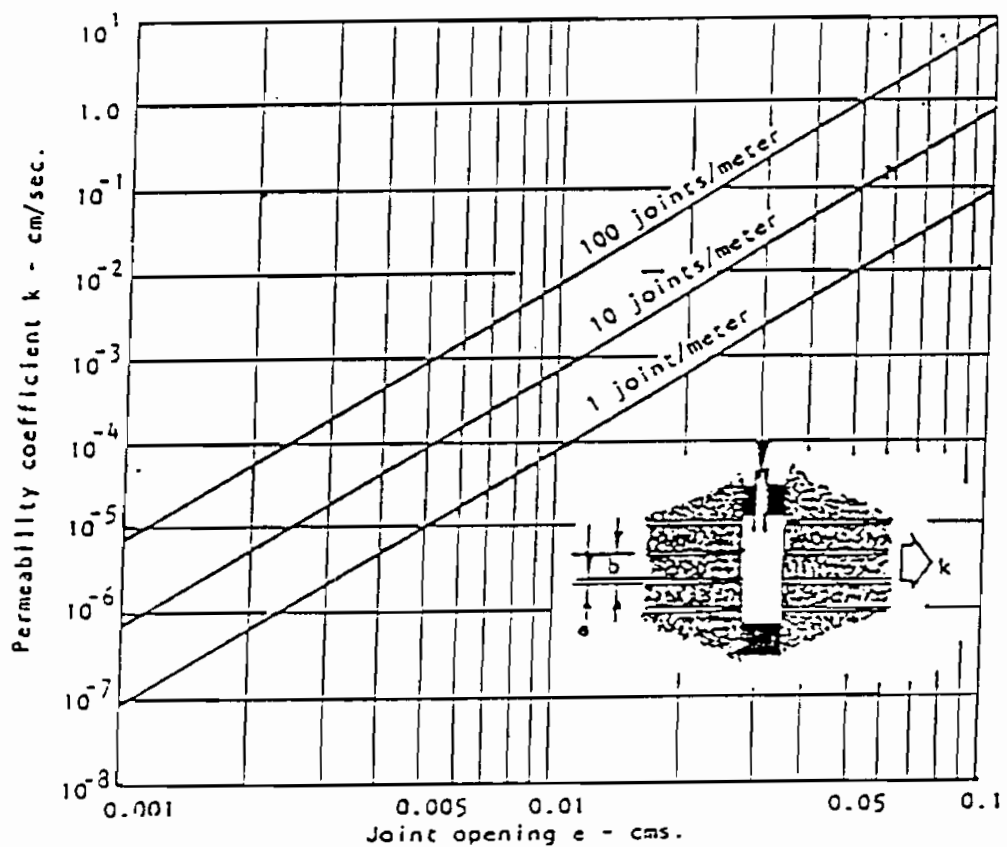

Figute 2.3: (a) Different types of bedrock pores (Ctow, 196-) (b) equivalent coefficient of permeability of a crack of opening e (Louis, 1967). 
Table 2.1

Coefficients of permeability for typical rocks and soils (Hoek and Bray, 1981).

\begin{tabular}{|c|c|c|c|c|}
\hline & $k-c m / s e c$ & Intact rock & Eractured rock & Soit \\
\hline 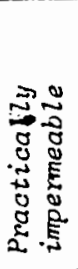 & $\begin{array}{l}10^{-10} \\
10^{-9} \\
10^{-8} \\
10^{-7}\end{array}$ & $\begin{array}{l}\text { Slate } \\
\text { Doiomite } \\
\text { Granite }\end{array}$ & & $\begin{array}{l}\text { Homogeneous clay } \\
\text { below zone of } \\
\text { weathering }\end{array}$ \\
\hline 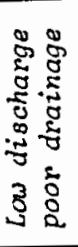 & $\begin{array}{l}10^{-6} \\
10^{-5} \\
10^{-4} \\
10^{-3}\end{array}$ & 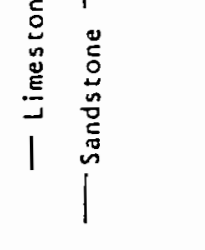 & $\begin{array}{c}\text { Clay-filled joints } \\
\text {. }\end{array}$ & $\begin{array}{l}\text { Very fine sands, } \\
\text { organic and inorganic } \\
\text { silts, mixtures of } \\
\text { sand and clay. glacial } \\
\text { till, stratified clay } \\
\text { deposits }\end{array}$ \\
\hline 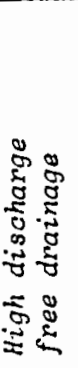 & $\begin{array}{l}10^{-2} \\
10^{-1} \\
1.0 \\
10^{1} \\
10^{2}\end{array}$ & & $\begin{array}{l}\text { Jointed rock } \\
\text { Open-jointed rock } \\
\text { Heavily fractured rock }\end{array}$ & $\begin{array}{l}\text { Clean sand, clean } \\
\text { sand and gravel } \\
\text { mixtures }\end{array}$ \\
\hline
\end{tabular}




\subsection{STABILITY ANALYSES OF SLOPES}

In the slope stability problem, failure occurs when the shear stresses due to loads equal or exceed the shear strength of the soil. Stability analyses of slopes can be classified as limit equilibrium analysis and deformation analysis. In limit equilibrium analysis, a failure surface is assumed and material above that surface is considered to be a free body. Equations of equilibrium can be formulated for the potential slide mass. Solution of these equations results in evaluation of stability along the assumed failure surface. Therefore, it is customary to repeat the calculations for a number of trial failure surfaces to find the critical one. The shape of failure surfaces can be plane or curved. Planar failure surfaces can be analyzed by wedge or sliding block method (Sultan and Seed, 1967 ; Terzaghi and Peck, 1967). Failure surfaces in cohesive material are usually curved surfaces, which according to Terzaghi and Peck (1967), have the least curvature at the upper end, greatest in the middle, and moderate at the lower end, and often resemble elliptical arcs. Solutions for curved failure surfaces are presented as stability charts for example: Taylor (1948), Bishop and Morgenstern (1960), Spencer (1967), and Huang (1975). Method of slices satisfies both force and moment equilibrium and is applicable to failure surfaces of any shape (see Janbu, 1954, 1973; Morgenstern and Price, 1965). Fredlund et al. (1981) presented a general limit equilibrium method of slices. They showed that the methods developed by Bishop, Spencer, Janbu, and Morgenstern and Price are special cases of their general formulation. Three-dimensional limit equilibrium analyses have been developed to study the effect of the third dimension for example: Baligh and Azzouz (1975), Chen and Chameau (1982), Anagnosti (1969), Leshchisky et al. (1985), and Zhang Xing (1988).

In case of uniform thin soil cover overlying a bedrock layer, the failure surface is constrained to be parallel to the slope, as shown in Fig. 2.4. When such a failure surface is long compared to its depth, it can be analyzed as an infinite slope. The infinite slope analysis is the simplest limit equilibrium analysis where the driving force at the upper end and the resisting 
force at the lower end of the slide mass cancel each other. The widespread use of the infinite slope model is a result of its simplicity and adequacy. Researchers have shown that infinite slope model is adequate for common failure types found in the mountainous areas, such as debris flow and debris avalanches, (Wu et al., 1979; Gray and Megahan, 1981; Prellwitz et al., 1983; Sidel et al., 1985). The factor of safety calculated from the infinite slope model corresponds closely (Singh, 1970; Wright, 1969) to that calculated for translational failures using a more rigorous method of slices, such as Janbu's or Spancer's methods. Burroughs (1984) showed that the infinite slope model gives almost same results as three dimensional analysis for blocks with width greater than $25 \sim 30$ feet because the resistance along sides of the block is not significant compared to resistance along the block's base.

The limit equilibrium analyses discussed above can not determine the stress distribution throughout the slope mass. The other approach of analyses of slopes, i.e. deformation analyses, provides the techniques to calculate stresses and deformation throughout the slope mass. The finite element method is the most general technique for calculation of stresses and deformation throughout soil mass. A recent review (Duncan, 1992) described more than 100 examples of application of finite element method to analysis of slopes. Information about the stress-strain behavior of soil is required for the finite element analysis of slopes. The finite element method can take into consideration the incremental process of forming the slope in case of embankments (e.g. Clough and Woodward, 1967) and in case of excavations (e.g. Dunlop and Duncan, 1970). 


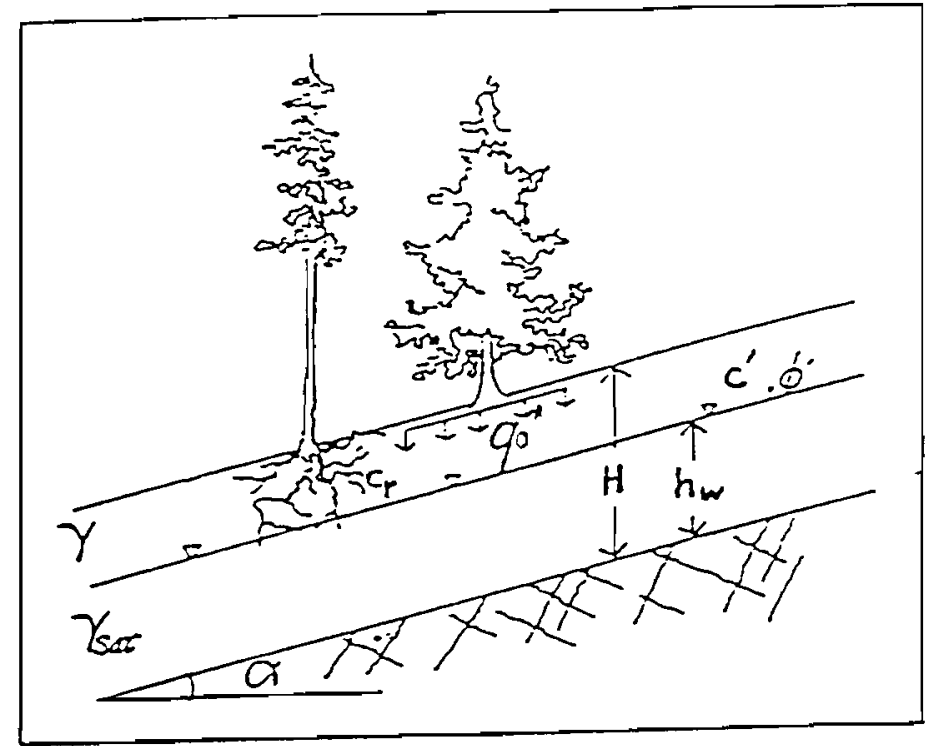

$$
F_{s}=\frac{c_{r}+\dot{c}+\cos ^{2} \alpha\left[q_{0}+\gamma H(1-Z)+\left(\gamma_{s a t}-\gamma_{w}\right) H Z\right] \tan \dot{\phi}}{\sin \alpha \cos \alpha\left[q_{0}+\gamma H(1-Z)+\gamma_{\text {ser }} H Z\right]}
$$

Figure 2.4: Infinite slope model and the input variables (Hammond et al., 1991). 


\section{$\underline{2.3}$ UNCERTAINTIES}

\subsubsection{Types of Uncertainties}

Uncertainties are unavoidable in the design and the analysis of an engineering systems. Uncertainties in engineering systems may be associated with physical phenomena that are inherently random or with predictions using incomplete information. Different types of uncertainties can be identified as:

1. systematic uncertainty due to insufficient information and measurement errors,

2. systematic uncertainty due to imperfection of the modeling of the physical process, and,

3. spatial variability due to

a. random variation within the same soil type, and

b. uncertainty about occurrence of different soil types.

The systematic uncertainty can be reduced at the expense of additional testing and accurate measurements. The uncertainty associated with prediction or modeling error can be reduced through the use of more accurate models. Spatial variability is essentially a state of nature and the resulting uncertainty may be reduced by additional samples. The tools of engineering analysis should include methods and concepts for evaluating the significance of uncertainties on system performance and design. The principles of probability theory offer the mathematical basis for modeling uncertainties.

\subsubsection{Systematic Uncertainty}

The systematic uncertainty about soil properties results from limited data and testing errors. Limited data pertaining to an observed soil property is a statistical uncertainty that can be reduced at the expense of additional testing. Test errors results from the difference between test conditions and in-situ conditions, sample disturbance, test imperfections, and human factors. The systematic uncertainty also occurs when empirical correlations are used to estimate 
engineering soil properties from index properties. The uncertainty in a model is also systematic but is fundamentally different from the uncertainty due to limited data or testing errors. If the uncertainty in a model is large, no amount of additional refinement in defining soil properties will substantially improve the reliability of the suggested design by that model. The systematic uncertainty may be expressed as the systematic coefficient of variation, $\Delta_{s}$, equals the systematic standard deviation divided by the mean.

\subsubsection{Spatial Variability}

The spatial variability of soil properties comes from the variations in the deposition of soil. It is necessary to distinguish between soil types and random variations. A soil stratum may contain more than one soil type. Even a supposedly homogeneous soil stratum may embody geological anomalies. Properties of different soil types can exhibit substantially different characteristics. Practically, it suffices to assume that different soil types are already incorporated in conventional subsoil modeling by dividing the soil stratum into different soil types (Vanmarcke, 1977). Random variation is the deviation from the mean within the same soil type. Numerous research has been performed to determine the random variations of soil properties (e.g. Mayerhof, 1970; Matsuo and Kuroda, 1974; Lumb, 1975; Corotis et al, 1975). The random variations can be expressed as a point variance, $\operatorname{Var}(\cdot)$, and a correlation distance, $\delta$ (Vanmarcke, 1977). Point variances and correlation distances of soil properties have been reviewed by Wu (1989) and Freeze (1980). The coefficient of variation of point data, $\Delta_{r}$, equals the point standard deviation divided by the mean.

\section{One Soil Type:}

In case of one soil type, the following statistical parameters are essential in the modeling of the random variability (Vanmarcke, 1983):

1. correlation distance of soil properties, $\delta$,

2. auto-correlation function $\rho(l)$, and its variance function, $\Gamma^{2}(l)$, and 
3. covariance between the spatial average and the point estimate.

The correlation distance, $\delta$, is defined by Vanmarcke (1983) as

$$
\delta=\int_{\infty}^{+\infty} \rho(l) d l
$$

where $\mathrm{p}(l)=$ correlation function, and $l=$ separating distance. $\delta$ represents the distance within which strong correlation between soil properties exists. Vanmarcke (1983) proposed a method to estimate this parameter from a set of observations of a soil property, sampled at discrete equidistant intervals.

The variance function represents a reduction of the point variance due to averaging over domain, $l$. In other words, the variance of a random variable averaged over a domain, $l$, can be obtained by multiplying the point variance by the variance function. The variance function, $\Gamma^{2}(l)$, for a single exponential correlation function, may be expressed as follows (Vanmarcke, 1983)

$$
\Gamma^{2}(l)=\frac{2 a^{2}}{l^{2}}\left(\frac{l}{a}-1+e^{-l l a}\right)
$$

where $a=\delta / 2$. Assuming only random variations, then the coefficient of variation of the average, $\Delta_{l}$, may be written as (Vanmarcke, 1983)

$$
\Delta_{l}=\Gamma(l) \Delta_{r}
$$

\section{Different Soil Types:}

Tang et al. (1989) derived the mean and the variance of the spatial average over some domain, $l$, within a random two-soil type medium. The properties of the two soil types can be drastically different, with each soil type subjected to systematic uncertainties or random variations. As shown in Fig. 2.5, two models were developed: the random field model and the random variable model (Tang et al., 1989). In the random field model, each soil type is represented by the mean, the point c.o.v., and the correlation distance, $\bar{x}_{1}, \Delta_{11}, \delta_{1}$ and $\bar{x}_{2}, \Delta_{22}, \delta_{2}$, 
respectively, where 1,2 stand for soil type 1,2 , respectively. In the random variable model, each soil type is represented by the mean and the systematic c.o.v. $\bar{x}_{1}, \Delta_{s 1}$ and $\bar{x}_{2}, \Delta_{s 2}$, respectively, where 1,2 stand for soil 1,2 , respectively. The random variable model would be satisfactory if the systematic error associated with the property is large relative to its random variation, which is ignored in that model.

Tang et al. (1989) modeled the occurrence of the two soil types as a renewal process as shown in Fig. 2.5. The duartion of soil 1 and 2 are assumed to be exponentially distributed where $1 / \mu_{1}$ and $1 / \mu_{2}$ are the mean durations of soil type 1 and 2 , respectively. Let $p$ be the fraction of the domain that lies in soil type 2 , then $\bar{p}$, the mean fraction of a domain, $l$, that lies in soil type 2, can be expressed as (Tang et al., 1989)

$$
\bar{p}=1 /\left(1+\alpha_{s}\right)
$$

where

$$
\alpha_{s}=\mu_{2} / \mu_{1}
$$

The variance, $\dot{p}$, of the fraction of a domain, $l$, that lies in soil type 2 is

$$
\dot{p}(l)=2 \frac{\alpha_{s}}{(1+\alpha)^{3}} \frac{1}{\mu_{1} l}\left[1-\frac{1}{\mu_{1} l(1+\alpha)}\left[1-e^{-\left(1+\alpha_{s}\right) \mu_{1} l}\right]\right]
$$

The mean of the spatial average soil property over a domain, $l, E\left(X_{\nu}\right)$, is the same for the two models and can be written as (Tang et al., 1989)

$$
E\left(X_{l}\right)=\bar{x}_{1}\left[1-\bar{p}\left(1-\beta_{s}\right)\right]
$$

where

$$
\beta_{s}=\bar{x}_{2} / \bar{x}_{1}
$$

where $\bar{x}_{1}$ and $\bar{x}_{2}$ are the mean soil properties for soil type 1 and 2 , respectively. The variances of the spatial average soil property over a domain, $l, \operatorname{Var}\left(X_{\nu}\right)$, for the random variable model and the random field model are given by Eqs 2.10 and 2.11, respectively. 


$$
\begin{aligned}
& \operatorname{Var}\left(X_{P}\right)=\bar{x}_{1}^{2}\left[(1-\bar{p})^{2} \Delta_{s 1}^{2}+\bar{p}^{2} \Delta_{s}^{2}\right]+\bar{x}_{1}^{2}\left(\beta_{s}-1\right)_{2} \dot{p}(l) \\
& \operatorname{Var}\left(X_{P}\right)=\frac{\bar{x}_{1}^{2}}{l\left(1+\alpha_{s}\right.}\left[\delta_{1} \Delta_{r 1}{ }^{2} \alpha_{s}+\delta_{2} \Delta_{r 2}{ }^{2} \beta_{s}{ }^{2}+\frac{\left(1-\beta_{s}\right)^{2} 2 \alpha_{s}}{\left(1+\alpha_{s}\right)^{2} \mu_{1}}\left[1-\frac{1-e^{-\left(1+\alpha_{s} \mu_{1} l\right.}}{\left(1+\alpha_{s} \mu_{1} l\right.}\right]\right]
\end{aligned}
$$

It may be concluded from Eqs. 2.10 and 2.11 that the total uncertainty about the spatial average can be viewed as the sum of either the systematic uncertainty and the occurrence uncertainty (Eq.2.10), or the random variability and the occurrence uncertainty (Eq.2.11).

\subsubsection{Analyses of Uncertainty}

\subsubsection{Introduction}

The various analyses of uncertainty developed so far can be divided into two main groups:

1. full distribution analyses, and

2. first and second moment analyses.

Full distribution analyses represent the most accurate procedures because the complete probability distributions of the dependent random variables can be obtained. Full distribution analyses can be subdivided into two classes: derived distribution method and Monte-Carlo simulations. In some situations these methods are impractical and prohibitively expensive.

The basic assumption underlying first and second moment analyses (FOSM) is that higher moments, such as skewness are negligible (see Ang, 1973; Cornell, 1971; Tang and Ang, 1973). This assumption is generally true in case of normally distributed random variables. When the distribution deviates from the normal, other stochastic methods such as Monte-Carlo simulation should be used to check the accuracy of FOSM. FOSM analyses can be used in two ways: perturbation analysis and analysis based on Taylor's series expansion. In perturbation analysis, the governing differential equation of flow, for example, is perturbed slightly, yielding a new equation that contains the random components of the variables as perturbation. Examples of the perturbation analysis can be found in Baker et al. (1978), Gutjahr et al. (1978), and Gelhar et al. 


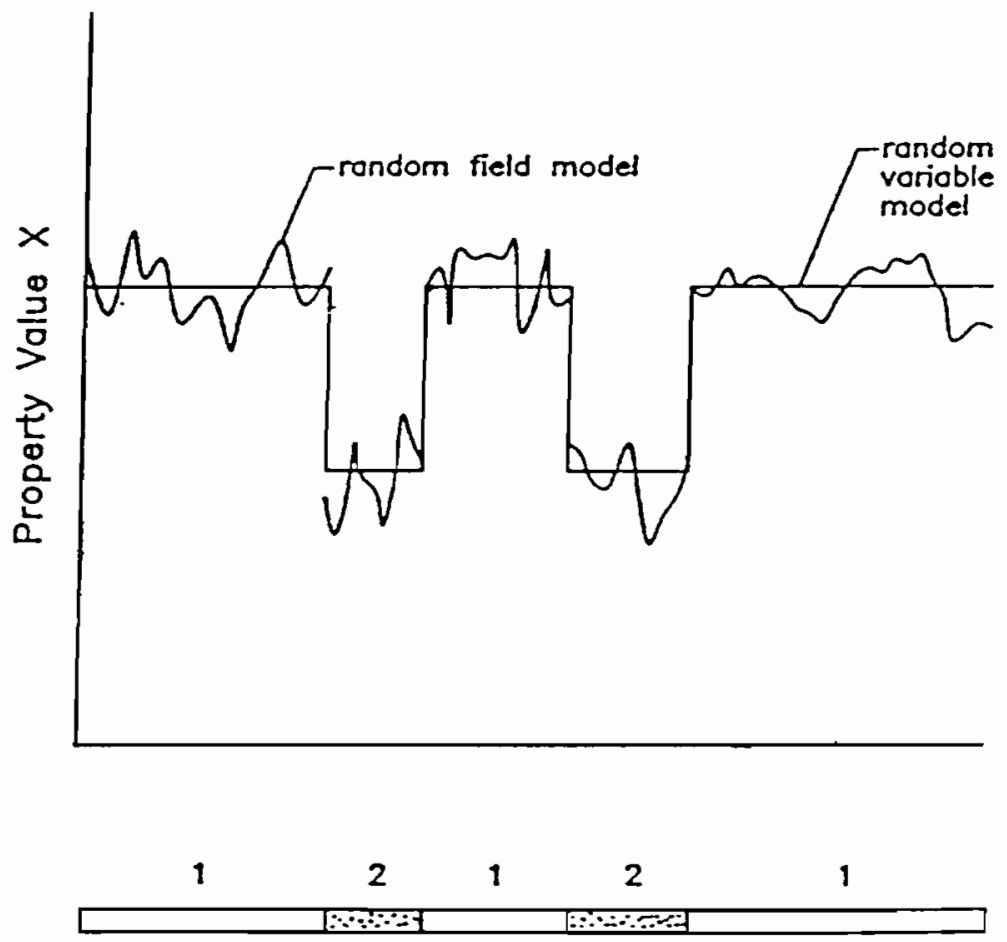

Occurrence and Property Value of a 1-Dimensional 2-State Medium

Figure 2.5: Random variable model and random field model (Tang et al., 1989). 
(1979). In FOSM analysis based on Taylor's series expansion, only first order terms of the functional expansion of the governing equation are used. Derivations of the mean and the variance of the functional relationship using Taylor's series expansion are given in Appendix C. Despite the approximate nature of FOSM method, it is a useful tool which can be used to assess the uncertainty and variability of many engineering problems. Advanced FOSM was introduced (Rackwitz, 1976) to account for nonlinear performance functions as well as the deviation from normal distribution. Evaluation of reliability using advanced FOSM generally requires iterations (Ang and Tang, 1984). Examples of applications of advanced FOSM in geotechnical problems may be found in Bouma et al. (1979), and Sidi (1985).

\subsubsection{Probabilistic Analysis of groundwater}

Probabilistic analyses of groundwater considered the stochastic nature of storms, the systematic uncertainty, the spatial variability of soil properties, and the geometric uncertainty of flow problems. Eagleson (1978) used the derived distribution approach to evaluate the water balance dynamics due to stochastic precipitation events. This approach was also adopted by Sagar and Kisiel (1972), and Dagan (1979). Freeze (1975) used Monte-Carlo simulations to study the effects of distribution of stochastic parameters on two flow problems: a steady state saturated flow and a transient consolidation of a saturated clayey layer. Other examples of Monte-Carlo simulation of flow problems can be found in Warren and Price (1961), Freeze (1977), and Smith and Freeze (1979).

Examples of application of the perturbation method in groundwater flow problem can be found in Baker et al. (1978), Gutjahr et al. (1978), and Gelhar et al. (1979). The first and second moment method based on Taylor's series expansion of the governing equation around the expected means has been applied successfully in groundwater modeling, e.g. Wilson and Dettinger (1978), Lee and Wu (1987), and Reddi and Wu (1991). 


\subsubsection{Probabilistic Analysis of slope stability}

\section{Reliability:}

The reliability of an engineering system may be formulated as a determination of the strength of that system to meet the required load. The available strength and the required load may be modeled as random variables. Define the following random variables: $X=$ the strength, and $\mathrm{Y}=$ the load. The objective of reliability analysis is to compute the probability $P(X>Y)$. If $\mathrm{X}$, and $\mathrm{Y}$ are statistically independent, then

$$
P_{f}=P(X<Y)=\int_{0}^{\infty} F_{X}(y) \cdot f_{Y}(y) d y
$$

Fig. 2.6 shows four different measures of reliability: the conventional factor of safety, $F_{s}$, the central factor of safety, CFS, the safety margin, $M_{r}$, and, the reliability index, $\beta_{r}$. They are defined as follows

$$
\begin{aligned}
& F_{s}=\frac{X}{Y} \\
& C F S=\frac{E(X)}{E(Y)} \\
& P_{f}=P\left(M_{r} \leq 0\right), \text { where } \quad M_{r}=X-Y \\
& \beta_{r}=\frac{E\left(M_{r}\right)}{\sigma_{M}}
\end{aligned}
$$

There are several requirements for any formal treatment of reliability:

1. clear delineation of the criteria for success or failure,

2. selection of a deterministic model relating the basic variables to the criteria for success or failure,

3. identification of the uncertainties concerning the basic variables, and

4. evaluation of the distribution functions or moments of the basic variables. 
Once these steps have been carried out, reliability analysis may then be made. One very obvious application of the reliability theory in geotechnical engineering is the analysis of the stability of slopes. In the simplest sense, the strength and the load are the resisting moment and the driving moment, respectively. A brief review of the application of reliability theory to the slope stability problem is given in the next section.

\section{Reliability of Slopes:}

The significance of uncertainties and errors involved in slope stability analysis has been long recognized. The literature is full of reported failures of nominally safe slopes, i.e. slopes having factors of safety greater than one. Most probabilistic methods of slope stability, described in the literature, focused on the analysis of individual slopes. They considered the variability of soil properties, the systematic errors or model errors in measurement of soil properties, and the model errors in analytical methods (Wu and Kraft, 1970; Cornell, 1971; Alonso, 1976; Tang et al., 1976; Vanmarcke, 1977; Duncan and Houston, 1983).

Assuming a probability distribution for the factor of safety, usually normal, log normal, or beta, Chowdhury and Tang (1987) derived a closed form solution for the mean and the standard deviation of the factor of safety. Variables such as soil depth and slope were not considered as stochastic variables in that study because the calculus needed to evaluate the integrals resulting from the derivation of the probability distribution of the factor of safety would not be tractable. In fact the closed form solution approach becomes extremely complicated unless applied to simple geometry. An alternative method to account for the large number of input variables is using Monte-Carlo simulation. The United States Department of Agriculture and Forest Service developed a computer program LISA (Hammond et al., 1991) that utilized Monte-Carlo simulations. Probabilistic solutions for slope stability are also obtained by FOSM method (Cornell, 1971; Tang et al., 1976; Wu et al., 1986). 
(a)

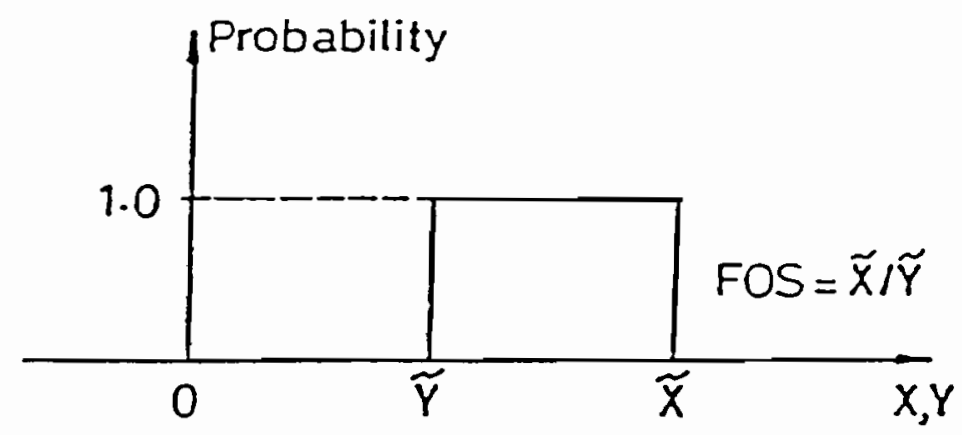

(b)

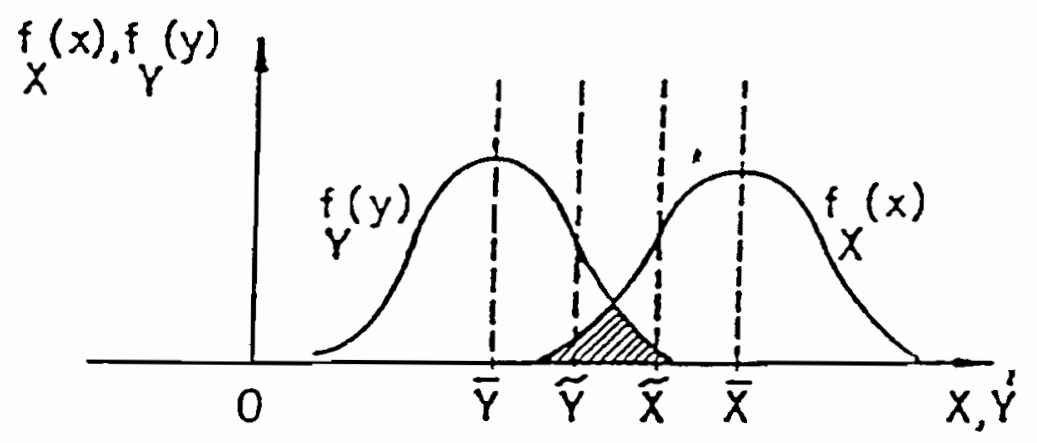

(c)

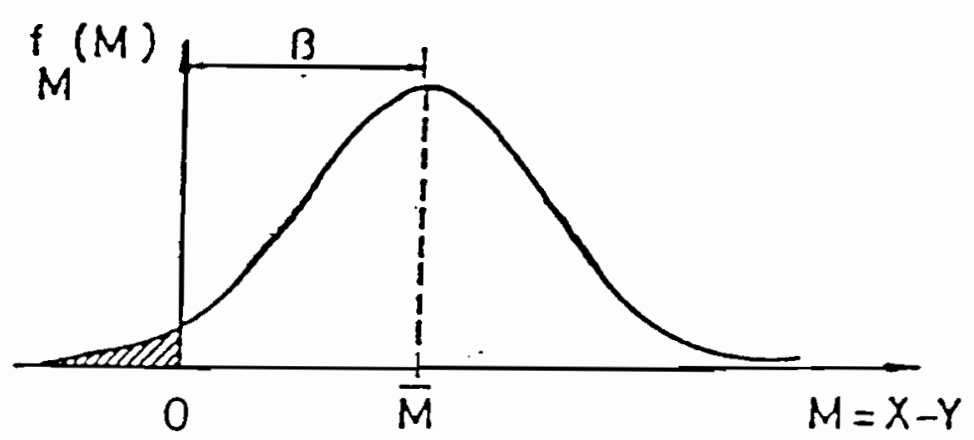

Figure 2.6: Reliability measures: (a) conventional factor of safety, (b) central factor of safety in supply-demand model, and (c) safety margin and reliability index (Dakhly, 1989). 
Recent refinements of reliability analysis of slopes include consideration of uncertainties about seepage (Bergado and Anderson, 1985), progressive failure (Chowdhury et al., 1987), and Hasofer-Lind reliability ( $\mathrm{Li}$ and Lumb, 1987). Comell (1971) pointed out that failure probability of a system of failure surfaces will be larger than that for any single failure surface. Oka and Wu (1991) studied the system reliability of the slope stability of the Congress Street cut. They pointed out the effect of spatial correlation of the soil properties on the system reliability.

\subsubsection{Model parameters}

\subsubsection{Groundwater parameters}

Information regarding the groundwater parameters are needed to solve groundwater flow problems. The basic groundwater parameters are permeability, $\mathrm{K}$, specific yield, $\mathrm{C}$, unsaturated parameters, $B$ and $\Psi$, and coefficient of evapotranspiration, $\alpha_{c}$. For definition of these parameters, refer to Appendices A and B. $K$ is the most important parameter governing the hillslope hydrologic response to a particular rain event. It has been well established that permeability varies with soil moisture content, $\theta$, in a highly nonlinear hysteric relationship (Hillel, 1982). Typical values of C with respect to grain sizes were reported by Eckis (1934) and Bear (1972) and are shown in Fig. A.1c. B and $\Psi_{s}$ were studied extensively by Holtan et al. (1968), and Clapp and Horenberger (1987). They reported the average values for different soil textural classes. $\alpha_{e}$ was studied by Black (1979); he suggested the range $0.6<\alpha_{e}<1.1$.

Permeability values usually show spatial variations within a geologic formation. They may also show variations with the direction of measurements. The first property is termed heterogeneity and the second, anisotropy. Studies of heterogeneity and anisotropy of permeability are available (see Freeze and Cheery, 1979, and Freeze, 1980). Many hydrogeologists have used statistical distribution to provide a quantitative description of the degree of heterogeneity in a geological formation. There is now a large body of evidence to support the statement that the 
probability density function for permeability is log-normal ( Warren and Price, 1961, Bennion and Griffith , 1966, and Freeze, 1975). The scale of fluctuation, $\delta$, is very much dependent on soil type. the scale of fluctuation of permeability varies from less than $1 \mathrm{~m}$ for varved clay to 6 m for glacial outwash deposit (Ali et al., 1980). Hoeg and Tang (1977) reported values of $\delta$ as large as $50 \mathrm{~m}$ for stiff clay till in the North Sea. Clapp and Horenberger (1978) reported the standard deviations of the unsaturated soil parameters for different soils.

\subsubsection{Shear Strength parameters}

The shear strength of soils results from the frictional resistance of particle-to-particle contact, the soil cohesion, and the supplemental cohesion provided by tree roots. Coulomb's equation of shear strength can be written as

$$
\tau=\grave{c}+\grave{c}+\dot{\sigma} \tan \dot{\phi}
$$

where $\tau=$ soil shear strength, $c^{\prime}=$ effective soil cohesion, $c_{r}^{\prime}=$ shear strength provided by roots, $\sigma^{\prime}=$ effective normal stress, and $\phi^{\prime}=$ effective angle of internal friction.

The soil strength parameters, $c$ and $\phi^{\prime}$, can be determined by means of laboratory tests, insitu tests, or indirect methods. For laboratory tests, great care and judgement are required in the sampling operation to preserve the in-situ structure and the water content of the soil. Systematic errors are unavoidable as a result of test imperfection, sample disturbance, and human factors. Direct shear test, unconfined test, and triaxial tests are the common laboratory shear tests (Lambe and Whitman, 1969). The uncertainties due to the discrepancies between in-situ and laboratory conditions were studied and evaluated (see Yucemen et al., 1973 and Yucemen and Tang, 1975). Common in-situ strength tests are cone penetrometer, and vane shear test. Test errors and uncertainties about test conditions were studied by Wu et al. (1987) and Tang et al. (1978). Indirect methods are used to estimate the soil shear strength parameters in the absence of soil testing and detailed site investigation. shear strength parameters may also be estimated 
from values reported in geological or geotechnical literature. The shear strength parameters may be inferred from other known soil properties such as gradation, plasticity, or relative density. This requires that the soil be classified according to the Unified Soil Classification System, (ASTM d2487-85), for instance Table 2.2. Typical correlation between $\phi^{\prime}$ and $c^{\prime}$ and other soil properties are available (see Lamb and Whitman, 1969; Prellwitz, 1981; Bjerrum and Simons 1960). Correlation errors are another source of systematic uncertainty; extrapolation from one site to another involves uncertainty due to different site conditions.

The parameters commonly used to describe the variability and uncertainty of the shear strength parameters are the point coefficients of variation, $\Delta_{r}$, the correlation distance, $\delta$, and the systematic coefficient of variation, $\Delta_{s}$. Consistently, the values of $\Delta_{r}$ for $\phi^{\prime}$ are smaller than $\Delta_{r}$ for $c^{\prime}$ ( Lumb, 1970; Alonso, 1976; Harr, 1977). Hansen (1967) and Meyerhof (1970) assigned values of $\Delta_{r}$ for $\phi^{\prime}$ between 0.1 and 0.15 . Alonso (1976) selected $\Delta_{r}=0.3$ for $c^{\prime}$ and $\Delta_{r}=0.15$ for $\phi$. $\delta$ was reviewed by Alonso (1975), Wu (1989), Chowdhury et al. (1987), and Tang (1984). The reported values of $\delta$ are between 1.0 and $5.0 \mathrm{~m}$. The reported values of $\Delta_{s}$ are in general smaller than $\Delta_{r}$ (see Chowdhury et al. 1987, and Tang et al., 1976). $c^{\prime}$ and $\Phi^{\prime}$ are generally considered to be inversely related. Cherubini et al. (1983) reported correlation coefficient values between -0.2 to -0.85 .

It is well documented that tree roots provide shear strength, $c_{r}$, to soil as represented by Eq. 2.17 (Gray and Leiser 1982). Some attempts have been made to quantify the magnitude of $c_{r}$ by measuring the tensile strength of individual roots, by direct shear tests on soil-root masses, by pull tests on large root systems or whole trees, and by back-analysis of existing failures (Wu, 1991). Table 2.3 summarizes measurements of the root strength per unit area of soil. The study by Greenway (1987) showed that differences between the root strength of species of the same family can be very large. There may be also large differences between the root strength of one 
Shear strength parameters for different soils (Hammond et al, 1991).

\begin{tabular}{|c|c|c|c|c|c|c|}
\hline USC & $\% D$ & 2o. por & C. psi & $\phi^{\prime}$. deg. & Source" & Macerial \\
\hline $\begin{array}{l}\text { GW } \\
\text { Loose }\end{array}$ & $\begin{array}{c}0-35 \\
- \\
0 \\
\end{array}$ & $\begin{array}{l}- \\
118-128 \\
98-111 \\
\end{array}$ & $\begin{array}{l}0 \\
0 \\
0\end{array}$ & $\begin{array}{l}35-38 \\
28-33.5 \\
36.3-39.3 \\
\end{array}$ & $\begin{array}{l}7 \\
15 \\
17\end{array}$ & 1. cruslied \\
\hline $\begin{array}{l}\text { Gw } \\
\text { Medium } \\
\text { Dense }\end{array}$ & $\begin{array}{c}35-65 \\
55 \\
5\end{array}$ & $\begin{array}{c}128-135 \\
12 ; \\
\end{array}$ & $\begin{array}{l}0 \\
0 \\
0\end{array}$ & $\begin{array}{l}38-41 \\
33.5-36.5 \\
38.4-39 \\
\end{array}$ & $\begin{array}{l}i \\
15 \\
11\end{array}$ & $50 \%$ R.5n gravel \\
\hline $\begin{array}{l}\text { Gll } \\
\text { Dense } \\
\text { to } \\
\text { very } \\
\text { dense }\end{array}$ & $\begin{array}{c}65-100 \\
= \\
= \\
70\end{array}$ & $\begin{array}{l}135-145 \\
125-135 \\
119.5-13 i \\
123-125.4\end{array}$ & $\begin{array}{c}0 \\
0 \\
0 \\
0 \\
790-1140\end{array}$ & $\begin{array}{l}41-45 \\
38.5-45 \\
>38 \\
39-46 \\
38.0-41.4\end{array}$ & $\begin{array}{l}7 \\
15 \\
16 \\
6 \\
3\end{array}$ & $\begin{array}{l}\text { SA-SR [alluvium] } \\
50-65 \% \text { SA-SR gravel }\end{array}$ \\
\hline $\begin{array}{l}\text { GP } \\
\text { Loose }\end{array}$ & $\begin{array}{c}0-35 \\
\cdots\end{array}$ & $108-118$ & $\begin{array}{l}0 \\
0 \\
\end{array}$ & $\begin{array}{l}33-3 \overline{0} \\
27.5-32.5\end{array}$ & 15 & \\
\hline $\begin{array}{l}\text { GP } \\
\text { Medium } \\
\text { dense }\end{array}$ & $\stackrel{35-65}{-}$ & $\begin{array}{l}0 \\
118-124 \\
11 i-122\end{array}$ & $\begin{array}{c}0 \\
0 \\
28 B-432 \\
\end{array}$ & $\begin{array}{l}36-39 \\
32.5-37 \\
38.7-40.4\end{array}$ & $\begin{array}{l}7 \\
15 \\
3\end{array}$ & $65.82 \%$ A gravel \\
\hline $\begin{array}{l}\text { GP } \\
\text { Dense } \\
\text { to } \\
\text { ver: } \\
\text { iense }\end{array}$ & $\begin{array}{c}65-100 \\
- \\
- \\
70 \\
90\end{array}$ & $\begin{array}{l}124-13 i \\
115-125 \\
111-12 i \\
126.5 \\
129.1\end{array}$ & $\begin{array}{l}0 \\
0 \\
0 \\
0 \\
432 \\
432\end{array}$ & $\begin{array}{l}39-43 \\
37-42.5 \\
>37 \\
38-42 \\
40.4 \\
44.4\end{array}$ & $\begin{array}{l}7 \\
15 \\
16 \\
6 \\
3 \\
3 \\
\end{array}$ & $\begin{array}{c}52-100 \% \text { SA-SR gravel } \\
\quad \text { [alluvium] } \\
65 \% \text { Agravel } \\
62 \% \text { Agravel }\end{array}$ \\
\hline $\begin{array}{l}\text { c.l1 } \\
\text { Loose }\end{array}$ & $\begin{array}{c}0-35 \\
0 \\
\end{array}$ & $\begin{array}{c}114 \\
51.5-91 \\
\end{array}$ & $\begin{array}{c}0 \\
- \\
104-200 \\
\end{array}$ & $\begin{array}{l}33-36 \\
33.6-43 \\
\end{array}$ & i1 & $\begin{array}{l}50 \% \text { R-SR giavel } \\
\text { Colluviuni igraymackef }\end{array}$ \\
\hline $\begin{array}{l}\text { Cis } \\
\text { Medium } \\
\text { dense }\end{array}$ & $65-100$ & 119 & $\begin{array}{r}0 \\
430\end{array}$ & $\begin{array}{l}30-39 \\
39.5\end{array}$ & $i$ & \\
\hline $\begin{array}{l}\text { Cst } \\
\text { Dense } \\
\text { to very } \\
\text { dense }\end{array}$ & $6 j-100$ & $120-135$ & $\begin{array}{l}0 \\
0\end{array}$ & $\begin{array}{l}39-43 \\
>37\end{array}$ & $i$ & \\
\hline $\begin{array}{l}G C \\
\text { Dense } \\
10 \\
\text { very } \\
\text { dense }\end{array}$ & $\begin{array}{l}65-100 \\
90 \% \text { of } \\
T 99 \text { ?mas }\end{array}$ & $\begin{array}{l}123-125 \\
106-118\end{array}$ & $\begin{array}{l}650-720 \\
0-360\end{array}$ & $\begin{array}{l}>31 \\
32.2-34.2 \\
33.6-14.7\end{array}$ & $\begin{array}{l}4 \\
9\end{array}$ & $\begin{array}{l}50-65 \% \text { SA-SR gravel } \\
\text { Clacial sill } \\
\text { [grayuacled }\end{array}$ \\
\hline
\end{tabular}


species growing in different locations (Wu, 1991). It is also known that root properties depend on site conditions but the relations are not well established. Hence extrapolation of data from site to another involves uncertainty. Considering the wide range of $c_{r}^{\prime}$ reported in Table 2.3, these values may only serve as a rough guide in the estimation of $c_{r}^{\prime}$. Ziemer (1981a,b) studied the effect of tree removal on $c_{r}$. He estimated that root strength could be 20 to $40 \%$ of its undisturbed value according to harvesting method as shown in Fig. 2.7. The root strength depends not only on the tensile strength of the individual root, but also on the pull-out resistance which depends on the morphology of the root system. That is, how many roots there are and whether they cross the failure plane. Fig. 2.8 describes four soil-root morphology types and the suggested corresponding probability distribution functions for both densely forested and clearcut conditions.

\subsubsection{Slopes}

The slope at a given point is defined by a plane tangent to the surface at that point. It comprises two components namely, gradient and aspect. Gradient is the maximum rate of change of elevation. Aspect is the compass direction of this maximum rate of change (Evans, 1980). Many authors use "slope" to mean gradient (e.g. Peuker et al., 1978, and Marks $t$ al., 1984). Following Peuker et al. (1978), all subsequence references to slope imply gradient. Slopes can be determined from contour maps or from data in digital elevation model (DEM). Slope, $\alpha$, between two points determined from contour map is simply the drop in elevation divided by the distance, $l$, between the two points. Then,

$$
\tan \alpha=(\Delta z / \Delta x)=\frac{z_{1}-z_{2}}{l}
$$

where $z_{1}$ and $z_{2}$ are elevations of points 1 and 2 , respectively, and $l$ is the distance between the two points. In case of DEM, slopes are usually derived locally for each cell on the DEM matrix by computations made within a $3 \times 3$ cell window, that successively moved over the map, Fig. 


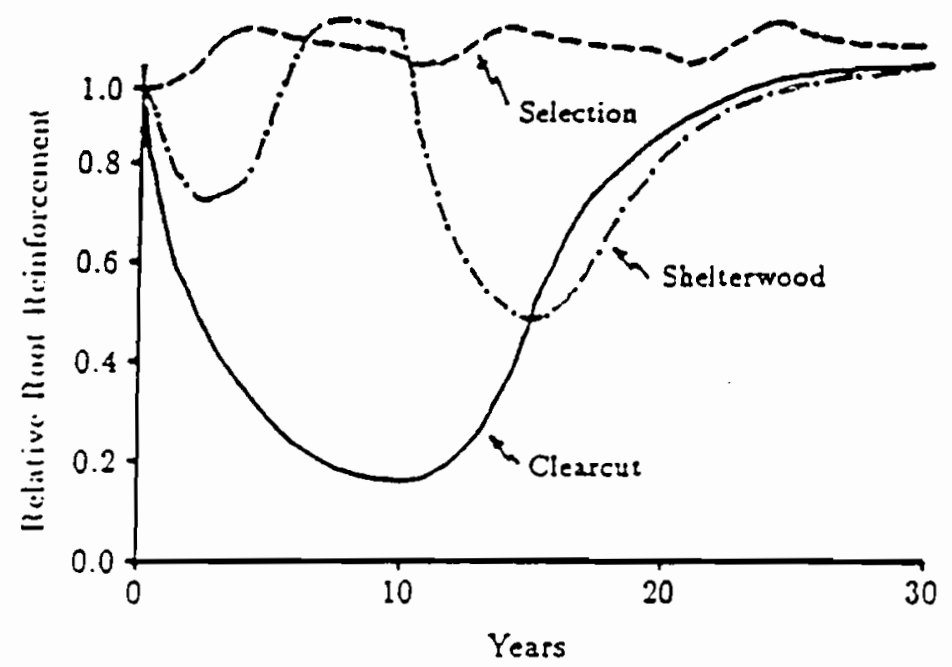

Figure 2.7: Effect of clearcut on root reinforcement (Ziemer, 1981). 
Table 2.3

Measurement of root shear strength per unit area (Hammond et al, 1991).

\begin{tabular}{|c|c|c|c|}
\hline Investigato: & Soil/Vegetatuon Type & $\begin{array}{l}\text { Root stren } \\
\mathrm{kPa}\end{array}$ & 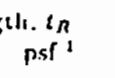 \\
\hline Endo \& Tsuruta $(1969 a)^{D}$ & cultiated nursery soil $/ 1-2 \mathrm{~m}$ alder saplings & $1.6-11.5^{2}$ & $3.3-240$ \\
\hline Endo \&. Tsu:uta $(1969 b)^{a, c}$ & $\begin{array}{l}\text { Poa annec, Ezo mugwort Ochada } 0-5 \mathrm{~cm} \text { depth } \\
\text { (Bamboo) } \\
5-20 \mathrm{~cm} \text { depth }\end{array}$ & $\begin{array}{l}10.7-12.1 \\
1.5-4.9\end{array}$ & $\begin{array}{l}224-253 \\
31-102\end{array}$ \\
\hline Burroughis \& Thomas (19iT) & $\begin{array}{l}\text { Tyee S.S. (SM)/coastal Oregon Douglas-fir } \\
\text { Idaho Batholith (SM)/ Douglas-fir }\end{array}$ & $\begin{array}{l}11.5-22.7 \\
4.2-14.0\end{array}$ & $\begin{array}{l}2+0-4 i 4 \\
8 i-293\end{array}$ \\
\hline $\begin{array}{l}\text { Wu and others }(1979)^{2} \\
\text { Waldiron \& Daiessian }(1981)^{\circ b}\end{array}$ & $\begin{array}{l}\text { Sar }\left(0^{\circ}=35-37^{\circ}\right) / \text { Mixed Silla spruce di hemlock } \\
\text { clay loam/Ponderosa pine seedlings }\end{array}$ & $\begin{array}{c}4.2-5.5 \\
5.0\end{array}$ & $\begin{array}{c}83-115 \\
104\end{array}$ \\
\hline $\begin{array}{l}\text { Zieme: }(19 S 1)^{*} \\
\text { O'Loughlin. Rowe \& Pierce }(1982)^{b, 3}\end{array}$ & $\begin{array}{l}\text { coastal sands/lodgepole } \\
\text { stony loam/beach }\end{array}$ & $\begin{array}{l}0.2-17.3^{2} \\
3.3\end{array}$ & $\begin{array}{c}4-362 \\
69\end{array}$ \\
\hline Waldron. Dakessisa \& Nemson $(1983)^{\circ}$ & clay loam/5-yess pine seedlings & $3.7-6.4$ & $i i-134$ \\
\hline \multirow[t]{2}{*}{ Reistenberg \&- Sovoniek-Dunford (19E3)* } & $\begin{array}{r}\text { sitiy clay }\left(0^{\prime}=12^{\circ}\right) / \text { sugar maples - head seasp } \\
\text { - slip surface }\end{array}$ & $\begin{array}{l}6.2-7.0 \\
3.8-1.6\end{array}$ & $\begin{array}{l}130-146 \\
79-96\end{array}$ \\
\hline & - average, entire slide & $\begin{array}{c}5.8 \\
5.0-12.6\end{array}$ & $\begin{array}{c}121 \\
11 i-263\end{array}$ \\
\hline \multirow{2}{*}{ Wu $(1984)^{*}$} & Sitica spruce & $3.7-7.0$ & $i i-146$ \\
\hline & yellow cedar & 5.4 & 113 \\
\hline Tsuliamoso \& Minemalsu $(1987)^{\circ}$ & nursery loam/Sugi & $1 . \varepsilon-5 . i$ & $3 \$-119$ \\
\hline
\end{tabular}

- Tensiie strength iests on individual roots

- Direct snear tesis

c Pull teses on roots

'Isolatei small trees and pulled - measuring basal shear resistance

1 i Pa $=20.9$ psí

: Mleasurec over a wide range of root densilies

3 Relerred to hy Sidle and others (1955) but not reviewed by these authors 

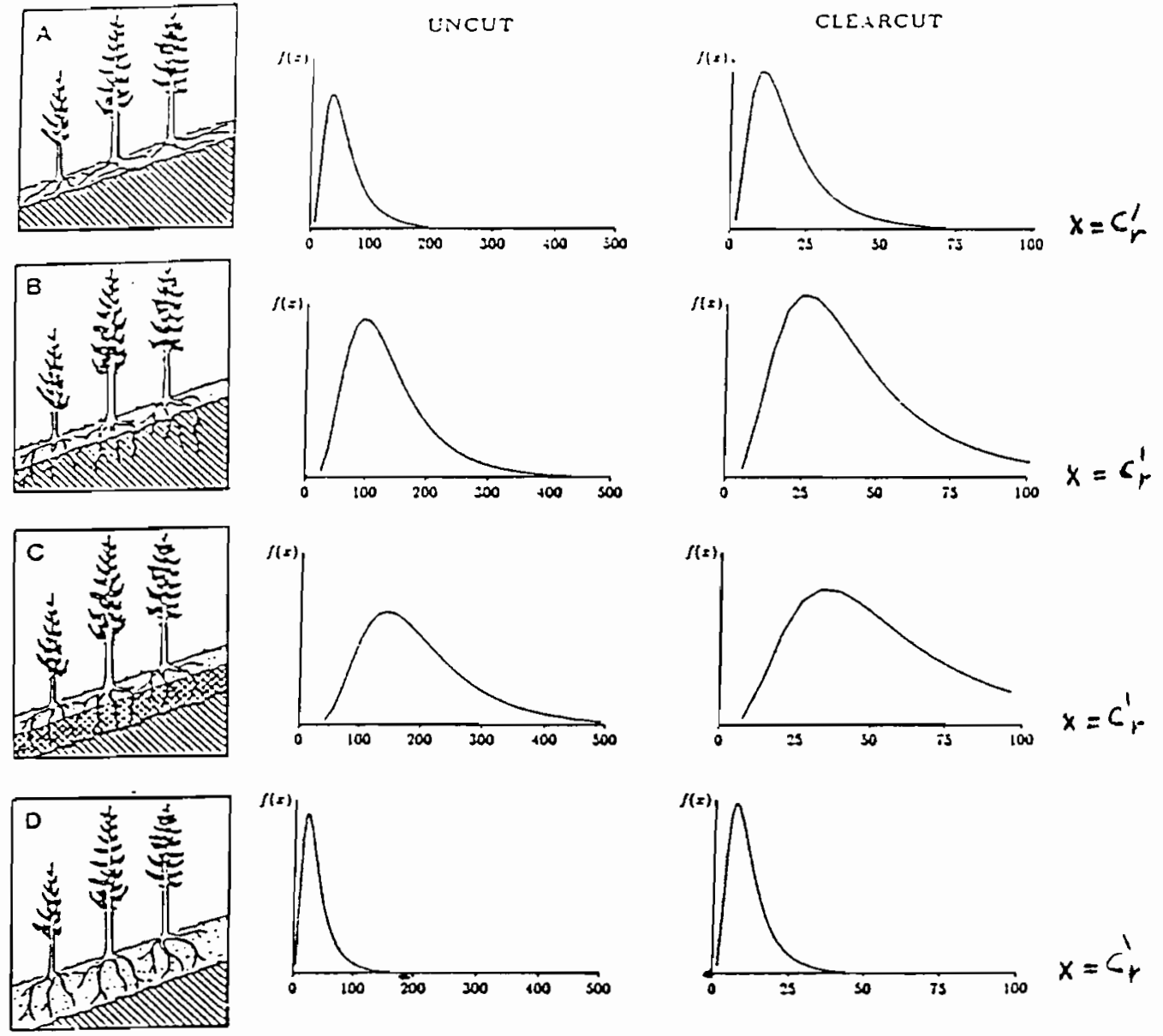

Figure 2.8: Root strength distribution for different morphology types (Tsukamoto and Kusakabe, 1984). 
2.9a. The slope is given by

$$
\tan \alpha=\left[(\partial z / \partial x)^{2}+(\partial z / \partial y)^{2}\right]^{1 / 2}
$$

where $\mathrm{x}, \mathrm{y}$, and $\mathrm{z}$ are the coordinate axes. The derivatives in Eq. 2.19 are computed by finite differences. The simplest finite difference estimate of gradient in the $\mathrm{x}$ direction at point ij in Fig. 2.9a, is

$$
[\partial z / \partial x]_{i, j}=\left(z_{i+1, j}-z_{i-1, j}\right) / 2 \delta x
$$

where $\delta x$ is the distance between cell centers. This estimator has the disadvantage that local errors in terrain elevations contribute heavily to errors in slope. A better estimator given by method of numerical analysis (Hom, 1981) is

$$
[\partial z / \partial x]_{i, j}=\left[\left(z_{i+1, j+1}+2 z_{i+1, j}+z_{i+1, j}\right)-\left(z_{i-1, j+1}+2 z_{i-1, j}+z_{i-1, j-1}\right)\right] / 8 \delta x
$$

The uncertainty about the elevation results in uncertainty about the calculated slope angle. The method of determining the elevation accuracy of contour map and DEM involves computation of residual error, $v$, between elevations derived from contour map or DEM and the corresponding true elevations. The root-mean-square-error (RMSE) is

$$
R M S E=\sqrt{\Sigma v^{2} /(n-1)}
$$

where $v$ is the difference between elevations from contour map or DEM and true measured elevation. The standard deviation, $S$, is

$$
S=\sqrt{\Sigma(v-\bar{X})^{2} /(n-1)}
$$

where $\bar{X}$ is the algebraic mean of the error and is defined as

$$
\bar{X}=\sum_{1}^{n} v / n
$$

then

$$
S=\sqrt{\left(R M S E^{2}-\bar{X}^{2}\right)}
$$

Three cases A, B, and C of the error $v$ are shown in Fig. 2.9b. Case A reflects a systematic shift of the surface and does not result in error in slope calculation. In case B the algebraic 
mean $\bar{X}=0$, then

$$
S=R M S E
$$

This is when $v$ cancels each other and the error is random. In case $\mathrm{C}, \bar{X} \neq 0$ and $v$ comprises systematic and random components. It is clear that errors in both cases A and C, Fig. 2.9b, are not as critical to slope calculation as errors in case B.

The accuracy of elevation on contour maps is based on the work of Koppe (see Lyytikainen, 1986) carried out in the first years of this century. He demonstrated that elevation errors increase in direct relation to terrain slope and established the following expression

$$
R M S E=A+B \tan \alpha
$$

where $\alpha=$ slope angle; $A$ and $B=$ constants established in relation to the scale and quality of mapping and are given in Table 2.4. The accuracy of elevation in DEM depends on the spatial resolution, i.e. grid spacing, quality of the source data, collection and processing procedures, and digitizing systems. Each DEM contains records of either estimated or computed RMSE. A RMSE of $7 \mathrm{~m}$ is considered to be a reasonable desired accuracy, attainable under a variety of terrain and instrument conditions (United States Gelogical Survey, 1990). A RMSE of $15 \mathrm{~m}$ is considered the maximum permitted error. Elevations in DEM are reported as integers which represents another source of error due to rounding.

The irregularity of the topographic surfaces represents another source of error in calculations of slopes. As shown in Fig. 2.9c, two forms of the same contour line; one has a high degree of resolution and the second does not. It is difficult to express the accuracy of the two contour line in numerical terms. However, Vieux (1991) showed that as the sampling interval increases with increasing cell size, the information loss is greater for surfaces with higher irregularities. The surface fractal dimension introduced by Mandelbort (1977) is a measure of irregularities of topographic surfaces. Thus the fractal dimension is an indication of how much information loss may occur due to sample interval. For example, for a plane surface with a fractal 
dimension equal to the Euclidian dimension of 2.0, the cell size will not influence the information loss. On the contrary, topographic surfaces possessing high variability with a fractal dimension greater than 2.0, will experience a higher degree of information loss as cell size increases. The information dimension is the fractal dimension computed by determining the information content as measured by entropy at different scales (Farmer and Ott, 1983). Vieux (1991) used the information dimension to measure the rate at which information are lost and errors are produced in the estimates of slopes. His results showed that the information loss in estimates of slope is $3 \%$ as the cell size increases from $30 \mathrm{~m}$ and $90 \mathrm{~m}$. The information loss increases to $20 \%$ as the cell size increases from $90 \mathrm{~m}$ to $210 \mathrm{~m}$. Values of fractal dimension of natural surfaces are in the order of 2.2 and 2.3 within scale $10 \mathrm{~m}$ to $1000 \mathrm{~m}$ (Mark and Aronson, 1984). These values are small and indicate also that the information loss due to sample interval may be neglected at sample interval of $30 \mathrm{~m}$.

Table 2.4

Values of A and B for high quality contour map (Imhof 1982).

\begin{tabular}{|l|l|l|}
\hline Scale & RMSE (m.) & RMSE for $\alpha=30^{\circ}$ (m.) \\
\hline $1: 1000$ & $0.1+0.3 \tan \alpha$ & 0.27 \\
$1: 5000$ & $0.4+3.0 \tan \alpha$ & 2.13 \\
$1: 10000$ & $1.0+5.0 \tan \alpha$ & 3.89 \\
$1: 25000$ & $1.0+7.0 \tan \alpha$ & 5.04 \\
$1: 50000$ & $1.5+10 . \tan \alpha$ & 7.27 \\
\hline
\end{tabular}


(a)
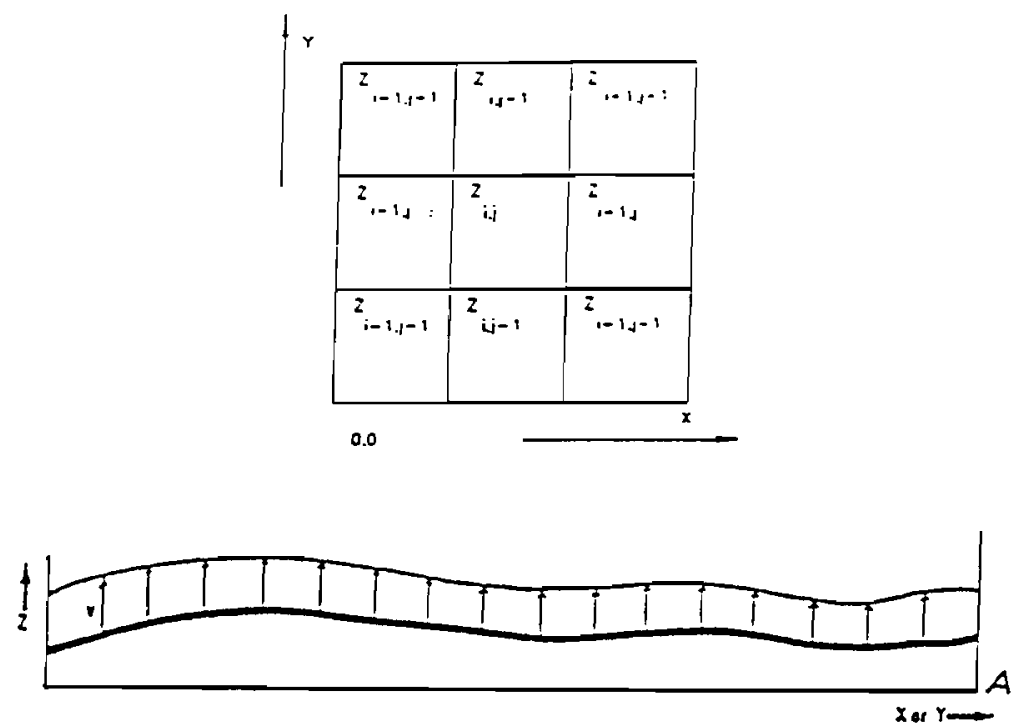

(b)
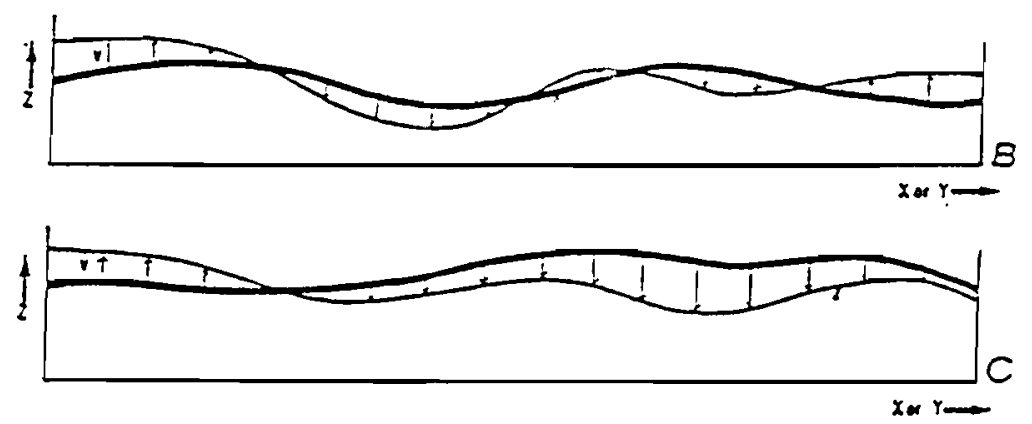

(c)

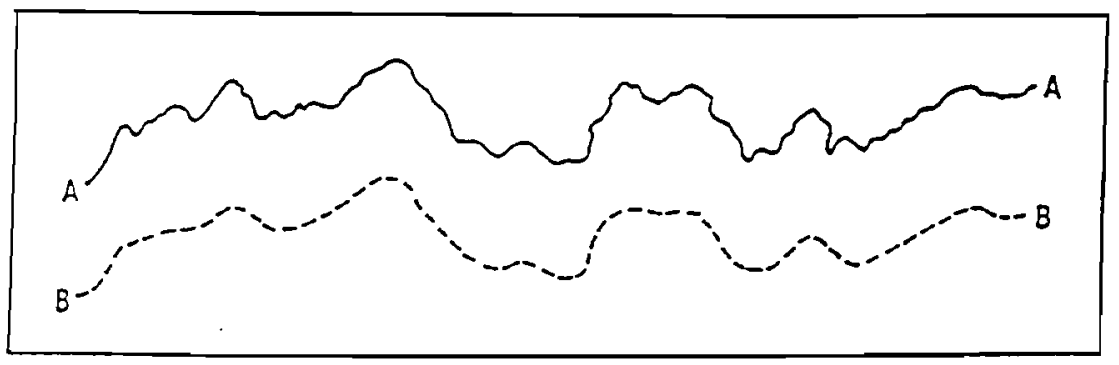

Figure 2.9. (a) Window used for computing derivatives of elevation, (b) modes of elevation errors, (c) precise and smooth representation of the same contour line (Shearer, 1980). 


\subsection{BAYESIAN UPDATING}

Classical estimation theory assumes that the parameters are unknown constants. Sample statistics are used as estimators of these parameters. Accurate estimates of parameters require large amounts of data. When data are limited, as is often the case in engineering, statistical estimates may be supplemented by judgmental information. In the classical statistical approach there is no provision for combining judgmental information with observational data in the estimation of the parameters. The Bayesian method approaches the estimation problem from another point of view; the unknown parameters are modeled as random variables. With this approach, subjective judgments based on intuition, experience, or indirect information can be incorporated systematically with observed data to obtain a balanced estimation (Ang and Tang, 1975). The Bayesian method is particularly helpful in cases where there is strong basis for such judgments. Let $\varepsilon$ denote the observed outcome of the experiment. Then Bayes' theorem is

$$
P^{*}\left(x=x_{i} \Pi \varepsilon\right)=\sum_{\sum_{i=1}^{n}} \frac{P\left(\varepsilon \prod x=x_{i}\right) P^{\prime}\left(x=x_{i}\right)}{P\left(\varepsilon=x_{i}\right) P^{\prime}\left(x=x_{i}\right)}
$$

where $P^{\prime}\left(x=x_{i}\right)$ and $P^{\prime}\left(x=x_{i}\right)$ are the prior and the posterior probabilities. Tang (1971) used the above formulation to obtain the probabilistic distribution of soil parameters such as shear strength and compressibility. Faloyan et al. (1970) used the Bayesian approach to show how the probability of success of an engineering analysis depends on the amount and nature of the engineer's previous experience with similar problems. Other examples of Bayesian updating applied to geotechnical problems can be found in Tang (1981), Cividini et al. (1983), Wu et al. (1987) and Ronold (1989).

Statistical decision theory concerns the situation in which a decision maker has to make a choice from a given set of available actions and where the loss of a given action depends upon a state of nature $x$ which is unknown. In Bayesian decision theory, $x$, is assumed to have a prior distribution. The decision maker combines prior knowledge of $x$ and stochastic information 
provided by an experiment to obtain a posterior distribution of $x$ and then choose the action that minimizes the expected loss over the posterior distribution. A statistical estimation problem is a special kind of statistical decision problem in which the decision made by analyst is the estimate of the value of an unknown parameter $x$. Depending on the particular choice of the estimator $\hat{x}$ and the actual value of the parameter $x$, a prediction error will result, generally followed by a loss. By modeling this estimation process in the context of decision analysis, the Bayes point estimator may be determined such that expected loss associated with the prediction error is minimized. Mathematically, if $\hat{x}$ is the estimator of a parameter whose actual value is governed by the distribution $f(x)$ then the expected loss resulting from the error in prediction is

$$
L=\int_{-\infty}^{+\infty} g(x, \hat{x}) f(x) d x
$$

where $g(x, \hat{x})$ is a loss function. Generally, a loss function is expressed in terms of the prediction error, namely $(x-\hat{x})$ (Ang and Tang, 1984). Since the Bayes estimator minimizes the expected loss it should satisfy the following equation

$$
\frac{d L}{d \hat{x}}=\frac{d}{d \hat{x}}\left(\int_{-\infty}^{+\infty} g(x, \hat{x}) f(x) d x\right)=0
$$

The Bayes estimator can be the mean, the median, or perhaps other values depending on the loss function appropriate for the problem ( Ang and Tang, 1984). Details of Bayesian decision theory are available (see Schweppe, 1973; Folayan et al., 1970; Martz and Waller, 1982; Iverson, 1984; Smith, 1988). Schweppe (1973) derived the Bayes estimator for a square loss function. Reddi and Wu (1991) used the Schweppe derivations to update the parameters of groundwater model using the observed piezometric levels. 


\section{CHAPTER III}

\section{MODEL OF SITE CONDITIONS}

\subsection{SOURCES OF INFORMATION}

Analyses of groundwater and landslide hazard were applied to the focus township that covers most of Glenoma and Mineral quadrangles, Washington. The site location is shown in Fig. 3.1. The site is also the location of the landslide inventory being conducted by M. J. Brunengo (1991). The site conditions are determined from the county soil survey report (Soil Conservation Services, 1987), the United States Geological Survey topographic data (USGS, 1990), and the geotechnical literature.

The county soil survey report provides a general soil map, which shows areas covered by different soil associations. Each soil association is related to a unique natural landscape. A soil association is named for the major soils and typically consists of one or more major soils and some minor soils. Fig 3.2a shows the soil associations in the focus township. The county soil survey report also provides a detailed soil map. Each detailed soil map unit on the the detailed soil map is a phase of a soil series. Soil series are soils that have unique profiles. Phases of a soil series have the same profile but they are different in texture of surface layer or underlying layers, slope, stoniness, wetness, and degree of erosion. Fig. 3.2b shows the phases of soil series in catchment \#77, identified in Fig. 3.3. The soil properties of each soil association and each soil series are given in the form of a range (Soil Conservation Services, 1987). Information are provided about saturated permeability, $K_{s}$, soil depth, H, and soil texture. 
Soil properties that are not listed in the soil report are: drainable porosity, $\theta_{d}$, saturated water content, $\theta_{s}$, unsaturated flow parameters, $\beta, \psi_{s}$, angle of internal friction, $\phi^{\prime}$, and cohesion $c^{\prime}$. Data from geotechnical literature (e.g. Tang et al, 1976; Schroeder, 1983 ; Clapp and Horenberger, 1978; Hammond et al, 1991) were used to estimate the soil properties and uncertainties that are not listed in the soil report. Table 3.1 shows the sources of information for each soil property.

Topographic data from USGS (1990) are available as contour maps or as Digital Elevation Models (DEM). The contour maps of Glenoma and Mineral quadrangles are from 7.5 minute series of scale 1:24000 (USGS, 1990) with contour interval of 40 feet (12.2 m). A raster-based DEM consists of a sampled array of elevations for a number of ground positions spaced at regular intervals of 98.4 feet $(30 \mathrm{~m})$.

Various maps were used in groundwater prediction and hazard prediction. Different maps show different information with different resolutions. A particular characteristic, such as elevation, soil type, etc., is shown to cover a given area, which is called a map unit. These map units are pixels, general soil map units, detailed soil map units, catchments, polygons, and quadrangles. Pixels are the units of the Digital Elevation Model (DEM). Their dimensions are 30x30 m. General soil map units or soil associations, shown in Fig. 3.2a, are identified from the county soil survey report (Soil Conservation Services, 1987). General soil map units are used to determine regional site conditions. Detailed soil map units or soil series, illustrated in Fig. 3.2b, are identified from the county soil survey report (Soil Conservation Services, 1987). Detailed soil map units or soil series are used to determine detailed site conditions.

Fig. 3.3 shows different map units used for mapping groundwater ratio, $h_{w} / H$, which is shown in Fig. 1.1, and landslide hazard which is defined as probability of slope failure. A catchment is the unit of the groundwater model. The topographic characteristics of a catchment affect groundwater flow. Extraction of topographic characteristics such as ridges, stream net- 
works, and boundaries of catchments from DEMs has been studied since early 1970 (Benosky, 1992). Many procedures have been developed to delineate catchments from DEM (see Bensoky (1992) for a list of these procedures). In these procedures, the user must decide on the minimum catchment size. Is is decided for the purpose of this study at the available level of information to use a catchment whose minimum size is set at 500 pixels or 111.2 acres. Fig. 3.3 shows the catchments delineated form Glenoma quadrangle with a minimum catchment area set at 500 pixels.

A polygon delineates an area where the variables that control slope stability are statistically homogenous. The size of a polygon depends on the scope of the analysis. Hammond et al. (1991) suggested that, for preliminary analysis, the user can start with available polygons such as land type map units delineated in landsystem inventories (LSI) used in Region 1 of USDA Forest Service, soil units delineated in the soil resource inventories (SRI) used in Region 6, or geologic units delineated in the geologic resources and conditions (GRC) maps also used in Region 6. Polygons can also be delineated based on bedrock type, surficial geology, or landform. A polygon can contain one or more catchments where site conditions, such as geology, soil properties, vegetation, and catchment characteristics are reasonably uniform. Similar site conditions may be expected to produce similar mass-movement characteristics, which are reflected in erosional and depositional features. Then mass-movement characteristics are expected to be similar within each polygon. Mass-movement characteristics have been used as a basis for delineating landform units in Washington (Brunengo 1981). So the landform unit is selected as the basis to delineate the polygons in this study. As an example, polygon \#1, \#2, and \#3 are shown in Fig. 3.3.

A quadrangle is a rectangular area of dimensions $13.9 \times 9.7 \mathrm{~km}$ covered in a $7.5^{\circ}$ topographic map. Table 3.2 list the different map units discussed above and used in the analyses of groundwater and slope stability. Table 3.2 also lists the soil map units used for these analyses. 


\subsection{SITE CONDITIONS}

\subsubsection{Regional Site Conditions}

The landscape in this region consists of long steep slopes ranging from 20 to 45 degrees with relatively straight parallel drainage ways. The average valley slope is $25^{\circ}$ with average length of 2000 feet $(620 \mathrm{~m})$. The elevation of ridges ranges from 1400 to 3200 feet (420 - 970 m.) above sea level. The main woodland species are mature Douglas Fir and Western Hemlock. The predominant soil associations on the valley slopes of the study area are Pheeney-Jonas, Vailton, and Stahl-Reichel. These soil associations are mainly gravelly loam and they are typically covered by 1 to 2 in $(2.5-5 \mathrm{~cm})$ of organic materials. The soil cover is shallow and ranges from 20 to 60 in $(0.5-1.5 \mathrm{~m})$. The soil properties of each soil association are given in the form of a range in values (Soil Conservation Service, 1987). The soil properties of these soil associations are very similar, such that the same averages may be used for all of these soil associations. The value of the saturated permeability, $K_{s}$, ranges from 0.2 to $6.0 \mathrm{in} / \mathrm{hr}(0.5-15 \mathrm{~cm} /$ hr). Since the probability distribution of $K_{s}$ is log-normal (Freeze, 1975), the geometric mean value of $K_{s}=0.028 \mathrm{~m} / \mathrm{hr}$ was used. For other soil properties, uniform distribution was assumed over the ranges of the soil properties reported either from the soil report or from the geotechnical literature, listed in Table 3.1.

Data in Schroeder (1983) and Bear (1972) were used to estimate the mean and variance of the saturated water content, $\theta_{s}$, and the drainable porosity, $\theta_{d} \cdot \theta_{s}$ and $\theta_{d}$ were chosen to be 0.45 and $\mathbf{0 . 3 4}$, respectively, for the case of gravelly sandy loam, the predominant soil type in the study area. Data in Clapp and Horenberger (1978) were used to estimate the mean and variance of B and $\Psi_{s}$ Table 3.3 shows the ranges and the mean values of soil properties used as input to the hydrologic model. No explicit information are provided about strength parameters $c^{\prime}$ and ф. Data in Prellwitz (1981), Hammond et al. (1991), and Schroeder (1983) were used to esti- 
mate the mean and c.o.v. of these parameters. The estimated ranges of strength parameters for the site are also listed in Table 3.3.

\subsubsection{Local Conditions}

For detailed analysis, the soil properties from the detailed soil map (Soil Conservation Services, 1987) were used. The ranges of $K_{s}$ and $H$ of each detailed soil map unit are reported in the county soil survey report (Soil Conservation Services, 1987). Mean and variance of $K_{s}$ and $H$ of each detailed soil map unit were calculated following the same steps as in evaluating regional site conditions. $\theta_{s}$ and $\theta_{d}$ were estimated from literature (Schroeder, 1983). B and $\Psi_{s}$ were estimated from literature (Clapp and Horenberger, 1978). Same ranges, means, and variances of $\theta_{s}, \theta_{d}, B$, and $\Psi_{s}$ were assigned to all detailed soil map units.

To estimate $c^{\prime}$ and $\phi^{\prime}$, each detailed soil map unit was first classified according to the Unified Soil Classification System (ASTM D2487-85). Then data reported by Prellwitz (1981), Schroeder (1983), and Hammond et al. (1991) were used to estimate the ranges of $c^{\prime}$ and $\phi^{\prime}$ for each detailed soil map unit.

\subsubsection{Geologic Anomalies}

Geologic anomalies include all geologic features that depart from regional site conditions stated in Table 3.3. These features are not described in the county soil survey report (Soil Conservation Services, 1987). The principal anomalies are: pervious inclusions, weathered zone in bedrock, and bedrock fractures. These were identified by Brunengo (1991) based on observations in the focus township.

In the focus township, pumice layers, composed of particles $1-2 \mathrm{~cm}$ in diameter, constitute the pervious inclusions. These layers may be up to $0.3 \mathrm{~m}$ in thickness and $20 \mathrm{~m}$ in length. The permeability of these layers is much larger than that of the regional site conditions. A hypothetical profile and cross-section are shown in Fig. 3.4a. A pumice layer may be broken or inter- 
rupted, as shown in Fig. 3.4a. However, the width of the break in the $\mathrm{Y}$ direction is expected to be less than $2 \mathrm{~m}$ and therefore the influence of the break in $\mathrm{Y}$ direction on the flow is ignored (Wu et al., 1993). For each detailed map unit, a continuous pumice layer is assumed to be present when "pumice" is mentioned in the soil profile reported by the county soil report (Soil Conservation Services, 1987).

Weathered zones are often observed in volcanic bedrock. These weathered layers are composed of coarse grained particles up to boulders of $0.3 \mathrm{~m}$ in diameter. The percentage of boulders increases with depth from 15\% at the surface to $65 \%$ near the soil-rock interface (Brunengo, 1991). The fractures and joints of bedrock are another type of geologic anomalies. The maximum dimension of interconnected joints is shown in Fig.3.4b. Without detailed field data on the continuity of the joints, we assumed that the probability that a continuous joint exist is $\mathbf{1 . 0}$ (Wu et al., 1993). The properties and the effect of these geologic anomalies are discussed in Section 5.4 in details.

\subsection{UNCERTAINTY ABOUT SOIL PROPERTIES}

\subsubsection{Systematic Uncertainty}

Systematic uncertainties arise because of insufficient data or observations used to compile the soil report. Systematic uncertainties of soil properties were predicted from the ranges of soil properties in the county soil survey report (Soil Conservation Services, 1987), and from literature review as described in Sections 3.3.1 and 3.3.2 and listed in Table 3.3. Uniform distributions were assumed over these ranges. The means, the systematic variances, and the systematic c.o.vs, $\Delta_{s}$, were calculated and they are listed in Table 3.3. 


\subsubsection{Random Variations}

Random variations, reviewed in Section 2.3 .2 .3 , denote the natural variability of site conditions from one point to another. The county soil survey report (Soil Conservation Services, 1987) provides no information about random variations. They were predicted from site observations and literature review. Observations by Brunengo (1991) in the focus township indicated that variations of $K_{s}$ within plus or minus $0.5 \mathrm{E}\left(K_{s}\right)$ can occur within distance of 3-7 m. However, variations of an order of magnitude were considered unlikely within a distance of $70 \mathrm{~m}$. Spatial variations in bedrock slope and soil thickness are illustrated in Fig. 3.4a. Observations in the focus township indicated that irregularities in the bedrock profile are not likely to exceed that shown in Fig. 3.4a (Brunengo, personal communication, 1991). The random variations of $K_{s}$ and $\mathbf{H}$ are of the same order as those measured at Kennel creek (Swanston, personal communication, 1985, see Reddi and $\mathrm{Wu}, 1991)$. So the latter was adopted for this region. The measurements of $\theta_{d}$ at Kennel Creek (Swanston, personal communication, 1985) were also used to predict its random variations. No information are available about the random variations of $\beta, \psi, \theta_{s}$. In the mean time, the effect of $\beta, \psi, \theta_{s}$ on $h_{d} / H$ is small as is shown in Section 5.1. Then, the random variations of $\beta, \psi, \theta_{s}$ were ignored.

Data in Alonso (1976), Lumb, (1970), and Harr, (1977), reviewed in Section 2.3.2.3, were used to estimate the point c.o.v., $\Delta$, for the strength parameters, $c^{\prime}$ and $\phi^{\prime}$. Data in Alonso (1976), Chowdhury (1987), Tang (1984), and Wu (1989) were used to estimate the correlation distance, $\delta$, of $c^{\prime}$ and $\dot{\phi}$. The estimated $\delta$ and $\Delta_{r}$, listed in Table 3.4 were used to calculate the random variation using Vanmarcke's random field model (1983). Recall Eq. 2.8 for random variation only

$$
\Delta_{l}=\Gamma(l) \Delta_{r}
$$


where $\Delta_{l}=$ c.o.v. of the spatial average over domain, $l, \Delta_{r}=$ point c.o.v., and $\Gamma(l)=$ an autocorrelation function defined by Eq. 2.7 and depends on $\delta$ and $l$ (Vanmarcke, 1983). Example of calculation of random variations at the pixel dimensions, i.e. $l=30 \mathrm{~m}$., for $c^{\prime}, \phi^{\prime}$, and $\mathrm{H}$, are given in Table 3.5.

\subsubsection{Occurrence Uncertainty}

It is clear from Fig. 3.3 that the size of a catchment or a polygon is large enough to contain several detailed soil map units. For brevity all subsequent references to soil unit imply detailed soil map unit. For instance, Fig. 3.2b shows catchment \#77 in Glenoma quadrangle and the different soil units within that catchment. The problem of identifying the spatial averages and their uncertainties is reviewed in Section 2.3.1.2. Tang et al. (1989) identified three different sources of uncertainty about the spatial average over a domain with dimension $l$ :

1. systematic uncertainty, discussed in Section 3.3.1,

2. random variation within the same soil type, discussed in Section 3.3.2, and,

3. occurrence uncertainty when there is more than one soil type within the domain.

The total uncertainty about the spatial average over a domain depends on the dimensions of the domain. If the domain dimensions are smaller than the soil unit dimensions, then only uncertainties of type 1 and type 2 exist.

The spatial average over a domain larger than soil unit such as a polygon or a catchment will have all three types of uncertainties listed above. However, The random variations is small because the ratio between the correlation distance, $\delta$, and the domain dimension, $l$, in Eq. 2.7 , is fairly small.

For a domain that comprises a quadrangle or a valley slope, all three types of uncertainty are present. If we use regional conditions, listed in Table 3.3, where only one set of soil properties is used, then occurrence uncertainty $=0$, and also random variations may be ignored because $l<<\delta$ for large areas such as valley slopes. 
Table 3.6 lists the different types of uncertainties associated with pixel, catchment, polygon, and valley slope based on their dimensions with respect to the detailed soil map unit dimensions. Detailed evaluation of different types of uncertainties are given in Chapter VI for groundwater and in Chapters VII, and VIII for slope stability.

\subsection{UNCERTAINTY ABOUT SLOPE}

The accuracy of topographic data, map or DEM, is reviewed in Section 2.3.3.3. Two types of errors in the topographic data are illustrated: the elevation error, $v$, illustrated in Fig. 2.9b, and the error as a result of surface irregularity, illustrated in Fig $2.9 \mathrm{c} . v$ consists of two parts: systematic error and random error. The systematic error, i.e. $\bar{X}$ in Eq. 2.24, does not affect slope calculations and no information is available about it. It is assumed that $\bar{X}=0$, i.e. RMSE $=S$, and $v$ is random in nature similar to case B in Fig. 2.9b. Then, the standard deviation of elevation error $=$ RMSE, i.e.

$$
\operatorname{Var} z=R M S E^{2}
$$

This assumption may result in overestimation of the error in slope. Also no information are available about correlation between RMSE and the distance between points. Then it is assumed in this study that there is no correlation between RMSE and the distance. Again this may result in overestimating the error in slope.

RMSE of elevation determined from contour maps is given in Table 2.4 (Imhof, 1982). For scale 1:24000, $R M S E=1+7 \tan \alpha$. As shown in Section 3.3.1 the average valley slope is $25^{\circ}$. Then RMSE $=4.76 \mathrm{~m}$. For simplicity, assume that $\tan \alpha \sim \alpha$ in radii. Then Eq. 2.18 becomes

$$
\alpha=\frac{z_{1}-z_{2}}{l}
$$

Using FOSM, Appendix C, on Eq. 3.2 then

$$
\operatorname{Var}(\alpha)=\frac{(1+1)}{t^{2}} \operatorname{Var}(z)
$$

Using Eq. 3.1, then 


$$
\operatorname{Var}(\alpha)=\frac{2}{l^{2}} R M S E^{2}
$$

As shown in Section 3.3.1, the average valley slope length, $l=620 \mathrm{~m}$. Then, Var $\alpha$ is $1.2 * 10^{-4}$; the standard deviation of $\alpha$ is $0.0108 \mathrm{rad} .\left(0.6^{\circ}\right)$, which is negligible.

For elevations evaluated from DEM, following the above approximation, i.e. $\tan \alpha \sim \alpha$, and assuming that $\alpha$ is in one direction only, i.e. downhill direction, $X$, to simplify the derivation. Then Eq. 2.19 becomes

$$
\alpha=\partial z / \partial x
$$

where the derivative $\partial z / \partial x$ is defined by Eq. 2.21. Using FOSM approximation, Appendix C, on Eq. 3.4 and 2.21, then the random variability of, $\alpha$, determined from DEM can be formulated as

$$
\operatorname{Var} \alpha=[\partial \alpha / \partial z]^{2} \operatorname{Var} z
$$

using Eq. 3.1, then

$$
=(1 / 8 \delta x)^{2}(1+1+1+1+4+4) R M S E^{2}=\frac{3}{16 \delta x^{2}} R M S E^{2}
$$

For RMSE $=7.0 \mathrm{~m}$ (USGS, 1990) and $\delta x=30 \mathrm{~m}$, which is the pixel spacing, then Var $\alpha=0.01$. The standard deviation is $0.1 \mathrm{rad}\left(\sim 5.7^{\circ}\right)$. Var $\alpha$, as a result of rounding elevations reported in the DEM was calculated in the same way; it is $0.0002 \mathrm{rad} .\left(\sim 0.01^{\circ}\right)$, which is negligible.

The error as a result of irregularities of topographic surfaces that is not captured by the resolution of the topographic map or the DEM is illustrated in Fig. 2.9c. Observation by Mark (1988) indicated that true pits or closed depression in natural topography are rare at scale of 10 m or greater. As illustrated in Section 2.3.3.3, analyses made by Vieux (1991) and Mark and Aronson (1984) indicated that, for a spatial resolution of $30 \mathrm{~m}$, the information loss is in the order of $3 \%$ which is very small. Then, the random variations associated with $\alpha$ as a result of irregularities of topographic surface is neglected. 
(a)

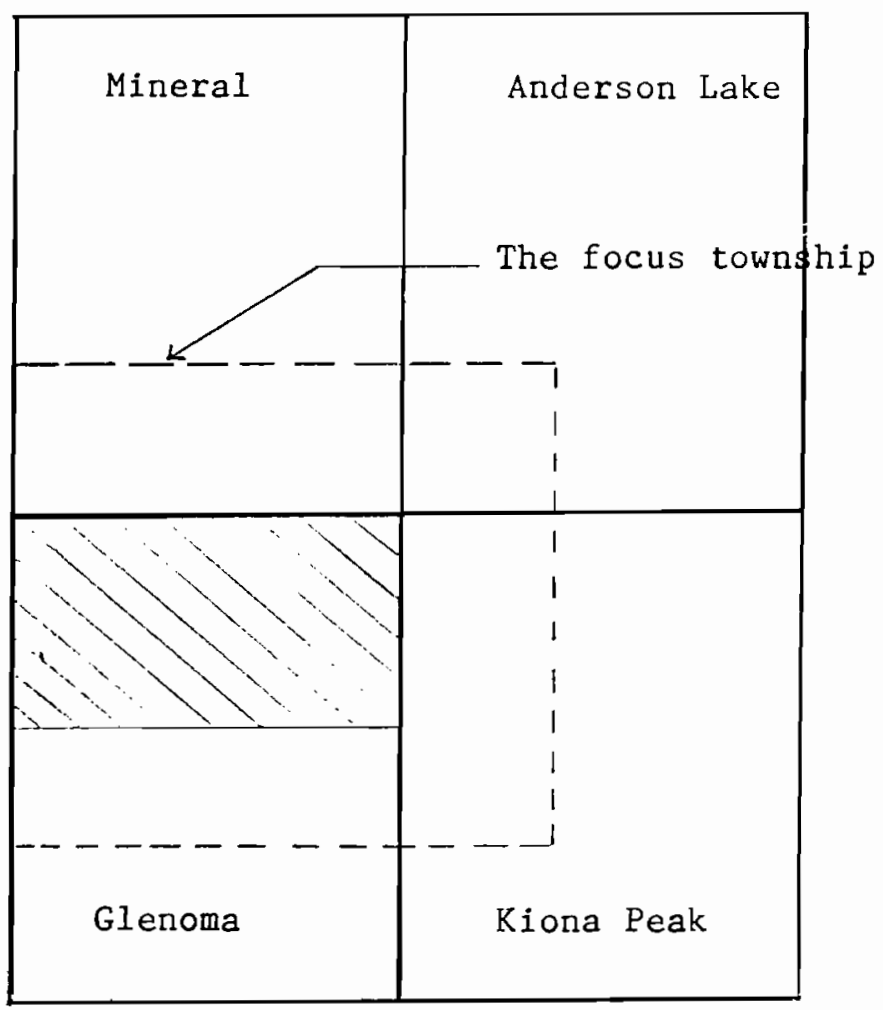

(b)

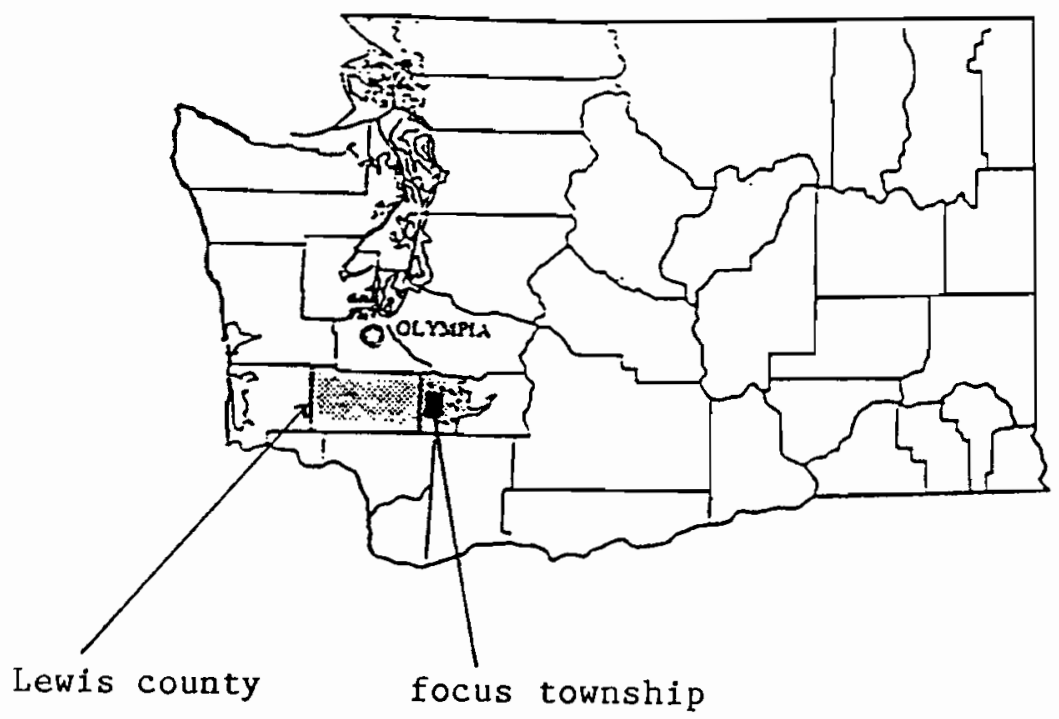

Figure 3.1: (a) The focus township, (b) the location of the focus township in Lewis county, Washington 
(a)

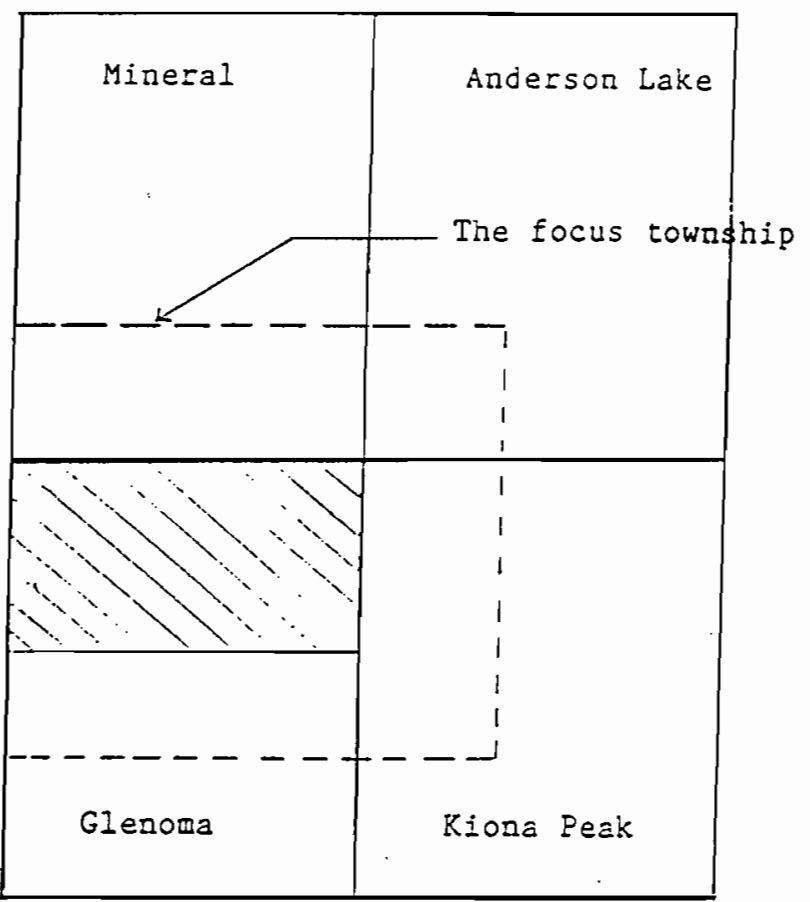

(b)

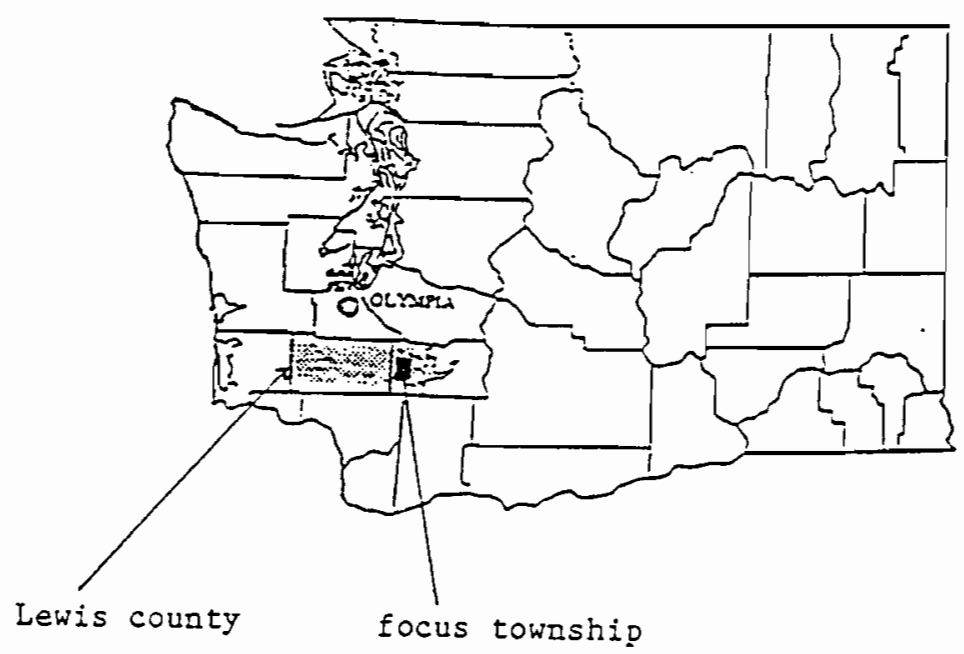

Figure 3.1: (a) The focus township, (b) the location of the focus township in Lewis county, Washington 


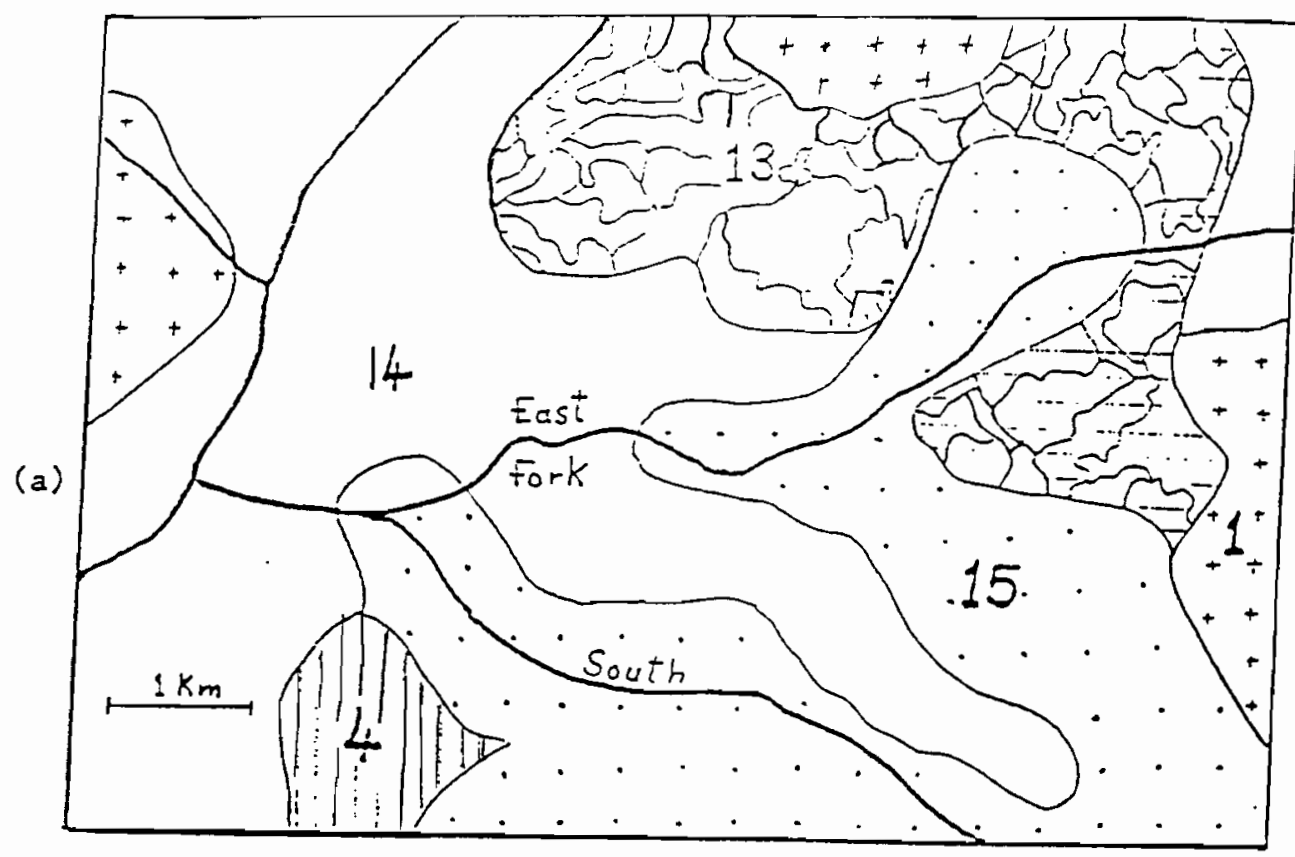

(b)

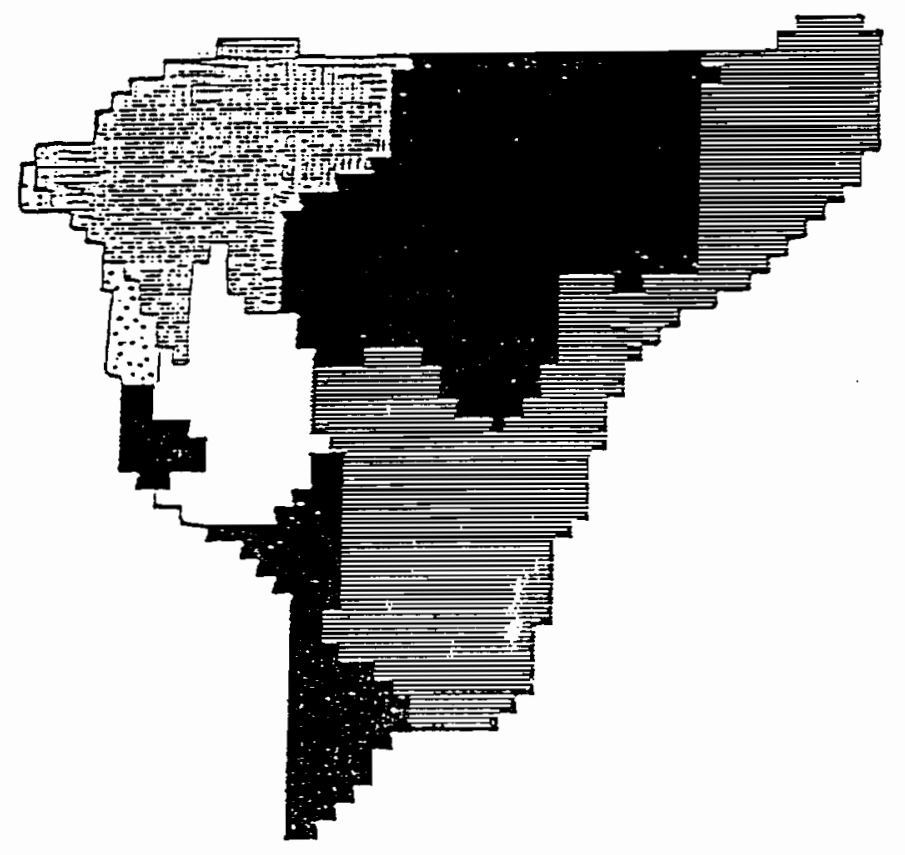

Figure 3.2: (a) Soil associations for the north part of Glenoma, the batched area in Fig. 3.1a. For scale illustration, soil series are snown within soil association $\# 13$. (b) Soil series of carchoment $\stackrel{\mu}{\pi} 77$ shown in Fig. 3.2. 


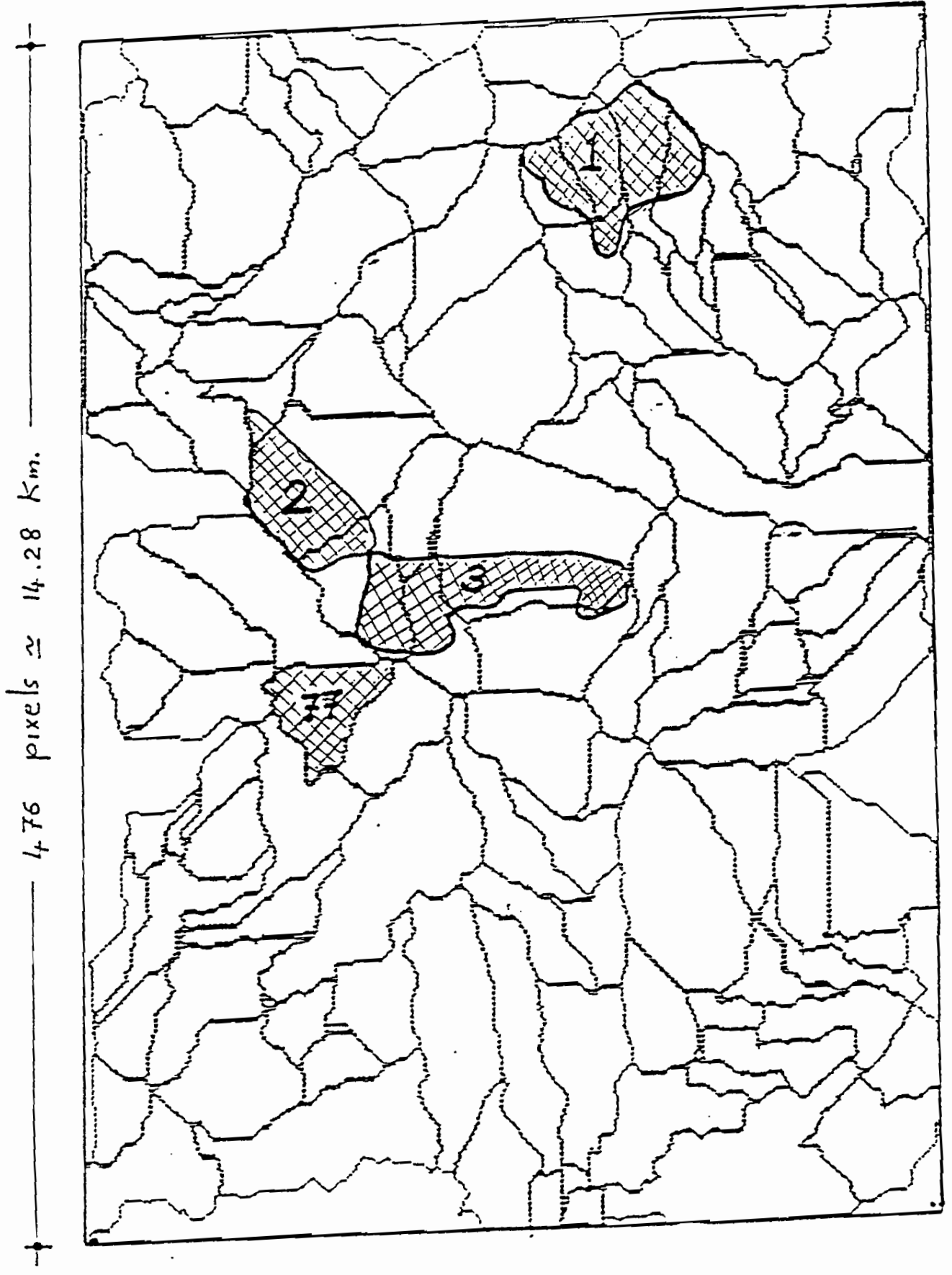

Figure 3.3: Catchments boundaries, and polygons $\frac{4}{\pi} 1, \pm 2$, and $\$ 3$, Gienoma quadrangle. 


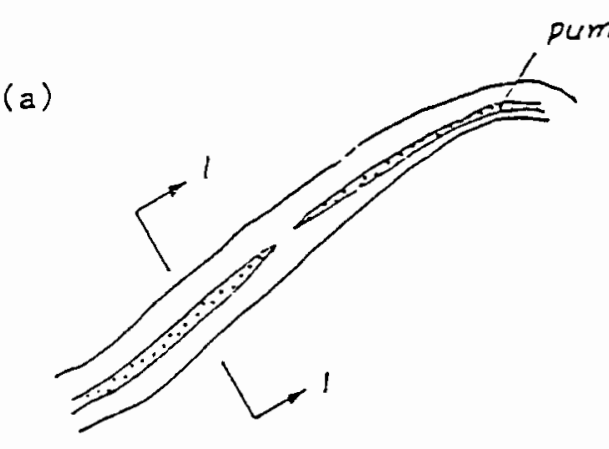

pumice

(a)

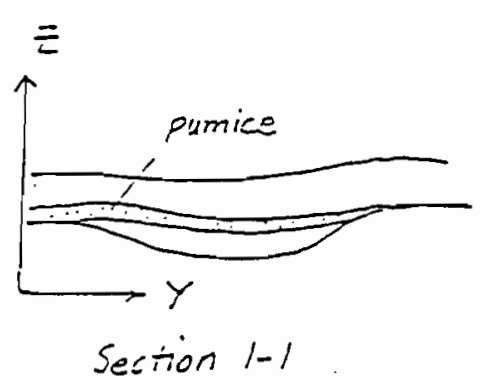

(b)

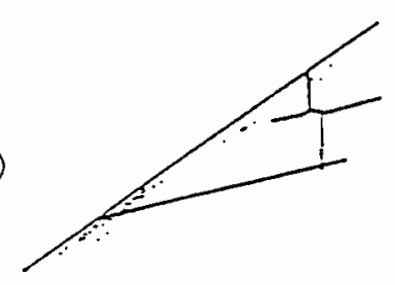

Sandstone
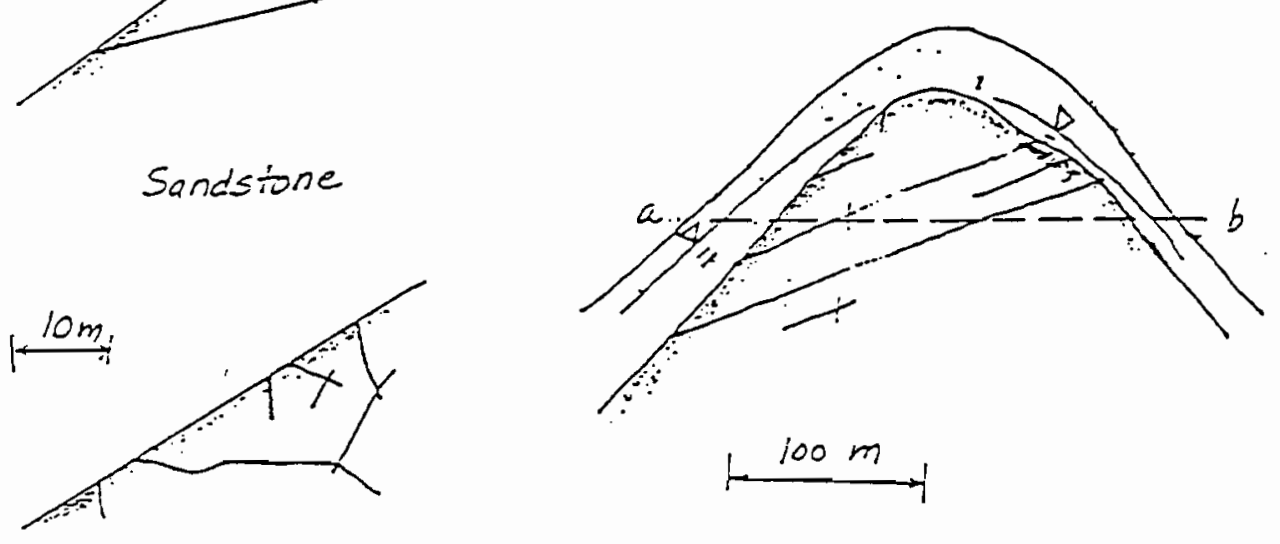

Voleanic rock

Figure 3.4: (a) Pervious inclusions in the soil layer, profile and section 1-1, (b) seepage through bedrock fractures (Wu et al., 1993). 
Table 3.1

Sources of information about soil properties.

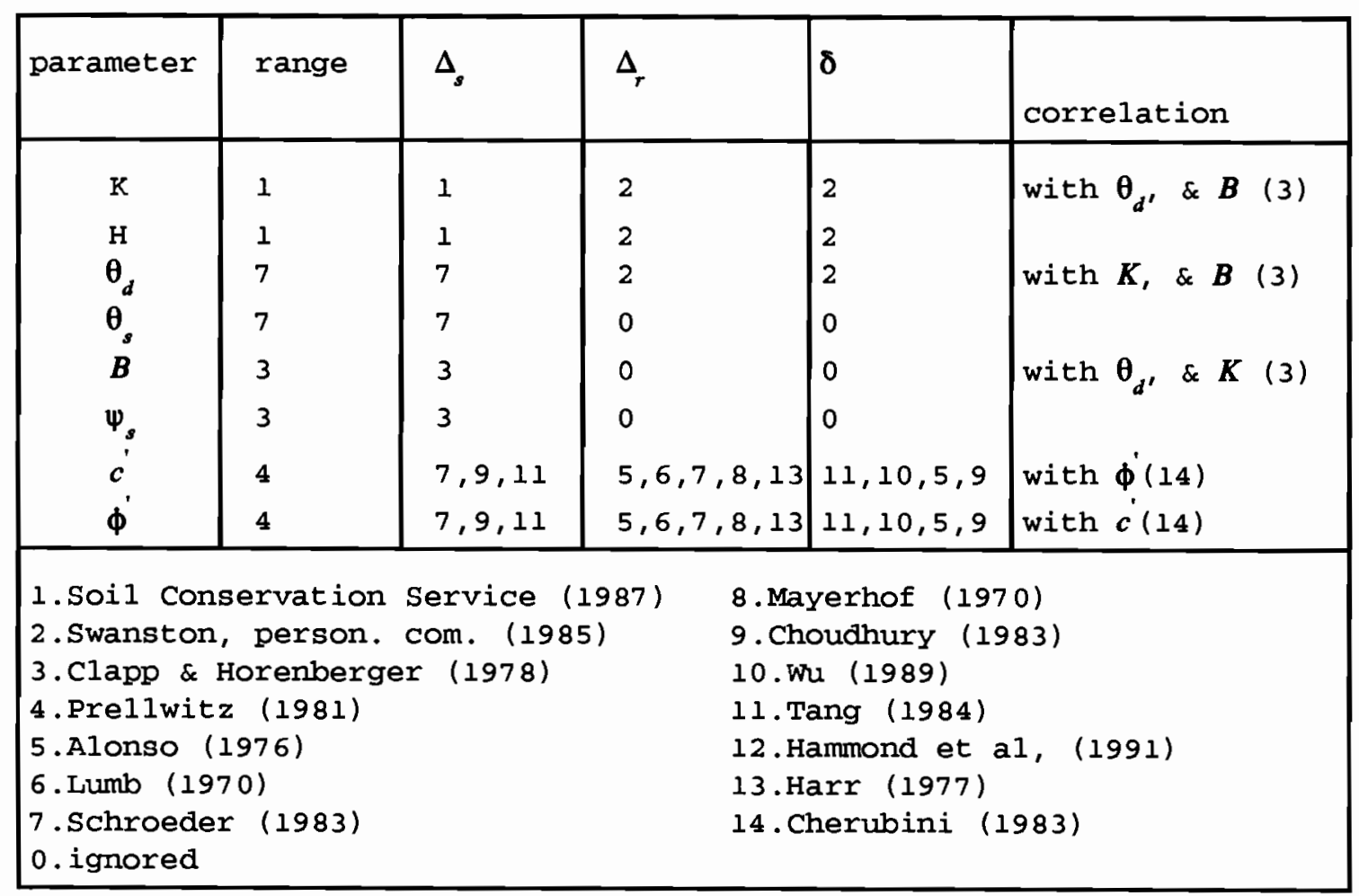


Table 3.2

Map units and corresponding soil units, models, and averages.

\begin{tabular}{|l|l|l|l|}
\hline map unit & soil units & model & site properties \\
\hline 1.pixel & $\begin{array}{l}\text { detailed soil } \\
\text { map unit } \\
\text { phases of soil } \\
\text { series }\end{array}$ & $\begin{array}{l}\text { converging } \\
\text { slope }\end{array}$ & $\begin{array}{l}\text { point } \\
\text { average }\end{array}$ \\
\hline 2.catchment & $\begin{array}{l}\text { detailed soil } \\
\text { map unit } \\
\text { phases of soil } \\
\text { series }\end{array}$ & $\begin{array}{l}\text { converging } \\
\text { slope }\end{array}$ & $\begin{array}{l}\text { local } \\
\text { average }\end{array}$ \\
\hline 3.polygon & $\begin{array}{l}\text { detailed soil } \\
\text { phases of soil } \\
\text { series }\end{array}$ & $\begin{array}{l}\text { converging } \\
\text { slope }\end{array}$ & $\begin{array}{l}\text { local } \\
\text { average }\end{array}$ \\
\hline $\begin{array}{l}\text { 4.quadrangle or } \\
\text { valley slope }\end{array}$ & $\begin{array}{l}\text { general soil } \\
\text { map unit } \\
\text { soil associations }\end{array}$ & $\begin{array}{l}\text { plane } \\
\text { slope }\end{array}$ & $\begin{array}{l}\text { segional } \\
\text { ite conditions }\end{array}$ \\
\hline
\end{tabular}


Table 3.3

Systematic uncertainty of soil parameters.

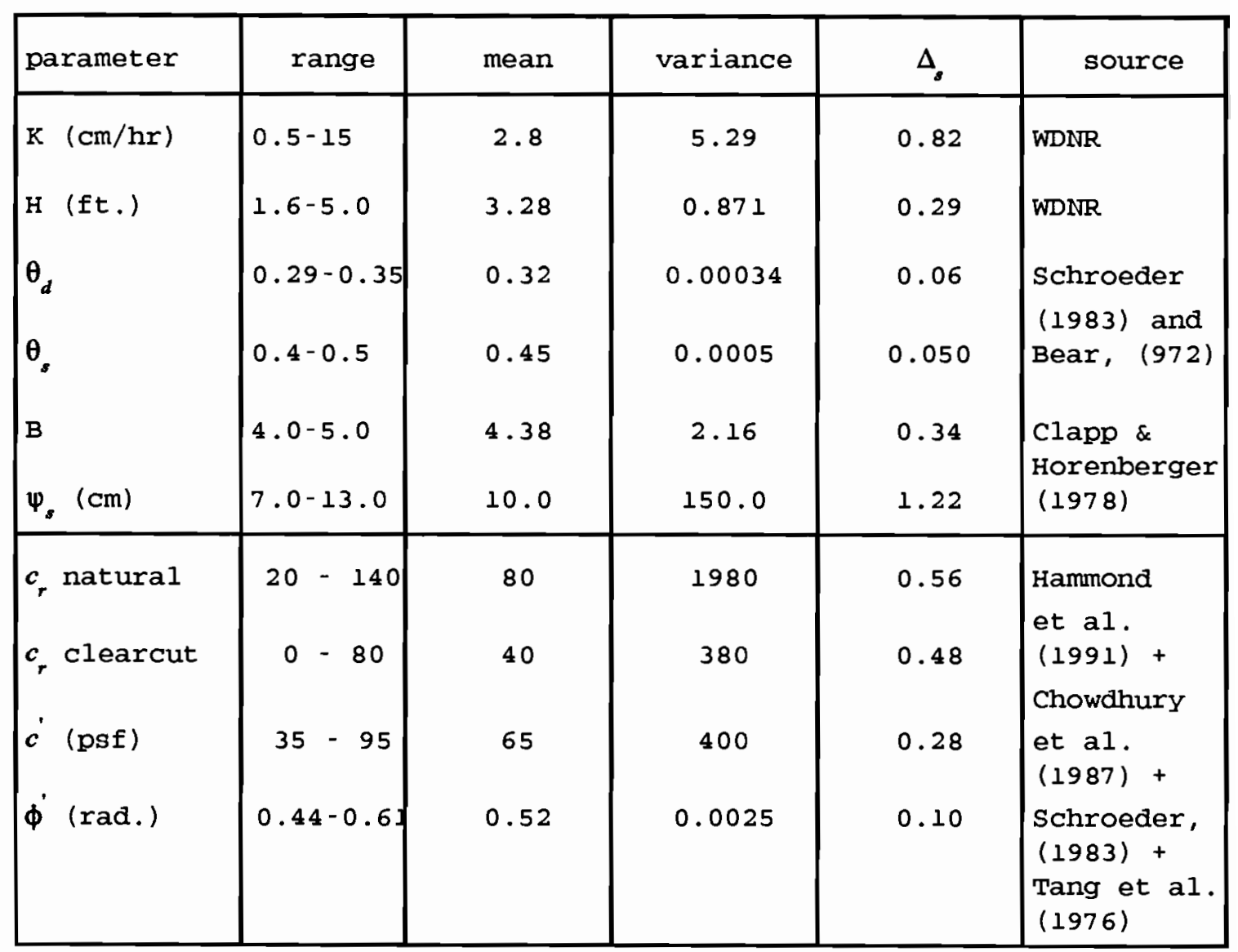


Table 3.4

Random variations of soil parameters.

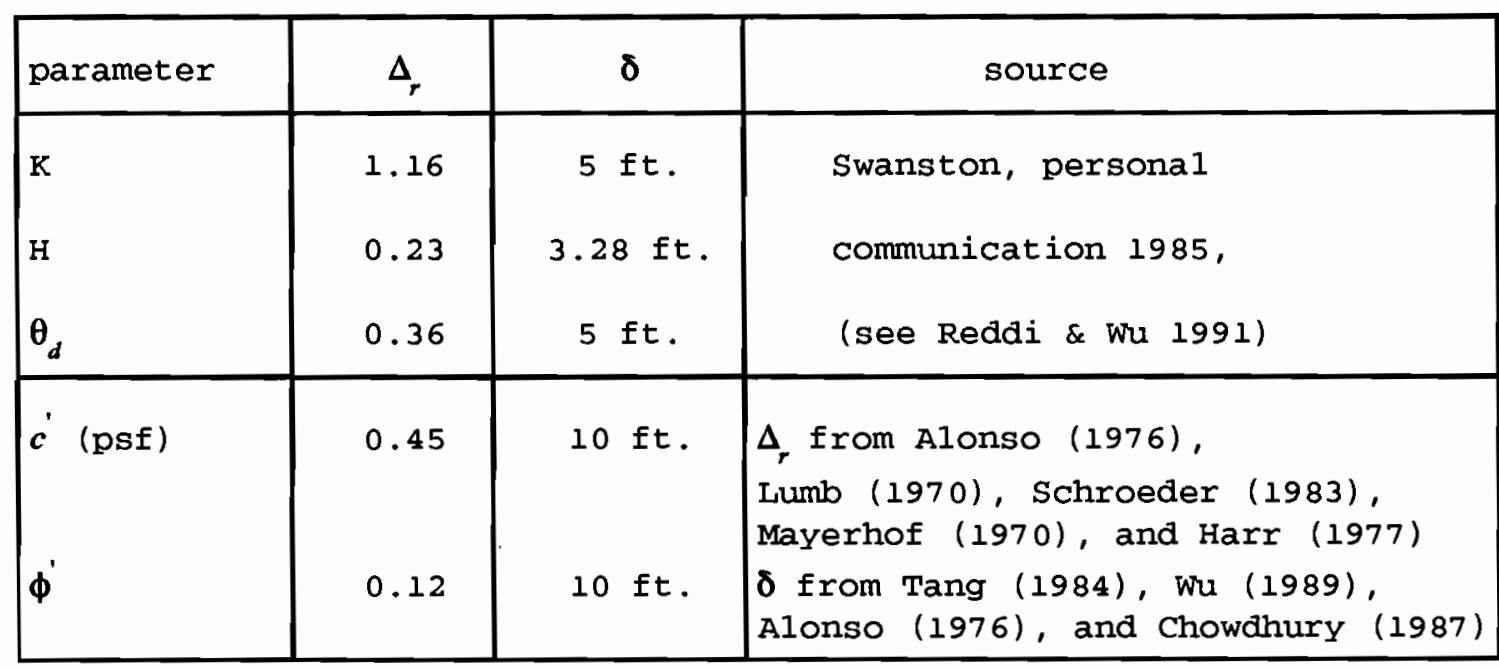

Table 3.5

Uncertainty of the parameters of stability model, pixel.

\begin{tabular}{|c|c|c|c|c|c|c|c|c|c|c|}
\hline Parameter & $\Delta_{s}$ & $\Delta_{r}$ & $\begin{array}{l}\delta \\
\mathrm{m} .\end{array}$ & $\begin{array}{l}1 \\
\mathrm{~m} .\end{array}$ & $\Gamma(l)$ & $\Gamma(l) \Delta_{r}$ & $\Delta$ & $\begin{array}{l}\text { system } \\
\text { Var. }\end{array}$ & $\begin{array}{l}\text { random } \\
\text { Var. }\end{array}$ & $\begin{array}{l}\text { tota1 } \\
\text { var. }\end{array}$ \\
\hline $\begin{array}{l}\text { c psf. } \\
\dot{\phi} \text { rad. } \\
\text { H ft. }\end{array}$ & $\begin{array}{l}.28 \\
.10 \\
.29\end{array}$ & $\begin{array}{l}.45 \\
.12 \\
.23\end{array}$ & $\begin{array}{l}10 \\
10 \\
3.28\end{array}$ & $\begin{array}{l}30 \\
30 \\
30\end{array}$ & $\begin{array}{c}.31 \\
.31 \\
.181\end{array}$ & $\begin{array}{l}.14 \\
.04 \\
.04\end{array}$ & $\begin{array}{l}.33 \\
.11 \\
.29\end{array}$ & $\begin{array}{l}400.0 \\
.0025 \\
.871\end{array}$ & $\begin{array}{l}61.0 \\
.0004 \\
.021\end{array}$ & $\begin{array}{l}461.0 \\
.0029 \\
0.893\end{array}$ \\
\hline
\end{tabular}


Table 3.6

Types of uncertainties and variations of map units.

\begin{tabular}{|c|c|c|c|c|}
\hline $\begin{array}{l}\operatorname{map} \\
\text { unit }\end{array}$ & $\begin{array}{l}\text { soil } \\
\text { unit }\end{array}$ & $\begin{array}{l}\text { systematic } \\
\text { uncertainty }\end{array}$ & $\begin{array}{l}\text { random } \\
\text { variation }\end{array}$ & $\begin{array}{l}\text { occurrence } \\
\text { uncertainty }\end{array}$ \\
\hline $\begin{array}{l}\text { l. } \\
\text { pixel }\end{array}$ & $\begin{array}{l}\text { soil } \\
\text { series }\end{array}$ & yes & yes & no \\
\hline $\begin{array}{l}2 \text {. } \\
\text { catchment }\end{array}$ & $\begin{array}{l}\text { soil } \\
\text { series }\end{array}$ & yes & $\begin{array}{l}\text { yes but ignored } \\
\text { because } \delta \text { is } \\
\text { small compared } \\
\text { to a catchment } \\
\text { dimensions. }\end{array}$ & yes \\
\hline $\begin{array}{l}3 . \\
\text { polygon }\end{array}$ & $\begin{array}{l}\text { soil } \\
\text { series }\end{array}$ & yes & $\begin{array}{l}\text { yes but ignored } \\
\text { because } \delta \text { is } \\
\text { small compared } \\
\text { to a polygon } \\
\text { dimensions. }\end{array}$ & yes \\
\hline $\begin{array}{l}4 . \\
\text { va11ey } \\
\text { slopes }\end{array}$ & $\begin{array}{l}\text { soil } \\
\text { association }\end{array}$ & yes & $\begin{array}{l}\text { yes but ignored } \\
\text { because } \delta \text { is } \\
\text { small compared to } \\
\text { a valley slope } \\
\text { dimensions. }\end{array}$ & no \\
\hline
\end{tabular}




\section{CHAPTER IV}

\section{RAINSTORM AND SNOWMELT MODELS}

\subsection{INTRODUCTION}

During a rain-on-snow event, snowmelt is produced due to the combination of relatively warm temperatures and moderate winds that accompany the storm. This snowmelt represents a significant source of water for infiltration. The total amount of infiltration is the sum of rainfall and snowmelt. Evaluation of the characteristics of infiltration is an essential step for groundwater and landslide hazard prediction. For this reason, the objective of the following analysis is to determine the suitable distributions of precipitation, snowmelt, storm duration, and intervals between a sequence of storms. Since groundwater and landslide hazard prediction are applied to the focus township. Then statistics of precipitation, snowmelt, etc. of this region are required. For this reason, Brunengo's statistics (1989) of winter storms in the central cascades of Washington were used.

Brunengo (1989) analyzed 38 years (1944 - 1982) of relatively complete storm data from six rain gauge stations in the central cascades of Washington. The locations of these stations are shown in Fig. 4.1. The data collected at 1 hour intervals were organized into annual maximum precipitation periods (AMP) of durations 1, 6, 12, 24, 48, and greater than 48 hours. Storms of moderate to heavy rainfall with duration greater than 48 hours bounded by six hours or more of little or no rainfall are called "long continuous storms" (LCS). Brunengo (1989) determined the distributions of storm date, storm duration, amount of rainfall, storm temperature, and wind speed. 

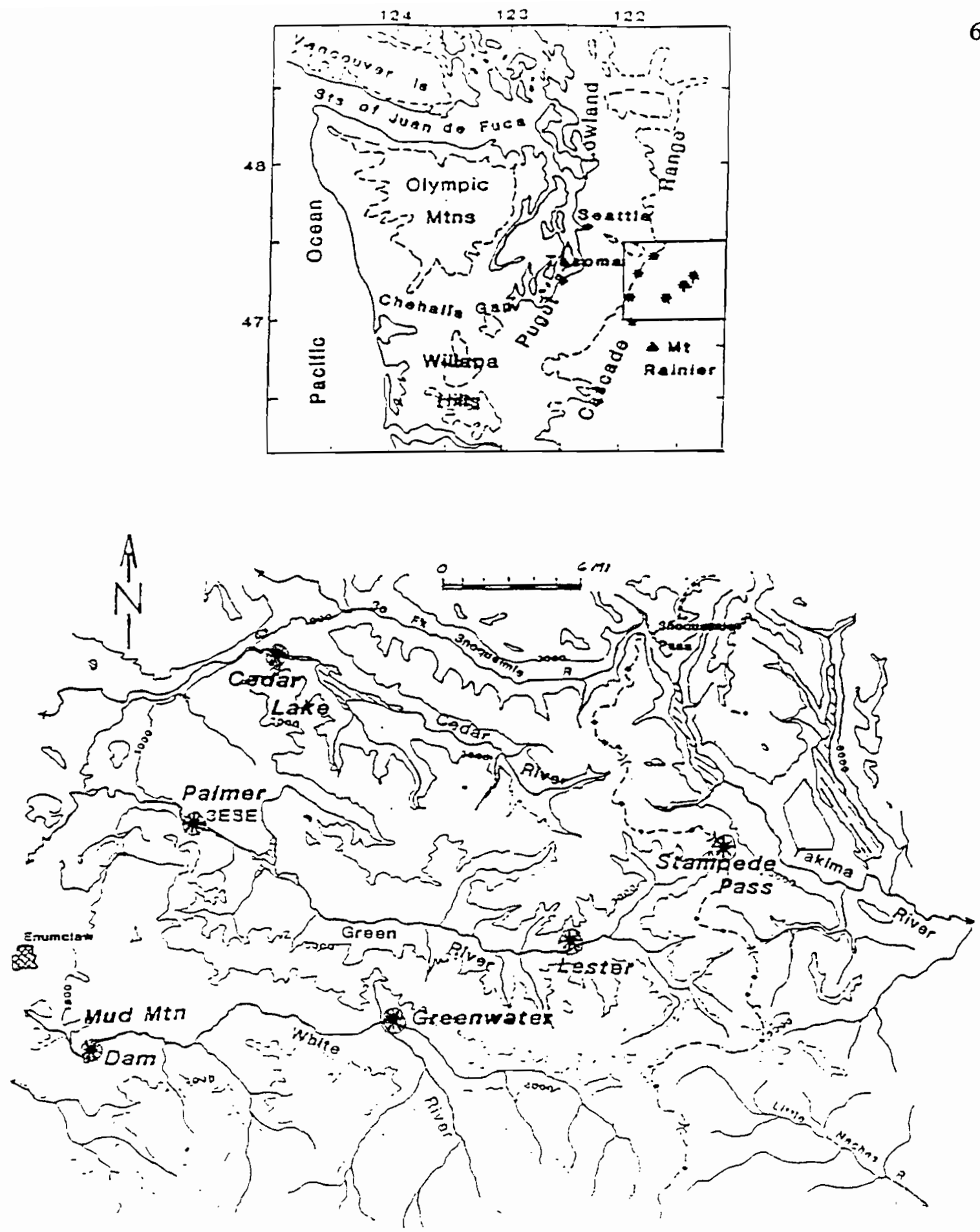

Figure 4.1: Locations of gauge stations. 


\subsection{STORM PRECIPITATION}

The storm precipitation, $R$, is modeled by the extreme value distribution, EV-1 (Brunengo, 1989)

$$
\begin{aligned}
& P(R \leq r)=\exp (-\exp (-y)) \\
& y=a(r-u)
\end{aligned}
$$

where $\mathbf{u}=$ location factor and $\mathbf{a}=$ inverse of a scale factor (Linsley et al 1982). The mean and standard deviation of the distribution are

$$
\begin{aligned}
& E(R)=u+\frac{\varepsilon}{a} \\
& \sigma_{R}=\frac{\pi}{a \sqrt{6}}
\end{aligned}
$$

where $\varepsilon=$ Euler's constant, which is approximately equal to 0.577 . The parameters $u$ and $1 / a$ can be estimated as a function of the mean, $E(R)$, and standard deviation, $\sigma_{R}$, from Eqs. 4.5 and 4.6, respectively.

$$
\begin{aligned}
& \frac{1}{a}=\sigma_{R} \frac{\sqrt{6}}{\pi}=.78 \sigma_{R} \\
& u=E(R)-\sigma_{R} \varepsilon \frac{\sqrt{6}}{\pi}
\end{aligned}
$$

The precipitation for a given exceedance probability, $\mathrm{P}$, or return period, $t_{\circ}$, can be calculated from Eqs. 4.7 and 4.8, respectively.

$$
\begin{aligned}
& R_{P}=u-\frac{1}{a}\left[\ln \ln \left(\frac{1}{1-P}\right)\right] \\
& R_{P}=u-\frac{1}{a}\left[\ln \ln \left(\frac{t_{0}}{t_{0}^{-1}}\right)\right]
\end{aligned}
$$

The average values of $u$ and $1 / \mathrm{a}$ for the region are 4.02 and 1.78, respectively (Brunengo, 1989). The corresponding $\mathrm{E}(\mathrm{R})$ and $\sigma_{R}$ are 5.04 in. and 2.28 in, respectively. 


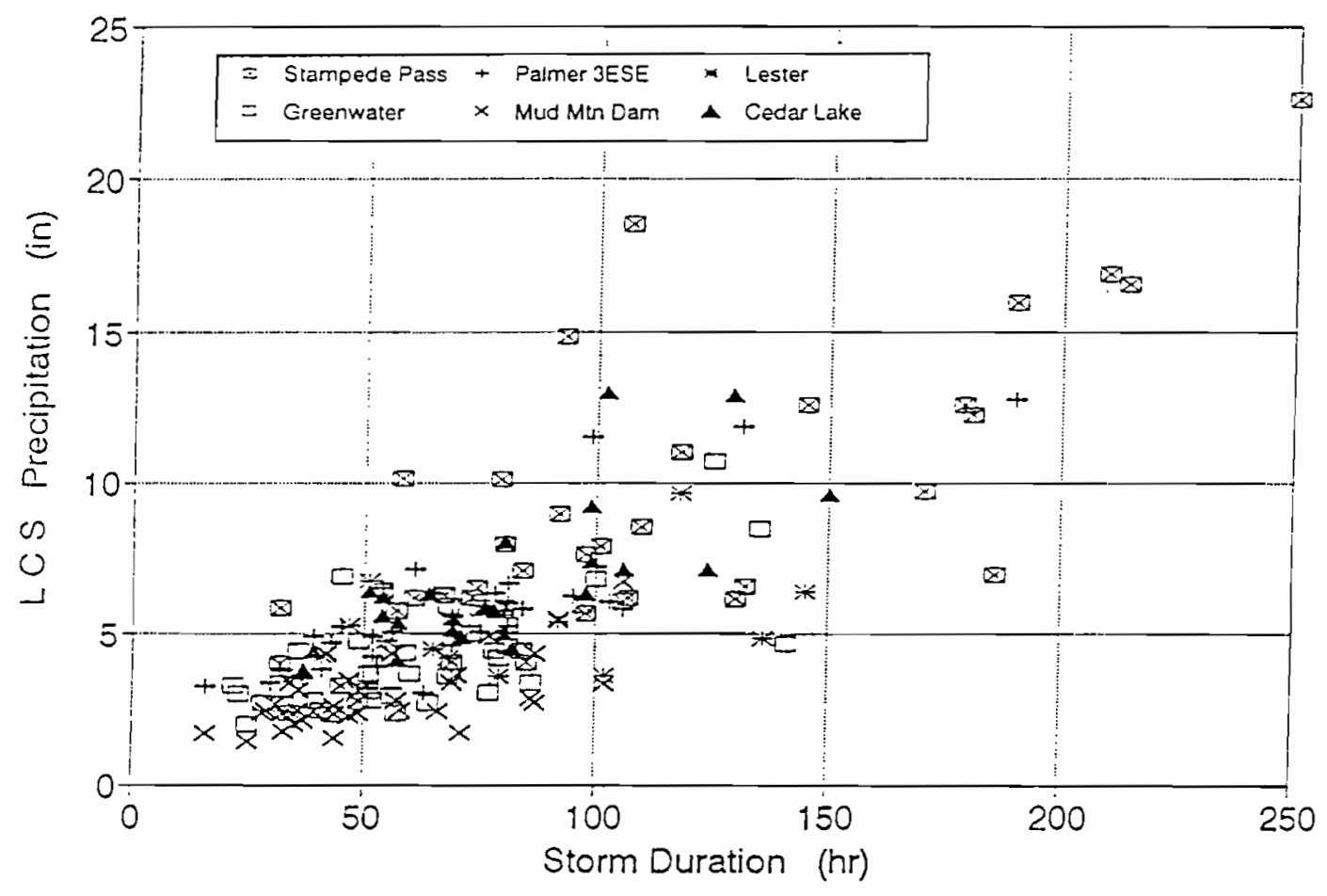

Figure 4.2: $\quad$ Scatter graph of storm duration vs. precipitation (Brunengo, 1989). 


\subsection{STORM DURATION}

The distribution of storm duration, D, was approximated as log normal distribution (Brunengo, 1989). The mean and the standard deviation for all stations are $66.97 \mathrm{hr}$ and $35.97 \mathrm{hr}$, respectively (Brunengo, 1989). Fig. 4.2 shows the plot of $D$ versus $R$ for 168 recorded storms. Brunengo (1989) found that $D$ is correlated to $R$ as expressed by Eq. 4.9

$$
R=0.0729 D
$$

where $D$ is the duration in hours and $R$ is the precipitation in inches. The correlation coefficient for Eq. 4.9 is 0.748 . Applying this relation to the average precipitation (5.04 in), then the average duration is $68.58 \mathrm{hr}$.

\subsection{SEQUENCE OF STORMS}

Campell (1975) reported that the amount of preceding precipitation is a controlling factor for debris flow initiation. He correlated a preceding precipitation of 10 in with landslide occurrence in California. Wieczorek (1987) showed that the threshold precipitation required to trigger debris flows in La-Honda, California, is also a function of the preceding precipitation. The preceding precipitation affects the moisture content in the soil cover, which in turn affects the infiltration because both the coefficient of permeability, $K$, and the suction, $\Psi$, are functions of moisture content. The statistics of antecedent moisture content is evaluated by analyzing the statistics of sequences of storms.

\subsubsection{Sequence of Long Continuous Storms}

Brunengo (1989) developed a Monte-Carlo simulation program to generate a sequence of long continuous storms (LCS) using assumption of independence between the dates of these storms. First, the storm date was generated from normal distribution which was the assumed probability distribution of storm date (Brunengo, 1989). The generation of storm dates was stopped when the last generated date was earlier than the preceding one. The season was con- 
sidered to have only one storm if the second generated date was earlier than the first one. The program was able to generate up to 7 storms per season. The precipitation of each storm was assumed to be independent of the number of occurrence of storms per season and only to be related to the duration of the storm. Fig. 4.3a shows the probability frequency function for number of storms per season. The mean number of storm occurrence is two storms per season.

The method of derived distribution (Ang \& Tang, 1975) was used to investigate the characteristics of the period between storms. For the case of a season with two storms, let $\mathrm{X}$ and $\mathrm{Y}=$ the date of first and the date of the second storm, respectively. The probability density function of the date of each storm is normal with $\mu=120.4$ days and $\sigma=43.82$ days (Brunengo, 1989). The joint distribution function for multivariate normal distribution of two independent random variables with the same $\mu$ and $\sigma$ is

$$
f_{X, Y}(x, y)=\frac{-1}{2 \pi \sigma^{2}} e^{\frac{-1}{2 \sigma^{2}\left((X-\mu)^{2}+(Y-\mu)^{2}\right)}}
$$

The random variable $\mathrm{V}$, the period between the two storms, is defined as

$$
V=\boldsymbol{Y}-\boldsymbol{X}, \boldsymbol{Y}>\boldsymbol{X}
$$

The probability distribution function of $\mathrm{V}$ is

$$
F_{V}(v)=\iint_{X} f_{X, Y}(x, y) d x d y=\int_{X}^{X-\infty} \int_{L_{x}}^{Y=v+x} f_{X, Y}(x, y) d x d y
$$

Fig. 4.3b shows a plot of the probability density function of V, calculated using Eq. 4.12. The mean of $\mathrm{V}$ is 29.5 days and the standard deviation is 21.3 days.

For a season with three storms, the previous procedure was repeated to derive the distribution of the period between the last two storms. A new random variable $\mathrm{Z}$ is defined as the date of the third storm. The random variable $\mathrm{W}$ is the period between the second and the third storms. The probability distribution function of $\mathrm{Z}$ is normal, with the same $\mu$ and $\sigma$ as $\mathrm{X}$ and $\mathrm{Y}$. The joint distribution function for multivariate normal distribution for three independent random variables, with the same $\mu$ and $\sigma$, is 


$$
f_{X, Y, Z}(x, y, z)=\frac{-1}{\sqrt{2^{3}} \pi \sigma^{2}} e^{\frac{-1}{2 \sigma^{2}}\left((X-\mu)^{2}+(Y-\mu)^{2}+(Z-\mu)^{2}\right)}
$$

The random variable $W$, the period between the last two storms, is defined as

$$
W=Z-Y, Z>Y>X
$$

The probability distribution function of $\mathrm{W}$ is

$$
F_{W}(w)\left(=\iiint_{X} f_{X, Y, Z}(x, y, z) d x d y d q=\int_{X_{0}}^{X-\infty} \int_{Y^{Y}-\infty}^{Z-w+y} \int_{Z^{\prime}}^{+y} f_{X, Y, Z}(x, y, z) d x d y d z\right.
$$

Fig. 4.3b shows a plot of the probability density function of $W$ calculated using Eq. 4.15. The mean of $W$ is 22.96 days with a standard deviation of 16.35 days.

\subsubsection{Sequence of Small Rain Events}

In addition to long continuous storms (LCS), whose characteristics are described in Sections 4.2, 4.3, and 4.4.1, we should consider small rain events that are not classified as LCS. Table 4.1 shows the number of days with precipitation greater than specific values (Brunengo, 1989). It is clear that during the rain season (September - May) most days are wet; precipitation is greater than $0.1 \mathrm{in} /$ day for at least 155 days out of 270 days. These small but frequent rain events increase soil moisture content and contribute to the build up of high piezometric levels when large storms occur. In order to estimate the effect of small rain events, a Monte-Carlo simulation program was written to simulate the occurrence of small events. Table 4.1 was used to produce the frequency function of number of days for a given range of precipitation. The frequency function is shown in Fig. 4.4a. It was assumed that storms with more than 1 in/day are LCS. This was done because Brunengo's smallest LCS is of magnitude of 2.7 in. in more than 48 hours. The occurrence of the small rain events and that of LCS were assumed to be independent. One realization of the simulation program is shown in Fig. 4.4b. The simulated small rain events were superimposed on the events of LCS. The groundwater response $\left(h_{o} / H, \theta_{1}, \theta_{2}\right)$ was 


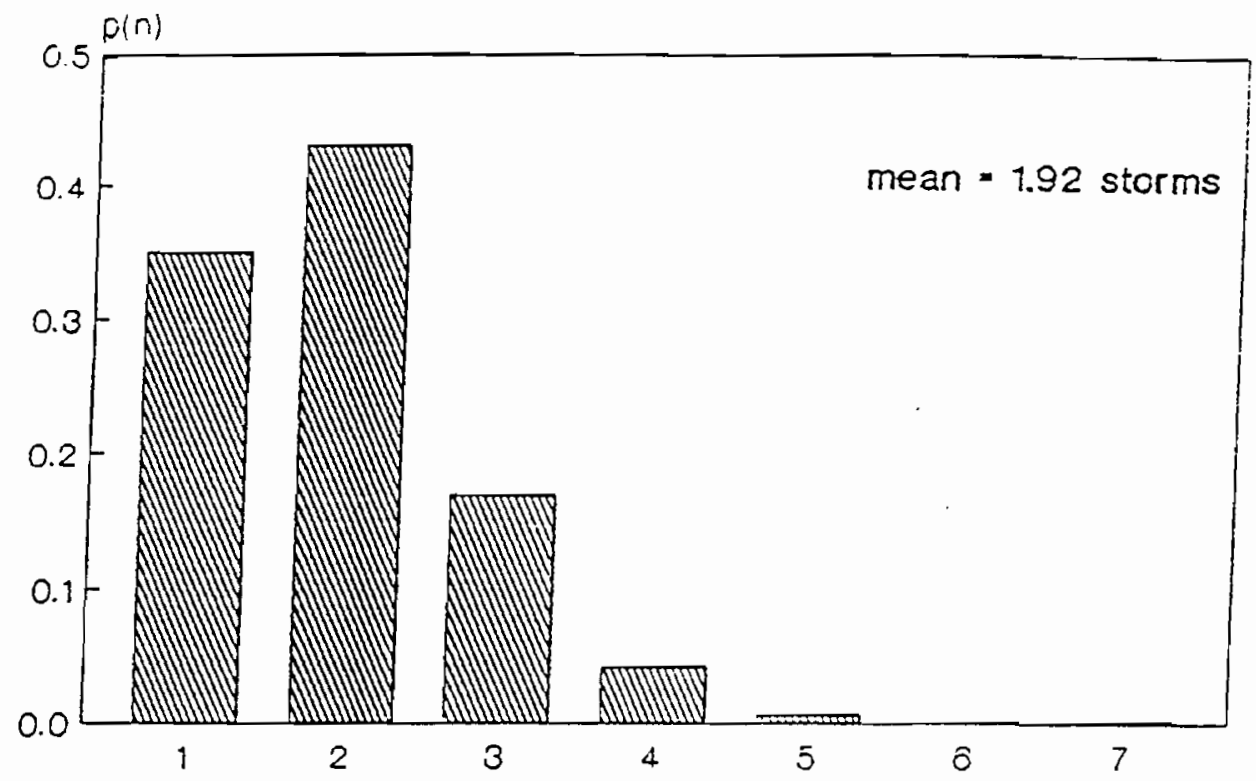

(a) number of storms per season

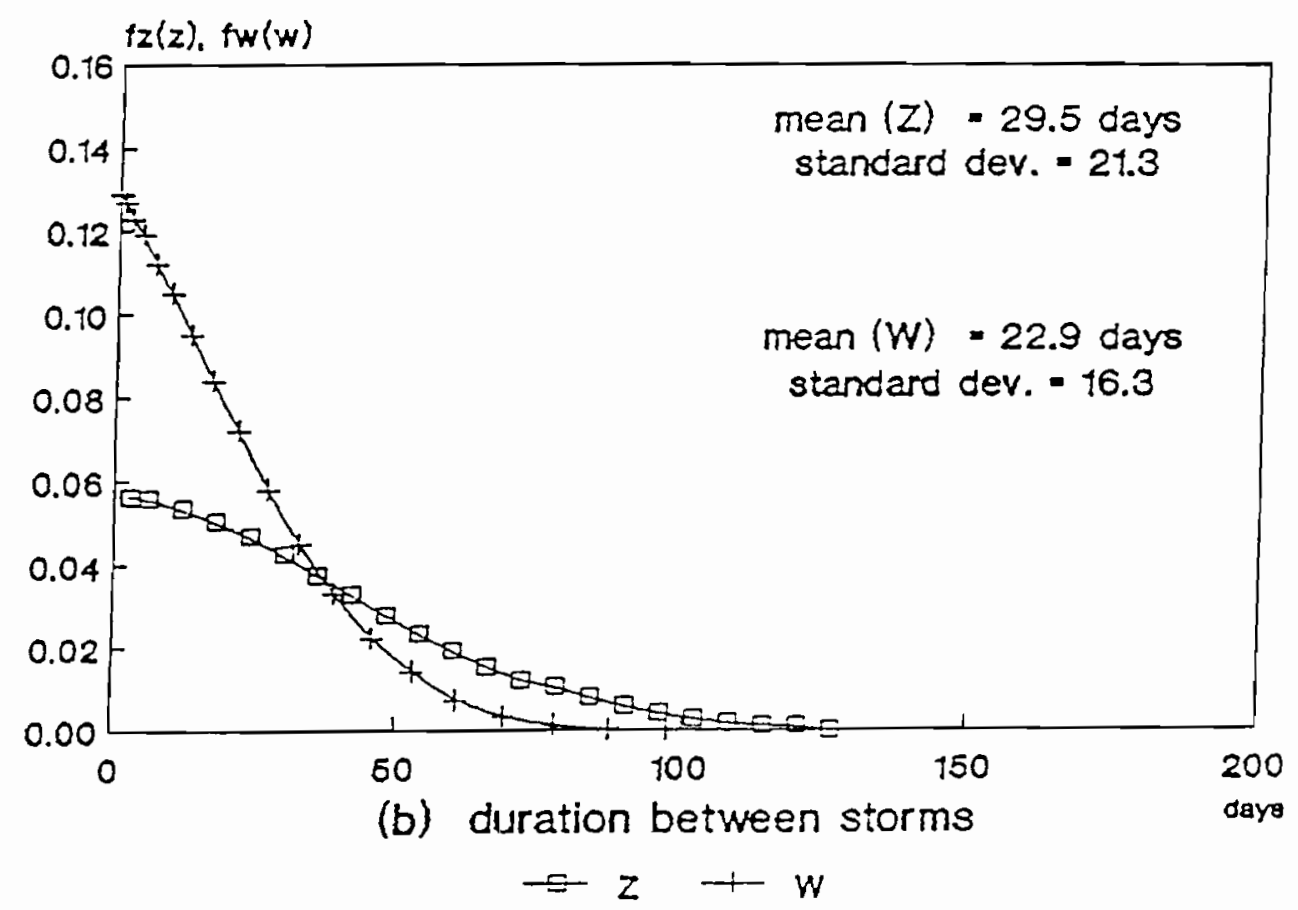

Figure 4.3: Probability function of (a) number of storms per season, (b) duration between storms in a 2-storm season and between the last two storms in a 3-storm season. 
calculated for each sequence of simulated storms. The procedure described above was repeated and the groundwater response was used to study the characteristics of antecedent moisture conditions, as shown in Section 6.2.2.

Table 4.1

Precipitation Data, Brunengo (1989).

\begin{tabular}{|l|l|l|l|l|l|}
\hline & Annual & September & \multicolumn{2}{|l|}{ Number of days of precipitation } \\
\hline Station & Mean & - May & $>0.1 "$ & $>0.50 "$ & $>1.0 "$ \\
\hline Stampede Pass & 92.57 & 84.32 & 148 & 65 & 29 \\
Palmer & 94.09 & 83.62 & 158 & 70 & 26 \\
Cedar 1ake & 102.41 & 91.74 & 155 & 76 & 32 \\
\hline
\end{tabular}

\subsection{MODEL OF SNOWMELT}

The main causes of snowmelt are the energy exchange by convection and condensation at air-snow interface, shortwave and longwave radiation, heat conduction from the ground, and heat conduction from precipitation. Wiberg (1990) used the United States Army Corps of Engineers Snowmelt model (USACES, 1956) to study the characteristics of snowmelt in the central cascades of Washington. The total amount of potential snowmelt, based on USACES model, is

$$
\begin{aligned}
M_{T} & =M_{C}+M_{S}+M_{R} \\
& =(0.029+0.0084 \mathrm{KU})\left(T_{a}-32\right) D+0.09 D+0.007\left(T_{a}-32\right) R
\end{aligned}
$$

where $M_{T}=$ total amount of potential snowmelt, $M_{C}=$ snowmelt due to convectioncondensation and longwave radiation, $M_{S}=$ snowmelt due to shortwave radiation and ground heat, $M_{R}=$ snowmelt due to precipitation, $\mathrm{K}=$ exposure constant equals to 1.0 in clearcut areas, $\mathrm{D}=$ the duration in days, $\mathrm{U}=$ wind velocity in $\mathrm{m} / \mathrm{hr}, T_{a}=$ air temperature in $F^{\circ}$, and $\mathrm{R}=$ precipitation in inches. The parameters $\mathrm{U}, \mathrm{T}, \mathrm{D}$, and $\mathrm{R}$ are all considered as random variables and 

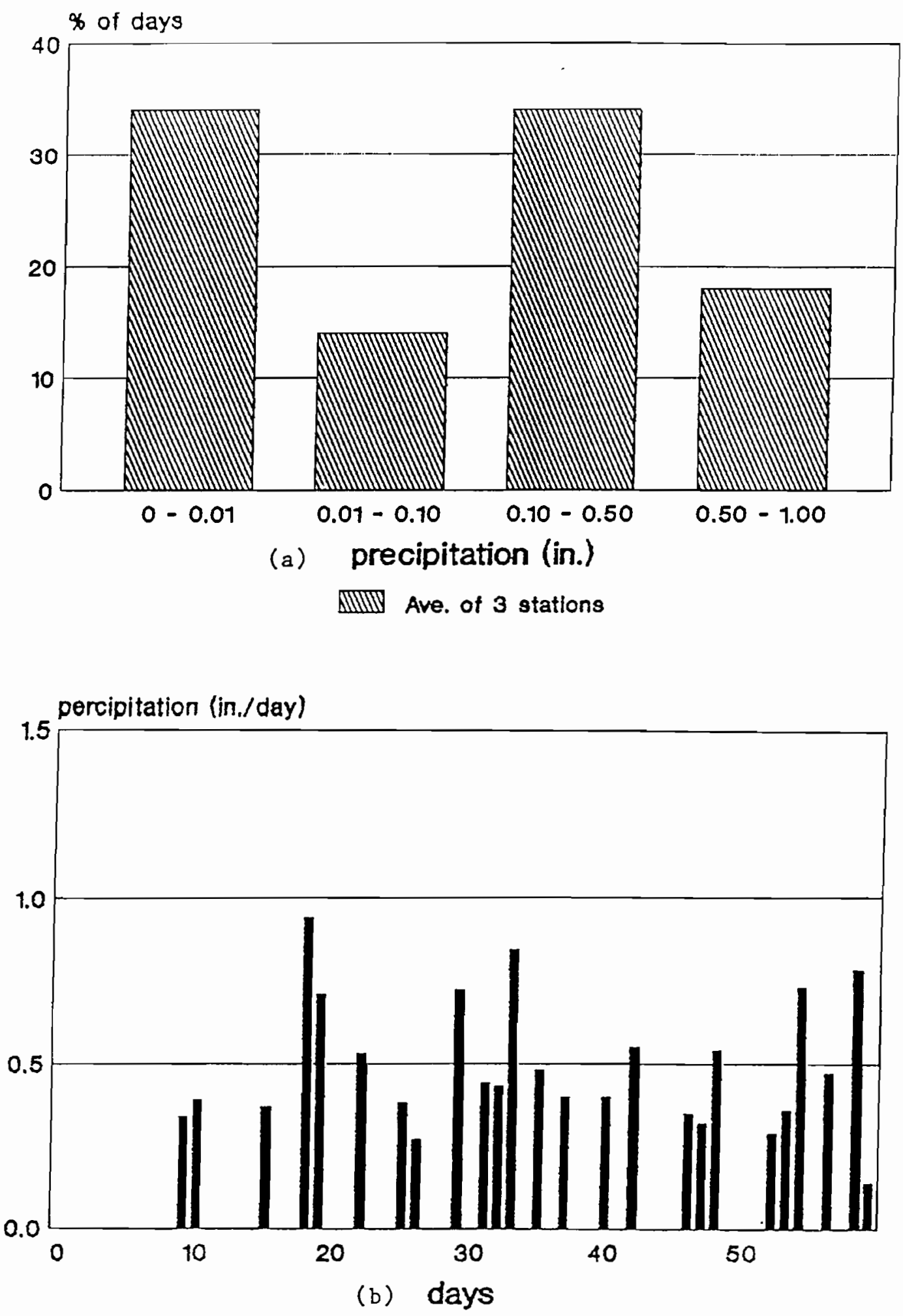

Figure 4.4: (a) Frequency function of number of days with a given range in precipitation, (b) simulated rain events. 
as a result $M_{T}$ is also a random variable (Wiberg, 1990). The average values of the parameters used in this study are $1,2.5$ days, $13.4 \mathrm{~m} / \mathrm{hr}, 35.61 F^{\circ}$, and 5.04 inch, for $\mathrm{k}, \mathrm{D}, \mathrm{U}, \mathrm{T}_{a}$ and $\mathrm{R}$, respectively (Brunengo, 1989).

Wiberg (1990) used numerical integration to compute the distribution of $M_{T}$ The probability density function of $M_{T}$ is shown in Fig. 4.5a. However, the actual melt, M, is constrained by the available snow-water-equivalent, $S$, on the ground. To account for that, two cases are possible. In the first case $S$ is greater than $M_{T}\left(M_{T}<S\right) ; M$ is equal to $M_{T}$. In the second case, $S$ is less than $M_{T}\left(M_{T}>S\right) ; M$ is equal to $S$. Both $M_{T}$ and $S$ are random variables and so is $M$. The distribution of $\mathrm{M}, f_{M}(m)$, is formulated as

$$
f_{M}(m)=\int_{S}^{\infty} f\left(M_{T}=m, S\right) d S+\int_{N_{m}}^{\infty} f\left(M_{T}, S=m\right) d M_{T}
$$

The result of the integration is shown in Fig. 4.5b. The mean value of $M$ is 1.358 in and the variance is $0.867 \mathrm{in}^{2}$.

\subsection{INFILTRATION}

The snowmelt, $M$, is added to the precipitation, $R$, to derive the distribution of total amount of water for infiltration, I. The two possible events are rain-on-snow, $(S>0)$, and rain-onground, $(S=0)$. The probability density function of, $\mathrm{I}$, for the two possible rain events is

$$
f_{i}(i)=f(R=i \mid S=0) P[S=0]+f(M+R=i \quad \mid S>0) P[S>0]
$$

The distribution of precipitation is given in Section 4.2 and is shown in Fig. 4.6a. The distribution of $M$ is given in Section 4.5 and is shown in Fig. 4.5b. The distribution of I, defined by Eq. 4.18, was computed numerically and the probability density function of $I$ is shown in Fig. 4.6b. The mean value of $I$ is 6.5 in and the variance is $8.5 \mathrm{in}^{2}$. 


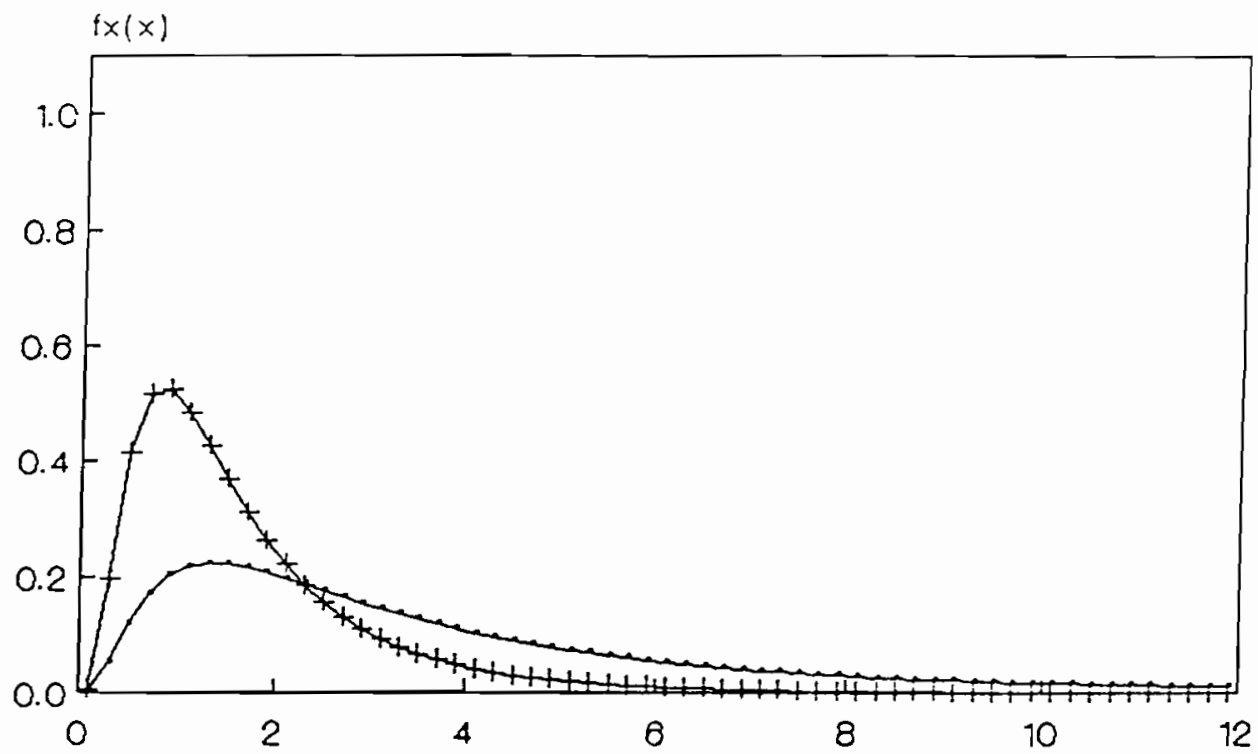

(a) pdf of snowmelt \& snow-water equiv.

- snow-water equiv. I snowmelt

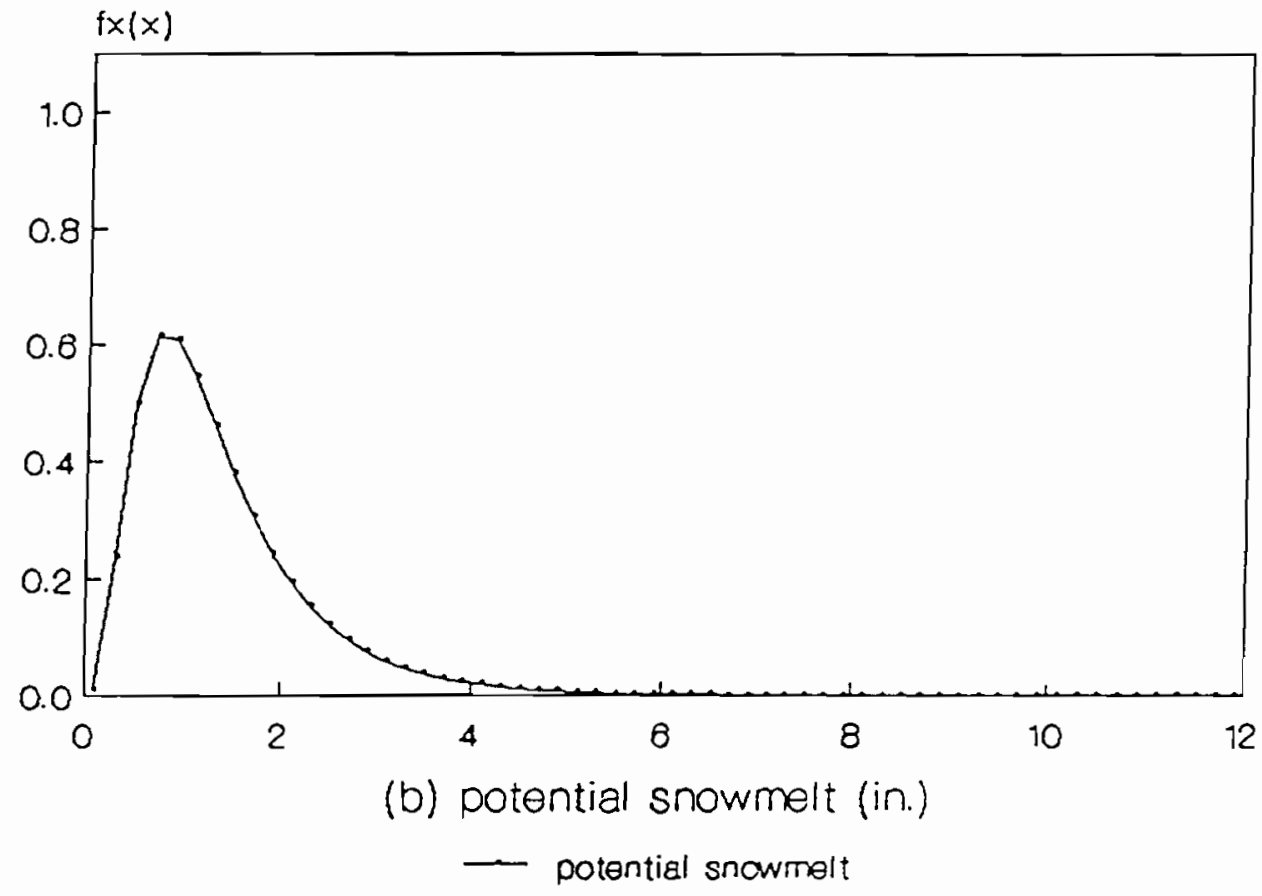

Figure 4.5: Probability density function of (a) snowmelt and snow-water equivalent (b) potential snowmelt. 

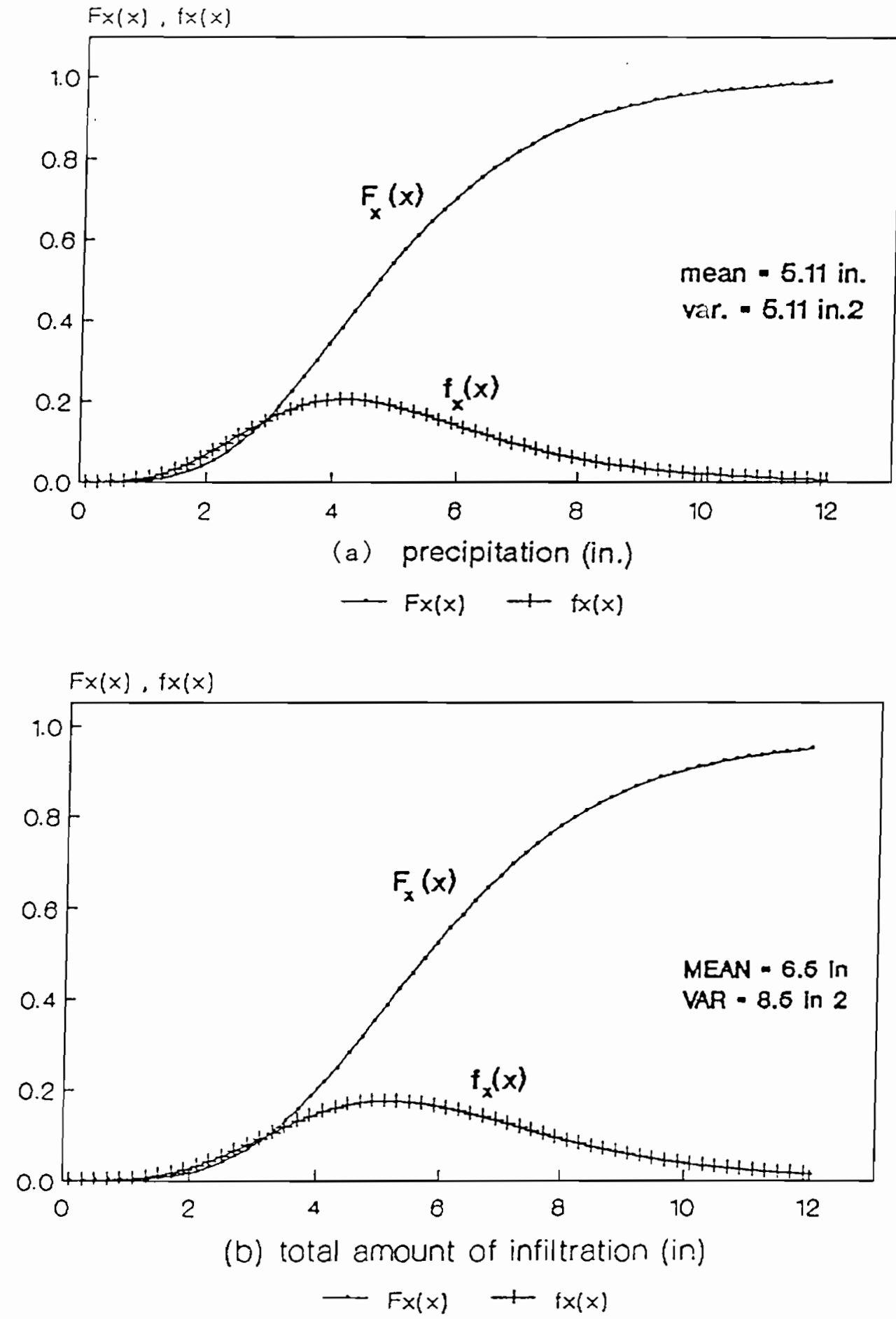

Figure 4.6: Probability density function and distribution function of (a) storm precipitation, (b) total amount of water available for infiltration = snowmelt plus precipitation. 


\subsection{DISTRIBUTION OF EXTREME INFILTRATION}

As explained in Section 4.6, the water available for infiltration, $I$, is the sum of precipitation, $R$, and snow melt, $M . M$ depends on $R$ as it appears in Eq. 4.16, however, the portion of $M$ due to $R$ is small, then $R$ and $M$ can be approximated as independent variables. The largest $I$ to happen in a given period is a random variable with statistics related to the distribution of $\mathbf{R}$ and M given by Eq. 4.1 and 4.17, respectively. The extreme of the sum of the two independent random variables, $R$ and $M$, can be formulated, however, $M$ does not has a unique distribution because its distribution is conditional on $S$ as explained in Section 4.5. In the meantime, $R$ is much larger than M, for the focus township, then the extreme of I is simplified to be the extreme of $\mathbf{R}$ falling on the mean of $M$.

To determine the extreme of R let $Y_{n}$ be

$$
Y_{n}=\max \left(R_{1}, R_{2}, \ldots \ldots \ldots, R_{n}\right)
$$

where $R_{1}, R_{2}, . ., R_{n}$ are random samples of amount of precipitation given by Eq. 4.1. The cumulative distribution of $Y_{n}$ is

$$
F_{Y_{n}}(y)=P\left(Y_{n} \leq y\right)=\left(F_{R}(y)\right)^{n}
$$

The corresponding probability density function for $Y_{n}$ is

$$
f_{Y_{y}}(y)=\frac{\partial F_{Y_{z}}(y)}{\partial y}=n F_{R}(y)^{n-1} f_{R}(y)
$$

This means that the functions $F_{Y_{s}}(y)$ and $f_{Y_{*}}(y)$ will shift to the right with increasing $\mathrm{n}$. The distribution of $Y_{n}$ are generally difficult to obtain in analytical form. The usefulness of extreme value statistics is greatly enhanced by the theory of asymptotic extreme distribution. The analytical derivation of the appropriate extreme distribution, given the distribution of the initial variate, is facilitated by Cramer's method (Cramer, 1946). Define the transformed random variable $\zeta_{n}$ such that 


$$
\zeta_{n}=n\left(1-F_{R}\left(y_{n}\right)\right)=g(y)
$$

then

$$
F_{\zeta_{n}}(\zeta)=1-\left(1-\frac{\zeta}{n}\right)^{n}
$$

As $n \rightarrow \infty$ we have

$$
F_{\zeta_{n}}(\zeta)=1-e^{-\zeta}
$$

and the corresponding asymptotic probability density function is

$$
f_{\zeta}(\zeta)=e^{-\zeta}
$$

Inverting Eq. 4.22 for $Y_{n}$, then

$$
Y_{n}=F_{R}^{-1}\left(1-\frac{\zeta_{n}}{n}\right)
$$

Hence the cumulative distribution function of $Y_{n}$ can be obtained from that of $\zeta_{n}$ as

$$
F_{Y_{n}}=\exp (-g(y))
$$

where $\mathrm{g}(\mathrm{y})$ is the right handside of Eq. 4.22. The probability density function of $Y_{n}$ is

$$
f_{Y_{n}}=-\frac{\partial g(y)}{\partial y} \exp (-g(y))
$$

Applying this method to the distribution of the amount of rainfall given by Eq. 4.1,

$$
g(y)=n\left\{1-\exp \left[\left(-a\left(y_{n}-u\right)\right)\right]\right\}
$$

Then

$$
F_{Y_{n}}=\exp \left\{-n\left[1-\exp \left(-\exp \left(-a\left(y_{n}-u\right)\right)\right)\right]\right\}
$$

and

$$
\begin{array}{rl}
f_{Y_{n}}=a & n \exp \left\{-n\left[1-\exp \left(-\exp \left(-a\left(y_{n}-u\right)\right)\right)\right]\right\} \\
& \left\{\exp \left[-\exp \left(-a\left(y_{n}-u\right)\right)\right]\right\} \exp \left(-a\left(y_{n}-u\right)\right)
\end{array}
$$


The plots of the probability distribution function and the probability density function of $Y_{n}$ are shown in Fig. 4.7a and 4.7b, respectively, for different values of $n$. A computer program using numerical integration was developed to compute the mean and the variance of the asymptotic distributions. The results of integrations are listed in Table 4.2 for different values of $\mathbf{n}$.

The asymptotic method used above can be applied to any distribution, however, for case of extreme type I distribition, Ang and Tang (1984) derived the distribution of the largest value in future $\mathrm{n}$ years to be of type I also with parameters $a_{n}, u_{n}$ as

$$
\begin{aligned}
& a_{n}=a \\
& u_{n}=u-\ln \left(\frac{n}{a}\right)
\end{aligned}
$$

These parameters were used for different values of $\mathbf{n}$ to compute the mean and the variance of the maximum rain. The results are listed in Table 4.2 for comparison with asymptotic calculations. The results are very close.

The distribution of extreme infiltration is obtained by setting $\mathrm{R}=Y_{n}$ in Eq. 4.18. The mean and the variance of the largest I, for a given period $n$, were calculated and the results are listed in Table 4.2. 
Table 4.2

Means and variances of rainfall and infiltration of maximum storm in $n$ years.

\begin{tabular}{|c|c|c|c|c|c|c|}
\hline \multirow[b]{2}{*}{$\begin{array}{c}n \\
\text { years }\end{array}$} & \multicolumn{2}{|c|}{$\begin{array}{l}\text { extreme } \\
\text { asymptotic rain }\end{array}$} & \multicolumn{2}{|c|}{$\begin{array}{l}\text { extreme } \\
\text { rain }\end{array}$} & \multicolumn{2}{|c|}{$\begin{array}{c}\text { extreme } \\
\text { infiltration }\end{array}$} \\
\hline & $\begin{array}{c}E(R) \\
\text { in }\end{array}$ & $\begin{array}{c}\operatorname{var}(\mathrm{R}) \\
\text { in }^{2}\end{array}$ & $\begin{array}{l}E(R) \\
\text { in }\end{array}$ & $\begin{array}{c}\operatorname{Var}(\mathrm{R}) \\
\text { in }^{2}\end{array}$ & $\begin{array}{c}E(I) \\
\text { in }\end{array}$ & $\begin{array}{c}\operatorname{Var}(I) \\
\text { in }^{2}\end{array}$ \\
\hline 5 & 7.72 & 6.94 & 7.81 & 5.2 & 9.03 & 8.69 \\
\hline 10 & 9.11 & 5.68 & 9.04 & 5.2 & 10.3 & 7.15 \\
\hline 20 & 10.4 & 5.46 & 10.27 & 5.19 & 11.58 & 6.54 \\
\hline 50 & 12.08 & 5.35 & 11.91 & 5.16 & 13.11 & 5.97 \\
\hline 100 & 13.33 & 5.32 & 13.13 & 5.13 & 14.16 & 5.63 \\
\hline
\end{tabular}



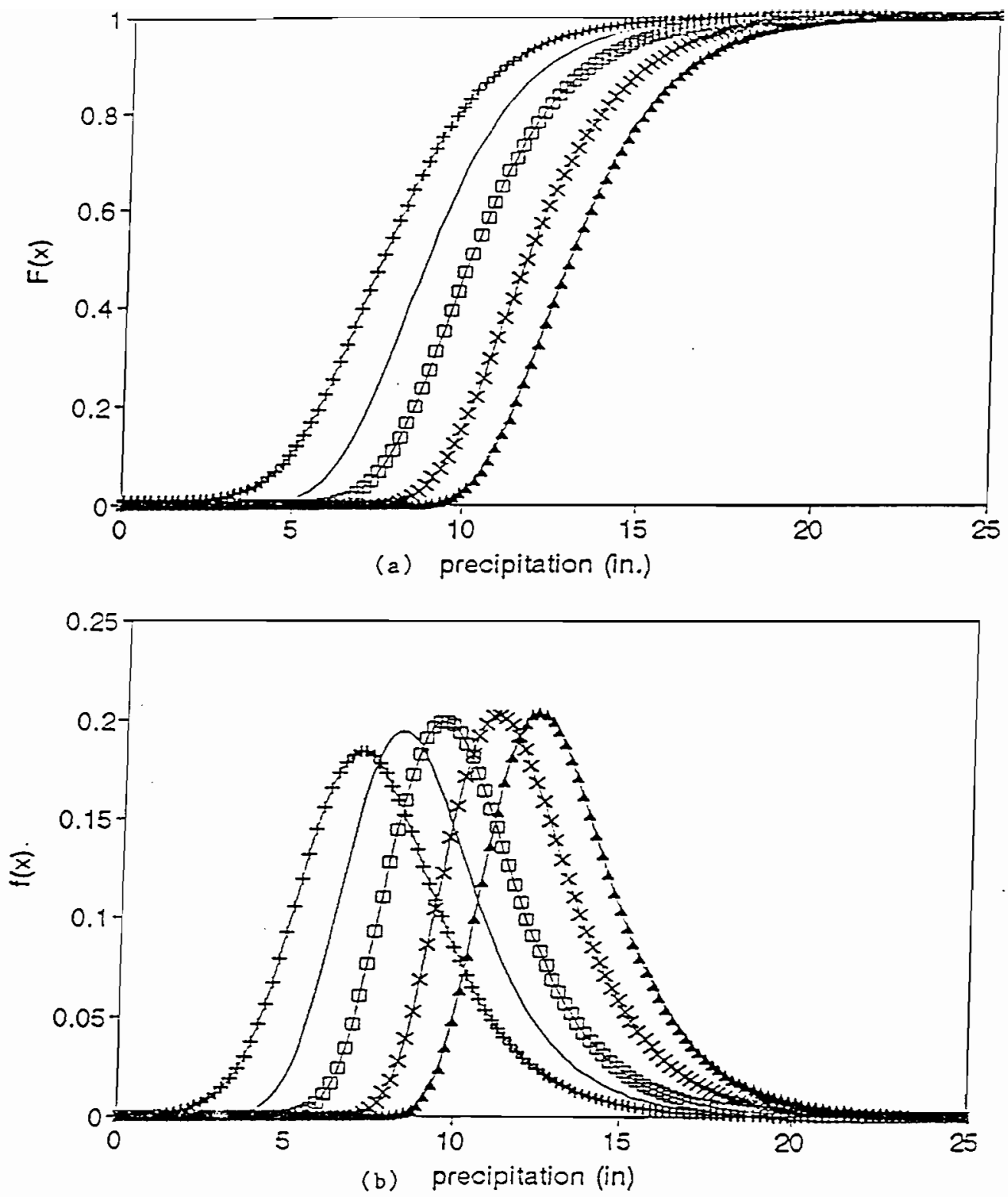

$$
\left[\begin{array}{l}
-5 \text { years }-10 \text { years }=20 \text { years } \\
\rightarrow-50 \text { years } \rightarrow 100 \text { years }
\end{array}\right.
$$

Figure 4.7: (a) Asymptotic probability distribution functions, and (b) asymptotic probability density functions of rainfall of maximum storm in $n$ years. 


\section{CHAPTER V \\ GROUNDWATER MODEL}

\subsection{INTRODUCTION}

In order to predict the changes in the groundwater levels, we need to evaluate techniques for solving flow problems for the site conditions and scales encountered in this research. In general, approximate methods are most suitable for evaluating regional conditions over a large area on small scale maps. In the absence of detailed site investigation, the prediction of groundwater levels using simple models is as good as predictions from complex models (Sloan and Moore, 1984). More precise methods can be used to study the departure from the regional conditions over smaller zones within a large area.

The approach adopted in this study is to use the lumped-parameter model of Reddi and Wu (1991), reviewed in Appendix B, and the finite difference model of Lee (1986), reviewed in Appendix A, to predict the changes in the groundwater levels as a result of storm events. Reddi and Wu's model was used to calculate the groundwater level, $h_{o}$, as shown in Fig. B.1b, and to calculate the sensitivity of $h_{o}$ to different input parameters. Results of the sensitivity analysis were used to identify the parameters that have the highest sensitivity and were also used as input to the probabilistic analysis of groundwater. Because the lumped parameter solution assumed a simplified groundwater profile, a better estimate of groundwater levels, $h_{w}$, at different points within a catchment were obtained by the two-dimensional finite difference model (Lee, 1986). This was used to identify the zones of high $h_{w}$ within individual catchments. 
The effect of geologic anomalies on $h_{w}$ was investigated by the finite difference model (Lee, 1986). This required input specific to the site under consideration. The specific site conditions were derived from observations of geology, slope, and soil characteristics made by Brunengo (1991) in the course of the landslide inventory. These effects were added to the average state.

\section{$\underline{5.2}$ SENSITIVITY ANALYSIS OF GROUNDWATER}

The lumped-parameter model of Reddi and $\mathrm{Wu}$ (1991) was used to investigate the effect of different soil parameters, slope length, L, infiltration, I, and storm duration, D, on the groundwater ratio, $h_{o} / H$. The soil parameters are saturated permeability, $K_{s,}$ soil depth, $\mathrm{H}$, drainable porosity, $\theta_{d}$, unsaturated parameter, $B$, and suction at saturation, $\Psi_{g^{\prime}}$ In these analyses the infiltration from mean annual storm $=6.5$ in, evaluated in Section 4.6, and the mean values of the antecedent moisture were used for the case of plane slope. To evaluate the sensitivity of $h_{o} / H$ to the different parameters, peak values of $h_{o} / H$ were computed for a range of values for a given parameter, while all other parameters were kept at their mean values listed in Table 3.3. The peak $h_{o} / H$ is critical to initiation of landslides. For brevity all subsequent references to $h_{o} / H$ imply the peak value. The results are shown in Figs. 5.1 to 5.4 for $\mathrm{L}, K_{s}, H, \theta_{d}, B, \Psi_{s}$, I, and D. The sensitivities of $h_{o} / H$ to I and D are $7.5810^{-2} \mathrm{in}^{-1}$ and $5.8^{*} 10^{-4} h r^{-1}$, respectively. The sensitivities of $h_{o} / H$ to the rest of parameters are listed in Table 6.1. The results, shown in Figs. 5.1 to 5.4, indicate that $\mathrm{I}, \mathrm{H}$, and $K_{s}$ are the parameters that have the most influence on $h_{o} / H . \theta_{d}$, B and $\Psi_{s}$ have little effect. The effect of $\mathrm{L}$, shown in Fig. 5.1a, is minor at the mean values of soil parameters listed in Table 3.3.

The results of the sensitivity analysis can be explained by examining the governing equations of the lumped parameter model of Reddi and Wu (1991), reviewed in Appendix B. $h_{o}$ 
depends on the relative rates of infiltration and drainage. The infiltration increases $h_{o}$ and it is directly proportional to $K_{s}$ and I. On the other hand, drainage decreases $h_{o}$ and it is directly proportional to $K_{s}$ and $\alpha$; inversely proportional to $\mathrm{L}$. For the regional site conditions, listed in Table 3.3, the effect of drainage is negligible. As a result of that $h_{o} / H$ is affected by the infiltration rate, i.e. $I K_{s} / H$, whereas the effect of the drainage parameters, $\mathrm{L}$ and $\alpha$, is minor. However, in case of small $\mathrm{L}$ and large $K_{s}$, the effect of drainage becomes noticeable. This can be shown in Fig. $5.1 \mathrm{a}$, for case of $K_{s}=28 \mathrm{~cm} / \mathrm{hr}$, the effect of $\mathrm{L}$ is considerable for $\mathrm{L}<300 \mathrm{~m}$. For $\mathrm{L}>300 \mathrm{~m}$, the effect of $\mathrm{L}$ is small because the amount of drainage is relatively small compared to the storage capacity of the slope.

\subsection{VARIATION OF GROUNDWATER WTTHIN A CATCHMENT}

The shape of natural slopes may be classified as plane, converging, and trapezoidal shapes. Fig. 5.5 shows different shapes of natural catchments as well as the topographic parameters required to analyze them. For a plane slope, the slope angle, $\alpha$, and the slope length, $\mathrm{L}$, are the required topographic parameters to calculate the storage capacity, $S_{d}$, defined by Eq. B.6. for a converging slope, the converging angle, $\beta$, is required, as well, to calculate $S_{d}$, Eq. B.7. For a trapezoidal slope, in addition to $\alpha, L$, and $\beta$, the width, $b$, of the catchment is required to calculate $S_{d} S_{d}$ for trapezoidal slope is formulated as

$$
S_{d}=h_{0} \theta_{d}\left[\frac{a \beta}{2}\left(2 L-\frac{a}{\cos \alpha}\right)\right]
$$

where $a$ is

$$
a=\frac{b}{2 \sin (\beta / 2)}
$$

The groundwater response of the three slopes was examined using both the lumped parameter model (Reddi and Wu, 1991) and the finite difference model (Lee, 1986). In both models, the analysis was conducted using the regional site conditions listed in Table 3.3 , and 

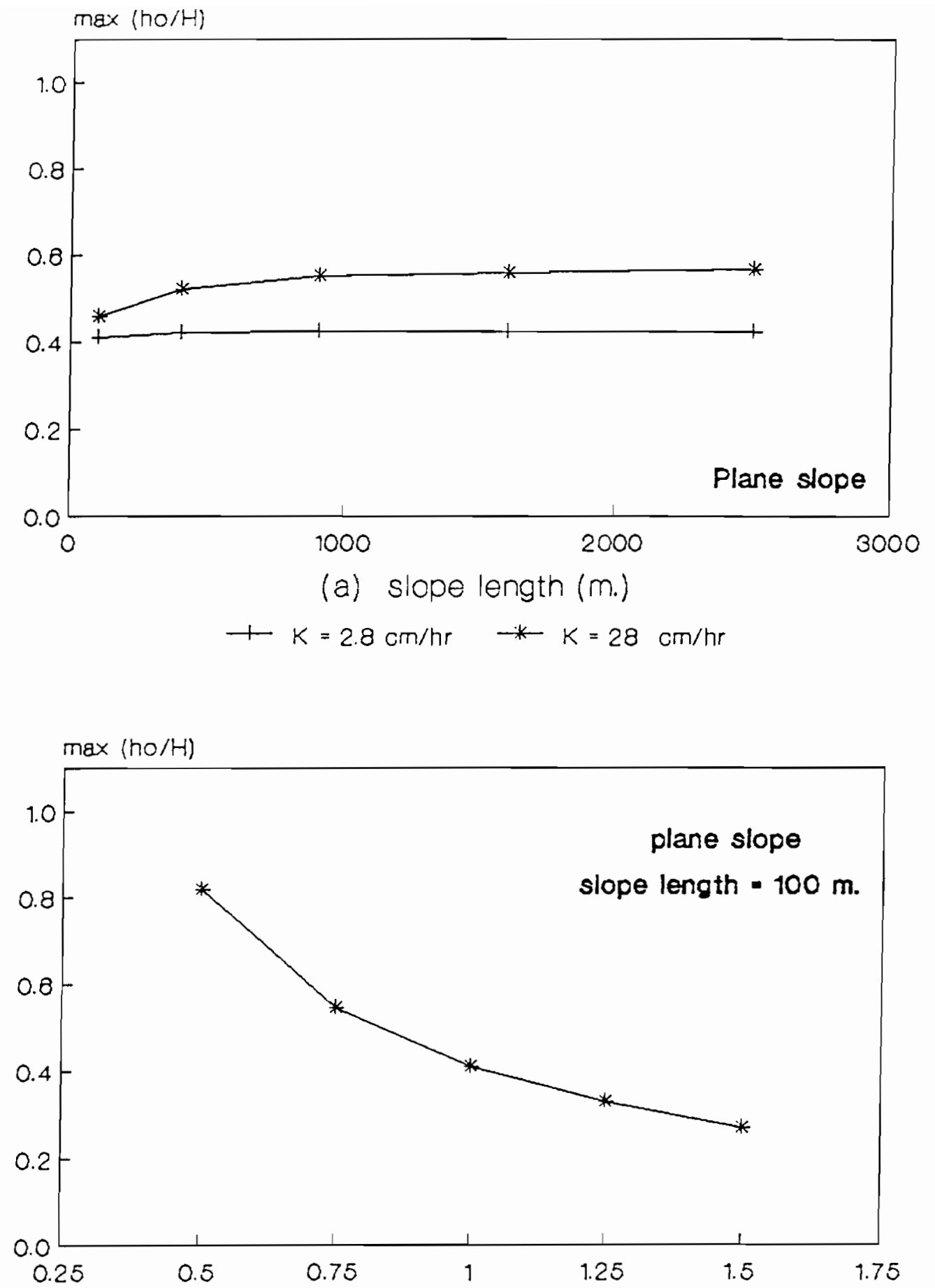

(b) depth of soil cover $(\mathrm{m}$.)

Figure 5.1: $\quad$ Effect of (a) slope length, $\mathrm{L},(\mathrm{b})$ soil depth, $\mathrm{H}$,. on $h_{o} / H$. Mean values of all other parameters were used. 


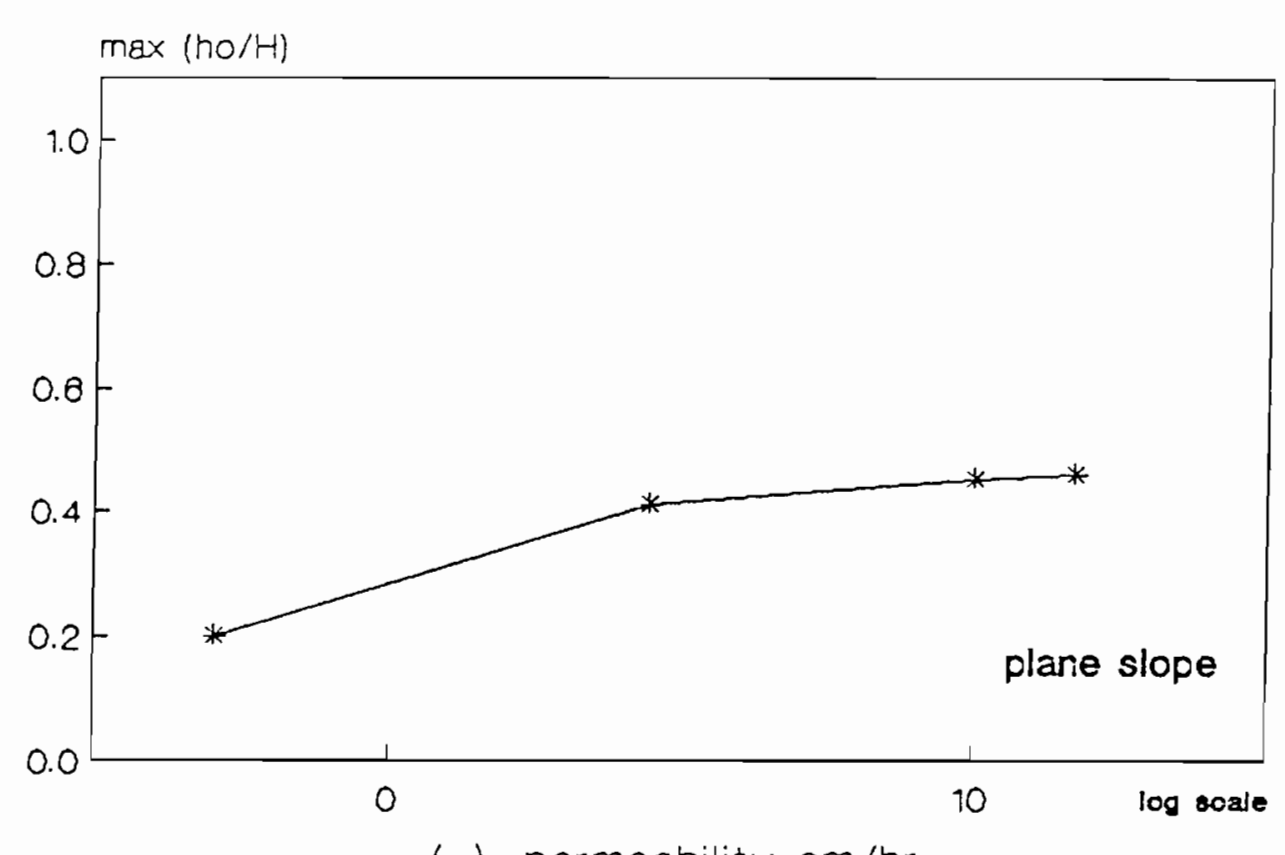

(a) permeability $\mathrm{cm} / \mathrm{hr}$

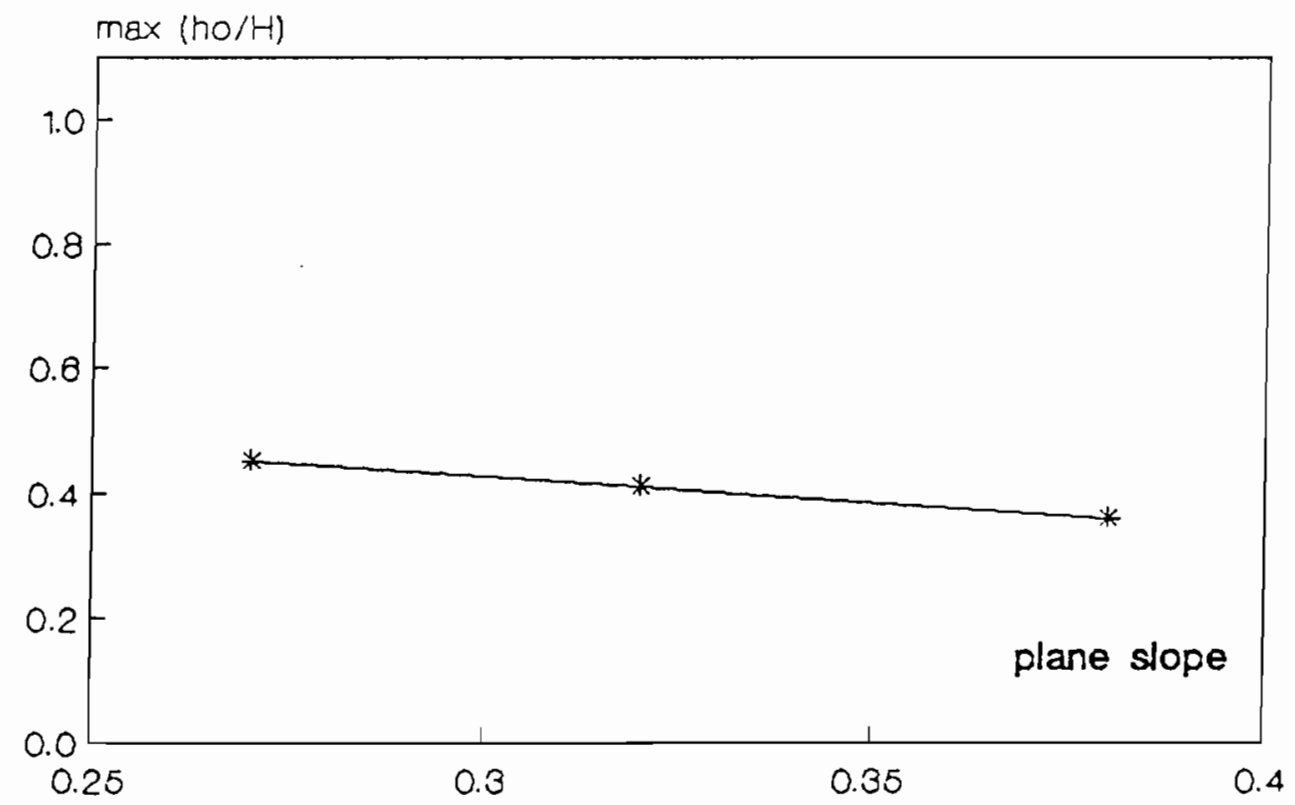

(b) drainable prosity

Figure 5.2: $\quad$ Effect of (a) permeability, K, (b) drainable porosity, $\theta_{d}$, on $h_{\sigma} / H$. Mean values of all other parameters were used. 


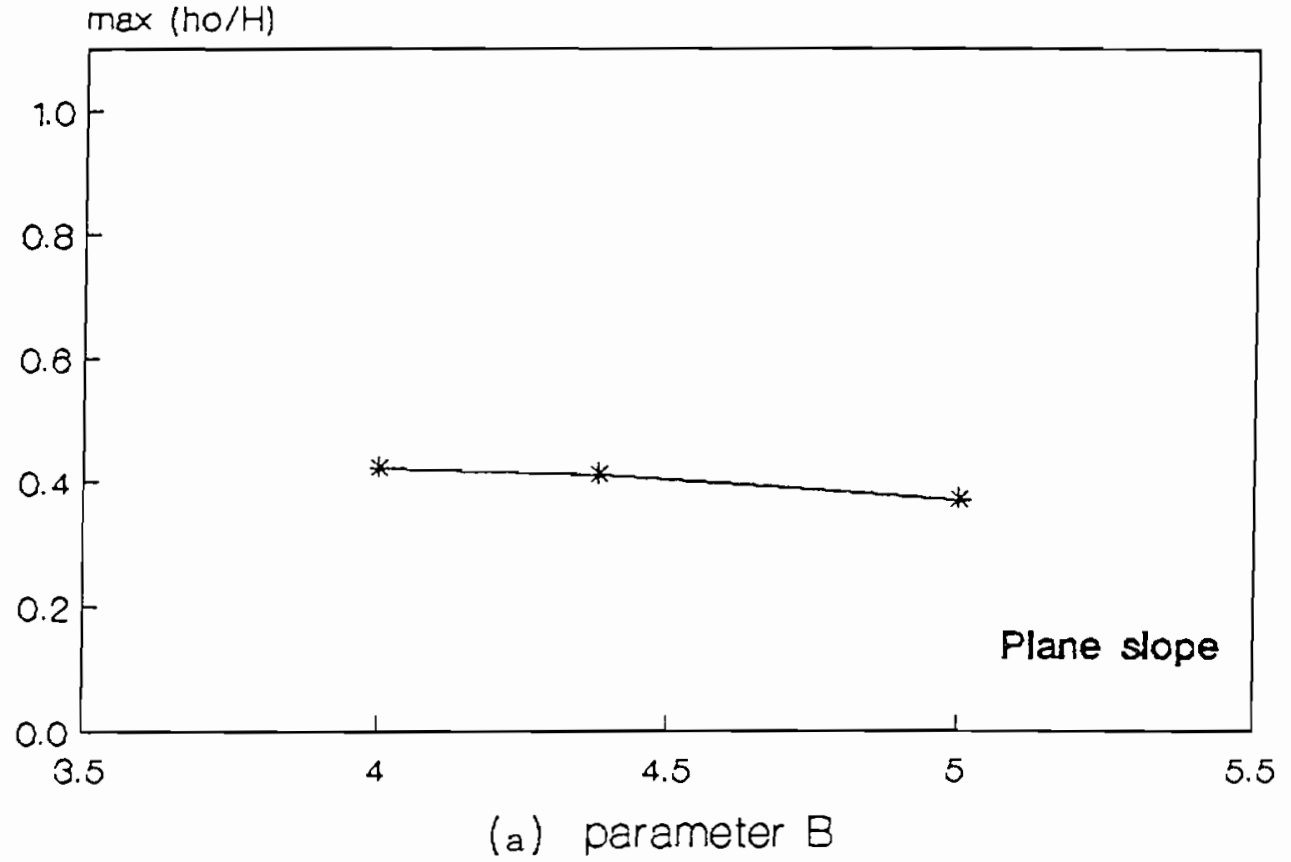

$\max (h o / H)$

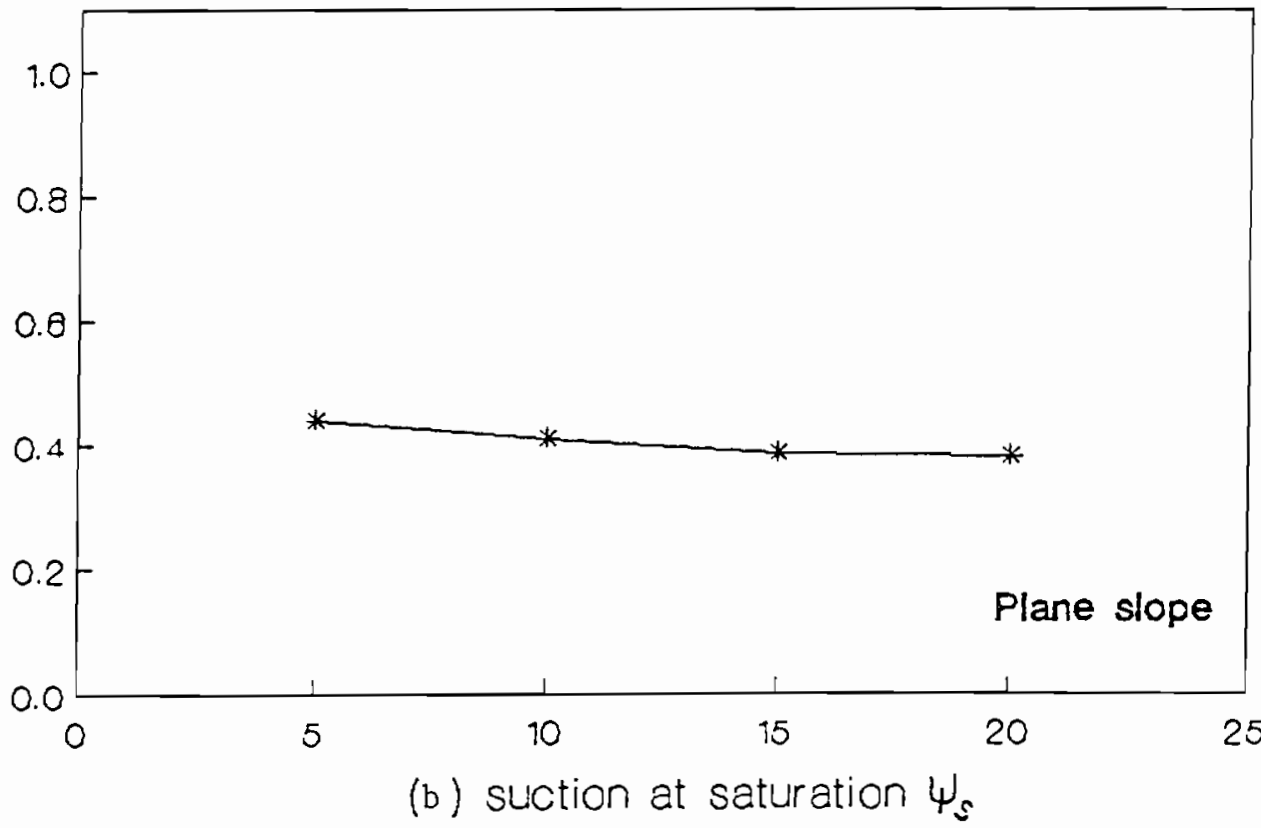

Figure 5.3: $\quad$ Effect of (a) parameter, B, (b) suction at saturation. $\psi_{s}$ on $h_{o} / H$. Mean values of all other parameters were used. 

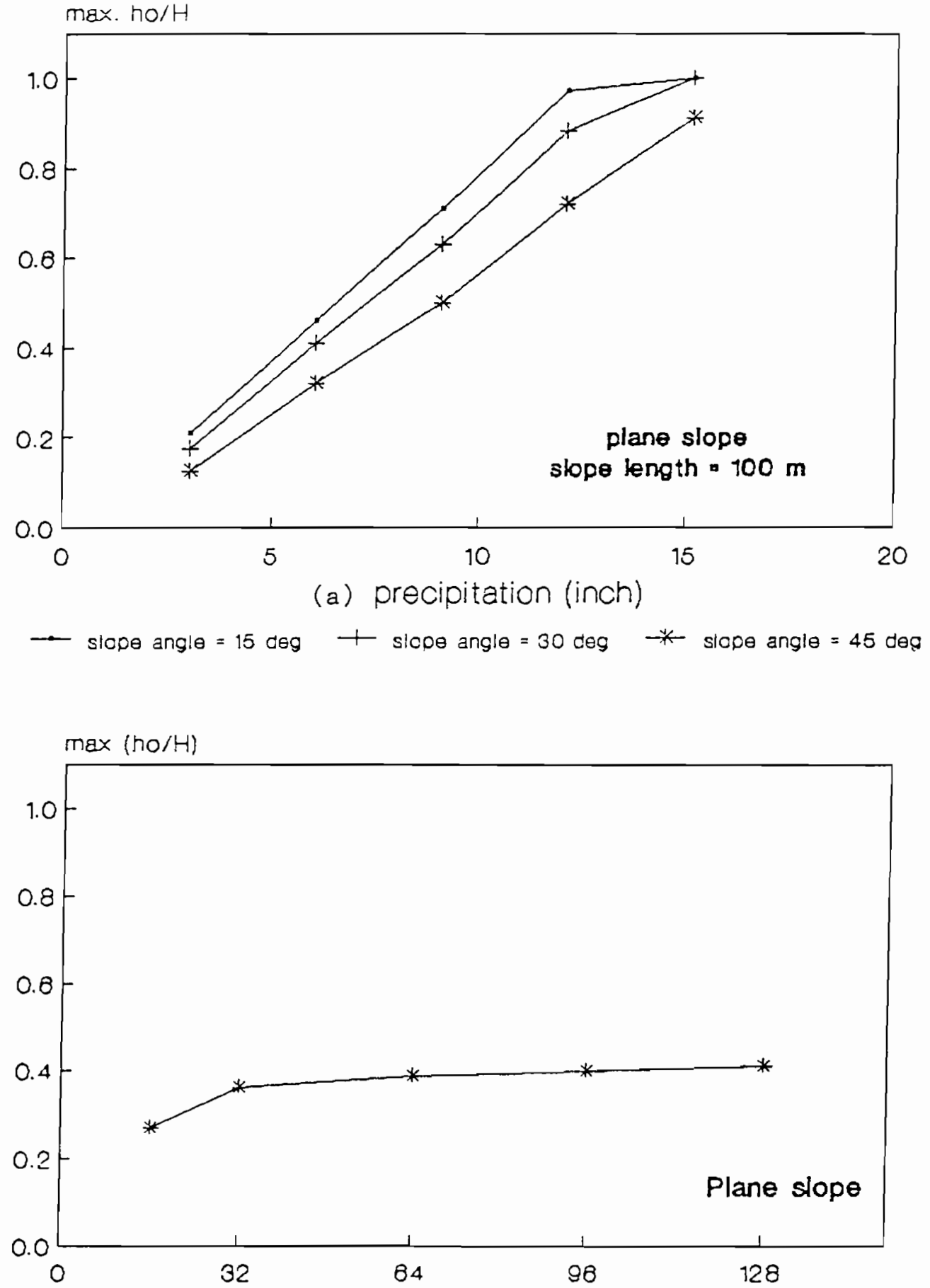

(b) duration D (nr.)

Figure 5.4: Effect of (a) precipitation, R, (b) storm duration, D, on $h / H$. Mean values of all other parameters were used. 
infiltration from mean annual storm $=6.5$ in, discussed in Section 4.6. Fig. 5.6a shows a comparison between the three slopes. It is clear that the converging slope has the highest $h_{o} / H$, whatever the slope angle is. Values of $h_{o} / H$ of the plane slope represent the lower bound whereas values $h_{o} / H$ of the trapezoidal slope are intermediate.

The two dimensional finite difference model (Lee, 1986) was used to investigate the variation of $h_{w} / H$ over the catchment area. The regional site conditions listed in Table 3.3 and the infiltration from mean annual storm $=6.5$ in, evaluated in Section 4.6 , were used in this analysis. The variation $h_{w} / H$ in the case of a converging slope is shown in Fig. 5.7. The average increase of $h_{w} / H$ over most of the catchment is about 0.22 . This increase of $h_{w} / H$ in the center of the catchment (axis 1,2$)$ is 0.6 . Such an increase is confirmed by both site observation (Johnson and Sitar, 1987) and analytical studies of flow pattern in converging slopes (O'Loughlin, 1986). Values of $h_{w} / H$ within different region of a catchment, shown in Fig. 5.8, may be approximately estimated using Eq. 5.3, by multiplying the predicted $h_{o} / H$ from Reddi and Wu's lumped model by a correction factor $\eta_{i}$ given in Table 5.1.

$$
h_{w} / H=\eta_{i} h_{0} / H, \quad i=\text { zone } i \text { shown in Fig. 5.8. }
$$

The values of $\eta$ reported in Table 5.1 are based on the regional site conditions of the \{cus township, listed in Table 3.3, and can only be generalized to other sites of similar conditions.

\subsection{FLOW THROUGH FRACTURES IN BEDROCK}

A two dimensional finite difference analysis was used to investigate the effect on the groundwater levels, $h_{w} / H$, caused by flow through fractures in bedrock. Fig. 5.9 illustrates the idealized problem. The following assumptions were adopted. (1) There is one continuous path through fractures in the bedrock layer. This means that the flow through fractures can be represented by a single hydraulic connection with an equivalent permeability. (2) The only potential 

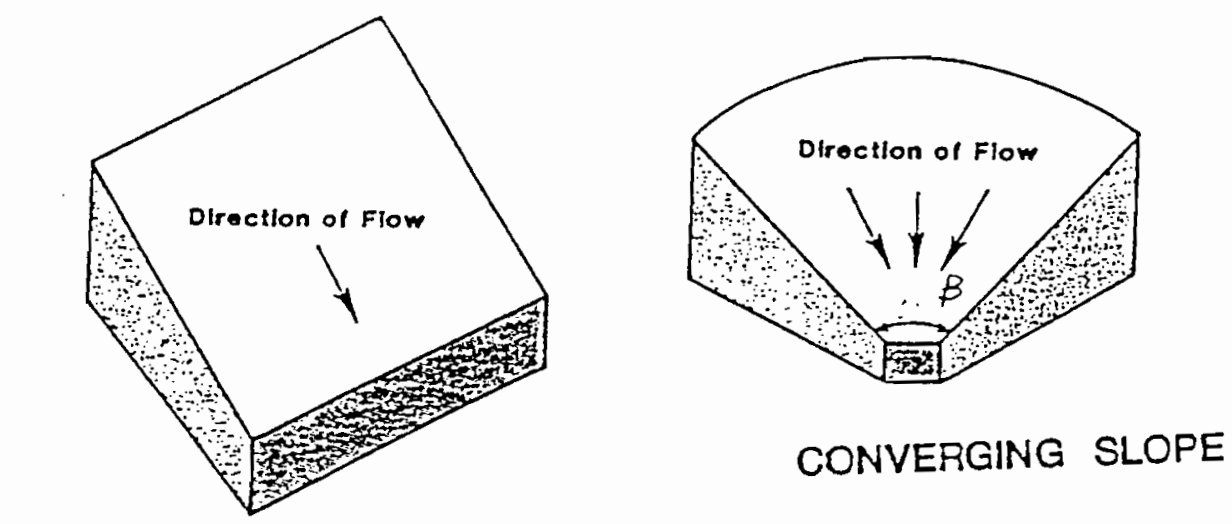

\section{PLANE SLOPE}

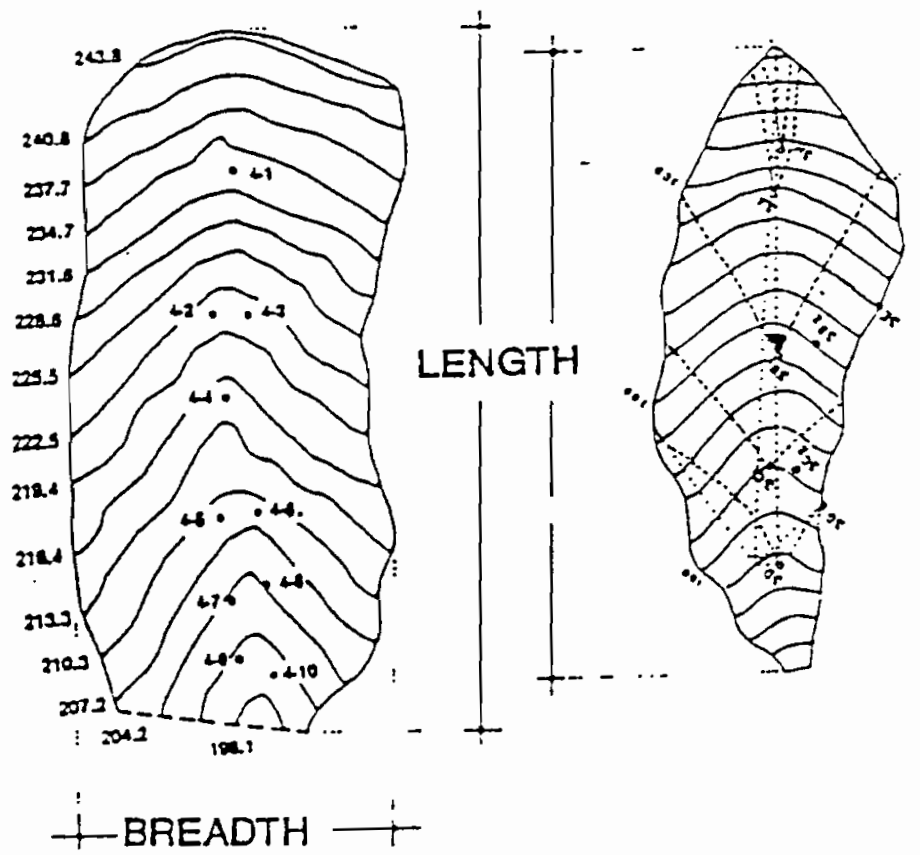

Figure 5.5: Different catchment shapes. 


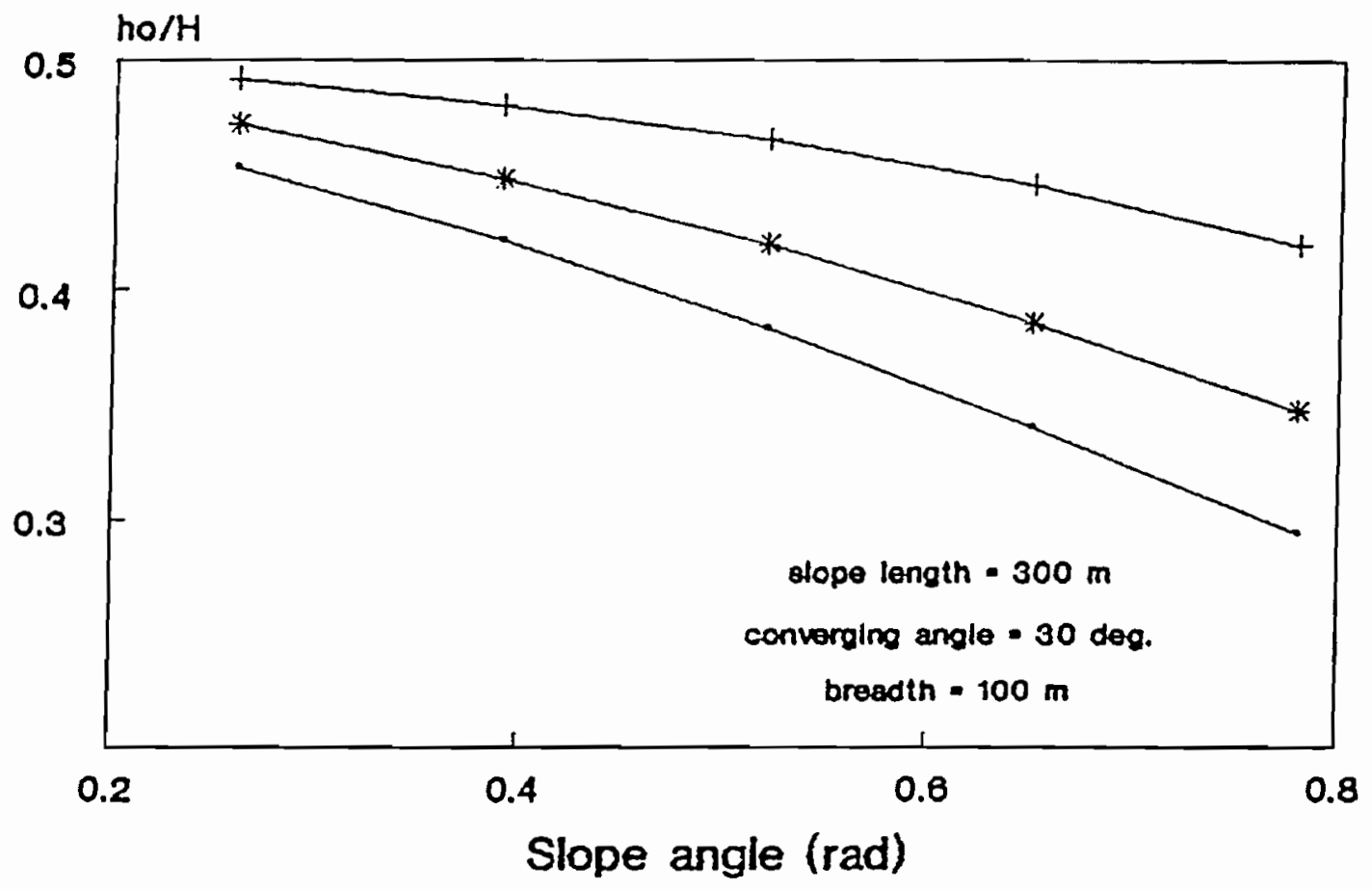

- plane slope + converging slope $\rightarrow$ trapezoidal slope

Figure 5.6: Comparison between groundwater for different catchment shapes. 


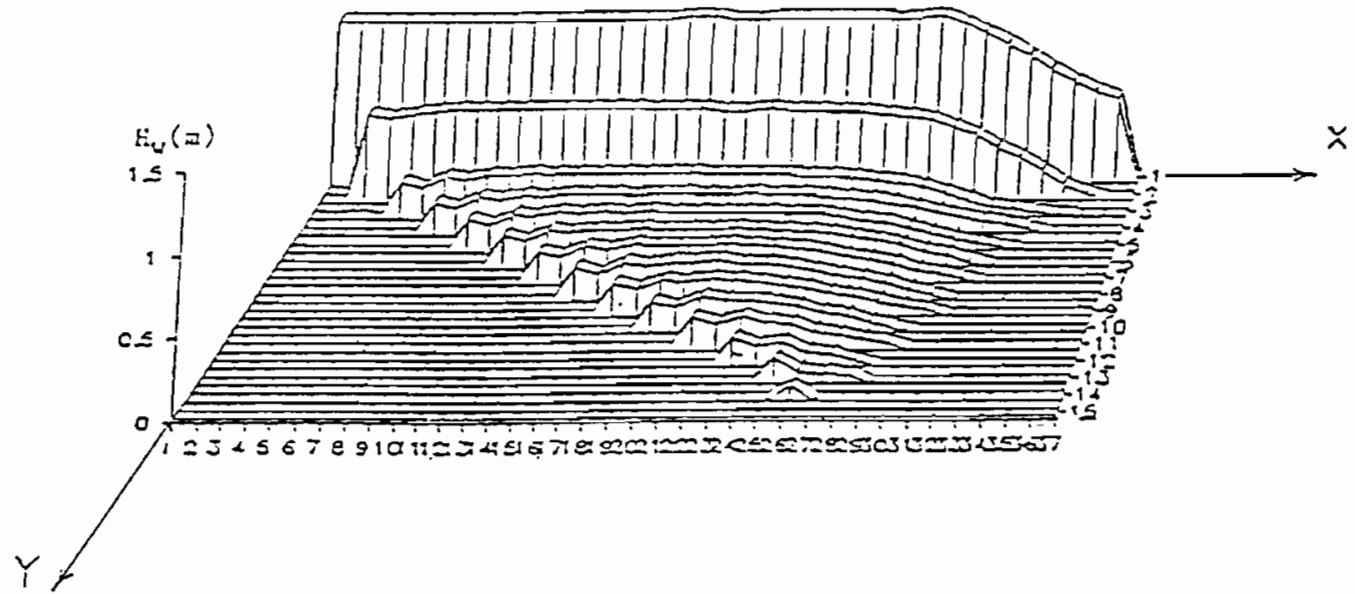

Figure 5.7: Variation of groundwater levels within a catchment. $K=2.8 \mathrm{~cm} / \mathrm{hr}, \mathrm{I}=6.5 \mathrm{in}$, slope angle $=30$, and $L=300 \mathrm{~m}$. 


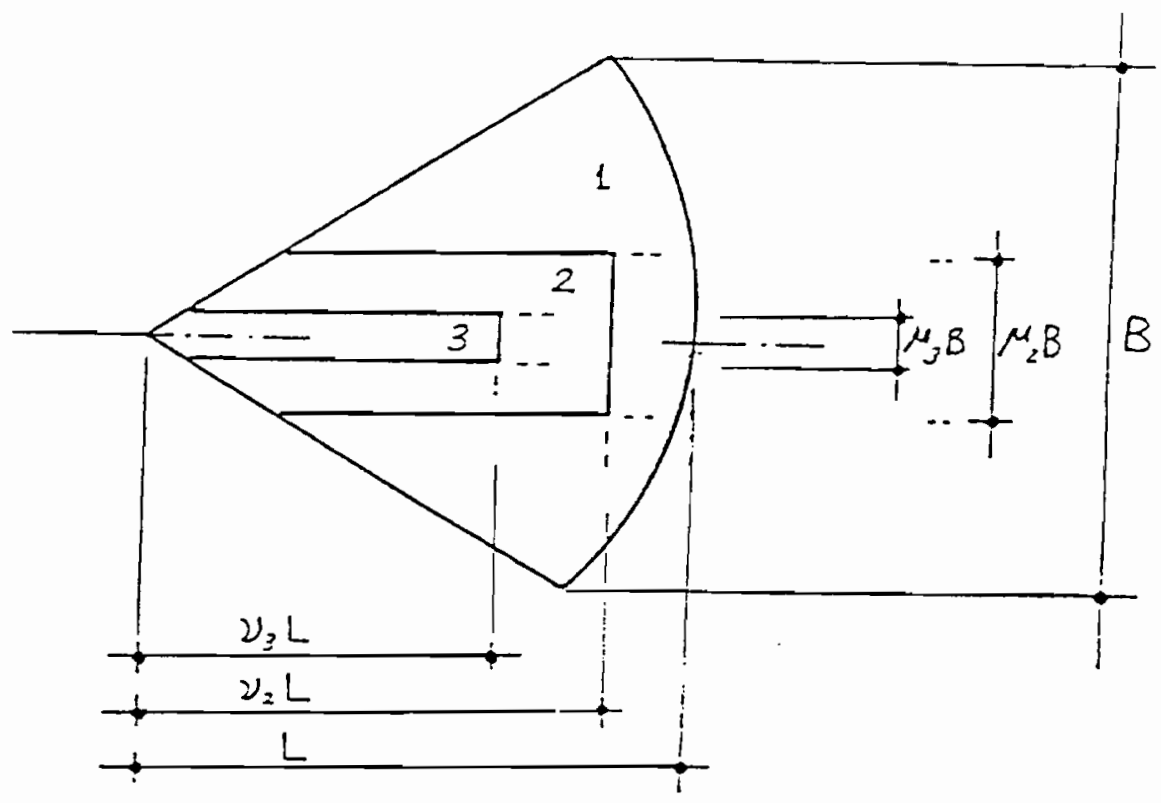

Figure 5.8: Piezometric level zones. To obtain values of $h_{w} / H$ for mapping, multiply $h_{\sigma} / H$ from Reddi's model by the fraction shown in Table 5.1. 
Table 5.1

Correction factor for mapping process.

\begin{tabular}{|c|c|c|c|c|}
\hline & $\begin{array}{c}\text { convergent } \\
\text { slope } \\
\text { no pumice }\end{array}$ & $\begin{array}{c}\text { convergent } \\
\text { slope } \\
\text { pumice }\end{array}$ & $\begin{array}{c}\text { plane } \\
\text { slope } \\
\text { no pumice }\end{array}$ & $\begin{array}{c}\text { plane } \\
\text { slope } \\
\text { pumice }\end{array}$ \\
\hline $\begin{array}{c}\text { Zone 1 } \\
\eta_{1}\end{array}$ & 0.5 & 0.3 & 0.5 & 1.0 \\
zone 2 & $1 / 15$ & $4 / 15$ & $2 / 15$ & $4 / 15$ \\
$\mu_{2}$ & 0.8 & 0.8 & 1.0 & 1.0 \\
$v_{2}$ & 1.0 & 1.2 & 1.0 & 3.0 \\
$\eta_{2}$ & $1 / 15$ & $1 / 15$ & $1 / 15$ & $1 / 15$ \\
Zone 3 & 0.6 & 0.6 & 1.0 & 1.0 \\
$\mu_{3}$ & saturated & saturated & saturated & saturated \\
$v_{3}$ & & & & \\
$\eta_{3}$ & saturat & & & \\
\hline
\end{tabular}

for the flow in the hydraulic connection is the groundwater head in the soil layer. (3) The fracture is saturated with water and the flow obeys Darcy's law. (4) The geometry of the irregular flow path was represented by a circular arc. This has little effect on the accuracy of calculation since the head difference does not depend on the shape of the flow path and the arc length is close to that of the irregular path. (5) The distance between the entrance and the exit points of the flow path i.e. points 1 and 2 in Fig. 5.9, was assumed to be at the one third points of the plane slope. This assumption is in accordance with the site observations reported by Brunengo (1991). A detailed study in Section 6.4 was done by varying the locations of the fracture, the distances between the entrance and the exit points, as well as the coefficient of permeability of the fracture. 
The two dimensional finite difference model of Lee (1986) was modified to solve the problem. Following Lee's derivation, the governing equation for flow in isotropic porous media at node 1 is

$$
\begin{aligned}
& C \frac{\partial h_{w}}{\partial t}=Q_{r} \cos \alpha-Q_{f}+\frac{\partial}{\partial y}\left[K_{s} h_{w}\left\{\cos \alpha\left(\frac{\partial h_{w}}{\partial y}+\frac{\partial H_{t}}{\partial y}-\frac{\partial H_{s}}{\partial y}\right)+\tan \gamma\right\}\right] \\
& +\frac{\partial}{\partial x}\left[K_{s} h_{w}\left\{\cos \alpha\left(\frac{\partial h_{w}}{\partial x}+\frac{\partial H_{t}}{\partial x}-\frac{\partial H_{s}}{\partial x}\right)+\sin \alpha\right\}\right]
\end{aligned}
$$

At node 2, the governing equation is

$$
\begin{aligned}
& C \frac{\partial h_{w}}{\partial t}=Q_{r} \cos \alpha+Q_{f}+\frac{\partial}{\partial y}\left[K_{s} h_{w}\left\{\cos \alpha\left(\frac{\partial h_{w}}{\partial y}+\frac{\partial H_{t}}{\partial y}-\frac{\partial H_{s}}{\partial y}\right)+\tan \gamma\right\}\right] \\
& +\frac{\partial}{\partial x}\left[K_{s} h_{w}\left\{\cos \alpha\left(\frac{\partial h_{w}}{\partial x}+\frac{\partial H_{t}}{\partial x}-\frac{\partial H_{s}}{\partial x}\right)+\sin \alpha\right\}\right]
\end{aligned}
$$

where $\mathrm{C}=$ specific yield, $Q_{r}=$ recharge to the saturated zone, and $Q_{f}=$ fracture flow, which is given by Eq. 5.6. Geometric variables used in Eqs 5.4 and 5.5 are explained in Fig. B.1b. For the flow through the fracture,

$$
Q_{f}=I_{g} b_{f} K_{f} t
$$

where

$$
I_{g}=\frac{x+\left(h_{w 1}-h_{w 2}\right) \cos \alpha}{\left(\pi a_{f}\right) / 2}
$$

where $\mathrm{x}=$ difference in elevation between points 1 and 2 in Fig. 5.9, $b_{f}=$ width of fracture, $a_{f}=$ distance between entrance and exit points, $K_{f}=$ permeability of the fracture, $Q_{f}=$ flow through the fracture, $\mathrm{t}=$ time, $h_{w 1}, h_{w 2}=$ groundwater levels at nodes 1,2 , respectively, and $I_{g}=$ hydraulic gradient. For a spacing of 1 fracture/meter and fracture opening $e=0.1$ to $1 \mathrm{~mm}$, the calculated $K_{f}$, using Eq. 2.4 , ranges from $10^{-4}-10^{-1} \mathrm{~cm} / \mathrm{sec}$. The lower limit is approximately equal to $K_{s}$, listed in Table 3.3, while the upper limit is several orders of magnitude larger. Without actual measurement of the coefficient permeability of the fractures, we evaluated the effects with values of $K_{f} / K_{s}$ of $0.1,1,10$ and 100 . 
The calculated results for a fracture of $b / b=0.1$, are shown in Fig. 5.10. $Y=7$ in Fig. 5.10 denotes the centerline of the fracture. The change in $h_{w 2} / H$ at the exit point 2 , as a function of time is shown in Fig. 5.11. For all cases, $h_{w 2} / H$ continued to build up after the end of storm, which corresponds to the delayed response described by Johnson and Sitar (1989).

\subsection{FLOW THROUGH PERVIOUS INCLUSIONS}

As explained in Section 3.2.3, weathered zones in volcanic rocks and pumice layers are present in areas of the focus township. The effect of flow through these pervious inclusions was treated by modifying the permeability of the section that has the pervious inclusion. The modified permeability, $K_{p}$, of a two layered system, shown in Fig. 5.12a, is

$$
K_{p}=\frac{K_{i} H_{i}+K_{s}\left(H-H_{i}\right)}{H}
$$

where $K_{i}=$ permeability of the inclusion, and $H_{i}=$ depth of the inclusion. The finite difference model (Lee, 1986) was modified to allow for $K_{p}$ in the area of the pervious inclusion. The same analysis can be used to model macropores or network of pipes within the soil layer using $K_{p}$ of these pervious inclusions. Fig. 5.12a illustrates the idealized configuration of the problem. Without actual measurement, the permeability of the pervious inclusion was assumed to be 10 times the permeability of the soil layer. The length of the pervious inclusion was assumed to be one third of the slope length and located in the middle third. The breadth was assumed to be equal to the plane slope breadth.

The results of the analysis are shown in Fig. 5.12b for the case of slope angle $=30^{\circ}$ and soil saturated permeability $=0.028 \mathrm{~m} / \mathrm{hr}$. $h_{w} / H$ downslope increases as a result of the presence of the pervious inclusions. A complete saturation of the soil cover may be anticipated at the downstream end of the pervious inclusion. For the assumed configuration, the increase of $h_{w} / H$ is 0.58 compared to 0.23 in case of homogenous soil cover. The location of the pervious 


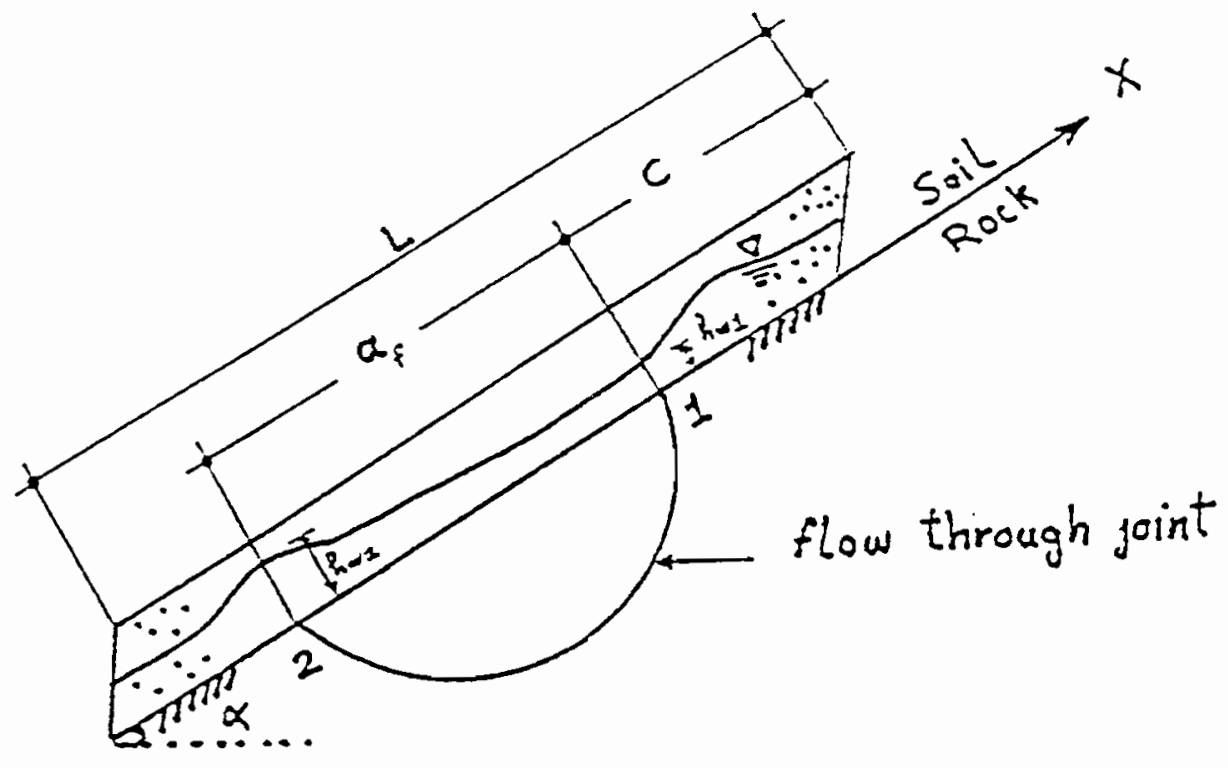

Figure 5.9. Model for flow through a fracture or joint, $b f=$ width of joint, $b=$ width of slope. 


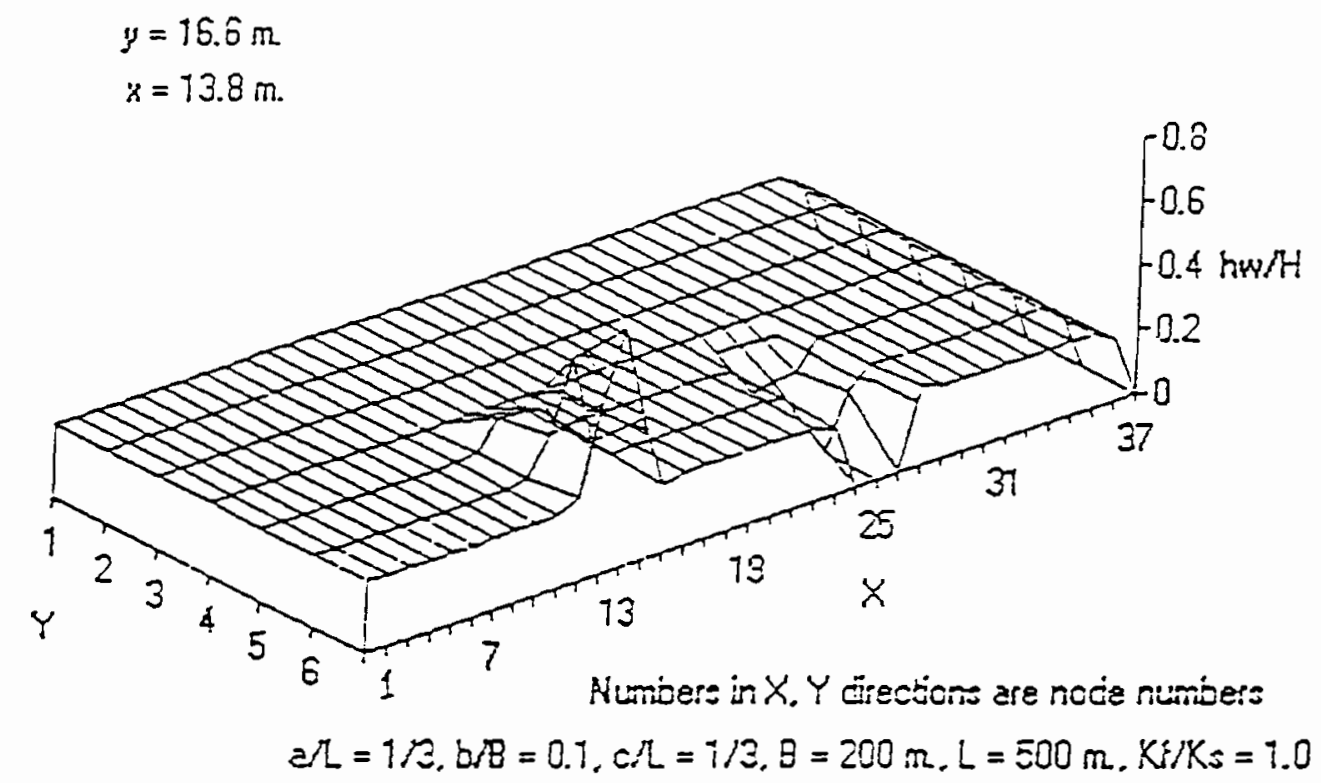

Figure 5.10. Groundwater levels within a slope with tow through Facure, $a=$ L/s, b= $10 \mathrm{~m}$. 


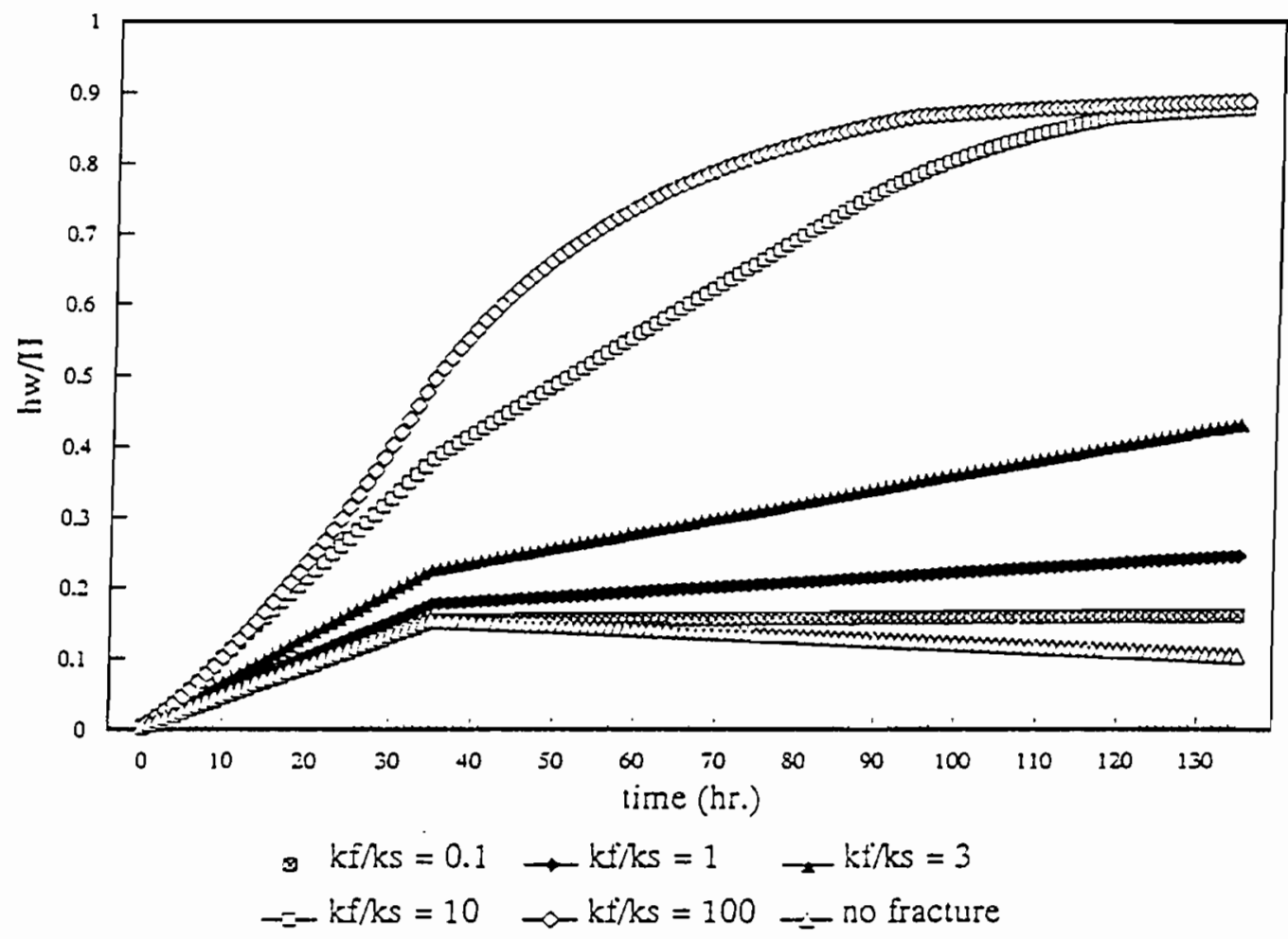

Figure 5.11: Change of hw / H at exit point with ine. 
inclusion and its dimension are the governing factors. The permeability and the layer thickness are of secondary significance given that the ratio of $K_{i} / K_{s}$ is large.

In the present study, the pumice layer is the pervious inclusion, and $K_{i}$ may be close to that of gravel, or as large as $3.6 \times 10^{2} \mathrm{~m} / \mathrm{hr}$. In Section 3.2.3, the pumice layer was considered to be continuous over the slope. Then, $K_{p}$ was used for $K_{s}$ in the drainage model wherever the pumice layer was considered to exist. Practically, $K_{p}$, is close to $K_{i}$ of pumice layer given that, $K_{i}$, is two order of magnitude greater than $K_{s}$.

\subsection{GROUNDWATER MAPPING}

Prediction and mapping groundwater levels can be made at several levels, with various degrees of refinement. Two prediction levels that can be used for landslide hazard mapping is presented. The first prediction is for different values of infiltration with soil properties that represent the regional site conditions throughout a large region as the focus township. This is the simplest approach. The precipitation and snow depth data were taken from the weather statistics compiled by Brunengo (1989) and the snowmelt model (U.S. Army Corps of Engineers, 1956) was used to calculate the snowmelt on a cleared slope. Infiltration for a given return period were calculated similar to calculations made in Section 4.6. These infiltration values were used as input to Reddi and Wu's model. A plane slope was assumed. The results of the calculations are shown in Fig. 5.13 as a plot of $h_{o} / H$ versus the return period of the storm. Such plots give a measure of the piezometric levels relative to the magnitude of the storm.

A more detailed prediction can be made for site conditions at different locations within a region such as the focus township. The detailed calculations considered the catchment shape, the variation of $h_{w} / H$ within a catchment, and the soil properties for the specific locations. The

results can be used to plot a map of groundwater ratio, i.e. value of $h_{w} / H$ at each pixel. The following steps were employed to make the map : 
(a)

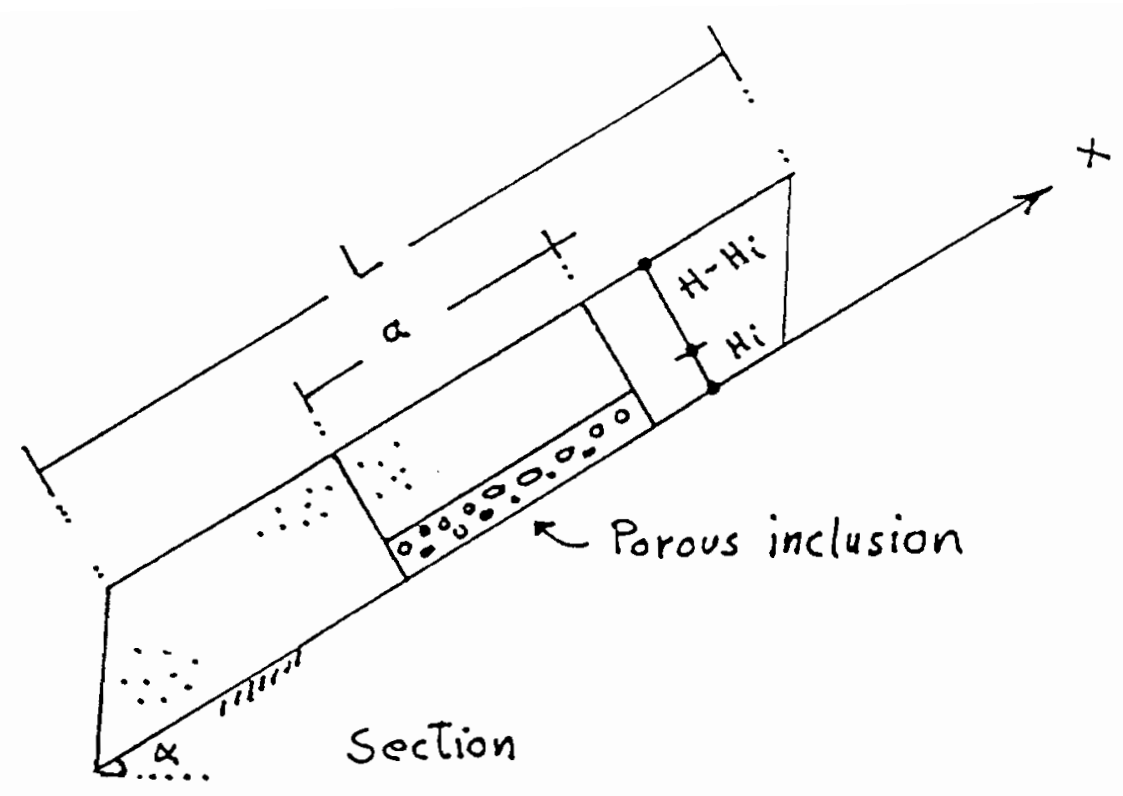

hW/H

(b)

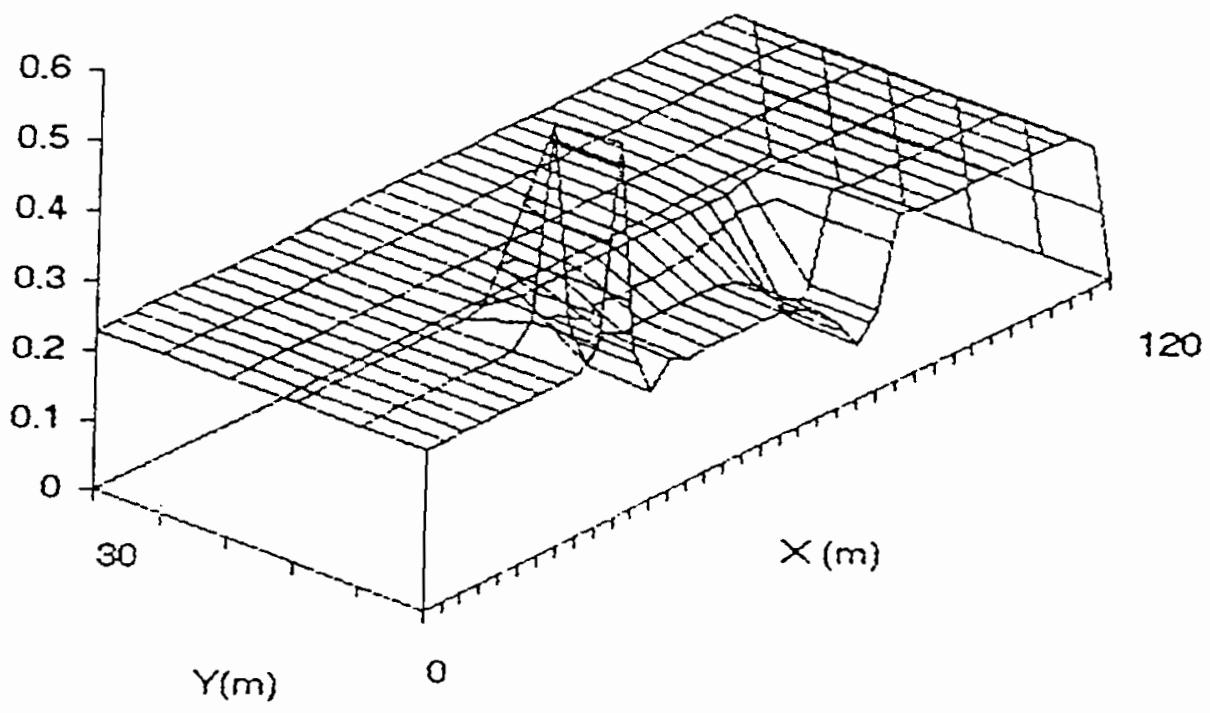

Figure 5.12: Flow through porous inclusion. (a) model for flow through porous inclusion, (b) variation of $h_{w} / H$ within a slope, $a=L / 3 \quad b=20 \mathrm{~m}$. 
(1) The Digital Elevation Model (DEM) of the U.S. Geological Survey was read into the Geographic Information System (GIS) and used to determine the physical characteristics of the catchments (Benosky, 1992). MicroImage's Map and Image Processing System (MIPS) and the Spatial Manipulating Language (SML) were used to identify the catchment boundaries and to extract the catchment features, which are perimeter, width, and flow path. The procedure is an outgrowth of the model developed by Jenson and Dominique (1988) and Marks et al. (1984). Specific software used in this project were written by Benosky (1992). The minimum size of a catchment was specified as 500 pixels $\left(0.45 \mathrm{~km}^{2}\right)$. Clearly, the smaller the minimum size gets, the more detailed the map is. In this case, we considered 500 pixels to be a reasonable compromise between details and volume of computations. Further refinement is probably not justifiable considering the limitations in the available data. Fig 5.14 and 5.15 show the boundaries of the individual catchments in Glenoma and Mineral quadrangles, respectively.

(2) The detailed soil map, provided by Soil Conservation Service (1987), was read into the GIS using Arc/Info format. For each catchment, the average soil property was the average of the properties of all soil units in the catchment. The pumice layer was assumed to be present when "pumice" was mentioned in the soil profile. Then the permeability was calculated using $\mathrm{Eq} 5.8$.

(3) The largest storm within a period of 10 years was assumed to fall on a cleared slope. The mean and variance of the infiltration of the largest storm was evaluated in Section 4.7. where the U.S. Army Corps of Engineer's Snowmelt model (1956) was used to compute the snowmelt. The value of $h_{o} / H$ was calculated for each catchment by Reddi and Wu's model (1991). The values of $h_{w} / H$ at different points within a catchment were calculated using the correction factors listed in Table 5.1. The computed $h_{w} / H$ for cleared slopes were plotted as maps for Glenoma and Mineral quadrangles. These are given in Figs 5.16 and 5.17, respectively. 


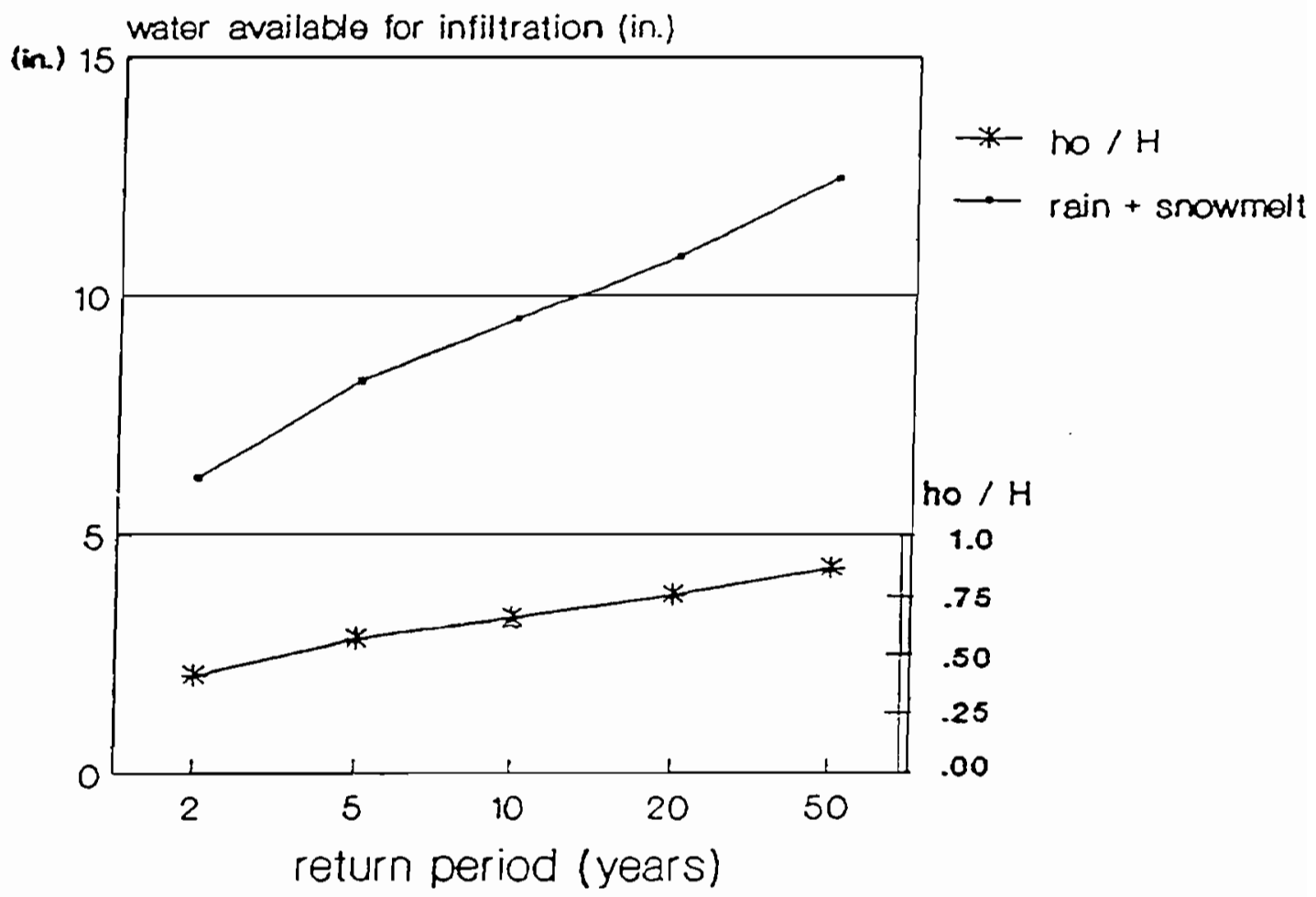

Figure 5.13: Mean piezometric level for storms of various return periods. 


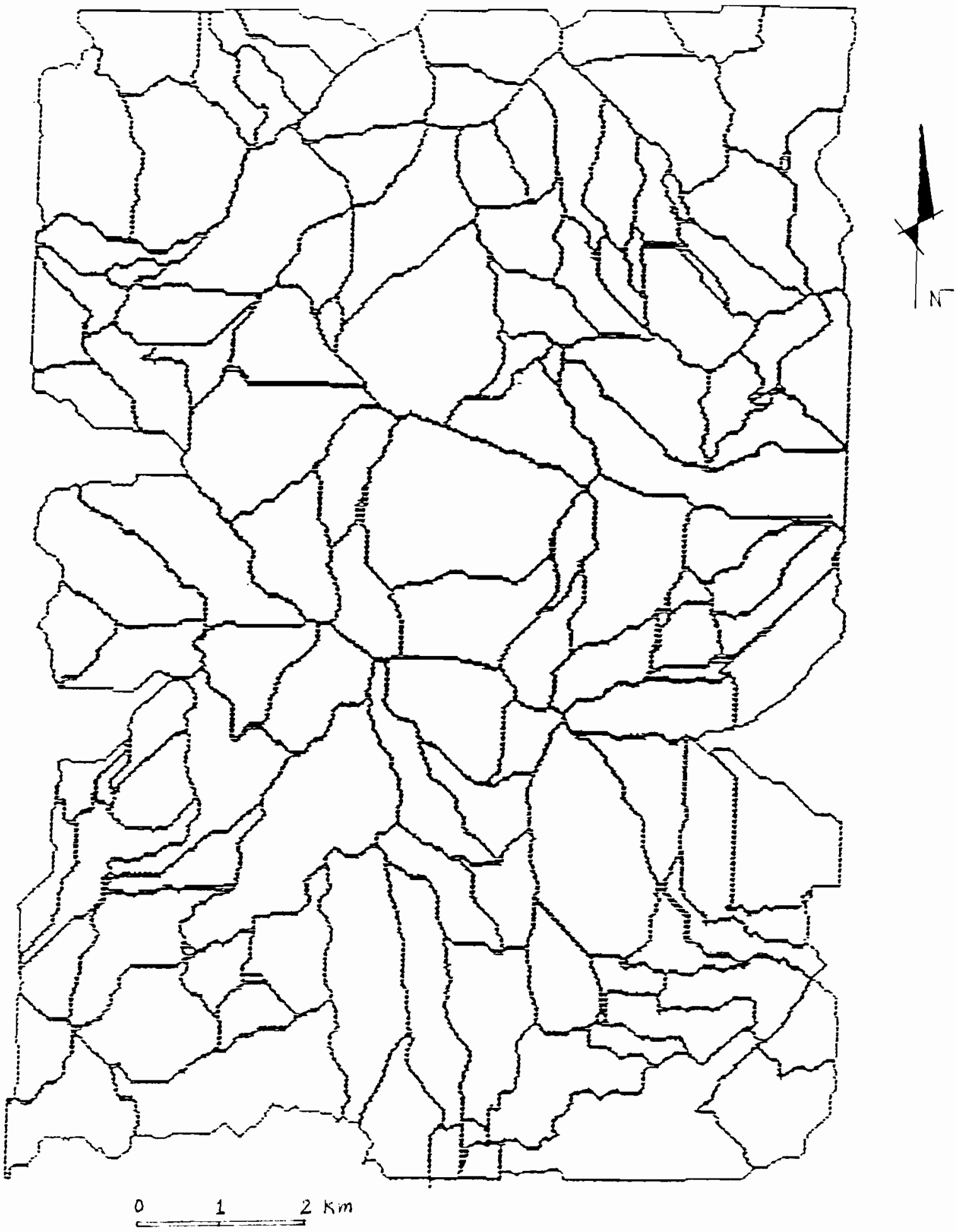

Figure 5.14: Catchment boundaries, Glenoma quadrangle, Washington. 


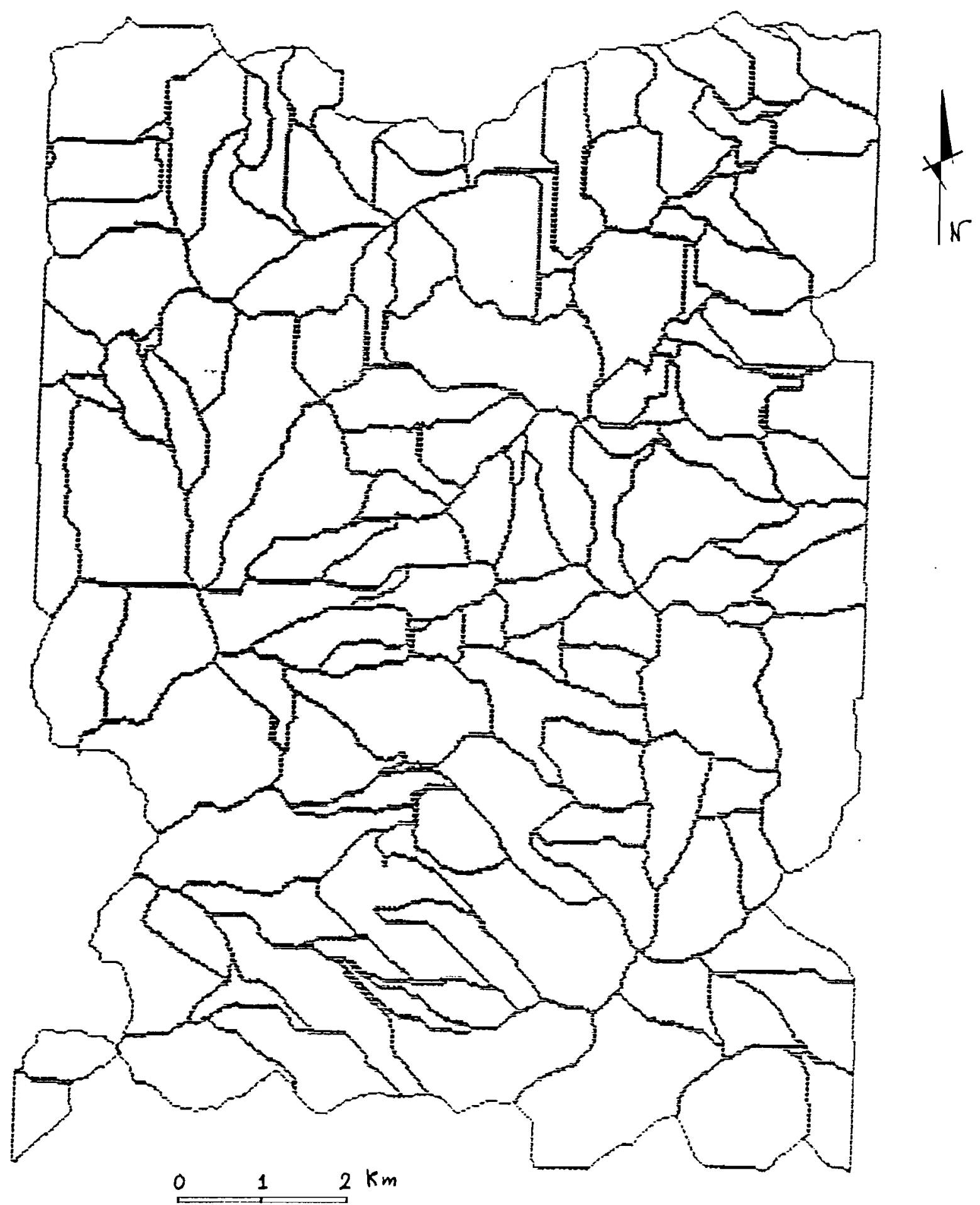

Figure 5.15: Catchment boundaries, Mineral quadrangle, Washington. 


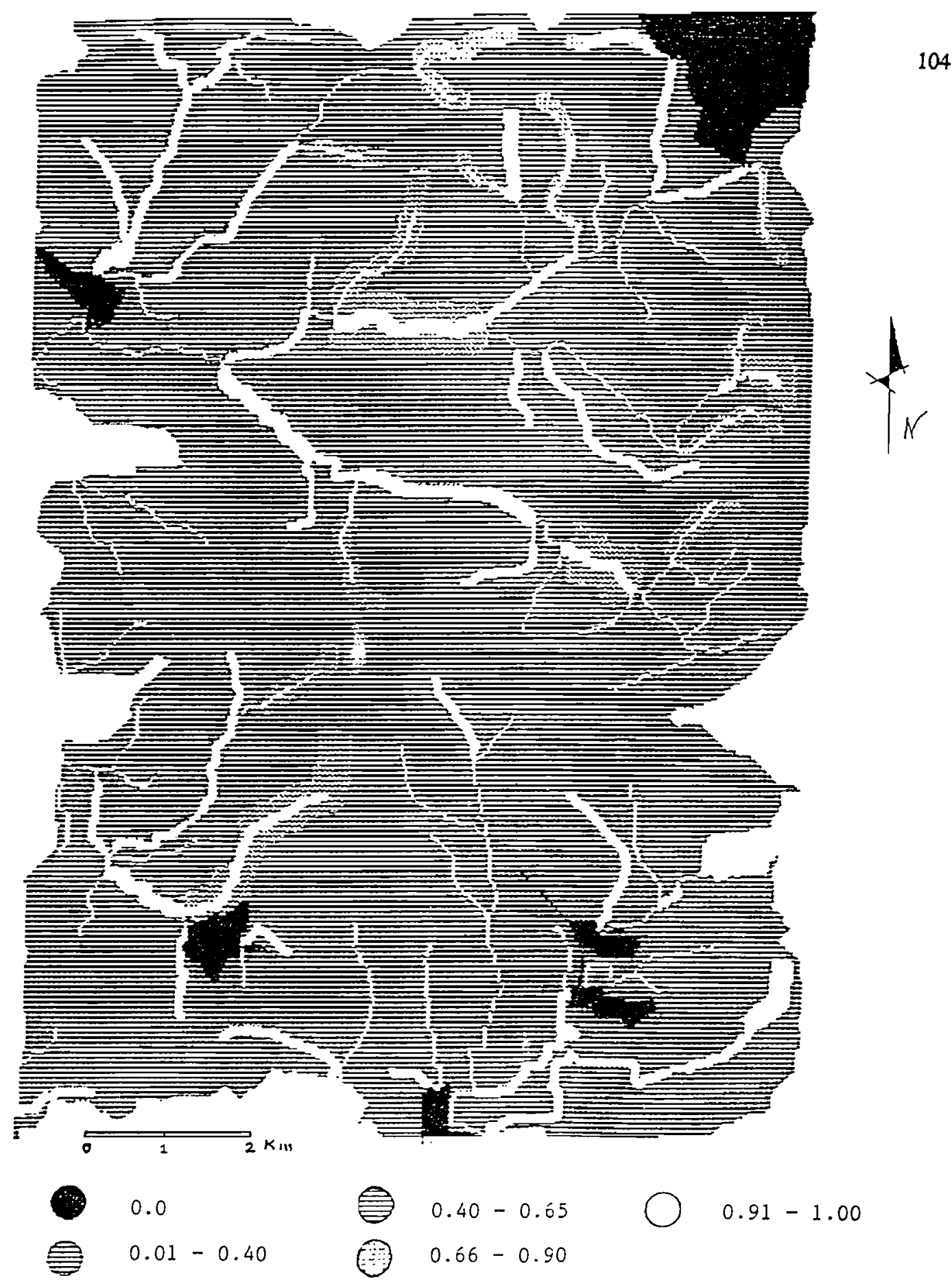

Figure 5.16: Piezometric level map for Glenorna quadrangle, Washington. 


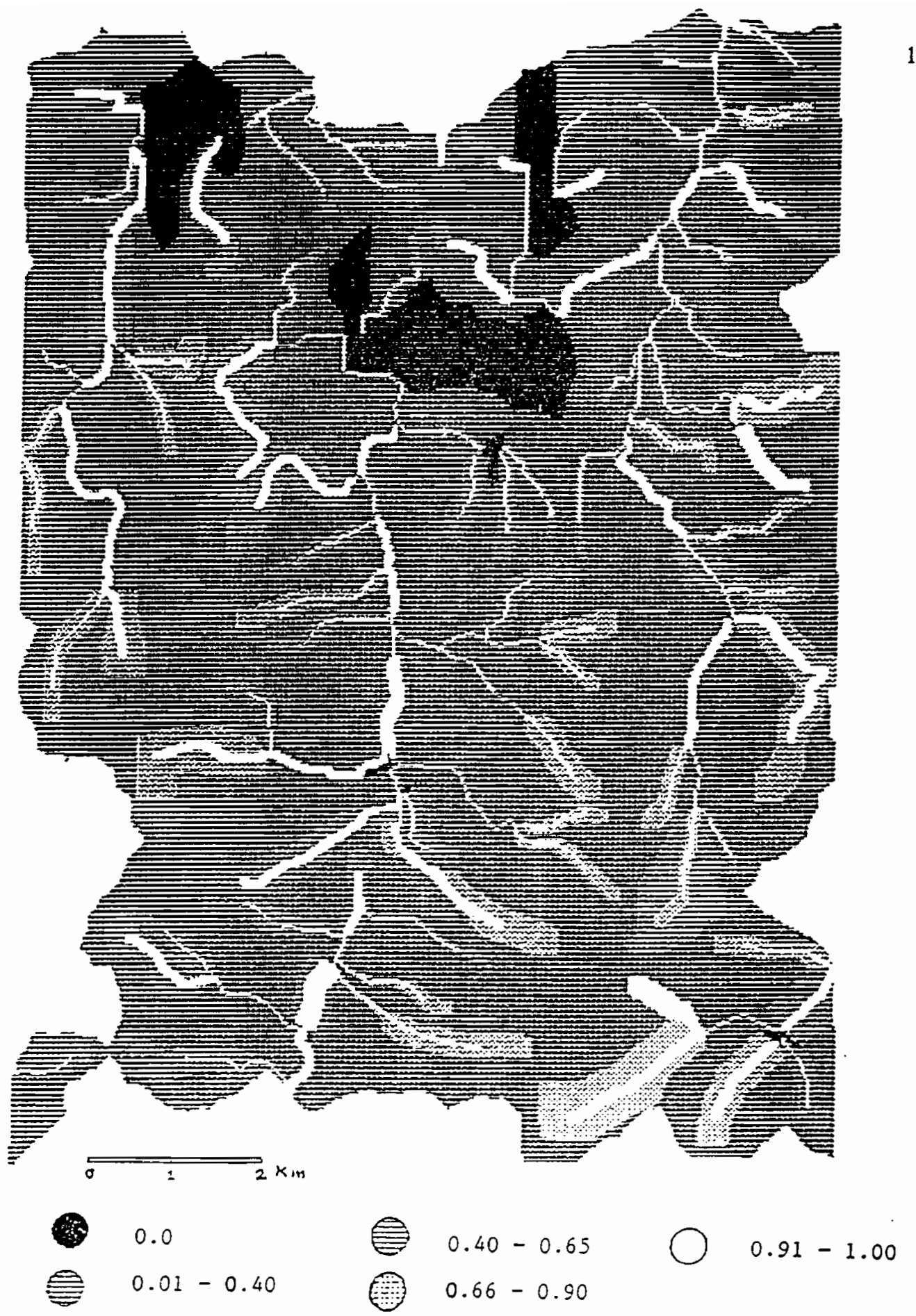

Figure 5.17: Piezometric level map for Mineral quadrangle, Washington. 


\section{CHAPTER VI}

\section{UNCERTAINTY ABOUT GROUNDWATER}

\subsection{INTRODUCTION}

Many of the groundwater parameters are highly variable and can only be estimated approximately. The objective of the probabilistic models is to evaluate how uncertainties and variations in the groundwater parameters influence the groundwater prediction. The sources of uncertainties about groundwater can be classified under the following groups:

1. uncertainty about storm characteristics and snowmelt, which results from

a. uncertainty about total amount of infiltration and duration, and

b. uncertainty about antecedent moisture conditions which is a function of

i. number of storms per season, and

ii. interval between major storms,

2. uncertainty about soil properties which results from

a. systematic uncertainty,

b. random variations, and

c. occurrence uncertainty,

3. uncertainty about geologic anomalies.

The objective of the analyses in this chapter is to evaluate the uncertainty and variability of the groundwater as a result of the previous sources of uncertainty and variability. FOSM was used to deduce the probabilistic moments of the groundwater (see Appendix C). The procedures is applied to the study area in the focus township. 
Although the uncertainties about antecedent moisture, soil properties and geologic Anomalies do not depend on the amount of infiltration, the sensitivity of $h_{w} / H$ to these parameters depends on the amount of infiltration. Then the uncertainty about $h_{w} / H$ depends also on the amount of infiltration, i.e. the storm return period or the maximum storm in $\mathbf{n}$ years. In this chapter, the uncertainty about $h_{w} / H$ was evaluated for the mean annual infiltration and for the maximum infiltration in 10 years and the results are shown in Table 6.4 for purpose of comparison.

\subsection{UNCERTAINTY DUE TO STORM CHARACTERISTICS}

\subsubsection{Storm Infiltration and Duration}

For a single storm, the variance of $h_{o} / H$ can be computed from the variance of infiltration, I, and duration, D. Using FOSM, Eq. C.4, then

$$
\operatorname{Var}\left(\frac{h_{o}}{H}\right)=\left(\frac{\partial \frac{h_{o}}{H}}{\partial I}\right)^{2} \operatorname{Var}(I)+\left(\frac{\partial \frac{h_{o}}{H}}{\partial D}\right)^{2} \operatorname{Var}(D)+\left(\frac{\partial \frac{h_{0}}{H}}{\partial I}\right)\left(\frac{\partial \frac{h_{o}}{H}}{\partial D}\right) \operatorname{Cov}(I, D)
$$

The sensitivities of $h_{d} / H$ to I and D were evaluated in Sections 5.1, and 5.2, respectively. They are $7.58 * 10^{-2} i n^{-1}$ and $5.8 * 10^{-4} h r^{-1}$, respectively. The variances of I and D were evaluated in Sections 4.7 and 4.3, respectively. They are $8.5 \mathrm{in}^{2}$ and $1296 h r^{2}$, respectively. The covariance of I and D is 0.748 (Brunengo, 1989). The computed variance of $h_{o} / H$ due to variances of I and $\mathrm{D}$ is $\mathbf{0 . 0 4 9 3 . ~ I n ~ f a c t , ~ m o s t ~ o f ~ t h e ~ u n c e r t a i n t y ~ o f ~} h_{\mathrm{o}} / H$ results from the uncertainty about I. 


\subsubsection{Antecedent Moisture}

The uncertainty of $h_{o} / H$ due to uncertainty about antecedent moisture consists of two parts. The first part is due to the uncertainty about the number of storms per season. The storm under consideration can be one of the storms in a season with one storm, or a season with two storms, etc. The antecedent moisture varies according to the number of storms per season and so does $h_{o} / H$. The second part is due to the uncertainty about the interval between storms. The variances of $V$ and $W$, calculated in Section 4.4, affect the antecedent moisture conditions and consequently $h_{o} / H$. In the next two sections, the two sources of uncertainty are discussed and the resulted uncertainties in $h_{o} / H$ are evaluated. The uncertainty as a result of the interval between storms is assumed to be independent of the uncertainty due to number of storms per season, although it is recognized that the interval between storms is correlated to the number of storms per season.

\subsubsection{Number of Storms}

Statistics of the number of long continuous storms (LCS) per season and of the interval between storms, discussed in Section 4.4.1, were used to compute $h_{o} / H$ by Reddi and Wu's model (1991) for seasons with 1 to 4 storms. For the computation of the mean values of $h_{o} / H$, the mean values of the input parameters for each category of storm number were used. Using the mean value of the interval between two storms, i.e. $E(V)=708 \mathrm{hr}$ and $\mathrm{E}(\mathrm{I})=6.5 \mathrm{in}$, the mean values of the antecedent moisture conditions were predicted, Fig. 6.1a. These mean values were used as input to the groundwater model to simulate the second storm in a two-storm season and the results are shown in Fig. 6.1b. Using the mean value of the interval between the last two storms for three-storm season, i.e. $\mathrm{E}(\mathrm{W})=550 \mathrm{hr}$ and $\mathrm{E}(\mathrm{I})=6.5 \mathrm{in}$, the mean antecedent moisture conditions for the third storm were predicted from Fig. 6.1b. These mean values were used as input to the groundwater model to simulate the third storm in a three-storm season 
and the results are shown in Fig.6.2a. The results shown in Figs 6.1a, 6.1b, 6.2a, and 6.2b were computed for a storm of $\mathrm{I}=6.5 \mathrm{in}, \mathrm{H}=1.00 \mathrm{~m}, K_{S}=0.028 \mathrm{~m} / \mathrm{hr}$, and different antecedent moisture conditions.

To include the effects of small rain events, the simulated small rain events, shown in Fig. $4.4 b$, were superimposed on the events of LCS, i.e. $E(I), E(V)$ and $E(W)$. The groundwater response $\left(h_{\delta} / H, \theta_{1}, \theta_{2}\right)$ was calculated using Reddi and Wu's model (1991) for each simulated sequence of storms. An example is shown in Fig. 6.3. The procedure described above was repeated and the output was used to study the characteristics of antecedent moisture conditions. Fig. 6.4a summarizes the mean values of the antecedent moisture conditions as well as the associated probabilities for different number of storms per season. Fig. $6.4 \mathrm{~b}$ shows the frequency function of $h_{o} / H$ calculated using the the probability mass function of antecedent moisture conditions shown in Fig. 6.4a. The figure shows the mean value of $h_{o} / H$ corresponding to a given number of LCS per season. The variance of $h_{o} / H$ due to the uncertainty about antecedent moisture conditions as a result of number of storms per season was calculated using the results shown in Fig. 6.4b and was found to be 0.088 .

\subsubsection{Interval Between Storms}

In Section 6.2.2.1, the mean values of the antecedent moisture conditions, $\theta_{i}$ and $h_{o_{i}}$, for a given number of storms per season, were used to calculate $h_{o} / H$. It should be noted that, even for a given number of storms per season, $\theta_{i}$ and $h_{\alpha i}$ are random variables, depending on the interval between storms. In Section 4.4.1, the interval between storms $\mathrm{V}$ and $\mathrm{W}$ were treated as random variables and their means and variances were calculated numerically. To account for the effect of the variation the interval between storms on $\theta_{i}$ and $h_{\alpha}$, FOSM was used to calculate the variances of $\theta_{i}$ and $h_{\alpha i}$ as a function of the variance of $\mathrm{V}, \mathrm{W}$, etc. 


$$
\operatorname{Var}\left(h_{o i}\right)=\left(\frac{\partial h_{o i}}{\partial V}\right)^{2} \operatorname{Var}(V)
$$

The derivatives of $\theta_{i}$ and $h_{w i}$ with respect to $\mathrm{V}$ ware derived from the relation between $\theta_{i}$ and $h_{w i}$ with time after the end of the first storm. For simplicity, only response to LCS, shown in Figs. 6.1 and 6.2, was considered. $\operatorname{Var}(V)$ was evaluated in Section 4.4. Then, Var $\left(\theta_{i}\right)$ and $\operatorname{Var}\left(h_{o i}\right)$ were computed using Eqs. 6.2 and 6.3, respectively. The variance of $h_{o} / H$ due to the variances of $\theta_{i}$ and $h_{o i}$ can then be written as

$$
\operatorname{Var}\left(\frac{h_{o}}{H}\right)=\left(\frac{\partial \frac{h_{o}}{H}}{\partial \theta_{i}}\right)^{2} \operatorname{Var}\left(\theta_{i}\right)+\left(\frac{\partial \frac{h_{o}}{H}}{\partial h_{d i}}\right)^{2} \operatorname{Var}\left(h_{o i}\right)
$$

The derivatives of $h_{o} / H$ with respect to $\theta_{i}$ and $h_{a i}$ were computed from the sensitivity of $h_{o} / H$ to these parameters shown in Fig 6.5.

The procedure was repeated for different number of storms per season. The total variance of $h_{o} / H$ due to the variation of the interval between storms is $2 * 10^{-5}$. This is very small compared to the variance due to the number of storms per season, which is 0.088 . It should be noted that $\theta_{i}$ and $h_{o i}$ are correlated as it appears from Figs. 6.1, 6.2, and 6.3. The number of storms and the interval between storms are also correlated. The effect of the correlation may be ignored because of the small variance due to variation of the interval between storms. 


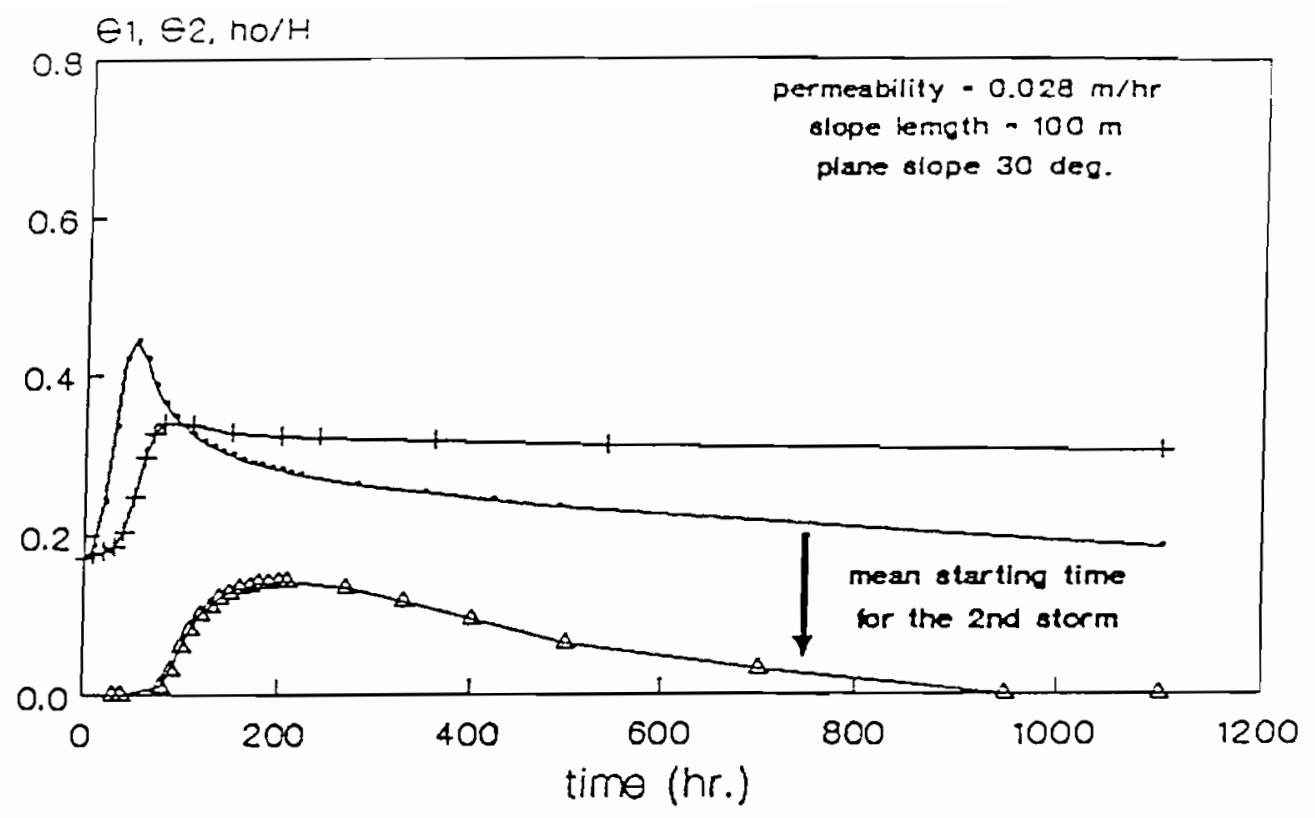

111

(a) $\rightarrow \theta_{1} \leftarrow \theta_{2} \rightarrow$ no/ $\mathrm{H}$

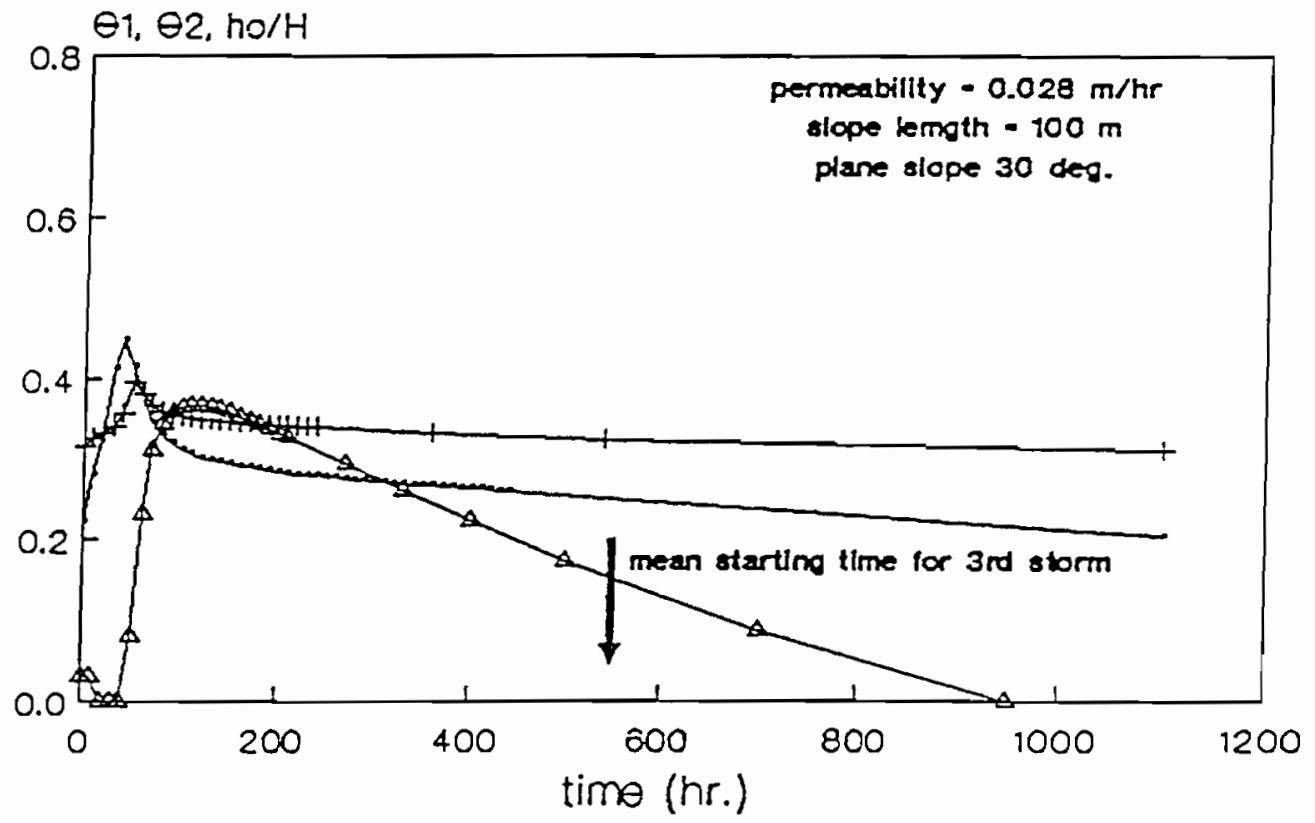

(b) $\rightarrow \theta_{1} \longrightarrow \theta_{2} \longrightarrow \mathrm{no} / \mathrm{H}$

Figture 6.1: Groundwater for 1-storm season and 2-storm season. Moisture content and $h_{\delta} / H$ vs. time for (a) 1 -storm, and (b) 2 -storms. 


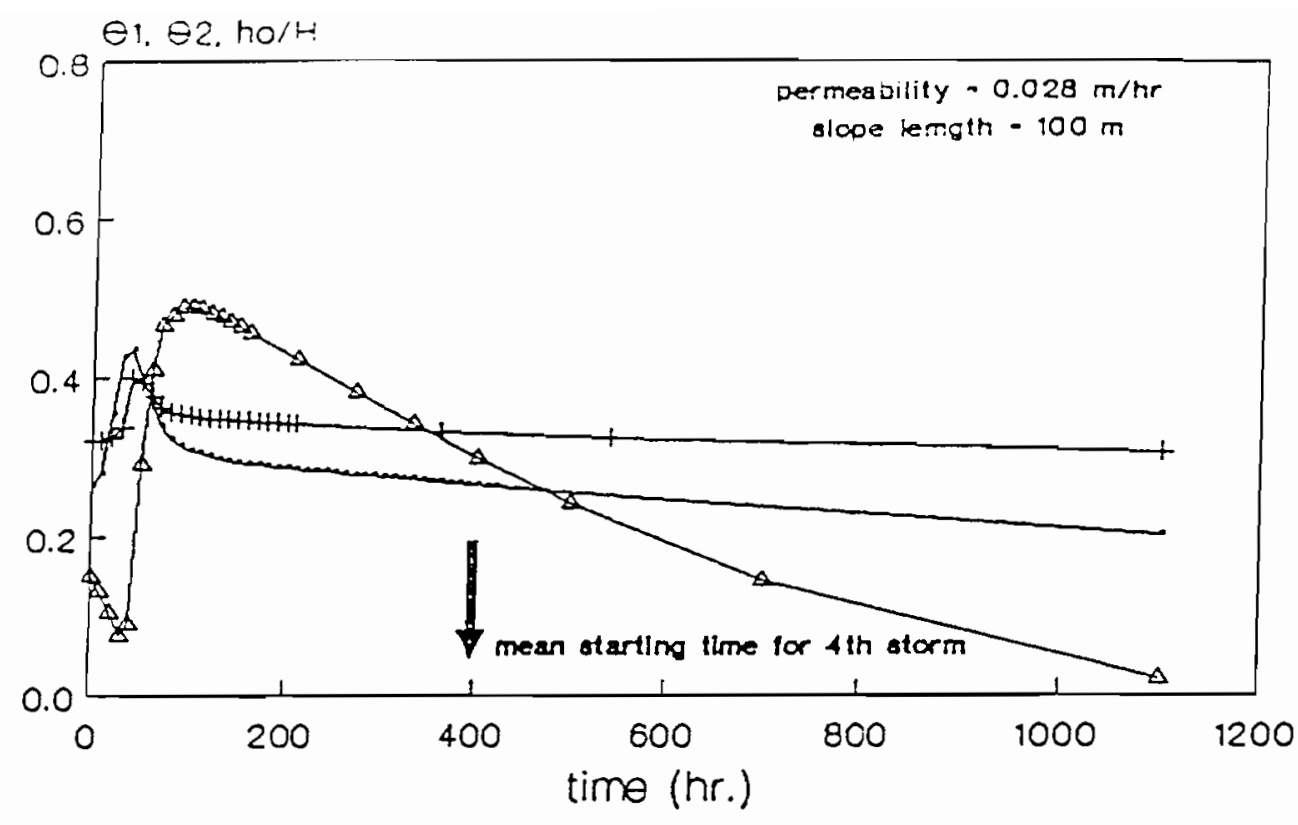

(a) $\rightarrow \theta_{1}+\theta_{2} \rightarrow \mathrm{no} / \mathrm{H}$

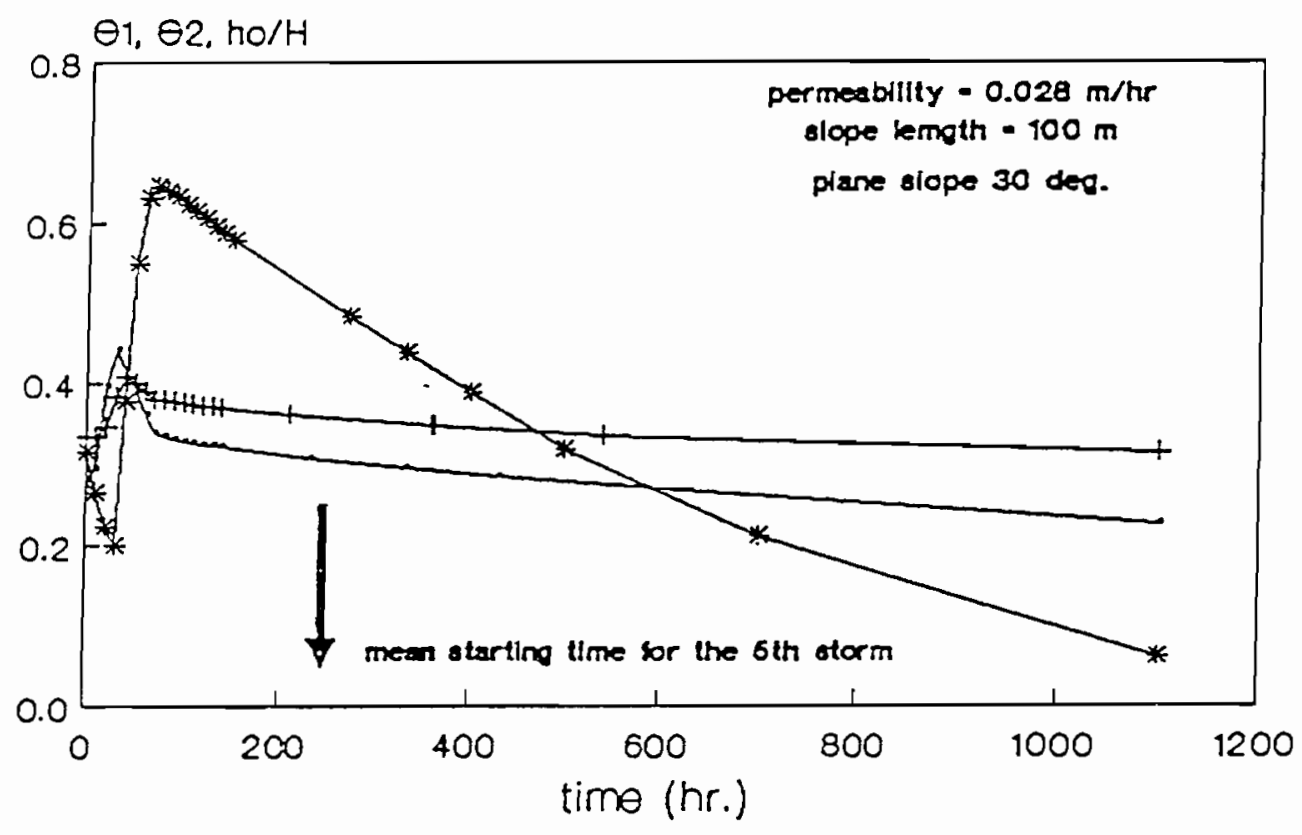

(b) $-\theta_{1}+\theta_{2} *$ ho/H

Figure 6.2: Groundwater for 3-storm season and 4-storm season. Moisture content and $h_{\delta} / H$ vs. time for (a) 3 -storms, and (b) 4 storms. 


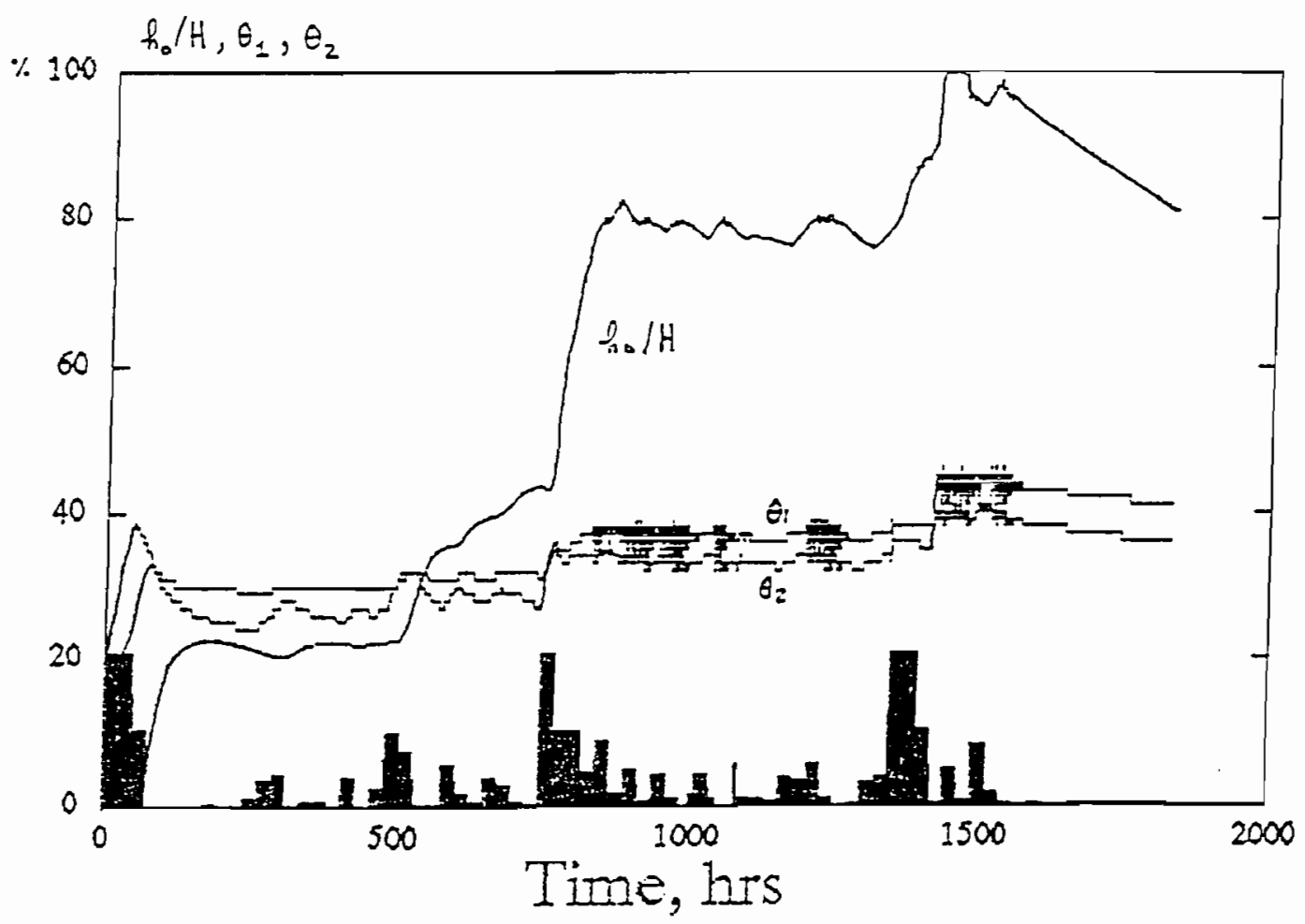

Figure 6.3: Groundwater response to a seouence of storms. 

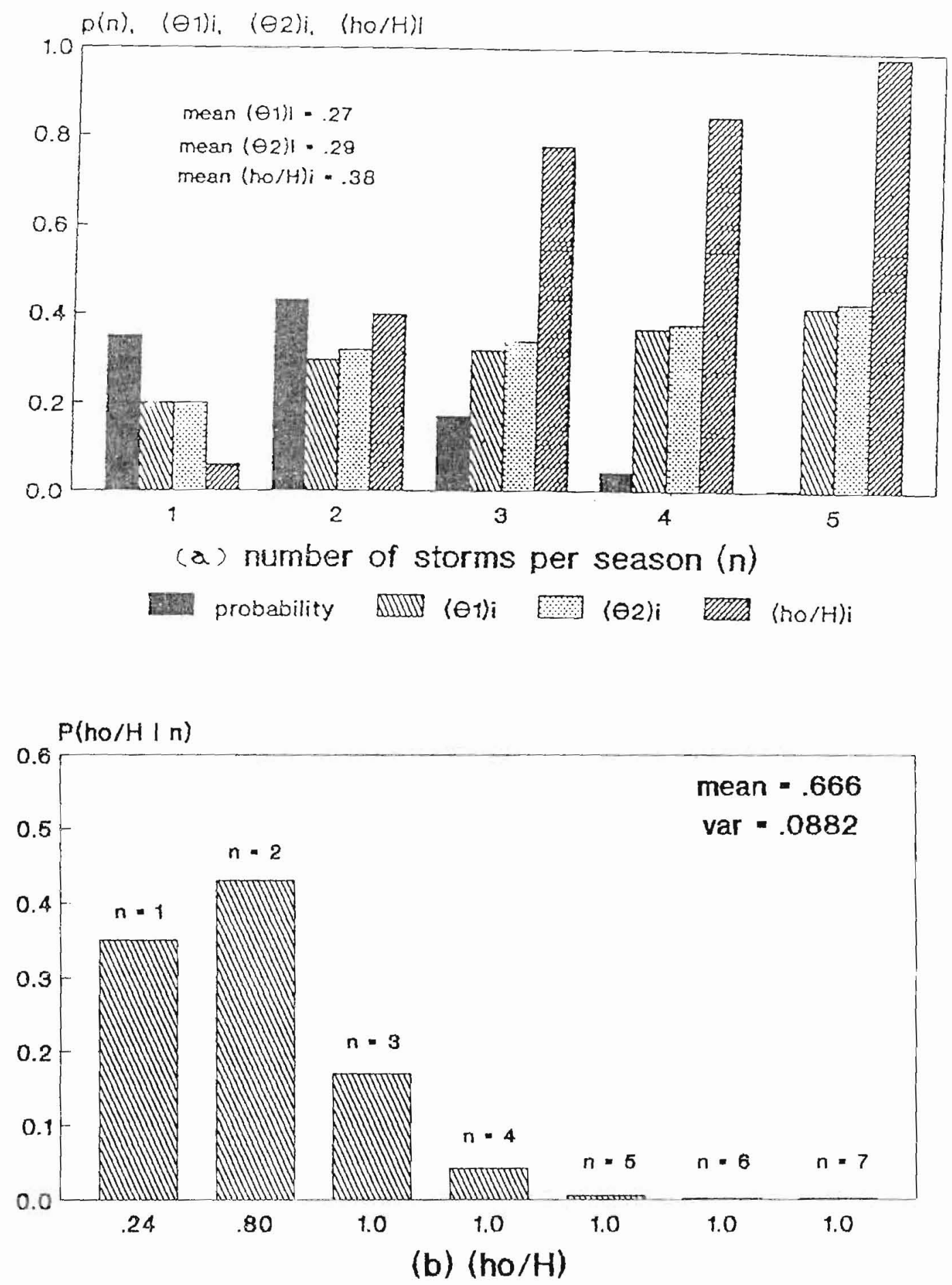

Figure 6.4: (a) Initial moisture conditions for different number of storms, (b) frequency of ho $/ \mathrm{H}$ for different number of storms. 


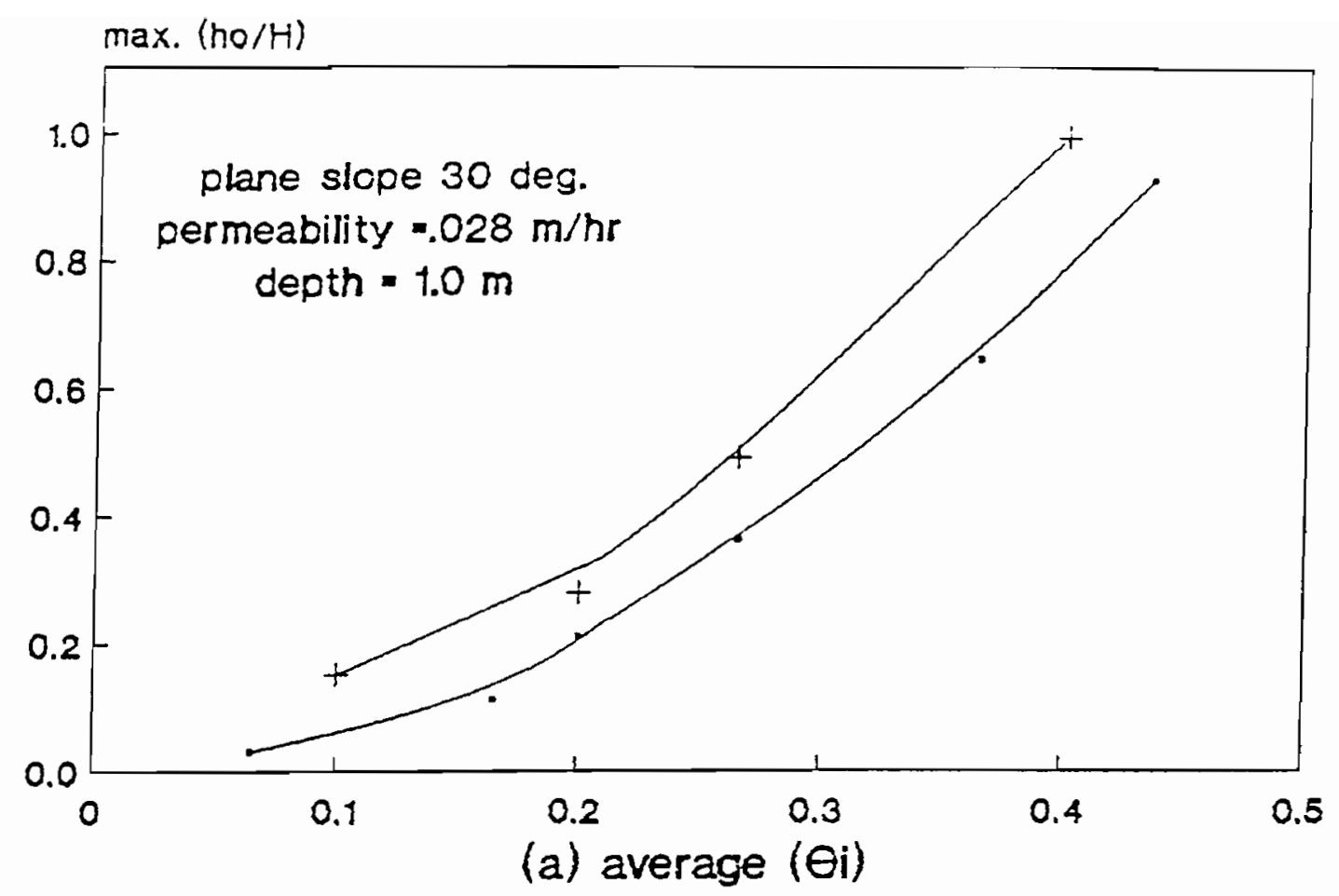

- 2-storm season 1 3-storm season

$\max .($ ho $/ \mathrm{H})$

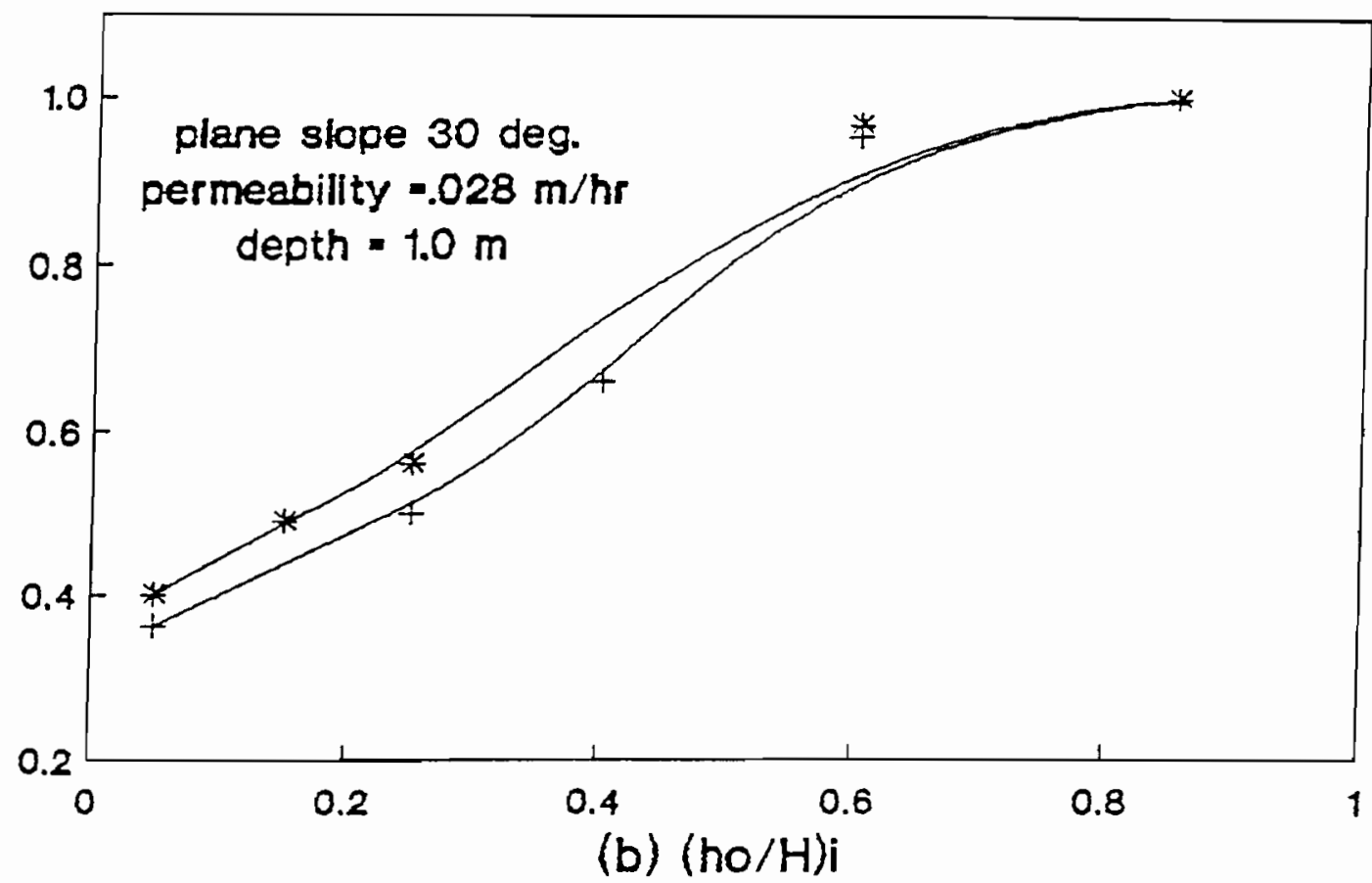

i 2-storm season * 3-storm season

Figure 6.5: Effect of initial moisture conditions on ground water for 2-storm and 3-storm seasons,. (a) average $(\theta)_{i}$, (b) $h_{o} / H_{i}$ 


\subsection{UNCERTAINTY ABOUT SOIL PROPERTIES}

\subsubsection{Systematic Uncertainty}

Systematic uncertainty about soil properties results from the insufficient information or observation used to compile the soil report and to estimate the soil properties as reviewed in Section 3.3.1. Figs 5.1 to 5.4 show the sensitivities of $h d H$ to different soil parameters. The sensitivities of $h_{o} / H$ and the variances of the parameters are listed in Table 6.1. FOSM was used to to calculate the variance of $h_{o} / H$ due to the systematic variances of soil properties (see Appendix C, Eq. C.4)

$$
\begin{aligned}
& \operatorname{Var}\left(\frac{h_{o}}{H}\right)=\left(\frac{\partial h_{o}}{H}\right)^{2} \operatorname{Var}\left(K_{s}\right)+\left(\frac{\partial \frac{h_{o}}{H}}{\partial B}\right)^{2} \operatorname{Var}(B)+\left(\frac{\partial \frac{h_{o}}{H}}{\partial \Psi}\right)^{2} \operatorname{Var}(\Psi)+\left(\frac{\partial \frac{h_{o}}{H}}{\partial \theta_{d}}\right)^{2} \operatorname{Var}\left(\theta_{d}\right) \\
& +\left(\frac{\partial \frac{h_{o}}{H}}{\partial \theta_{s}}\right)^{2} \operatorname{Var}\left(\theta_{s}\right)+\left(\frac{\partial \frac{h_{o}}{\partial H}}{\partial H}\right)^{2} \operatorname{Var}(H)+\left(\frac{\partial \frac{h_{o}}{H}}{\partial K}\right)\left(\frac{\partial h_{o}}{H}\right) \operatorname{Cov}\left(K_{s}, \theta_{d}\right) \\
& +\left(\frac{\partial \frac{h_{o}}{H}}{\partial \theta_{d}}\right)\left(\frac{\partial \frac{h_{o}}{H} c}{\partial B}\right) \operatorname{Cov}\left(\theta_{d}, B\right)+\left(\frac{\partial \frac{h_{o}}{H}}{\partial K}\right)\left(\frac{\partial \frac{h_{o}}{H}}{\partial B}\right) \operatorname{Cov}\left(K_{s}, B\right)
\end{aligned}
$$

Correlation coefficients among various parameters are not available to calculate the covariances. A strong positive correlation is expected between drainable porosity, $\theta_{d}$ and permeability, $K_{s}$ Therefore, $\operatorname{Cov}\left(\theta_{d}, K_{s}\right)$ was chosen to be 0.8 . A study conducted by Clapp and Horenberger (1978) showed a positive correlation between $B$, and mean clay fraction of soil type. On the other hand, mean clay fraction is negatively correlated with $K_{s}$ and $\theta_{d}$. Then, a negative correlation coefficient of -0.8 among $K_{s}, \theta_{d}$, and $B$ was chosen. Clapp and Hornberger (1978) showed also that there is no correlation between $\Psi_{s}$ and other parameters. Accordingly, $\Psi_{s}$ was 
assumed to be uncorrelated with other parameters. The variance of $h_{o} / H$ as a result of the systematic uncertainty about soil properties was found to be 0.033 .

\section{Table 6.1}

Parameters used in computations of infiltration and drainage.

\begin{tabular}{|c|c|c|c|c|c|c|}
\hline parameter & range & mean & $\begin{array}{l}\text { system. } \\
\text { variance }\end{array}$ & $\Delta_{s}$ & $\frac{\partial h_{o} / H}{\partial x_{i}}$ & source \\
\hline $\mathrm{K}(\mathrm{cm} / \mathrm{hr})$ & $0.5-15$ & 2.8 & 5.29 & 0.821 & 0.0263 & WDNR \\
\hline $\mathrm{H} \quad(\mathrm{m})$ & $0.5-1.5$ & 1.0 & .0816 & 0.285 & -0.436 & WDNR \\
\hline$\theta_{d}$ & $0.29-0.35$ & 0.32 & 0.00034 & 0.057 & -0.818 & Schroeder \\
\hline$\theta_{s}$ & $0.4-0.5$ & 0.45 & 0.0005 & 0.049 & -1.6 & Bear, (972) \\
\hline $\begin{array}{l}\text { B } \\
\Psi,(\mathrm{cm})\end{array}$ & $\begin{array}{l}4.0-5.0 \\
7.0-13.0\end{array}$ & $\begin{array}{l}4.38 \\
10.0\end{array}$ & $\begin{array}{l}2.16 \\
150.0\end{array}$ & $\begin{array}{l}0.335 \\
1.221\end{array}$ & $\begin{array}{l}-0.05 \\
-0.006\end{array}$ & $\begin{array}{l}\text { Clapp \& } \\
\text { Horenberger } \\
(1978)\end{array}$ \\
\hline
\end{tabular}

\subsubsection{Random Variations}

As discussed in Section 3.3.4, only general observation of random variations in $K_{s}$ and $\mathrm{H}$ are available. These are in general agreement with measurements made in the Kennel Creek watershed by Swanston (personal communications, 1985, see Reddi and Wu, 1991). Hence, the data from Kennel Creek were used to evaluate the effect of random variations of these parameters. The Kennel Creek watershed is shown in Fig. 6.6. The measured values of $K_{s}, \mathrm{C}$, and, $\mathrm{H}$ and the $\mathrm{X}, \mathrm{Y}$ coordinates of the sampling points are shown in Table 6.2. The values of $K_{s}, \mathrm{C}$, and $\mathrm{H}$ at unobserved points were estimated by Kriging (Lee, 1986) and the results are shown in Fig 6.7. The two-dimensional finite difference model of Lee (1986) was used to calculate $h_{w} / H$ for mean infiltration of $\mathrm{s} 6.5$ in on a plane slope. The results are shown in Fig. 6.8. The error $N_{r}$ 
as a result of using the average values of $H, K_{s}$ and, $C$ is expressed as

$$
N_{r}=\frac{\left(h_{w} / H\right)_{r}}{\left(h_{w} / H\right)_{a}}
$$

where $\mathrm{r}$ and a stand for calculations based on random and average soil properties, respectively. The mean of $N_{r}$ is close to 1 and the variance of $N_{r}$ is 0.026 . No information are available about random variability of $\Psi_{s}, B$, and $\theta_{s}$. In the meantime, the two-dimensional model (Lee, 1986) does not account for the unsaturated flow. So, the effect of random variability of these parameters is neglected. 
Table 6.2

Soil properties for Kennel Creek watershed (Sivanston, 1985).

\begin{tabular}{|c|c|c|c|c|c|c|c|}
\hline variable & $\begin{array}{l}\text { No.of } \\
\text { data } \\
\text { points }\end{array}$ & value & $\begin{array}{c}\mathrm{x} \\
\mathrm{m} .\end{array}$ & $\begin{array}{c}\mathrm{Y} \\
\mathrm{m} .\end{array}$ & $\begin{array}{c}\delta \\
\mathrm{m} .\end{array}$ & mean & var \\
\hline $\begin{array}{l}\text { Permeability } \\
\text { m/day }\end{array}$ & 9 & $\begin{array}{l}.7032 \\
.6576 \\
.6576 \\
3.740 \\
.2904 \\
1.272 \\
.4080 \\
.1944 \\
.1656 \\
.246\end{array}$ & $\begin{array}{l}7.54 \\
10.27 \\
10.27 \\
1.04 \\
10.48 \\
1.26 \\
9.89 \\
7.54 \\
1.34 \\
4.19\end{array}$ & $\begin{array}{l}11.20 \\
15.53 \\
15.53 \\
24.15 \\
33.93 \\
43.70 \\
54.05 \\
55.78 \\
60.95 \\
64.40\end{array}$ & 1.5 & $\begin{array}{l}9640 \\
m / d a y\end{array}$ & $\begin{array}{l}1.254 \\
m / d a y^{2}\end{array}$ \\
\hline Specific Yield & 9 & $\begin{array}{l}.18 \\
.17 \\
.32 \\
.14 \\
.20 \\
.16 \\
.12 \\
.10 \\
.22\end{array}$ & $\begin{array}{l}7.54 \\
10.27 \\
1.04 \\
10.48 \\
1.26 \\
9.89 \\
7.54 \\
1.34 \\
4.19\end{array}$ & $\begin{array}{r}11.20 \\
5.53 \\
24.15 \\
33.93 \\
43.70 \\
54.05 \\
55.78 \\
60.95 \\
64.40\end{array}$ & 1.5 & .178 & .0042 \\
\hline $\begin{array}{l}\text { soil depth } \\
\text { m. }\end{array}$ & 10 & $\begin{array}{l}.71 \\
.61 \\
.40 \\
.33 \\
.44 \\
.51 \\
.53 \\
.61 \\
.48 \\
.66\end{array}$ & $\begin{array}{l}-0.84 \\
1.68 \\
2.10 \\
-0.63 \\
2.51 \\
0.00 \\
1.89 \\
10.00 \\
2.60 \\
0.84\end{array}$ & $\begin{array}{l}5.75 \\
7.48 \\
13.22 \\
14.38 \\
20.82 \\
21.28 \\
32.20 \\
40.25 \\
40.42 \\
54.63\end{array}$ & 1.0 & $\begin{array}{l}0.528 \\
m\end{array}$ & $\mathrm{~m}^{2.0144}$ \\
\hline
\end{tabular}



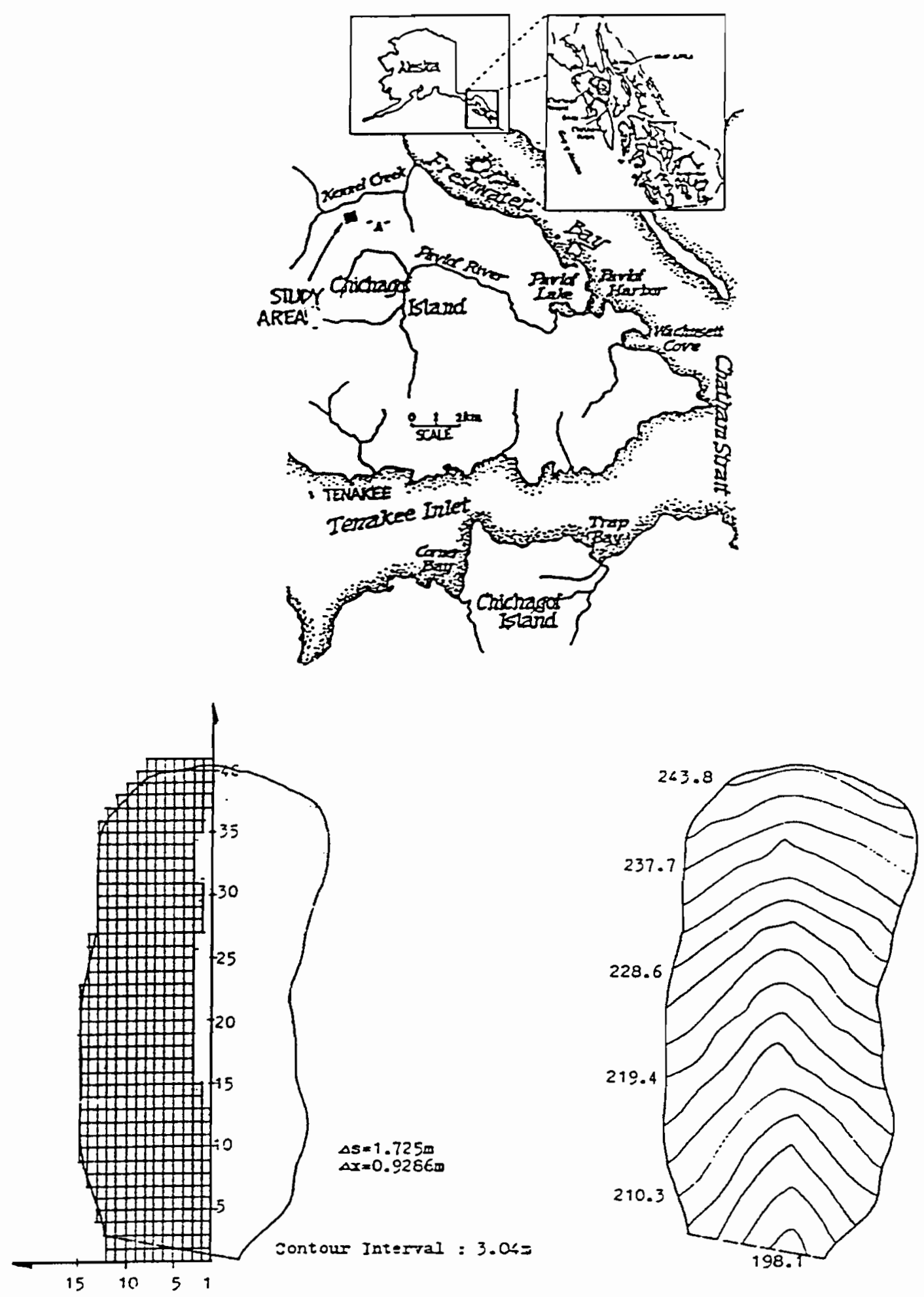

Figure 6.6: Kennel creek watershed. 


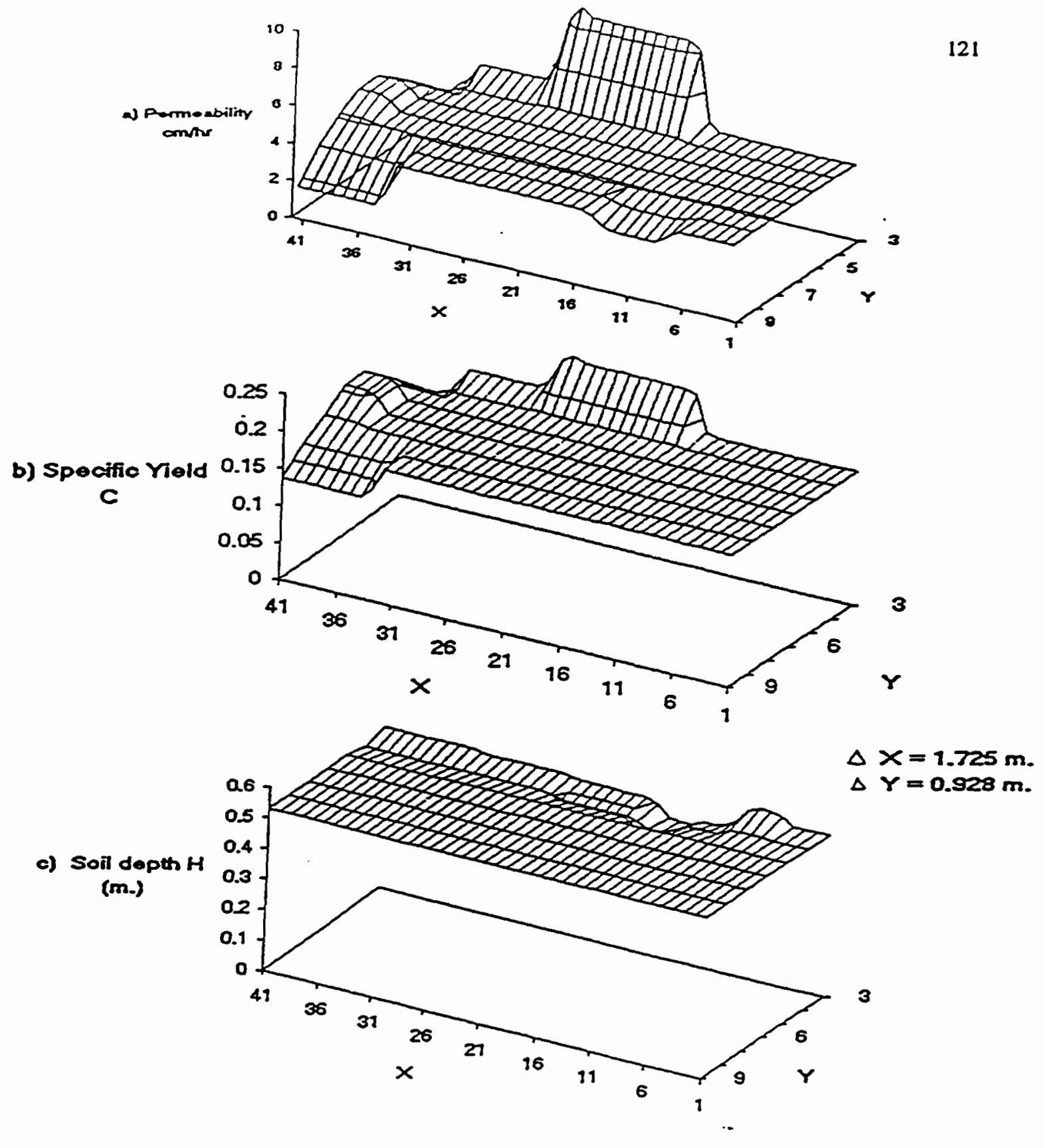

numbers in $X$, and $Y$ directions are node numbers

Figure 6.7: Values of (a) K, (b) $\mathrm{C}$, and, (c) $\mathrm{H}$, for Kennel creek warershed. 
Hw (m.)

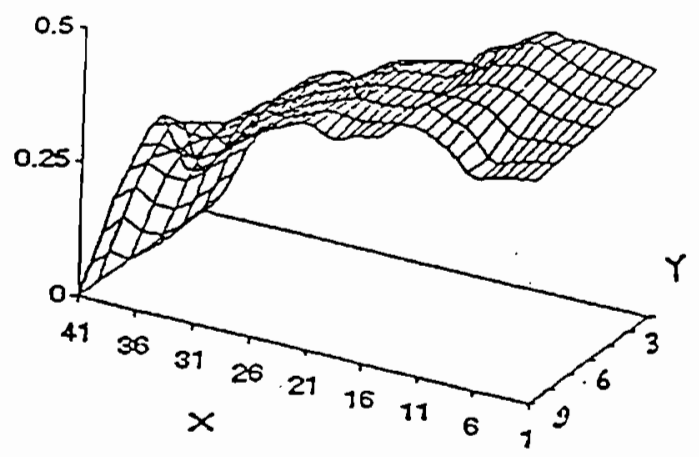

(a)

(b)

numbers in $X$ and $Y$ dirncions are node numbers

$\Delta X=1.725 \mathrm{~m}$

$\Delta Y=0.028 \mathrm{~m}$
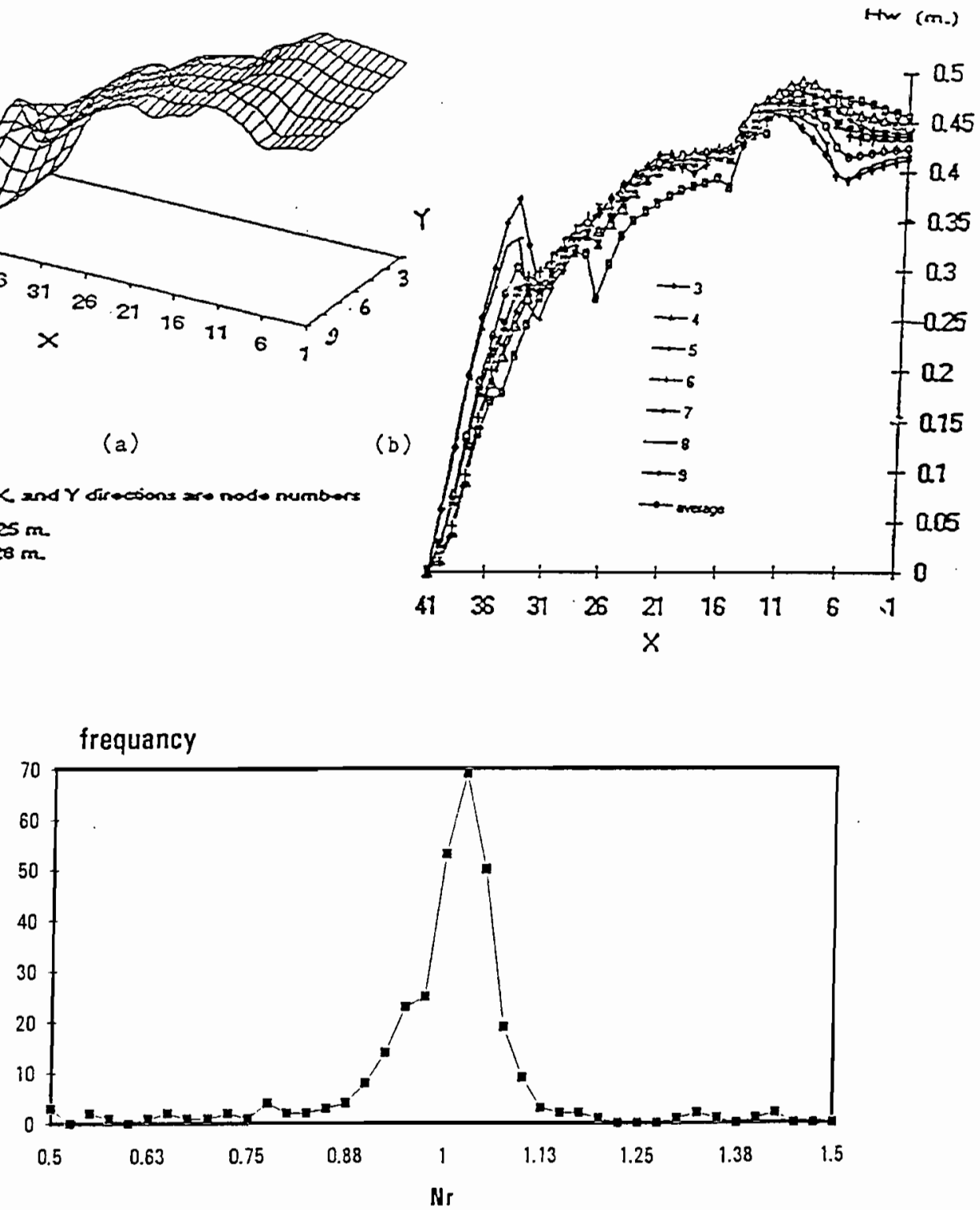

Figure 6.8: Effect of random variations in $\mathrm{K}, \mathrm{C}$, and $\mathrm{H}$ on groundwater ratio for a plane slope, (a) 3-D view of groundwater, (b), plane view, (c) frequency of $\mathrm{Nr}$ 


\subsubsection{Occurrence Uncertainty}

The average size of the detailed soil map unit, discussed in Section 3.2, is smaller than the chosen size of a catchment ( $\sim 500$ pixel). Therefor, a catchment may contain more than one soil unit, as shown in Fig. 3.2b. The lumped parameter model (Reddi and Wu, 1991), which was used to map the ground water levels, utilizes one soil type. This means that the soil variations within a catchment are replaced by a spatial average. The effect of having different soils within the catchment is occurrence uncertainty if the effect of the different soils is ignored, as is the case in Reddi and Wu's model.

The error introduced by replacing the different soil types by one soil with average soil properties was investigated using Reddi and Wu's model (1991). The groundwater ratio, $h_{o} / H$, was calculated twice for each of the 240 catchment in the Mineral and Glenoma quadrangles, shown in Figs. 5.14 and 5.15. The first calculation used the spatial averages of the soil properties of each catchment; a procedure that has been used as a first step to map $h_{w} / H$ in Section 5.5. The second calculation used the soil properties of the detailed soil map unit that covers the area of the exit of each catchment. The reason of choosing the soil unit at the exit is its influence on the drainage process and consequently on $h_{o} / H$. The error, $N_{o}$ as a result of using the spatial average of the soil properties instead of actual soil distribution within the catchment, is defined as

$$
N_{o}=\frac{\left(h_{w} / H\right)_{1}}{\left(h_{w} / H\right)_{2}}
$$

where 1 and 2 stand for calculation based on the spatial average of the soil properties and soil properties at the catchment exit, respectively. Frequency of $N_{o}$ for the 240 watershed is shown in Fig. 6.9. The variance of $N_{o}$ is 0.0335 . 


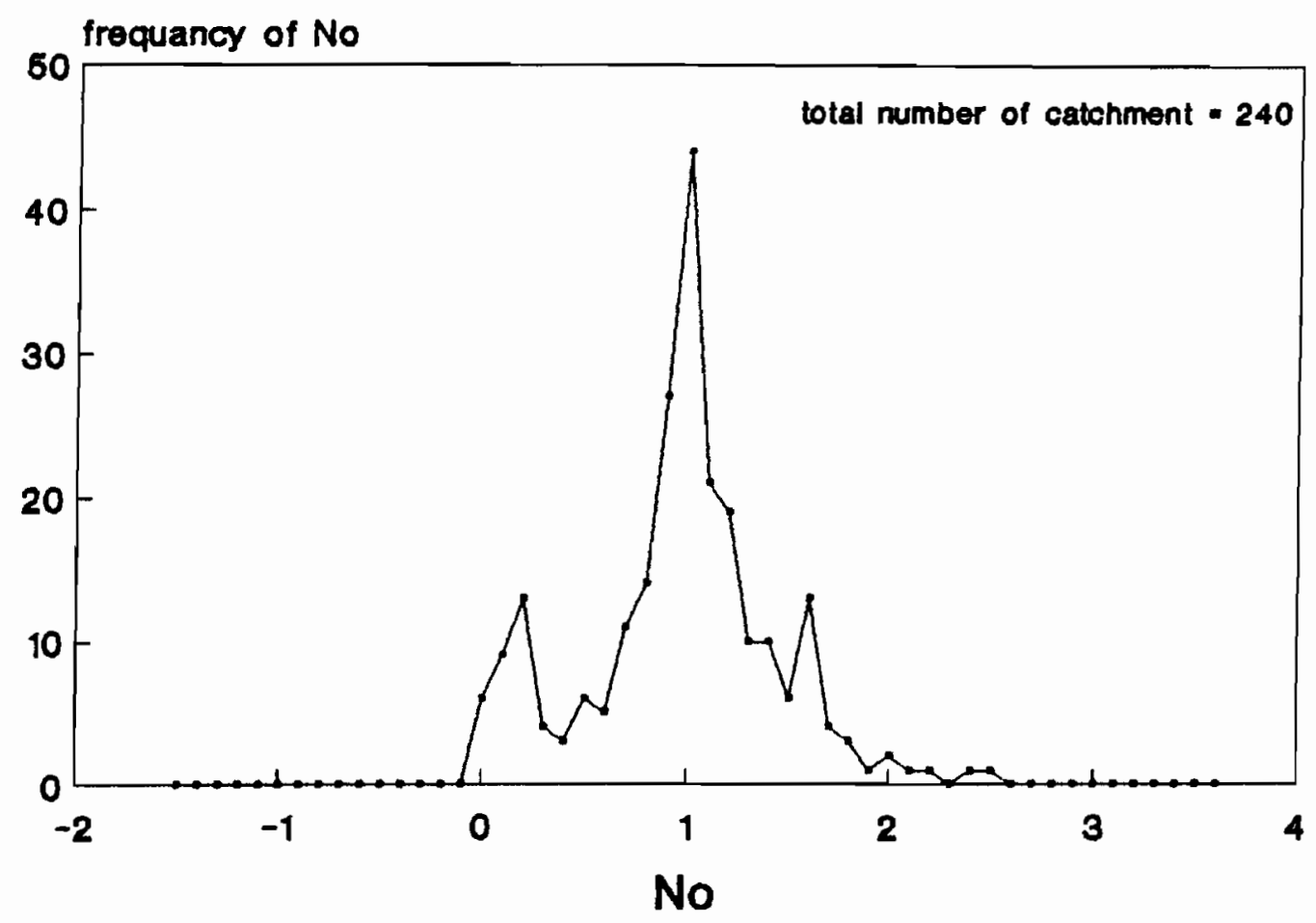

Figure 6.9. Effect of using spatial average soil properties, frequency of $N_{o}$ 


\subsection{UNCERTAINTY DUE TO GEOLOGIC ANOMALIES}

In order to evaluate the effect of fracture flow, calculations were made to evaluate the sensitivity of $h_{w} / H$ at fracture exit to the parameters a, $b_{f}, c$, and $K_{f}$, shown in Fig. 5.9. The results in Fig. 6.6 show that $h_{w} / H$ is only sensitive to $b_{f} / b$. Without detailed field data on the continuity of the joints, we assumed that the probability that a continuous joint exits is 1.0 and the distributions of $b_{f} / b$ and $K_{f} / K_{s}$ are as given in Table 6.3. The model error $N_{g}$ due to geologic anomalies is defined as

$$
N_{8}=\frac{\left(h_{w} / H\right)}{\left(h_{w} / H\right)}{ }_{a} b_{f}
$$

where $\mathrm{g}$ and a stand for calculations based on existence of geologic anomalies and average soil properties, respectively. The model error, $N_{g}$, has a mean close to 1 because fracture flow increases $h_{w} / H$ at the exit point but reduces it at the entrance point. Using FOSM, derived in Appendix $\mathrm{C}$, the variance of $\mathrm{N}$ can be written as

$$
\operatorname{Var} N_{g}=\operatorname{Var}\left(K_{f} / K_{s}\right)\left(\frac{\partial N_{g}}{\partial\left(K_{f} / K\right)}\right)^{2}+\operatorname{Var}\left(b_{f} / b\right)\left(\frac{\partial N_{g}}{\partial\left(b_{f} / b\right)}\right)^{2}+\ldots . .
$$

The variances of $b / b, K / K_{s} a / L$, and $c / L$ are given in Table 6.3 and the derivatives were calculated from the slopes in Fig. 6.10. These were used to obtain $\operatorname{Var} N_{g}=0.038$.

Table 6.3

Distribution of parameters for jointed rock.

\begin{tabular}{|l|l|l|l|l|l|}
\hline variable & distribution & range & mean & variance & sensitivity \\
\hline $\begin{array}{l}K_{f} / k_{s} \\
a / L\end{array}$ & lognormal & $.1-100$ & 3 & 23.26 & .0334 \\
$b_{f} / b$ & uniform & $.1-.67$ & .333 & .037 & -.0564 \\
$c / L$ & lognormal & $.01-.9$ & .1 & $5.61 \times 10^{-3}$ & 1.508 \\
& uniform & $.1-.67$ & .333 & .037 & -.06 \\
\hline
\end{tabular}



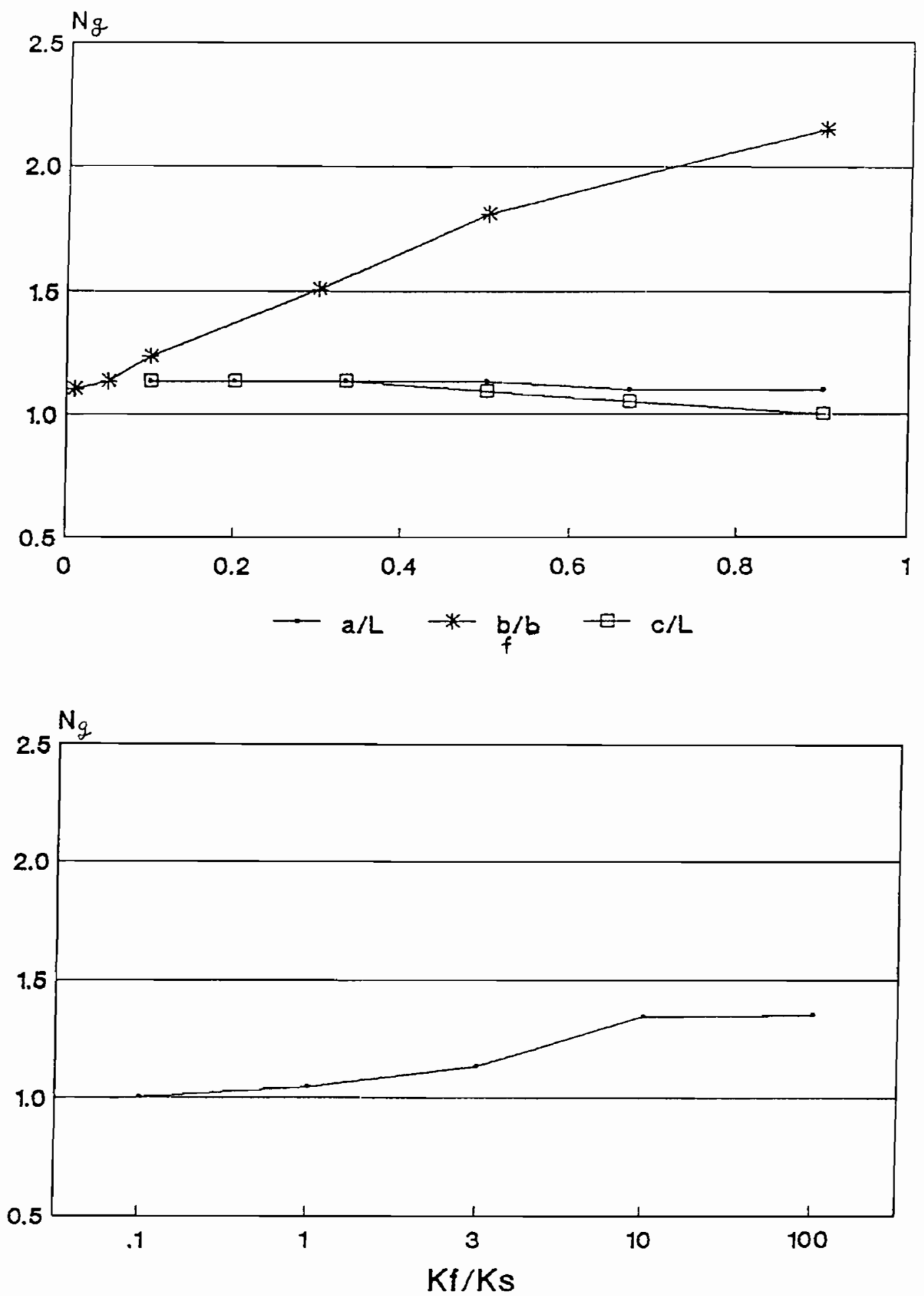

Figure 6.10. Sensitivity of fracture flow to input parameters,. $a / L, b_{f} / b, c / L$, and $K_{f} / K_{s}$. 


\subsection{SUMMARY}

The uncertainties and variations of $h d H$ are summarized in Table 6.4 for the mean annual infiltration and the infiltration from maximum storm in 10 years. It is clear that the interval between storms has a minor effect on the uncertainty about $h_{o} / H$. There is also a substantial difference in the uncertainty of $h_{\delta} / H$ depending on the infiltration case. The total uncertainty of $h_{o} / H$ can be reduced significantly, if a specific rain event is considered; most of the uncertainty about the infiltration, and the antecedent moisture conditions can be eliminated in such a case. The uncertainties in Table 6.4 were used to calculate the hazard of natural slopes in Chapter VII.

Table 6.4

Summary of the uncertainties due to input to hydrologic model.

\begin{tabular}{|c|c|c|}
\hline Source of Uncertainty & \multicolumn{2}{|c|}{ Variance of $h_{0} / H$} \\
\hline & $\begin{array}{c}\text { average } \\
\text { annual storm }\end{array}$ & $\begin{array}{l}\text { maximum } \\
\text { in } 10 \text { years }\end{array}$ \\
\hline $\begin{array}{l}\text { duration and amount } \\
\text { infiltration (Sec. } 6.2 .1 \text { ) } \\
\text { number of storms per } \\
\text { season (Sec.6.2.2.1) } \\
\text { interval between storms (Sec.6.2.2.2) } \\
\text { systematic uncertainty (Sec.6.3.1) } \\
\text { random variation (Sec.6.3.2) } \\
\text { occurrence uncertainty (Sec.6.3.3) } \\
\text { fractures in rock (Sec.6.4) }\end{array}$ & $\begin{array}{c}0.049 \\
0.088 \\
0.00002 \\
0.033 \\
0.026 \\
0.033 \\
0.038\end{array}$ & $\begin{array}{c}0.021 \\
0.031 \\
0.00 \\
0.003 \\
0.032 \\
0.011 \\
0.048\end{array}$ \\
\hline tota 1 & 0.261 & 0.146 \\
\hline
\end{tabular}




\section{CHAPTER VII}

\section{PROBABLISTIC ANALYSIS OF SLOPE STABHLTY}

\subsection{INTRODUCTION}

Stability of slopes is usually analyzed by methods of limit equilibrium analyses. the infinite slope model, reviewed in Section 2.2.2, is commonly used for the case of relatively shallow soil mantle. It is recognized, as shown in Chapters III, and VI, that there are uncertainties and variabilities in the parameters of the stability model. Because of the uncertainties, a slope with a computed factor of safety of $\mathbf{0 . 9}$ may not fail, whereas a one with a computed factor of safety of 1.1 may fail. These facts give the reason for the need of probabilistic analysis to quantify the uncertainty and variability associated with slope stability problem. FOSM provides a formal procedure to predict the landslide hazard of slopes. The objective of the analysis in this chapter is to predict and map the hazard of natural slopes with application to the focus township.

\subsection{FIRST ORDER SECOND MOMENT OF SLOPE STABILITY}

The safety factor for the infinite slope model, shown in Fig.2.4, is

$$
\begin{aligned}
& F_{s}=\frac{c_{r}+c^{\prime}+\cos ^{2} \alpha\left[q_{0}+\gamma H(1-Z)+\left(\gamma_{s a t}-\gamma_{w}\right) H Z\right] \tan \phi^{\prime}}{\sin \alpha \cos \alpha\left[q_{0}+\gamma H(1-Z)+\gamma_{s a t} H Z\right]} \\
& Z=h_{w} / H \\
& P_{f}=P\left(F_{s}<1.0\right)
\end{aligned}
$$

The parameters considered to be random variables in Eq. 7.1 are :

1. soil cohesion, $c^{\prime}$, 
2. angle of internal friction, $\phi^{\prime}$,

3. slope angle, $\alpha$,

4. soil depth, $\mathrm{H}$, and

5. groundwater ratio, $\mathrm{Z}$.

The vector of random variables, $u$, is:

$$
u=\left(\begin{array}{l}
c^{\prime} \\
\dot{\phi} \\
H \\
\alpha \\
z
\end{array}\right)
$$

The mean value of the factor of safety $F_{s}$, computed using Eq 7.1 using the mean value of augmented vector, $\mathrm{u}$, is associated with a variance, $\Sigma_{F_{0}}$ As shown in Appendix C, Eq. C.3, $\Sigma_{F_{0}}$ can be approximated using FOSM as:

$$
\Sigma_{F_{v}}=\left(D_{u} F_{s}\right) \Sigma_{u}\left(D_{u} F_{s}\right)^{T}
$$

Eq. 7.5 can be expanded as

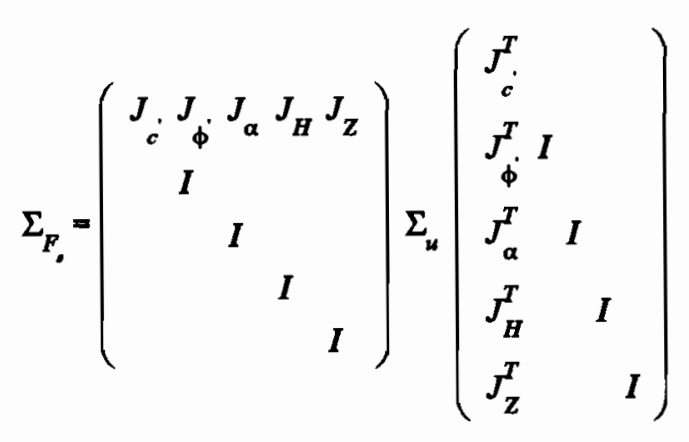

where

$$
\Sigma_{u}=\Sigma_{u 1}+\Sigma_{u 2}+\Sigma_{u 3}
$$

where, $\Sigma_{u}=$ total variance matrix, $\Sigma_{u 1}=$ systematic variance matrix, $\Sigma_{u 2}=$ random variance matrix, and $\Sigma_{u 3}=$ occurrence variance matrix, As discussed in Section 3.3.3; $J_{c^{\prime}}, J_{\phi^{\prime}}, J_{\alpha}, J_{H}$, and $J_{Z}$ are sensitivities of $c^{\prime}, \phi^{\prime}, \alpha, H$, and $Z$, respectively, and given by 


$$
\begin{aligned}
& J_{c_{0}}=\frac{\partial F_{s}}{\partial c^{\prime}}=\frac{1}{B} \\
& J_{\phi}=\frac{\partial F_{s}}{\partial \phi}=\frac{\cos \alpha^{2}\left(q_{0}+\gamma H(1-Z)+\left(\gamma_{s}-\gamma_{w}\right) Z H\right)}{B \cos \phi^{2}} \\
& J_{\alpha}=\frac{\partial F_{s}}{\partial \alpha}=\frac{B(-2 \cos \alpha \sin \alpha)\left(A-c_{r}-c\right)-A\left(1-2(\sin \alpha)^{2}\right)\left(q_{0}+\gamma H(1-Z) \gamma_{s} Z H\right)}{B^{2}} \\
& J_{H}=\frac{\partial F}{\partial H}=\frac{\cos \alpha^{2} \tan \phi\left(\gamma(1-Z)+\left(\gamma_{s}-\gamma_{w}\right) Z\right) B-A \sin \alpha \cos \alpha\left[\gamma(1-Z)+\gamma_{s} Z\right]}{B^{2}} \\
& J_{Z}=\frac{\partial F_{s}}{\partial Z}=\frac{B \cos \alpha^{2} \tan \phi\left(-\gamma H+\left(\gamma_{s}-\gamma_{w}\right) H\right)-A \sin \alpha \cos \alpha\left(-\gamma H+\gamma_{s} H\right)}{B^{2}}
\end{aligned}
$$

where

$$
A=c_{r}+c^{\prime}+\cos ^{2} \alpha\left[q_{0}+\gamma H(1-Z)+\left(\gamma_{s}-\gamma_{w}\right) H Z\right] \tan \dot{\phi}
$$

and

$$
B=\sin \alpha \cos \alpha\left[q_{0}+\gamma H(1-Z)+\gamma_{s} H Z\right]
$$

The variance of the factor of safety, $\Sigma_{F,}$, depends on the variance of the augmented vector, $\Sigma_{w}$, and the sensitivities $J_{i}, J_{\phi}, J_{\alpha}, J_{H}$, and $J_{Z}$. The probability distribution of $F_{s}$ is assumed to be lognormal (Chowdhury and Tang, 1987). Landslide hazard is defined as $P(F, \leq 1.0)$. A computer program was developed to compute $F_{s}$, the sensitivities of $F_{s}, \Sigma_{F}$, and the landslide hazard.

The vector, $u$, and its variance matrix, $\Sigma_{u}$, depend on the accuracy and the scale of the analysis. In the next section, the effect of the accuracy of the analysis on $u$ and $\Sigma_{u}$ is addressed. In the next chapter, the effect of the scale of analysis on $u$ and $\Sigma_{u}$ is addressed. 


\subsection{SLOPE STABILITY HAZARD MAPPING}

In the previous section equations of landslide hazard of slopes were derived using FOSM method. These equations were applied to the focus township to predict and map the landslide hazard of natural slopes. Two different hazard maps, a macro-hazard-map and a micro-hazardmap, were produced. In both mapping procedures, hazard of natural slopes was evaluated for the case of maximum infiltration in 10 years, evaluated in Section 4.7. Table 7.2 shows the main features of each hazard map. The map unit for the macro-hazard-map is the valley slope with soil properties equal the regional site conditions, listed in Table 3.3. The map unit for the micro-hazard-map is the pixel with soil properties equal the local site conditions from the detailed soil map.

\subsubsection{Macro-Hazard-Map}

The purpose of this mapping procedure is to provide a quick estimate of of the landslide hazard. Glenoma quadrangle was divided into valley slope units as shown in Fig. 7.1. The average slope of each valley slope unit was determined from the contour map and is listed in Table 7.2. The uncertainty about slope angle $\alpha$ determined from contour map was calculated as described in Section 3.4; the results is $\operatorname{Var}(\alpha)=1.2 * 10^{-4}$. The groundwater level, $h_{o} / H$, was computed for case of plane slope with $\alpha, \mathrm{L}, \theta_{s}, \theta_{d}, K_{s}, \Psi, B$, and $H$ equal to the regional averages, listed in Table 3.3 and infiltration from maximum storm in 10 years. A single value of $h_{o} / H$ was assigned to all valley slope units. The systematic uncertainty about $h_{o} / H$ was computed as a result of systematic uncertainty about soil properties, $\theta_{s}, \theta_{d}, K_{s}, \Psi, B$, and $H$, the uncertainty about antecedent moisture conditions, and the uncertainty about total amount of infiltration. The regional averages and the systematic variances of $c^{\prime}, \phi^{\prime}$, and $\mathrm{H}$, listed in Table 3.3, were used. The random variations of soil properties were not considered because the valley slope dimensions $>>\delta$ and to comply with the simplified input. 
The uncertainty model, developed in Section 7.2, Eq. 7.6, was used to compute the landslide hazard for each valley slope unit in Glenoma quadrangle. Table 7.2 shows the slope angle, the factor of safety, and the landslide hazard for each valley slope unit.

\subsubsection{Micro-Hazard-Map}

The analysis of landslide hazard of natural slopes may be conducted on a large area such as a quadrangle or several quadrangles. In this case, the input parameters for such a large site can be handled using the capabilities of the Geographic Information System (GIS). Although slope angles, $\alpha$, can be determined from contour maps, using Eq. 2.18, GIS can be used to calculate $\alpha$ at each pixel from data in DEM with accuracy and reasonable computation effort, using Eq. 2.21. Since one of the objective of this research is to predict and map landslide hazard over several quadrangles located in Washington, it was decided to use the capabilities of GIS and the data in DEM as a step toward automating the mapping process. This means that the landslide hazard is calculated at each pixel by applying the infinite slope model to each pixel assuming that these pixels are independent. This assumption is reasonable in case of a uniform slope with a uniform shallow soil cover and a uniform groundwater ratio. The soil cover of the site under study is shallow, then a failure surface within a pixel is not expected to extend to affect the stability of adjacent pixels. Also, reported dimensions of landslides, identified in the landslide inventory, are generally small and in the order of the pixel dimensions, (see Table 8.12). For these reasons the assumption of independence between adjacent pixels might be reasonable.

In this mapping procedure, the piezometric level map, shown in Fig. 5.16, was used to represent the groundwater ratio. The piezometric level map considered catchment shape, variation of $h_{w} / H$ within the catchment, and used soil properties for specific locations from the detailed soil map provided by the county soil survey report (Soil Conservation Services, 1987). The details of the procedures used to produce the groundwater map are described in Section 5.6. Soil strength properties $c^{\prime}$ and $\phi^{\prime}$ were estimated for each detailed soil map unit using data in 
Schroder (1983), and Prellwitz (1981) as explained in Section 3.2.2. Soil depth, H, was identified for each pixel from the detailed soil map. Slope angle, $\alpha$, was calculated for each pixel using the data in DEM and Eq. 2.21 .

As discussed in Sec. 3.3.3, only systematic uncertainty and random variation exist at pixel dimension. Then, Eq. 7.7 can be written as

$$
\Sigma_{u}=\Sigma_{u 1}+\Sigma_{u \Omega}
$$

where

$$
\Sigma_{u 1}=\left(\begin{array}{lllll}
\Sigma_{c 1} & \Sigma_{c \phi 1} & & & \\
\Sigma_{c \phi 1} & \Sigma_{\phi 1} & & & \\
& & \Sigma_{H 1} & & \Sigma_{H Z 1} \\
& & \Sigma_{\alpha 1} & \\
& & \Sigma_{H Z 1} & & \Sigma_{Z 1}
\end{array}\right)
$$

and

$$
\Sigma_{h 2}=\left(\begin{array}{ccccc}
\Sigma_{c 2} & \Sigma_{c \alpha 2} & & & \\
\Sigma_{\alpha \phi 2} & \Sigma_{\phi 2} & & & \\
& & \Sigma_{H 2} & & \Sigma_{H Z 2} \\
& & \Sigma_{\alpha 2} & \\
& & \Sigma_{H Z 2} & & \Sigma_{Z 2}
\end{array}\right)
$$

The diagonal elements of $\Sigma_{u 1}$ were computed from the range of soil properties listed in Table 3.3. The diagonal elements of $\Sigma_{k 2}$ were computed using Eq. 2.8 for $\mathrm{H}, c^{\prime}$, and $\phi^{\prime}$ similar to the calculations used to obtain values given in Table 3.5. The uncertainty about $h_{w} / H$ at each pixel results from the systematic uncertainty about soil properties, the uncertainty about antecedent moisture condition, the uncertainty about total amount of infiltration, the uncertainty as a result of geologic anomalies, the effect of random variations of soil properties within the soil unit, and the effect of having more than single soil type in the catchment. A summary of the uncertainties of $h_{w} / H$ is given in Table 6.4. All these listed sources of uncertainty are systematic except the 
random variations of soil properties. Then $\Sigma_{z 1}=0.20443$, and $\Sigma_{z}=0.00080$. Only random variations were considered for $\alpha$, as discussed in Section 3.3.2; $\operatorname{Var}(\alpha)$ is 0.01 . For the nondiagonal elements, i.e. the covariances between parameters, relations were only considered between $\phi^{\prime}$ and $c^{\prime} ; \mathrm{Z}$ and $\mathrm{H}$. As reviewed in Sec. 2.3.2.3, $c^{\prime}$ and $\Phi^{\prime}$ are considered to be inversely correlated. A correlation coefficient of -0.7 was selected from data in Cherubini et al. (1983). As shown in Fig. 5.1b, $h_{o} / H$ and $\mathrm{H}$ are inversely correlated. The relation is approximately linear. The correlation coefficient was calculated from Fig. $5.1 \mathrm{~b}$ and is found to be $-\mathbf{0 . 5 5}$. This value, - 0.55, was used to compute the covariance between $h_{w} / H$ and $H$. The total, the systematic, and the random variations matrices, $\Sigma_{u}, \Sigma_{u 1}$, and $\Sigma_{u 2}$, for a sample pixel are listed in Table 7.3.

The uncertainty model developed in Section 7.2, Eq. 7.6, was used to compute the landslide hazard, $\mathrm{p}$, for each pixel in Glenoma quadrangle. The areas of $p>0.1$ are shown in Fig. 7.2 for Glenoma quadrangle.

\subsubsection{Macro-Hazard-Map at Pixel Level}

The map unit in the macro-hazard-map, Section 7.3.1, is the valley slope unit. However, since data of DEM were read into GIS and used to determine the slope angle at each pixel in the micro-hazard-map, Section 7.3.2, it was easy to produce a "macro-hazard-map at pixel level" with the slope, $\alpha$, of a pixel and regional averages listed in Table 3.3. Also, reported dimensions of landslides, identified in the landslide inventory and listed in Table 8.12, are in the order of the pixel dimensions This map can be compared to micro-hazard-map to study the effect of simplified input on the accuracy of the landslide hazard prediction.

The value of $\alpha$ was computed at each pixel using the DEM data and Eq. 2.21. The same groundwater ratio as in Section 7.3.1 $=0.5 h_{o} / H$ was assigned to all pixels in Glenoma quadrangle. Values of $c^{\prime}, \phi^{\prime}$, and $\mathrm{H}$, listed in Table 3.3, were assigned to all pixels in Glenoma quadrangle. 
Although random variations exist at pixel dimensions, the random variation part in Eq. 7.7 was neglected to be consistent with the simplified input in this mapping procedure. The uncertainty model developed in Section 7.2, Eq. 7.6, was used to compute the landslide hazard , p, for each pixel in Glenoma quadrangle. A map of areas of $p>0.1$ is shown in Figs. 7.3 for Glenoma quadrangle. This map is very approximate because of the simplified input and it is suitable for purpose of regional planning.

\subsection{COMPARISON WITH THE LANDSLIDE INVENTORY}

The results of the landslide inventory for Glenoma quadrangle, conducted by Brunengo, are shown in Figs. 7.4. The predicted locations of landslides in the macro-hazard-map at pixel level and micro-hazard-map are shown in Fig 7.3 and 7.2, respectively. Comparing the landslide areas predicted in Figs. 7.2 and 7.3 with identified landslides in Fig 7.4 revealed the following points:

1. the simplified procedures used to produce the micro hazard map and the macro hazard map at pixel level were able to predict some of the landslides that has been identified in the landslide inventory,

2. the match between predicted areas and identified areas is better for the micro hazard map and,

3. some identified landslides did not show up in either map.

The accuracy of the prediction of the micro-hazard-map procedure may be referred to the use of detailed soil properties instead of regional site conditions, the use of the piezometric level map, instead of mean piezometric levels, and the consideration of all sources of uncertainties and variations. The reason that some landslides did not show up in the maps may be referred to that these landslides are mostly around streams banks where soil depth is much thicker. for such a case, both the groundwater models and the slope stability model should be modified in order to come up with proper predictions. 


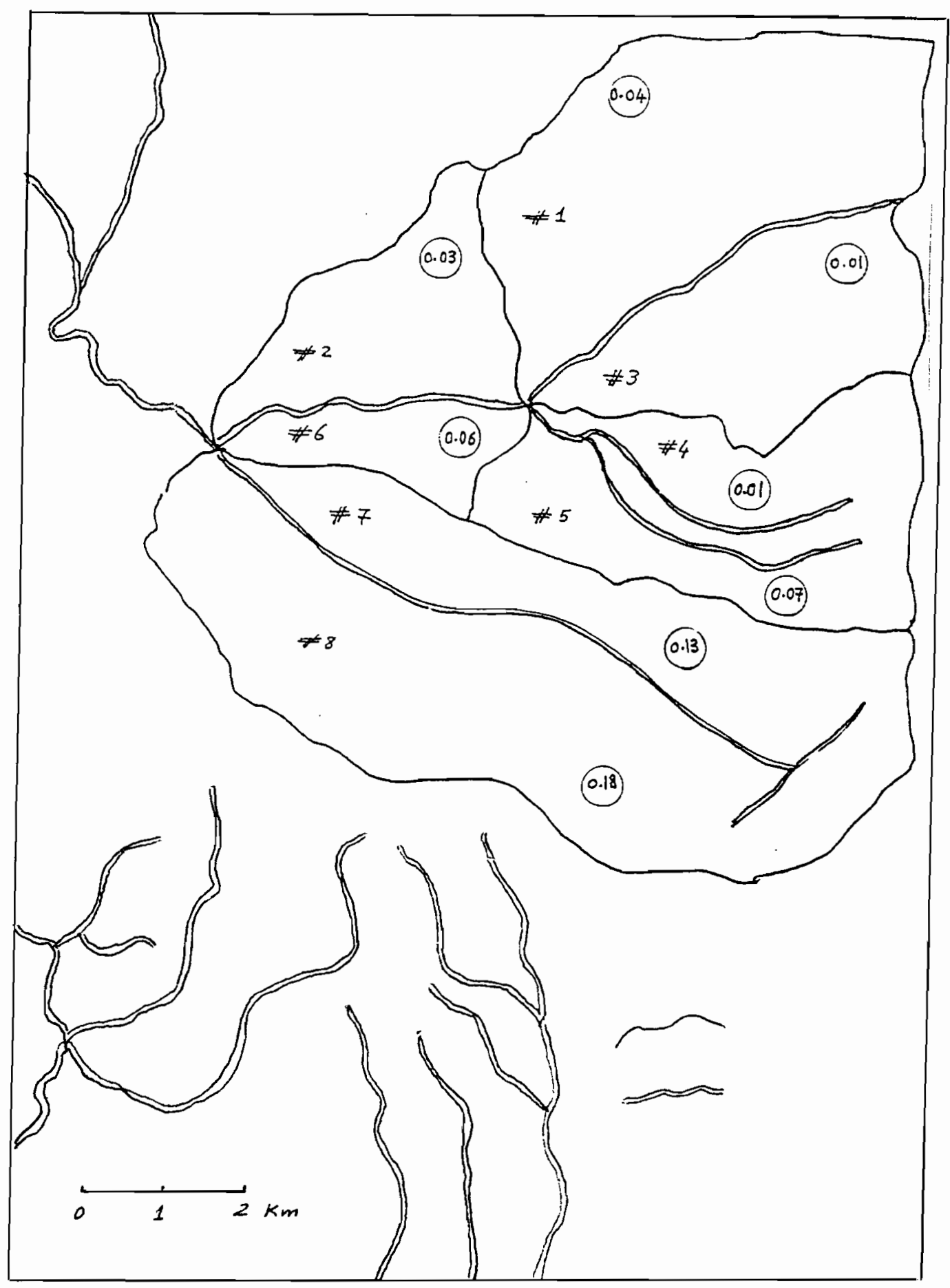

Figure 7.1: Probability of failure of valley slopes, macro-hazard-map, Glenoma, Washington. 


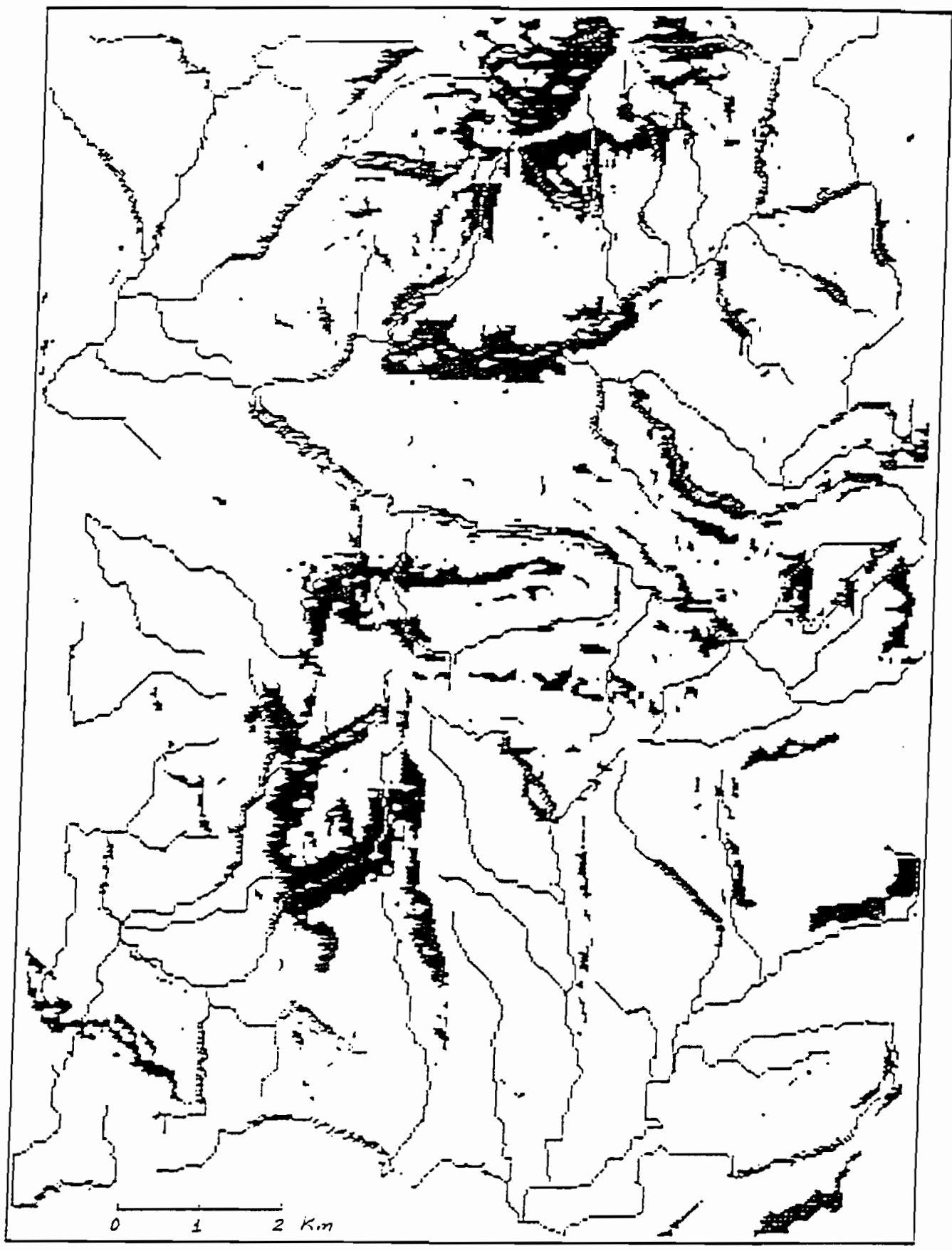

Figure 7.2: $\quad$ Map of probability of failure $>0.1$, micro-hazard-map, Glenoma, Washington. 


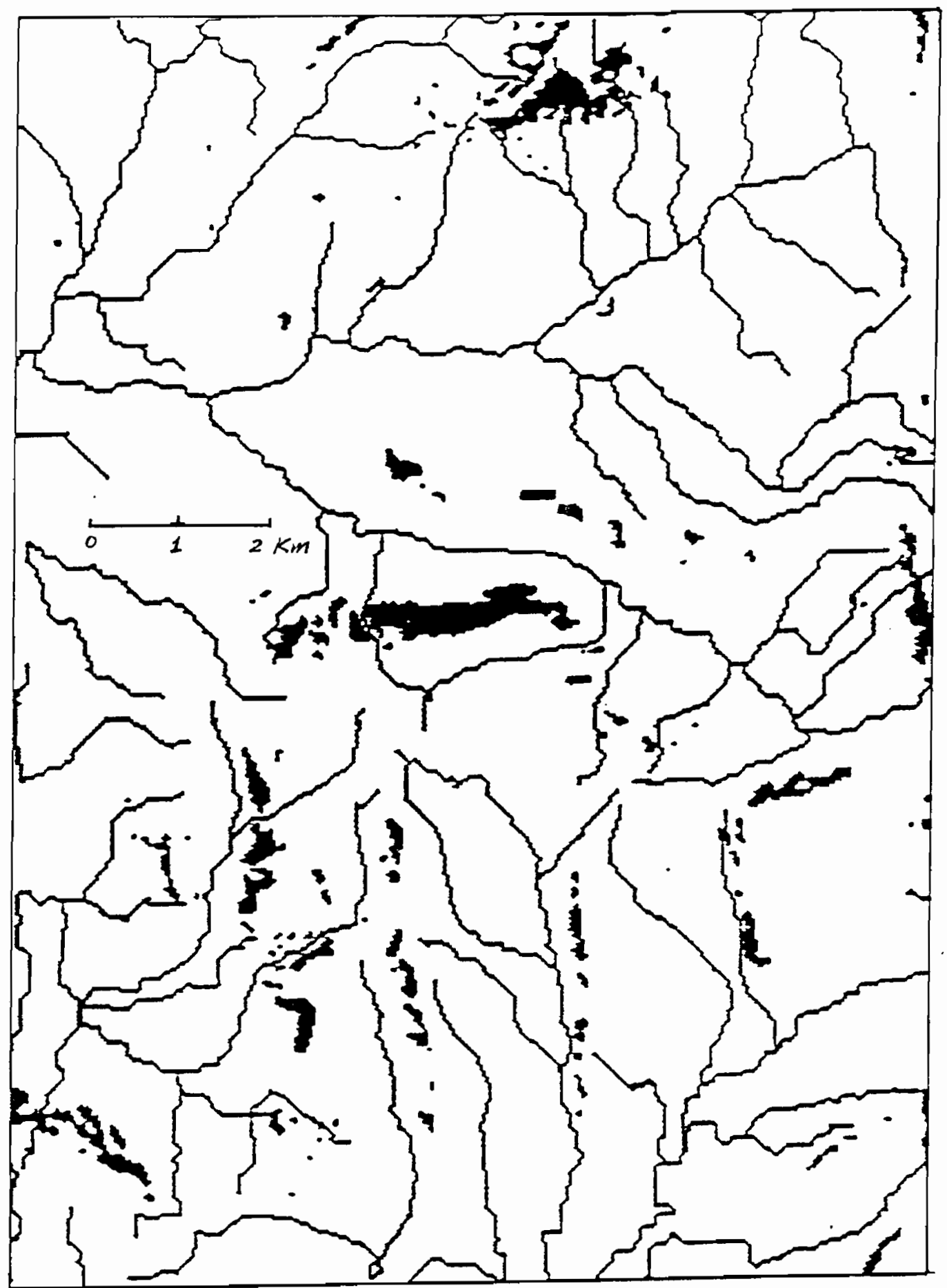

Figure 7.3: $\quad$ Map of probability of failure $>0.1$, macro-hazard-map at pixel level, Glenoma, Washington. 


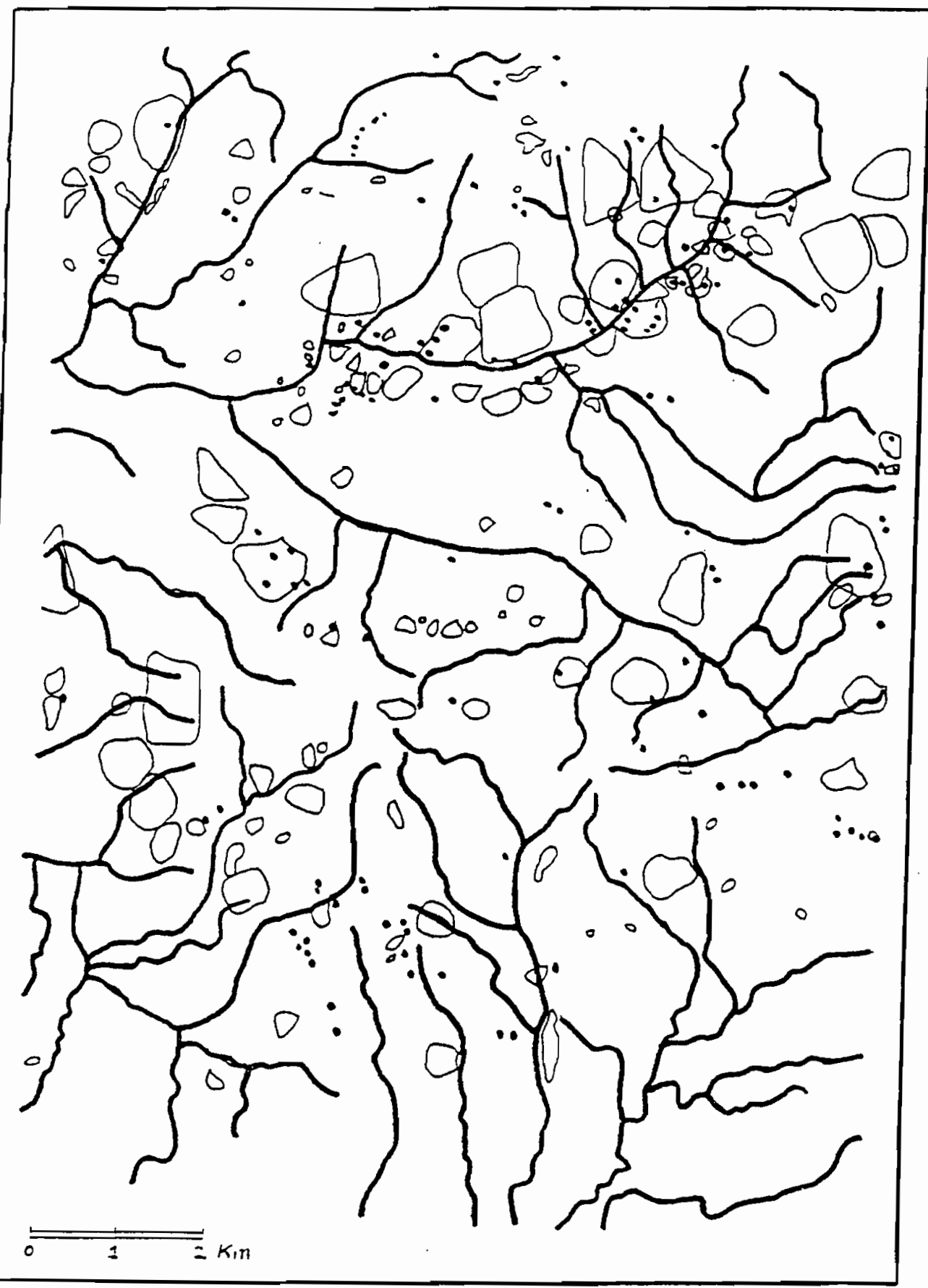

Figure 7.4: Landslide inventory map for Glenoma, Washington (Brunengo, 1991). 
Table 7.1

Different procedures used for mapping slope reliability.

\begin{tabular}{|c|c|c|c|c|c|c|}
\hline $\begin{array}{l}\text { groundwater } \\
\text { model }\end{array}$ & $\begin{array}{c}\text { soil } \\
\text { properties }\end{array}$ & $\begin{array}{l}\text { stability } \\
\text { model }\end{array}$ & \multicolumn{4}{|c|}{$\begin{array}{c}\text { uncertainty } \\
\text { Type }\end{array}$} \\
\hline & & & system & random & occur. & total \\
\hline \multicolumn{7}{|c|}{ Macro-hazard-map } \\
\hline $\begin{array}{l}\text { plane slope } \\
\text { ave. piezo. } \\
\text { level, } \\
h_{w} / H=.5 h_{0} / H \\
\text { Fig. } 5.13\end{array}$ & $\begin{array}{l}\text { average } \\
\text { site } \\
\text { condition } \\
\text { from } \\
\text { general soil } \\
\text { map units }\end{array}$ & $\begin{array}{l}\text { Fosm for } \\
\text { each valley } \\
\text { slope }\end{array}$ & $\Sigma_{41}$ & $\begin{array}{l}\text { negle- } \\
\text {-cted } \\
\text { because } \\
\text { it is } \\
\text { very } \\
\text { small }\end{array}$ & No & $\Sigma_{u 1}$ \\
\hline \multicolumn{7}{|c|}{ Macro-hazard-map at pixel level } \\
\hline $\begin{array}{l}\text { plane slope } \\
\text { ave. piezo. } \\
\text { level, } \\
h_{w} / H=.5 h_{0} / H \\
\text { Fig. } 5.13\end{array}$ & $\begin{array}{l}\text { average } \\
\text { site } \\
\text { condition } \\
\text { from } \\
\text { general soil } \\
\text { map units }\end{array}$ & $\begin{array}{l}\text { FOSM for } \\
\text { each pixel }\end{array}$ & $\Sigma_{u 1}$ & $\begin{array}{l}\text { negle- } \\
\text {-cted } \\
\text { as } \\
\text { approx }\end{array}$ & No & $\Sigma_{z 1}$ \\
\hline \multicolumn{7}{|c|}{ Micro-Hazard-Map } \\
\hline $\begin{array}{l}\text { converging } \\
\text { slopes } \\
\text { groundwater } \\
\text { map Fig } 5.16\end{array}$ & $\begin{array}{l}\text { detailed } \\
\text { soil } \\
\text { map } \\
\text { units }\end{array}$ & $\begin{array}{l}\text { F.O.S.M. for } \\
\text { each } \\
\text { pixel }\end{array}$ & $\Sigma_{u 1}$ & $\Sigma_{k R}$ & No & $C_{x 1}+\Sigma_{x R}$ \\
\hline
\end{tabular}


Table 7.2

Calculations of reliability for the macro-hazard-map.

\begin{tabular}{|l|l|l|l|l|l|}
\hline $\begin{array}{c}\text { valley } \\
\text { slope }\end{array}$ & $\begin{array}{c}\text { length } \\
\mathrm{m}\end{array}$ & $\begin{array}{c}\boldsymbol{\alpha} \\
\mathbf{2}\end{array}$ & $\begin{array}{c}\text { factor of } \\
\text { safety }\end{array}$ & variance & $\begin{array}{c}\boldsymbol{P}_{f} \\
\text { lognormal }\end{array}$ \\
\hline 1 & 1000 & 24.6 & 1.45 & 0.09 & 0.042 \\
2 & 740 & 20.9 & 1.59 & 0.18 & 0.027 \\
3 & 760 & 18.2 & 1.83 & 0.16 & 0.011 \\
4 & 500 & 20.0 & 1.65 & 0.17 & 0.014 \\
5 & 250 & 25.9 & 1.38 & 0.08 & 0.069 \\
6 & 570 & 25.6 & 1.39 & 0.08 & 0.060 \\
7 & 570 & 28.1 & 1.28 & 0.14 & 0.129 \\
8 & 580 & 32.3 & 1.13 & 0.36 & 0.180 \\
\hline
\end{tabular}

Table 7.3

Systematic uncertainty, random variation, and, total uncertainty matrices for sample pixel.

\begin{tabular}{|c|c|c|c|c|c|c|}
\hline variable & mean & \multicolumn{5}{|c|}{ systematic uncertainty matrix $\Sigma_{u 1}$} \\
\hline$H$ ft. & 3.085 & 0.871 & 0 & 0 & -.055 & 0 \\
\hline$c$, psf. & 69.86 & & 400 & -.50 & & 0 \\
\hline$\phi$ rad. & 0.464 & & -.50 & .0025 & 0 & 0 \\
\hline$h_{w} / H$ & 0.640 & -.055 & 0 & 0 & .204 & 0 \\
\hline$\alpha$ rad. & 0.425 & 0 & 0 & 0 & 0 & 0 \\
\hline variable & mean & \multicolumn{5}{|c|}{ random variation matrix $\Sigma_{u}$} \\
\hline $\boldsymbol{H}$ ft. & 3.085 & 0.021 & 0 & 0 & -.055 & 0 \\
\hline c, psf. & 69.86 & 0 & 61 & -.50 & 0 & 0 \\
\hline$\phi$ rad. & 0.464 & 0 & -.50 & .0004 & 0 & 0 \\
\hline$h_{w} / H$ & 0.640 & -.055 & 0 & 0 & .001 & 0 \\
\hline$\alpha$ rad. & 0.425 & 0 & 0 & 0 & 0 & 0.01 \\
\hline variable & mean & \multicolumn{5}{|c|}{ total uncertainty matrix $\Sigma_{u}$} \\
\hline$H$ ft. & 3.085 & 0.893 & 0 & 0 & -.055 & 0 \\
\hline$c_{s}$ psf. & 69.86 & 0 & 461 & -.50 & 0 & 0 \\
\hline$\phi$ rad. & 0.464 & 0 & -.50 & .0029 & 0 & 0 \\
\hline$h_{w} / H$ & 0.640 & -.055 & 0 & 0 & .205 & 0 \\
\hline$\alpha$ rad & 0.425 & 0 & 0 & 0 & 0 & 0.01 \\
\hline
\end{tabular}




\section{CHAPTER VIII}

\section{BAYESIAN UPDATING}

\subsection{INTRODUCTION}

As a result of the lack of detailed site investigation, the parameters of the slope stability model were estimated from inadequate data. A systematic way to improve our knowledge about these parameters, is to compare the model output, i.e. predicted landslide hazard, with real observation. Bayesian updating provides a formal procedure to update the prior information through observation. The estimated parameters from soil survey report, site investigation, and data from similar sites, represent the prior information. The landslide inventory constitute the observation. The updated distributions of the parameters, which are termed posterior distributions, can be used to evaluate the landslide hazard for other areas of similar geology.

In order to use the observations in the landslide inventory to update the prior information, relation between the observations and the prior information should be established. The observations in the landslide inventory, conducted by Brunengo (1991), are mostly the locations and the dimensions of the landslides. These observations was transformed through the observation model in Section 8.5 into the observed hazard of the area that contains these landslides. Thus, the prior model should include the prior hazard in addition to the other parameters to be updated. One way to formulate the updating model is to compare the prior information of an area with observations on that area. The area of comparison can be a pixel, a catchment, a polygon, or a quadrangle. As shown in Section 3.2, polygons delineated based on landform criteria are expected to have similar mass-movement characteristics. Therefore the polygon was selected to 
be the unit of the updating model. In Section 7.3.2, landslide hazard was evaluated for each pixel. The same analysis can be conducted over an area of several pixels - thousands of pixels such as a polygon. In the next sections the updating model, the prior model, and the observation model are introduced.

\subsection{BAYESIAN UPDATING MODEL}

The observation, $z$, on a system of variables, $x$, can be expressed as

$$
z=\Xi x+v
$$

where $z=$ the observation on the system; $x=$ the vector of variables to be estimated; $\Xi=$ mathematical model that relates the observation and the variables to be estimated; $v=$ unknown observation error. These four quantities are the basic requirements of any estimation theory. Let $\hat{x}$ denotes an estimate of the mean value of $x$, then the objective of any estimation theory is to find an operator $\mathrm{W}$ such that

$$
\hat{x}=W(z)
$$

There are different ways to choose the estimator, $W$ depending upon the nature of $x$ and $v$ (Schweppe, 1973). When both $x$ and $v$ are random vectors, then the estimator is Bayesian. The Bayesian model can be defined by the following conditions

$$
\begin{aligned}
& z=\Xi x+v \\
& E\{x\}=m_{x} \\
& E\left\{\left(x-m_{x}\right)\left(x-m_{x}\right)^{T}\right\}=\Psi \\
& E\{v\}=0 \\
& E\left\{v v^{T}\right\}=\Omega \\
& E\left\{x v^{T}\right\}=0
\end{aligned}
$$

Schweppe (1973) showed that the estimator

$$
\hat{x}=W z+W_{0}
$$


yields the minimum error covariance matrix for all $\mathrm{W}$ and $W_{0}$ when

$$
\begin{aligned}
& W=\Sigma_{f} \Xi^{T} \Omega^{-1} \\
& W_{0}=\Sigma_{\varepsilon} \Psi^{-1} m_{x}
\end{aligned}
$$

The minimum error covariance matrix is

$$
\Sigma_{\hat{x}}=\left(\Xi^{T} \Omega^{-1} \Xi+\Psi^{-1}\right)^{-1}
$$

Using Eq. 8.5 and matrix manipulation, then Eqs. 8.4 and 8.6 can be written as

$$
\begin{aligned}
& \hat{x}=m_{x}+\Psi \Xi^{T}\left(\Xi \Psi \Xi^{T}+\Omega\right)^{-1}\left[z-\Xi m_{x}\right] \\
& \Sigma_{\hat{x}}=\Psi-\Psi \Xi^{T}\left(\Xi \Psi \Xi^{T}+\Omega\right)^{-1} \Xi \Psi
\end{aligned}
$$

$\hat{x}$, and $\Sigma_{\hat{\imath}}$ are the updated mean and variance matrices, respectively; $m_{x}, \Psi$ are the prior mean and variance matrices, respectively; $z, \Omega$ are the observations mean and variance matrices, respectively. The sensitivity of the estimated parameters to the observations depends on the relation between these parameters and the observed variable. In general, if the observations are made on a variable which is not sensitive to the parameters, the observations will not be very informative about the parameters. In the mean time, if the observation error, $\Omega$, is significant, then the parameters will not be affected by the observations.

\subsection{HAZARD FOR A POLYGON}

As explained in Section 8.1, the polygon is selected to be the unit of the updating model. In general, the area delineated by a polygon can be chosen arbitrary. However, practical and logical rules should be applied to come up with a consistent procedure. In Section 3.2, it was shown that the landform criteria is a logical measure for delineation of polygons and it was used to delineate polygons \#1, \#2, and \#3, shown in Fig. 3.3. The observations in the landslide inventory are mostly the locations and the dimensions of the landslides which were transformed into the observed hazard of a polygon through the observation model in Section 8.5. Then we 
need to evaluate hazard of a polygon based on the prior information to compare it with the observed hazard.

\subsubsection{Polygon Scale and Uncertainty}

Different types of uncertainties are associated with stability depending on the dimensions of the domain under consideration, as explained in Section 3.3.3. For a domain of dimensions greater than the soil unit dimensions, such as a catchment or a polygon, all uncertainties, i.e. systematic, random, and occurrence exist. The random variations were neglected because the polygon dimensions are $>>\delta$. The total variance matrix, $\Sigma_{u}$, defined by Eq. 7.7 , at polygon scale is

$$
\Sigma_{u}=\Sigma_{u 1}+\Sigma_{u 3}
$$

where $\Sigma_{u 1}$ is given by Eq. 7.12, and $\Sigma_{u 3}$ is given by Eq. 8.9:

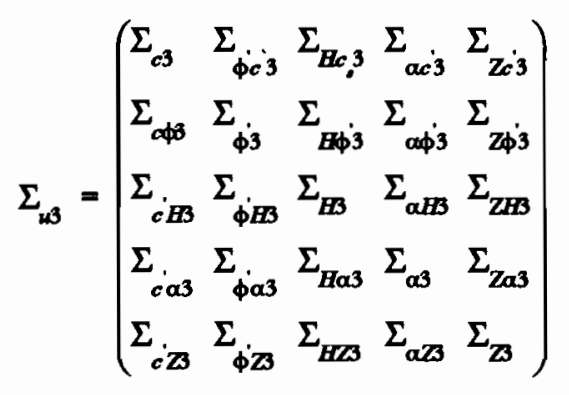

A computer program was written to compute the occurrence variances and covariances from the actual realization of detailed soil map units. For example, the equations used to compute the mean, the occurrence variance, and the occurrence covariance for angle of internal friction , $\dot{\phi}$, are

$$
E(\dot{\phi})=\frac{\sum_{i=1}^{n} A_{i} \dot{\phi}_{i}}{\sum_{i=1}^{n} A_{i}}
$$




$$
\begin{aligned}
\Sigma_{\phi 3}= & \frac{\sum_{i=1}^{n}\left(A_{i} \phi_{i}-E(\phi)\right)^{2}}{\sum_{i=1}^{n} A_{i}^{2}} \\
\Sigma_{\phi c 3} & =\frac{\sum_{i=1}^{n}\left(A_{i} \phi_{i}-E(\phi)\right)\left(A_{i} c_{i}-E(c)\right)}{\sum_{i=1}^{n} A_{i}^{2}}
\end{aligned}
$$

where $A_{i}, \dot{\phi}_{i}^{\prime}$, and $c_{i}^{\prime}$ are the area, the angle of internal friction, and the cohesion of soil unit $i$, identified from the detailed soil map; $\mathbf{n}$ is the different detailed soil map units within the polygon; $\Sigma_{\phi \beta}$ and $\Sigma_{\phi c 3}$ are the occurrence variance and covariance of $\phi^{\prime}$ and $c^{\prime}$. The results for polygon \#1, \#2, and \#3 are listed in Tables $8.3,8.4$, and 8.5 , respectively.

The random variable model of Tang et al. (1989), described by Eqs. 2.9 and 2.10, was used to evaluate the above calculations of occurrence uncertainty. It should be noted that the model of Tang et al. (1989) is for two-state domain, whereas, a polygon is a multi-state domain. So, in the following analysis $x_{1}$ and $x_{2}$ in Eq. 2.9 were selected to be the largest and smallest values of the soil properties within the polygon, respectively. It should be noted also that the occurrence variances are determined separately for each random variable or soil property because Eq. 2.10 is formulated for a single random variable and it does not account for correlation between random variables. The ratio between systematic and occurrence uncertainties depends on the ratio between the mean of soil properties, $\beta_{s}$, and the ratio of the mean duration of the soils, $\alpha_{s}$ as reviewed in Section 2.3.2.2, Eq. 2.9. Tang et al. (1989) have shown that the mean and the variance of the spatial average is not sensitive to $\alpha_{s}$ when $\beta_{s}$ is close to 1 . In this analysis, it was assumed that $\alpha_{s}=1$, i.e. the soil properties $x_{1}$ and $x_{2}$ have the same mean duration. Fig. 8.1 shows the ratio between the systematic uncertainty and occurrence uncertainty for different val- 
ues of $\beta_{s}$ as a function of $\Delta_{s}$. The values of $\Delta_{s}$, listed in Table 3.3, were used together with Fig. 8.1 to calculate the occurrence uncertainty. Sample calculations of the occurrence variance for polygon \#1 for $c^{\prime}, \phi$, and $H$ are given in Table 8.1. The occurrence variances computed using Eq. 8.11 and listed in Table 8.3 are in a good agreement with the variances computed using the model of Tang et al. and listed in Table 8.1.

\subsubsection{Application}

The parameters that define stability, $h_{w} / H, c^{\prime}, \phi^{\prime}, H$, and $\alpha$ were identified for each pixel using the same steps as in the micro-hazard-map procedure, Section 7.3.2. Table 8.2 shows a comparison between micro-hazard-map and hazard for a polygon. The spatial averages of the parameters were calculated using Eq. 8.10. It should be noted that the topographic data are older than the identified landslides from the landslide inventory, i.e. 20 years old, as discussed in section 8.5.1. This means that the topographic data can be used to predict the locations of the identified landslides. However, since hazard for the polygon was computed based on the spatial averages, then even if we use recent topographic data the error is very small.

The types of uncertainties and the variations associated with a polygon are discussed in Section 8.3.1, and given by Eq. 8.8. Table 8.3 lists the systematic uncertainty matrix, $\Sigma_{u 1}$, and the occurrence uncertainty matrix, $\Sigma_{u 3}$, for polygon $\# 1$. The same procedure was repeated for polygons \#2, and \#3. Tables 8.4, and 8.5 list the input statistics for polygons \#2 and \#3, respectively. The uncertainty model developed in Section 7.2, Eq. 7.6, was applied to polygons \#1, $\# 2$, and \#3. Using Eq. 7.1 and 7.6, the factor of safety and its variance for polygon \#1 are 1.775, 0.41 , respectively. The landslide hazard, $P_{f}=0.078$, assuming lognormal distribution (Chowdhury and Tang, 1987). The computed $P_{f}$ are $0.006,0.065$ for polygon \#2, and \#3, respectively. These $\boldsymbol{P}_{f}$ are compared to the observed hazard evaluated from the landslide inventory to update the prior information. 


\subsubsection{Interpretation of Probability of Failure}

In the previous chapter, the hazard for a pixel, $p$, was evaluated to produce the microhazard-map. In this chapter, the hazard for a polygon, $P_{f}$, was evaluated. The uncertainties of the parameters of the slope stability model in each case are different as shown in Table 8.2. Then, the interpretation $p$ and $P_{f}$ is also different.

It is common to view the probability of an event as the likelihood of occurrence of that event. In the micro-hazard-map, the uncertainties of the parameters result from the systematic uncertainty plus the random variations. However, the random variations are small compared to the systematic uncertainty as shown in Table 7.3. This means that $p$ reflects primarily the systematic uncertainty about the parameters. So, $p$ can be viewed as the likelihood of the pixel to slide.

In a polygon, the total uncertainty results from the systematic uncertainty and the occurrence uncertainty, Eq 8.8. Tables 8.3, 8.4, and, 8.5 show that the occurrence uncertainty represents a major part of the total uncertainty. This means that $P_{f}$ reflects primarily the occurrence uncertainty of the parameters. It is more logical to think of $P_{f}$ of a polygon as the frequency of area expected to slide, i.e. $P_{f}=\%$ of population with F.S. $<1.0$. An area of $P_{f}$ of 0.2 means that $20 \%$ of that area might be subjected to landslide. This definition is justifiable because all valley slopes that have the same slope angle do not all fail at the same time because of differences in site conditions.

Relation between $p$ and $P_{f}$ can be modeled using binomial distribution. Let $p_{i}=$ hazard for pixel $\mathrm{i}$, which reflects the likelihood of failure, $P_{f}=$ hazard for a polygon which reflects frequency of failure, and $\mathrm{n}=$ number of pixels within that polygon. First assume that $p$ is constant over the entire polygon. Then, for a polygon where all $\mathrm{n}$ pixels have the same $p$, the mean number of failures within that polygon $=n p$, and the variance $=n p(1-p)$ from binomial distribution. But $P_{f}$ is defined as the frequency of failure, i.e. 


$$
P_{f}=\frac{\text { failed area }}{\text { total area }}
$$

then

$$
E\left(P_{f}\right)=\frac{n p}{n}=p
$$

and variance of $P_{f}$ is

$$
\operatorname{Var}\left(P_{f}\right)=\frac{n p(1-p)}{n^{2}}=\frac{p(1-p)}{n}
$$

However, the value of $p$ is different for each pixel within the polygon. Fig. 8.3 shows the variation of $p$ over polygons \#1, \#2, and \#3. The mean value of $p, \bar{p}$, can be calculated using Eq 8.15

$$
\bar{p}=\frac{\sum_{i=1}^{n} p_{i}}{n}
$$

The variance of $p, \operatorname{Var}(p)$, can be calculated using Eq. 8.16

$$
\operatorname{Var}(p)=\frac{\sum_{i=1}^{n}\left(p_{i}-\bar{p}\right)^{2}}{n}
$$

using, Eq. 8.15, the mean and the variance of $P_{f}$ for case of variable $p$, can be formulated as shown in Appendix D, Eq. D.6, as

$$
\begin{aligned}
& E\left(P_{f}\right)=\bar{p} \\
& \operatorname{Var}\left(P_{f}\right)=\frac{\bar{p}(1-\bar{p})}{n}
\end{aligned}
$$

$\bar{p}$ was calculated using Eq. 8.15 for polygons $\# 1, \# 2$, and $\# 3$, from results of micro-hazardmap. $P_{f}$ was calculated in Section 8.3.2 for polygons \#1, \#2, and \#3. The results of computations of $\bar{p}$ and $P_{f}$ for polygon $\# 1, \# 2$, and $\# 3$ are listed in Table 8.6. According to Eq. 8.17, $P_{f}$ should be equal to $\bar{p}$. The difference between the calculated $P_{f}$ and its estimation $\bar{p}$, shown in Table 8.6, can be related to the assumption that $\boldsymbol{P}_{f}$ denotes frequency of failure due to spatial 
variations and the assumption that $p$ denotes likelihood of failure due to systematic uncertainty. However, the actual uncertainty in both cases includes both systematic uncertainty and spatial variations, although systematic uncertainty is most important in $p$ and random variation is most important in $P_{f}$

\subsubsection{Comparison with Monte-Carlo Simulation Technique}

Monte-Carlo simulation method was used to verify the accuracy of the calculations of hazard made using FOSM method. The computer program LISA (Hammond et al., 1991) applies Monte-Carlo simulations to compute the hazard of a polygon, $P_{f}$, using the spatial distribution of the parameters of the infinite slope model over that polygon. $P_{f}$ in this case is the number of Monte-Carlo iterations with calculated factor of safety less than 1.0 divided by the total number of iterations.

Data in Tables 8.3, 8.4, and 8.5 were used as the input statistics to LISA for polygons \#1, $\# 2$, and \#3, respectively. Representative statistics of simulated values for polygon \#1 are listed in Table 8.7. Table 8.8 shows the results of computing $P_{f}$ for polygon \#1, \#2, and \#3 using both FOSM and Monte-Carlo simulation methods. It is clear from Table 8.8 that there is no significant difference in values of $P_{f}$ computed by either method. LISA allows using different probability distributions for all the input parameters. the probability distributions can be uniform, normal, lognormal, beta, triangular, or histogram. A study was conducted by varying the type of the distribution of the stochastic parameters in Eq. 7.4. The results show that there is no significant effect on the computed $P_{\rho}$ 
Table 8.1

Systematic and occurrence variances of the parameters of stability model for polygon \#1.

\begin{tabular}{|c|c|c|c|c|c|c|c|c|}
\hline Parameter & $\bar{x}_{1}$ & $\bar{x}_{2}$ & $\Delta$ & $\frac{\bar{x}_{1}}{\bar{x}_{2}}$ & $\begin{array}{r}\Gamma(T) \\
\end{array}$ & system. var & occurr. var & total var \\
\hline $\begin{array}{ll}\dot{c} & \text { psf. } \\
\dot{\phi} & \text { rad. } \\
H & \text { ft. }\end{array}$ & $\begin{array}{l}80.0 \\
0.49 \\
5.00\end{array}$ & $\begin{array}{l}60.0 \\
0.45 \\
2.50\end{array}$ & $\begin{array}{l}0.28 \\
0.10 \\
0.29\end{array}$ & $\begin{array}{l}1.30 \\
1.07 \\
2.00\end{array}$ & $\begin{array}{l}0.0 \\
0.0 \\
0.0\end{array}$ & $\begin{array}{l}400.0 \\
0.0025 \\
0.871\end{array}$ & $\begin{array}{l}38.80 \\
0.0001 \\
0.945\end{array}$ & $\begin{array}{l}438.80 \\
0.0026 \\
1.816\end{array}$ \\
\hline
\end{tabular}

Table 8.2

Comparison betiveen micro-hazard-map and hazard-for-a-polygon.

\begin{tabular}{|c|c|c|c|c|c|c|}
\hline \multirow[t]{2}{*}{$\begin{array}{c}\text { groundwater } \\
\text { model }\end{array}$} & \multirow[t]{2}{*}{$\begin{array}{c}\text { soil } \\
\text { properties }\end{array}$} & \multirow[t]{2}{*}{$\begin{array}{c}\text { stability } \\
\text { model }\end{array}$} & \multicolumn{4}{|c|}{$\begin{array}{c}\text { uncertainty } \\
\text { Type }\end{array}$} \\
\hline & & & system & random & occur. & total \\
\hline \multicolumn{7}{|l|}{ Micro-hazard-map } \\
\hline $\begin{array}{l}\text { converging } \\
\text { slopes } \\
\text { groundwater map } \\
\text { Fig } 5.16\end{array}$ & $\begin{array}{l}\text { detailed } \\
\text { soil map }\end{array}$ & $\begin{array}{l}\text { F.O.S.M. for } \\
\text { each } \\
\text { pixel }\end{array}$ & $\Sigma_{w 1}$ & $\Sigma_{n a}$ & No & $\Sigma_{w 1}+\Sigma_{w 2}$ \\
\hline \multicolumn{7}{|l|}{ Hazard for a polygon } \\
\hline $\begin{array}{l}\text { converging slopes } \\
\text { groundwater map } \\
\text { Fig } 5.16\end{array}$ & $\begin{array}{l}\text { spatial } \\
\text { average } \\
\text { using } \\
\text { detailed } \\
\text { soil map }\end{array}$ & $\begin{array}{l}\text { F.O.S.M. or } \\
\text { Monte-carlo } \\
\text { simulat. } \\
\text { for each } \\
\text { landform } \\
\text { unit }\end{array}$ & $\Sigma_{w 1}$ & $\begin{array}{l}\text { vanish } \\
\text { or } \\
\text { very } \\
\text { small }\end{array}$ & $\Sigma_{\mu \beta}$ & $\Sigma_{u 1}+\Sigma_{z 3}$ \\
\hline
\end{tabular}


Table 8.3

Uncertainty, polygon \#1.

\begin{tabular}{|c|c|c|c|c|c|c|}
\hline variable & mean & \multicolumn{5}{|c|}{ systematic uncertainty $\Sigma_{u 1}$} \\
\hline$H$ ft & 3.085 & 0.878 & 0 & 0 & -.055 & 0 \\
\hline$c$, psf. & 69.86 & 0 & 400 & -.50 & 0 & 0 \\
\hline$\phi \mathrm{rad}$ & 0.464 & & -.50 & .0025 & 0 & 0 \\
\hline$h_{w} / H$ & 0.640 & -.055 & 0 & 0 & .205 & 0 \\
\hline$\alpha$ rad. & 0.425 & 0 & 0 & 0 & 0 & 0 \\
\hline variable & mean & \multicolumn{5}{|c|}{ occurrence uncertainty, $\Sigma_{u 3}$} \\
\hline$H$ ft. & 3.085 & 1.132 & 2.796 & -0.017 & -0.140 & -0.058 \\
\hline$c$, psf. & 69.86 & 2.796 & 38.17 & -0.142 & -0.44 & -0.174 \\
\hline$\phi$ rad. & 0.464 & -0.017 & -.142 & 0.0008 & 0.004 & 0.0009 \\
\hline$h_{w} / H$ & 0.640 & -0.14 & -0.440 & -0.004 & 0.357 & -0.008 \\
\hline$\alpha$ rad. & 0.425 & -0.058 & -0.174 & 0.0009 & -0.008 & 0.018 \\
\hline
\end{tabular}

Table 8.4

Uncertainty, polygon \#2.

\begin{tabular}{|c|c|c|c|c|c|c|}
\hline variable & mean & \multicolumn{5}{|c|}{ systematic uncertainty $\Sigma_{u 1}$} \\
\hline$H$ ft. & 4.59 & 0.878 & 0 & 0 & -.055 & 0 \\
\hline$c$, psf & 74 & 0 & 400 & -.50 & 0 & 0 \\
\hline$\phi \mathrm{rad}$ & .436 & 0 & -.50 & .0025 & 0 & 0 \\
\hline$h_{w} / H$ & 0.535 & -.055 & 0 & 0 & .205 & 0 \\
\hline$\alpha$ rad. & 0.279 & 0 & 0 & 0 & 0 & 0 \\
\hline variable & mean & \multicolumn{5}{|c|}{ occurrence uncertainty, $\Sigma_{u s}$} \\
\hline$H$ ft & 4.59 & 0.173 & 0 & 0 & 0.071 & -0.026 \\
\hline$c$, psf & 74 & 0 & 0 & 0 & 0 & 0 \\
\hline$\phi$ rad. & 0.436 & 0 & 0 & 0 & 0 & 0 \\
\hline$h_{w} / H$ & 0.535 & 0 & 0 & 0 & 0.216 & -0.019 \\
\hline$\alpha$ rad. & 0.279 & -0.026 & 0 & 0 & -0.019 & 0.01 \\
\hline
\end{tabular}


Table 8.5

Uncertainty, polygon \#3.

\begin{tabular}{|c|c|c|c|c|c|c|}
\hline variable & mean & \multicolumn{5}{|c|}{ systematic uncertainty, $\Sigma_{u 1}$} \\
\hline$H$ ft. & 2.75 & 0.878 & 0 & 0 & -.055 & 0 \\
\hline$c_{s}$ psf. & 68.60 & & 400 & -.50 & 0 & 0 \\
\hline$\phi \mathrm{rad}$ & 0.474 & & -0.50 & .0025 & 0 & 0 \\
\hline$h_{w} / H$ & 0.666 & -0.055 & 0 & 0 & 0.205 & 0 \\
\hline$\alpha$ rad. & 0.468 & 0 & 0 & 0 & 0 & 0 \\
\hline variable & mean & \multicolumn{5}{|c|}{ occurrence uncertainty, $\Sigma_{u s}$} \\
\hline$H$ ft. & 2.75 & 0.533 & 0.989 & -0.007 & 0.02 & -0.029 \\
\hline$c_{s}$ psf. & 68.6 & 0.989 & 3.67 & -0.024 & 0.22 & -0.088 \\
\hline$\phi$ rad. & 0.474 & -0.007 & -0.024 & 0.0002 & -0.016 & 0.0006 \\
\hline$h_{w} / H$ & 0.666 & -.02 & 0.22 & -0.016 & -0.175 & -0.015 \\
\hline$\alpha \mathrm{rad}$ & 0.468 & -0.029 & -0.088 & -0.000 & $5-0.015$ & 0.016 \\
\hline
\end{tabular}

Table 8.6

Relation between $p$ and Pf.

\begin{tabular}{|c|c|c|c|c|}
\hline polygon No. & $\bar{p}$ & $P_{f}$ & $\begin{array}{c}\mathrm{n} \\
\text { pixel }\end{array}$ & $\operatorname{Var}\left(\boldsymbol{P}_{f}\right)$ \\
\hline 1 & 0.033 & 0.078 & 2146 & 0.000015 \\
2 & 0.018 & 0.006 & 2224 & 0.000008 \\
3 & 0.044 & 0.065 & 1781 & 0.000025 \\
\hline
\end{tabular}


Table 8.7

Statistics of simulated values, polygon \#1.

\begin{tabular}{|l|l|l|l|l|}
\hline variable & minimum & maximum & mean & variance \\
\hline $\boldsymbol{H}$ ft. & 0.67 & 5.54 & 3.16 & 2.02 \\
$\boldsymbol{c}_{\boldsymbol{s}}$ psf. & 6.34 & 134.53 & 68.60 & 433.89 \\
$\phi \mathrm{rad}$. & 0.29 & 0.627 & 0.46 & 0.0032 \\
$\boldsymbol{h}_{\boldsymbol{w}}$ H & 0.00 & 1.00 & 0.65 & .51 \\
$\alpha \mathrm{rad}$. & 0.038 & 0.71 & 0.42 & 0.0175 \\
\hline
\end{tabular}

Table 8.8

Calculation of probability of failure using FOSM and Monte-Carlo simulation.

\begin{tabular}{|c|c|c|}
\hline polygon No. & FOSM & Monte-Carlo \\
\hline 1 & 0.078 & 0.069 \\
2 & 0.006 & 0.006 \\
3 & 0.065 & 0.072 \\
\hline
\end{tabular}




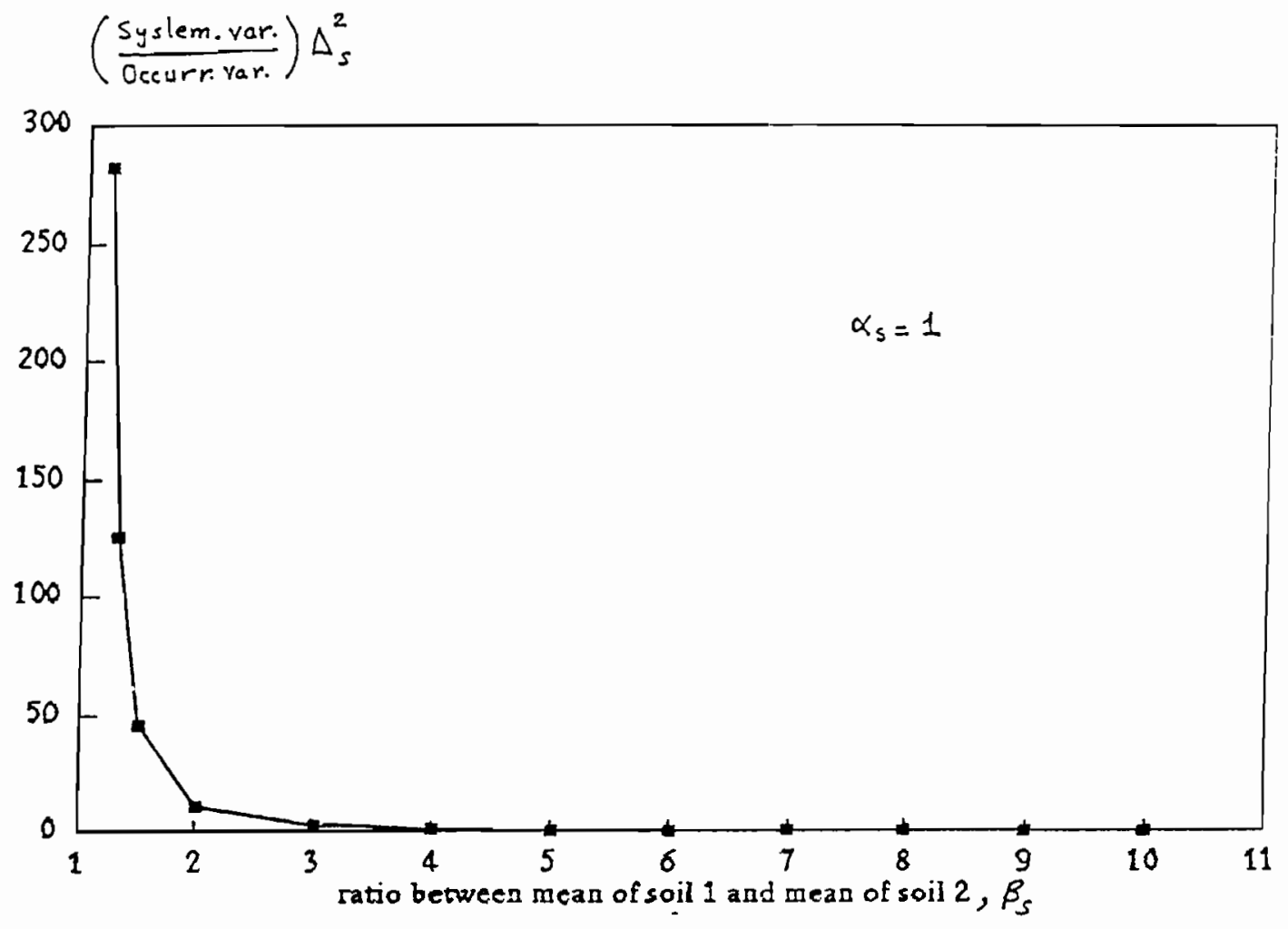

Figure 8.1: Ratio between systematic uncertainty and occurrence uncertainty based on random variable model (Tang et al., 1989). 


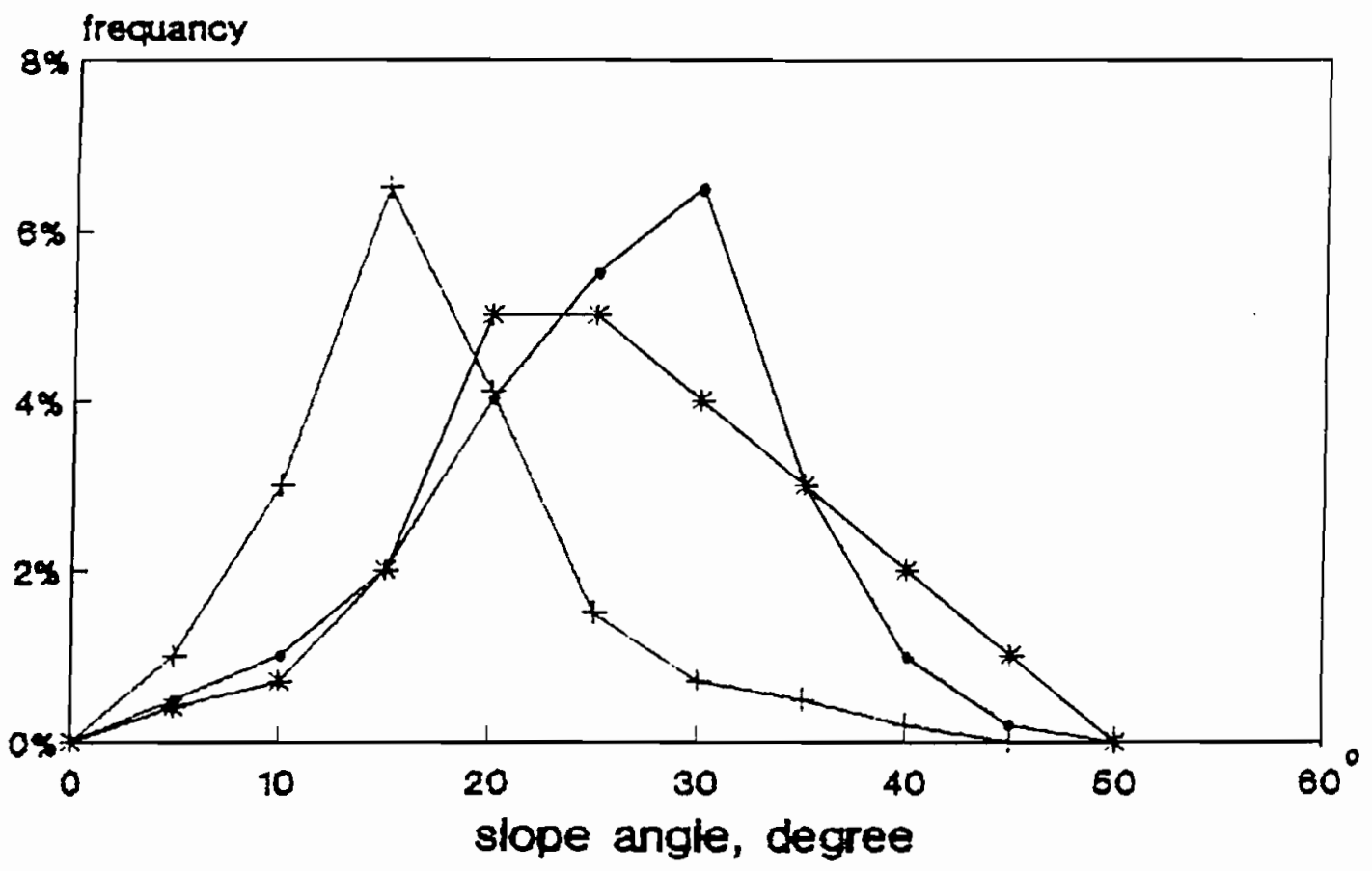

$\rightarrow$ polyson \#1 1 polygon \#2 $*$ polygon \#3

Figure 8.2: Variations of slope angle over polygons $\# 1, \# 2$, and $\# 3$, Glenoma quadrangle. 


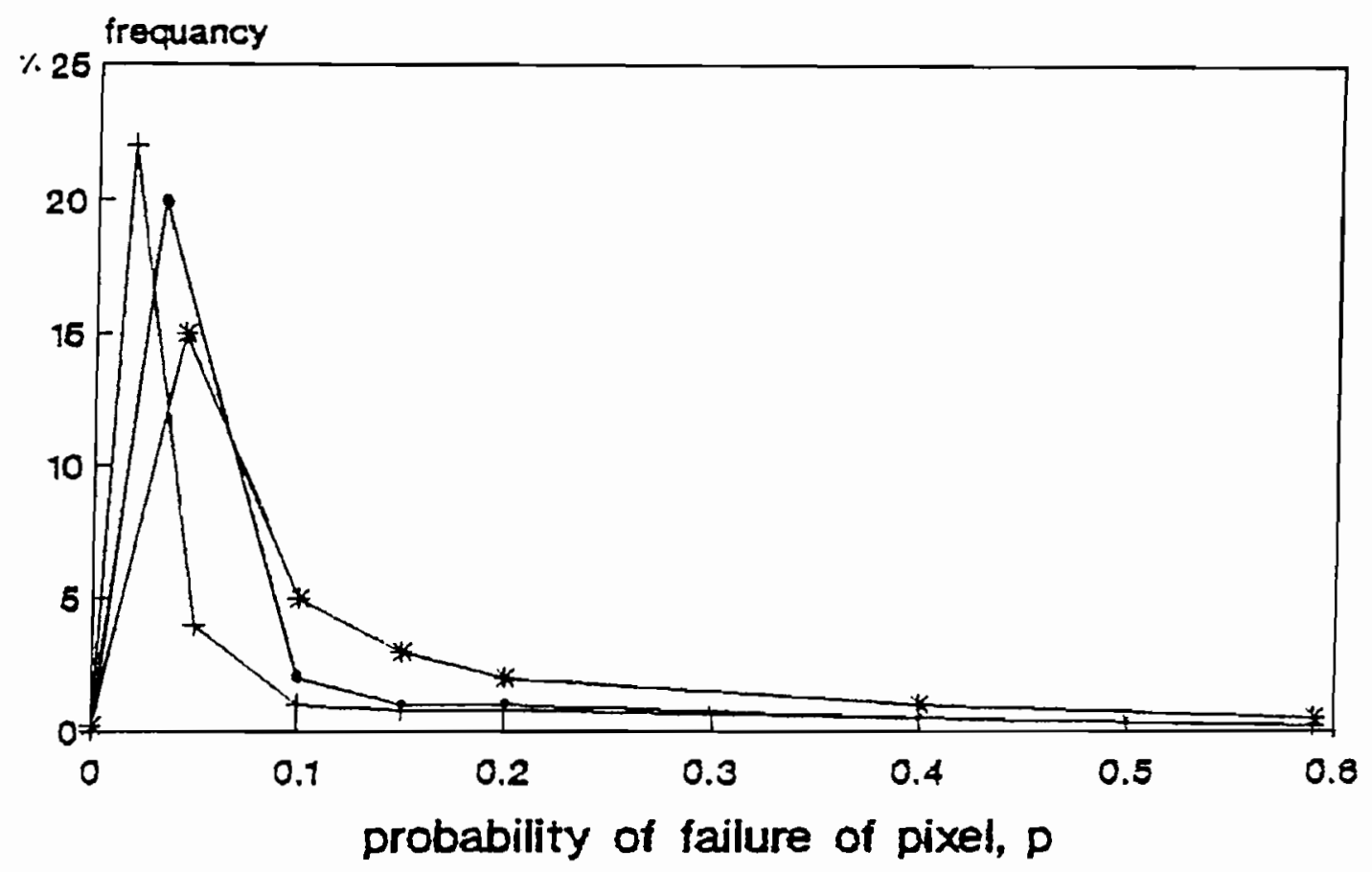

$\rightarrow$ polygon \#1 + polyoon \#2 * polygon \#3

Figure 8.3: Variations of, p, over polygons $\# 1, \# 2$, and $\# 3$. 


\subsection{PRIOR MODEL}

The prior information collected from the soil report and the geotechnical literature, explained in Section 3.1, represent the level of knowledge about site conditions before conducting the landslide inventory. The vector $x$, defined by Eq. 8.1, is similar to augmented vector $u$, defined by Eq. 7.4, except that the slope angle, $\alpha$, is illuminated because its uncertainty is minor compared to the uncertainties about $h_{w} / H, \mathrm{H}, c^{\prime}$, and $\Phi^{\prime}$. As explained in Section 8.1, the observations in the landslide inventory are mostly the locations and the dimensions of the landslides which were transformed to observed $P_{f}$ in Section 8.5. Then the prior model should contain prior $\boldsymbol{P}_{f}$ to be compared to observed $\boldsymbol{P}_{f}$. Then the mean and the variance of $\boldsymbol{P}_{f}$ are added to the prior model. The prior mean and variance matrices $m_{x}$ and $\Psi$ are

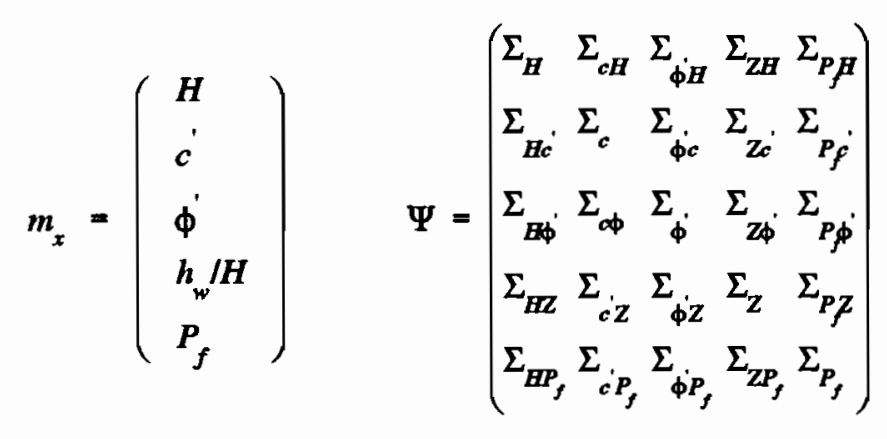

where $\Sigma_{p_{f}}$ was computed using Eq. 8.18. The covariances between $P_{f}$ and $\mathrm{H}, \mathrm{Z}, \phi^{\prime}$, and $c^{\prime}$ were estimated from the covariances between $p$ and $\mathrm{H}, \mathrm{Z}, \phi^{\prime}$, and $c^{\prime}$ using Eq. 8.12. The mean and the variances of $H, Z, \phi^{\prime}$, and $c^{\prime}$ were calculated in Section 8.3. The prior mean and the variance matrices are shown in Tables $8.9,8.10$, and 8.11 for polygons $\# 1, \# 2$, and $\# 3$, respectively. 
Table 8.9

Prior and posterior matrices for polygon \#1.

\begin{tabular}{|c|c|c|c|c|}
\hline variable & mean $\boldsymbol{m}_{\boldsymbol{x}}$ & \multicolumn{3}{|c|}{ variance-covariance $\Psi$} \\
\hline$H$ & 3.085 & 2.796 & $-0.0175-0.195$ & 0.0018 \\
\hline$c$ & 69.86 & 438.17 & $-0.642-0.44$ & 0.0013 \\
\hline$\phi$ & 0.464 & $-0.0175-0.642$ & $0.003 \quad 0.0036$ & 0 \\
\hline$h_{w} / H$ & 0.640 & $-0.195-0.44$ & $0.0036 \quad 0.562$ & -0.0002 \\
\hline$P_{f}$ & 0.078 & $0.0018 \quad 0.0013$ & -0.000 & 20.000015 \\
\hline variable & mean $\hat{x}$ & \multicolumn{3}{|c|}{ variance-covariance $\Sigma_{\hat{k}}$} \\
\hline $\boldsymbol{H}$ & 2.80 & 2.78 & $-0.0175-0.193$ & 0.0017 \\
\hline$c$ & 69.65 & 438.16 & -0.439 & 0.0012 \\
\hline$\phi$ & 0.464 & $-0.0175-0.643$ & $0.003 \quad 0.0036$ & 0 \\
\hline$h_{w} / H$ & 0.671 & $-0.1933-0.438$ & $0.0036 \quad 0.561$ & -0.0002 \\
\hline$P_{f}$ & 0.076 & $0.0017 \quad 0.0012$ & -0.000 & 20.000014 \\
\hline
\end{tabular}

Table 8.10

Prior and posterior matrices for polygon \#2.

\begin{tabular}{|c|c|c|c|c|c|c|}
\hline variable & mean $m_{x}$ & \multicolumn{5}{|c|}{ variance-covariance $\Psi$} \\
\hline $\boldsymbol{H}$ & 4.59 & 1.0515 & 0 & 0 & 0.0156 & -0.0007 \\
\hline$c$ & 74 & 0 & 400 & -0.5 & 0 & 0 \\
\hline$\phi$ & 0.436 & 0 & -0.5 & 0.0025 & 0 & 0 \\
\hline$h_{w} / H$ & 0.536 & 0.0156 & 0 & 0 & 0.421 & -0.0003 \\
\hline$P_{f}$ & 0.006 & -0.0007 & 0 & 0 & -0.000 & $38 E-6$ \\
\hline variable & mean $\hat{x}$ & \multicolumn{5}{|c|}{ variance-covariance } \\
\hline $\boldsymbol{H}$ & 4.58 & 1.051 & 0 & 0 & 0.015 & -0.0007 \\
\hline$c$ & 74 & 0 & 400 & -0.5 & 0 & 0 \\
\hline$\phi$ & 0.436 & 0 & -0.5 & 0.0025 & 0 & 0 \\
\hline$h_{w} / H$ & 0.534 & 0.015 & 0 & 0 & 0.42 & -0.0003 \\
\hline $\boldsymbol{P}_{f}$ & 0.006 & -0.0007 & 0 & 0 & -0.000 & $38 \mathrm{E}-6$ \\
\hline
\end{tabular}


Table 8.11

Prior and posterior matrices for polygon \#3.

\begin{tabular}{|c|c|c|c|c|c|}
\hline variable & mean $m_{x}$ & \multicolumn{4}{|c|}{ variance-covariance $\Psi$} \\
\hline$H$ & 2.753 & 0.989 & -0.0071 & -0.0355 & $5-0.0281$ \\
\hline$c$ & 74 & 403.67 & -0.524 & 0.22 & -0.0048 \\
\hline$\phi$ & 0.474 & $-0.0071-0.524$ & 0.0027 & -0.016 & 0.00004 \\
\hline$h_{w} / H$ & 0.665 & -0.03550 .223 & -0.016 & 0.380 & -0.0073 \\
\hline $\boldsymbol{P}_{f}$ & 0.065 & \multicolumn{4}{|c|}{$-0.0281-0.00480 .00004-0.00730 .0061$} \\
\hline variable & mean $\hat{x}$ & \multicolumn{4}{|c|}{ variance-covariance $\Sigma_{\hat{f}}$} \\
\hline$H$ & 2.767 & 1.306 & -0.007 & -0.062 & -0.0055 \\
\hline$c$ & 74.00 & 403.66 & -0.52 & 0.215 & -0.0009 \\
\hline$\phi$ & 0.474 & $-0.007-0.524$ & 0.0027 & -0.0155 & $96.87 E-6$ \\
\hline$h_{w} / H$ & 0.669 & $\begin{array}{lll}-0.062 & 0.218\end{array}$ & -0.015 & 0.373 & -0.0014 \\
\hline $\boldsymbol{P}_{f}$ & 0.062 & $-0.0055-0.0005$ & $6.87 E-6$ & $5-0.001$ & 10.0012 \\
\hline
\end{tabular}




\subsection{OBSERVATION MODEL}

\subsubsection{Landslide Inventory}

Landslide inventories provide the best means to verify the calculated landslide hazard. they traditionally have been used to assess relative hazard of natural slopes. Areas with many observed landslides should have a high probability of failure. Published landslide inventories reported areas of landslides of the order $0.5 \%$ to $15 \%$ of the area inventoried (Ice, 1985). A simple landslide inventory can be just identification of landslides and their locations. In detailed inventories, other parameters may be investigated such as soil type, depth of soil cover, shear strength of soil, shear strength of root system, and age of landslide. Observations are always associated with uncertainties because a landslide, that happened 10 or 20 year ago, is relatively difficult to discover because of the growth of trees and grass.

A landslide inventory was conducted in the focus township (Brunengo 1991). The identified landslides in polygons \#1, \#2, and \#3 are shown in Fig 8.4. Each identified landslide is denoted by $F_{i}$, where $\mathrm{i}=$ the identification number of the landslide. The collected information about each landslide included classification according to Varnes's system (1978), the landslide depth, $H_{i}$, and the landslide area, $a_{i}$. No information were collected on soil properties. Each landslide, $F_{i}$, was assigned an activity, $v_{i}$, and a certainty, $c_{i}$, to reflect the age and reliability of the information about that landslide. $v_{i}$ has value from 1 to 4 , where $1=$ ancient, $2=$ dormant, 3 $=$ recent, and $4=$ active. $c_{i}$ has value from 1 to 4 , where $1=$ definite, $2=$ probable, $3=$ questionable, and 4 = unreliable observation. Details of information about active and recent landslides are shown in Table 8.12.

The age of landslides is one of the variables investigated in the landslide inventory through the activity, $v$, of that landslide. The age of landslides can be divided into two categories: ancient and dormant landslides, i.e. age $>20$ years; recent and active landslides, i.e. age $<20$ years. The landslides of age $>20$ years may results from other triggering causes rather than 
from storm precipitations. Earthquakes are one of the major causes of landslides; they are known to have occurred in the focus township. For this reason, we limit the use of the observations from the landslide inventory to the recent and the active landslides only.

The age is used to estimate the storm precipitation that caused the failure. For example, a 20 year old landslide, is assumed to result from the largest storm in 20 years. This assumption represents the best estimate of the triggering cause of failure in the absence of recorded data of storms that cause each landslide. A more efficient landslide inventory is to identify the new landslides just after the end of a major storm. In this case, the variance of the amount of precipitation, duration, and antecedent moisture content may be small and the uncertainty about the groundwater may be reduced significantly.

Most recent and active landslides are small in size compared to the pixel size. The lengths of these landslides range from $6 \mathrm{~m}$ to $240 \mathrm{~m}$ with only $15 \%$ of them of length $>120 \mathrm{~m}$, as shown in Table 8.12. For this reason, the analysis of these landslides should consider the occurrence uncertainty of stability parameters throughout the polygon.

\subsubsection{Uncertainty About Observations}

The certainty, $c_{i}$, of each landslide is quantified by assuming the following probability rules:

$$
\begin{aligned}
& P\left(F_{i} \text { is a slide } \mathrm{J} c_{i}=1\right)=0.9 \\
& P\left(F_{i} \text { is not a slide } \mathrm{I} c_{i}^{=1}\right)=0.1 \\
& P\left(F_{i} \text { is a slide } \mathrm{I} c_{i}=2\right)=0.7 \\
& P\left(F_{i} \text { is not a slide } \mathrm{I} c_{i}=2\right)=0.3 \\
& P\left(F_{i} \text { is a slide } \mathrm{J} c_{i}=3\right)=0.3 \\
& P\left(F_{i} \text { is not a slide } \mathrm{I} c_{i}=3\right)=0.7 \\
& P\left(F_{i} \text { is a slide } \mathrm{I} c_{i}=4\right)=0.1
\end{aligned}
$$




$$
P\left(F_{i} \text { is not a slide } \mathrm{I} \quad c_{i}=4\right)=0.9
$$

The above probability rules define the uncertainty about the occurrence of each landslide. Each polygon contains several landslides of different uncertainties. Then, calculation of uncertainty about all landslides in a polygon should combine the uncertainty of each landslide, for all landslides within that polygon. Two assumptions are made to calculate the mean and the uncertainty of the total landslide area in a polygon and consequently the mean and the uncertainty of the observed landslide hazard for a polygon. These two assumptions are:

1. there is no bias, i.e. the decision to chose the type of certainty of the landslide $F_{i}$ to be $c_{i}$ is independent of the decision to chose the type of certainty of the landslide $F_{j}$ to be $c_{j}$, when $c_{i} \neq c_{p}$, and,

2. the decisions are consistent, i.e. the decision to chose the type of certainty of the landslide $F_{i}$ to be $c_{i}$ is correlated to the decision to chose the type of certainty of the landslide $F_{j}$ to be $c_{j}$, when $c_{i}=c_{j}$

This means that

$$
\begin{aligned}
& P\left(F_{i} \cap F_{j} \text { are slides }\right)=P\left(F_{i} \text { is a slide }\right) \cdot P\left(F_{j} \text { is a slide }\right), \text { when } c_{i} \neq c_{j} \\
& P\left(F_{i} \cap F_{j} \text { are slides }\right)=P\left(F_{i} \text { is a slide }\right)=P\left(F_{j} \text { is a slide }\right), \text { when } c_{i}=c_{j}
\end{aligned}
$$

Let $n_{c}$ be the number of landslides of certainty type $c$ within a polygon, and $A_{c}=$ the total area of landslides of certainty type, $c$, within that polygon. Then

$$
A_{c}=\sum_{i=1}^{i=n_{j}} a_{i}
$$

According to Eq. 8.22

$$
\begin{aligned}
& P\left(A_{c} \text { is a slide area } \mathrm{I} c=1\right)=0.9 \\
& P\left(A_{c} \text { is not a slide area } \mathrm{I} c=1\right)=0.1
\end{aligned}
$$

The probability of having a total landslide area, A, within the polygon 


$$
\begin{aligned}
& A=\sum_{c=1}^{c=4} A_{c} \\
& P\left(A_{1} \cap A_{2} \cap A_{3} \cap A_{4} \text { are slides }\right)=\prod_{c=1}^{c-4} P\left(A_{c} \text { is a slide }\right)
\end{aligned}
$$

where $A_{c}$ is defined by $\mathrm{Eq} 8.23$, and $\mathrm{c}=$ type of certainty. Different combinations of $\mathrm{A} 1, \mathrm{~A} 2$, A3, and A4 can be written and the probability of each combination may be calculated similar to Eq. 8.27.

In Section 8.3.3 the interpretation of the hazard for a polygon, $P_{f}$, is discussed and is found to reflect the frequency of failure, i.e.

$$
P_{f}=\frac{\text { area of observed landslides within a polygon }}{\text { total area of that polygon }}
$$

Eq. 8.28 was used to compute the observed $P_{f}$. The uncertainty about observed $P_{f}$ was calculated using Eqs. 8.21, 8.22, and 8.27. This model was applied to the landslide inventory of polygons \#1, \#2, and \#3. The locations of the landslides within these polygons are shown in Fig. 8.4. The detailed information of these landslides are listed in Table 8.12. The means and variances of observed $P_{f}$ and $\mathrm{H}$ are listed in Table 8.13, for the landslides of activity $v_{i}>2$, i.e. recent and active landslides. 

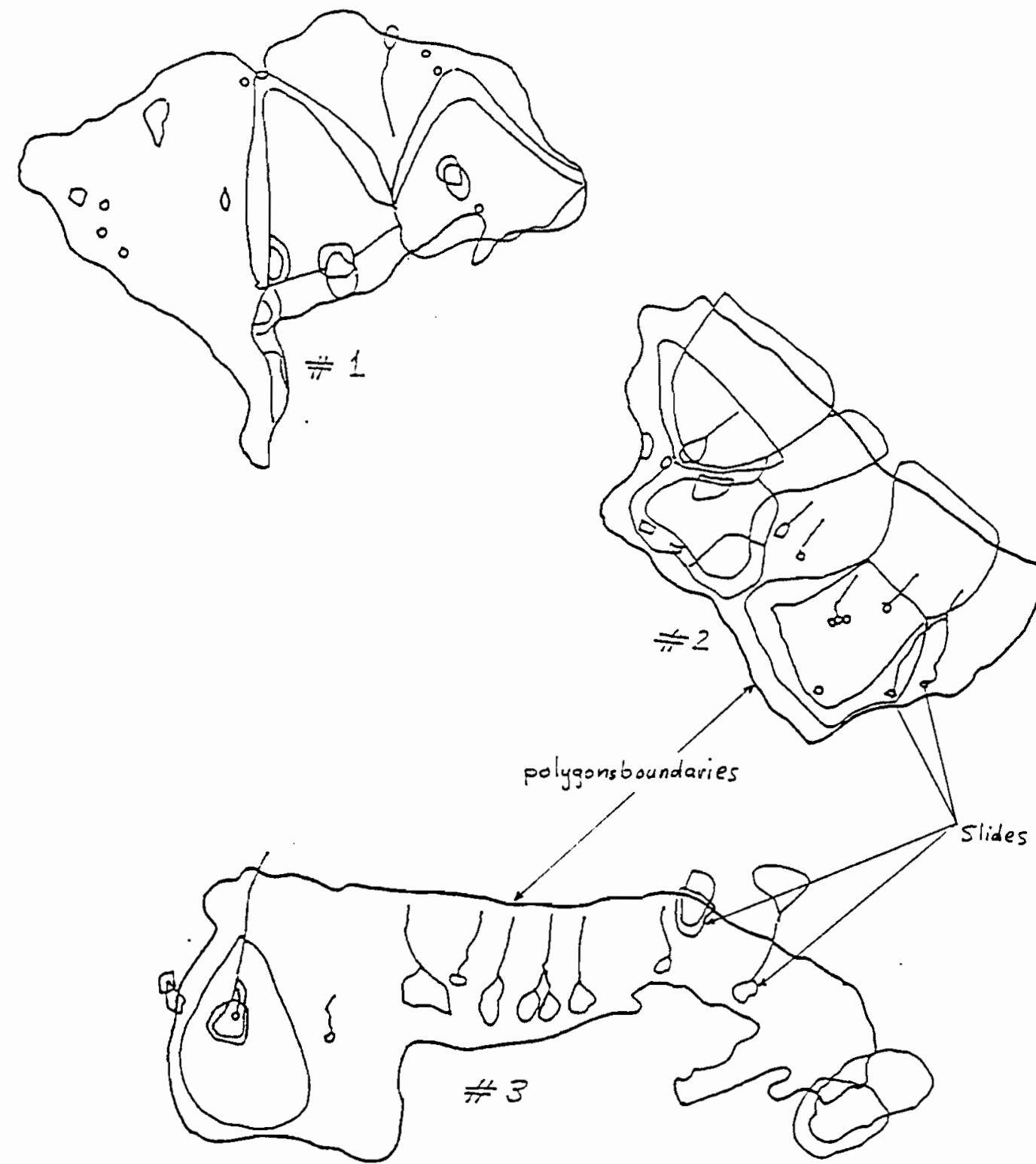

Figure 8.4: Results of landslide inventory for polygons \#1, \#2, and \#3 (Brinengo, 1991). 
Table 8.12

Information about the landslides in polygons \#1, \#2, and \#3.

\begin{tabular}{|c|c|c|c|c|c|c|c|}
\hline $\begin{array}{l}\text { slide } \\
\text { number } i\end{array}$ & activity & $\begin{array}{l}\text { certainty } \\
c\end{array}$ & $\begin{array}{l}\text { slope } \\
\text { angle }\end{array}$ & $\begin{array}{l}\text { length } \\
\text { ft. }\end{array}$ & $\begin{array}{l}\text { width } \\
\text { ft. }\end{array}$ & $\begin{array}{l}\text { depth } \\
\text { ft. }\end{array}$ & $\begin{array}{l}\text { area } \\
\mathrm{ft} .2\end{array}$ \\
\hline 1 & 3 & 1 & 31 & 30 & 40 & 4 & 3773 \\
\hline 2 & 3 & 1 & 18 & 600 & 400 & 4 & 80000 \\
\hline 3 & 3 & 1 & 48 & 20 & 80 & 4 & 5027 \\
\hline 4 & 3 & 2 & 26 & 400 & 320 & 20 & 40000 \\
\hline 5 & 3 & 2 & 28 & 70 & 70 & 5 & 15394 \\
\hline 6 & 3 & 2 & 39 & 50 & 50 & 5 & 7854 \\
\hline 7 & 3 & 2 & 39 & 50 & 50 & 5 & 7854 \\
\hline 8 & 3 & 2 & 55 & 70 & 70 & 5 & 15394 \\
\hline 9 & 3 & 4 & 33 & 30 & 40 & 4 & 3770 \\
\hline 10 & 3 & 4 & 35 & 30 & 40 & 4 & 3770 \\
\hline 1 & 3 & 4 & 28 & 90 & 70 & 25 & 19792 \\
\hline 2 & 3 & 3 & 24 & 194 & 100 & 8 & 60947 \\
\hline 3 & 4 & 2 & 28 & 800 & 500 & 40 & 40000 \\
\hline 4 & 4 & 2 & 27 & 800 & 800 & 50 & 200000 \\
\hline 5 & 4 & 2 & 27 & 500 & 400 & 40 & 600000 \\
\hline 6 & 3 & 2 & 25 & 70 & 60 & 12 & 13195 \\
\hline 7 & 3 & 2 & 22 & 150 & 200 & 4 & 94248 \\
\hline 8 & 3 & 2 & 23 & 50 & 50 & 4 & 7854 \\
\hline 9 & 3 & 1 & 24 & 50 & 50 & 4 & 7854 \\
\hline 1 & 3 & 2 & 58 & 80 & 470 & 4 & 100000 \\
\hline 2 & 3 & 2 & 46 & 150 & 470 & 4 & 200000 \\
\hline 3 & 3 & 2 & 59 & 70 & 260 & 4 & 57177 \\
\hline 4 & 3 & 2 & 58 & 50 & 365 & 4 & 57334 \\
\hline 5 & 3 & 2 & 59 & 70 & 365 & 4 & 80268 \\
\hline 6 & 3 & 2 & 67 & 315 & 470 & 4 & 500000 \\
\hline 7 & 3 & 2 & 64 & 130 & 155 & 4 & 63303 \\
\hline 8 & 3 & 2 & 61 & 50 & 50 & 4 & 7854 \\
\hline 9 & 3 & 3 & 45 & 60 & 60 & 4 & 11310 \\
\hline 10 & 3 & 3 & 38 & 30 & 40 & 4 & 3770 \\
\hline 11 & 3 & 3 & 59 & 80 & 260 & 4 & 65345 \\
\hline
\end{tabular}


Table 8.13

Results of application of the observation model to polygons \#1, \#2, and \#3.

\begin{tabular}{|c|c|c|c|c|c|c|c|}
\hline \multirow[t]{2}{*}{$\begin{array}{l}\text { polygon } \\
\text { number }\end{array}$} & $\begin{array}{l}\text { area } \\
f^{2}\end{array}$ & \multicolumn{2}{|c|}{$\begin{array}{c}\text { area of slides } \\
f^{2}\end{array}$} & \multicolumn{2}{|r|}{$P_{f}$} & \multicolumn{2}{|c|}{$\begin{array}{c}\text { depth of slides } \\
f\end{array}$} \\
\hline & & mean & variance & mean & variance & mean & variance \\
\hline $\begin{array}{l}1 \\
2 \\
3\end{array}$ & $\begin{array}{ll}2.07 & E+7 \\
2.15 & E+7 \\
1.73 & E+7\end{array}$ & $\begin{array}{ll}0.96 & E+6 \\
2.10 & E+6 \\
0.77 & E+6\end{array}$ & $\begin{array}{ll}0.1 & E+12 \\
2.9 & E+12 \\
0.2 & E+12\end{array}$ & $\begin{array}{l}0.044 \\
0.095 \\
0.061\end{array}$ & $\begin{array}{l}2.10 \mathrm{E}-4 \\
0.015 \\
0.15 \mathrm{E}-4\end{array}$ & $\begin{array}{l}7.94 \\
25.75 \\
4.00\end{array}$ & $\begin{array}{l}13.38 \\
176.86 \\
0.00\end{array}$ \\
\hline
\end{tabular}

\subsection{APPLICATION OF BAYESIAN MODEL}

The models, developed in Sections 8.2, 8.3, and 8.4, were applied to the focus township. The updating problem was solved for two cases:

1. the available information in the landslide inventory consist only of the locations and the dimensions of the landslides, which would be the case of a quick landslide inventory based for example on aerial photo, and

2. the available information in the landslide inventory include the depths of the landslides in addition to their locations and dimensions.

\subsubsection{Case \# 1.}

It was assumed in this case that information were only available about the landslides locations and dimensions, which were used to calculate the observed $P_{f}$ in Section 8.5. Since observations were limited only to $P_{f}$, then the matrix $\Xi$ in Eq. 8.1 is $\left[\begin{array}{lllllll}1 & 0 & 0 & 0 & 0\end{array}\right]$. Using the results of the application of the observation model to polygon \#1, listed in Table 8.13, then Eq. 8.1 can be written as 


$$
z_{1}=P_{f}=\left(\begin{array}{lllll}
1 & 0 & 0 & 0 & 0
\end{array}\right)\left(\begin{array}{l}
P_{f} \\
\dot{c} \\
\dot{\phi} \\
H \\
h_{w} / H
\end{array}\right)=\left(\begin{array}{ll}
0.0445
\end{array}\right) \quad, \quad \Omega_{1}=\left(\begin{array}{ll}
0.00021
\end{array}\right)
$$

The prior mean and variance matrices, $m_{x}$, and $\Psi$, computed in Section 8.3, are listed in Table 8.9 for polygon \#1. The posterior mean and variance matrices, $\hat{x}$ and $\Sigma_{\hat{x}}$, were computed using Eqs. 8.7, and are listed in Table 8.9. It is clear that the variances of the parameters are reduced significantly even without direct observations on them. The same procedure was repeated for polygon $\# 2$, and \#3, where

$$
\begin{array}{ll}
z_{2}=(0.096) & , \Omega_{2}=(0.015) \\
z_{3}=(0.061) & , \Omega_{3}=(0.0015)
\end{array}
$$

The prior mean and variance matrices are listed in Tables 8.10 and 8.11 for polygon \#2, and \#3, respectively. The posterior mean and variance matrices are listed in Tables 8.10 and 8.11 for polygon $\# 2$, and $\# 3$, respectively.

\subsubsection{Case \# 2}

In this case, the observations about the depth of soil, $\mathrm{H}$, was used in addition to the observed $P_{f}$ Using the results of the application of the observation model to polygon \#1, listed in Table 8.13; Eq. 8.1 can be written as:

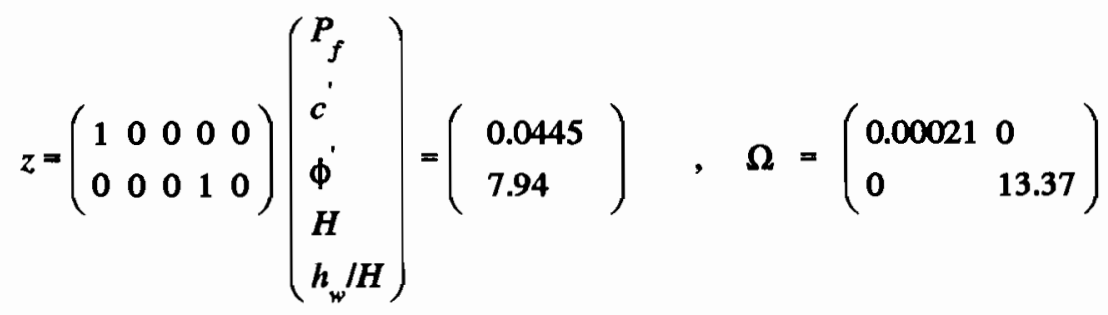

The prior mean and variance matrices are the same as in case \#1 and are listed in Table 8.9. Using the Bayesian model Eq. 8.8, the posterior mean, $\hat{x}$, and variance, $\Sigma_{\ell}$, were computed and 
are listed in table 8.14. Comparing the posterior variances of cases \#1 and \#2 listed in Tables 8.9 and 8.14, it is clear that the uncertainty is reduced even more in case \#2. This means that the more the collected information in the landslide inventory, the less the uncertainty in the updated parameters.

Table 8.14

Posterior matrices for Polygon \#1, case \#2.

\begin{tabular}{|l|c|lllll|}
\hline variable & mean $\hat{x}$ & \multicolumn{5}{|c|}{ variance-covariance $\Sigma_{\hat{x}}$} \\
\hline $\boldsymbol{H}$ & 3.48 & 1.736 & 2.42 & -0.015 & -0.168 & 0.0014 \\
$\boldsymbol{c}$ & 70.59 & 2.42 & 437.65 & -0.63 & -0.403 & 0.0009 \\
$\boldsymbol{\phi}^{\prime}$ & 0.458 & -0.015 & -0.63 & 0.003 & 0.003 & $1.9 \mathrm{E}-6$ \\
$\boldsymbol{h}_{\boldsymbol{w}} / \boldsymbol{H}$ & 0.605 & -0.168 & -0.40 & 0.003 & 0.559 & -0.0002 \\
$\boldsymbol{P}_{\boldsymbol{f}}$ & 0.076 & 0.0014 & 0.0009 & $1.91 \mathrm{E}-6$ & -0.0002 & 0.00001 \\
\hline
\end{tabular}




\section{CHAPTER IX}

\section{CONCLUSIONS}

The problem of the landslides initiated by rainfall and snowmelt was analysed. The water generated by rainfall and snowmelt infiltrates the soil and causes a rise in the groundwater levels, $h_{w}$, which reduces the soil shear strength and results in the landslides. The research concentrated on mapping the groundwater levels, $h_{w}$, and the landslide hazard, which is defined as the probability of slope failure, following rainfall and snowmelt events. The developed mapping procedures were applied to the focus township that covers areas of Glenoma and Mineral quadrangles of Washington, where a landslide inventory has been conducted (Brunengo, 1991).

The factors that influence $h_{w}$ were identified as meteorological parameters, soil properties, topography, and presence of geologic anomalies such as fractures in bedrock and pervious inclusions. The effect of meteorological parameters and soil properties on $h_{w}$ was studied using Reddi and Wu's lumped parameter model (1991). A sensitivity analysis showed that, for the regional site conditions in the focus township, the changes in $h_{w}$ are sensitive to infiltration, I, and soil depth, $\mathrm{H}$; less sensitive to drainable porosity, $\theta_{d}$, and saturated permeability, $K_{s}$; not sensitive to slope length, $\mathrm{L}$, and unsaturated parameters B and $\Psi_{s}$. The finite-difference model (Lee, 1986) was used to study the variations in $h_{w}$ within a catchment due to topography. Methods have been developed to account for flow through fractures in bedrock and flow through pervious inclusions. 
Reddi and Wu's model was used to produce a chart that shows $h_{w}$ in a plane slope as a function of the storm return period (Fig. 5.13). Piezometric-level maps were made for Glenoma Mineral quadrangles by application of Reddi's and Lee's models to individual catchments, which were delineated by MIPS operating on data in the GIS (Figs 5.16 and 5.17).

The stochastic nature of storms was studied. Distributions of rainfall, snowmelt, number of storms and intervals between storms were evaluated. Probability distributions of material properties, which include those of the soil and rock fractures were evaluated. These uncertainties were used as input to the slope stability model to calculate the landslide hazard.

The landslide hazard of natural slopes was evaluated at different scales and accuracy using first order second moment method (FOSM). Two hazard maps for areas of the focus township were produced: macro hazard map and micro hazard map. The areas of the landslide hazard identified in the micro hazard map showed a better agreement with the landslides identified by Brunengo (1991), in the landslide inventory. The accuracy of the analysis made by FOSM method was investigated by comparing the calculated landslide hazard with that obtained using a Monte-Carlo simulation program, LISA (Hammond et al., 1991). In spite of the large number of the random variables involved in the slope stability model, the hazard calculated using FOSM method is close to that obtained by Monte-Carlo simulation method.

A Bayesian updating model was developed to use the observations from the landslide inventory to update the parameters of the slope stability model. An observation model was developed to evaluate the uncertainty in the observations. The application of the Bayesian updating model to areas of the focus township showed that the posterior variances of the parameters are reduced significantly. 


\section{Appendix A}

\section{TWO-DIMENSIONAL FINITE DIFFERENCE MODEL}

Lee (1986) developed a two-dimensional finite difference program to calculate groundwater levels, $h_{w}$, as a result of rainfall. The stream lines were assumed to be parallel to the bedrock in the downhill direction, following the extended Depuit Forchheimer assumption. The stream lines were assumed to be horizontal in the transverse direction following the Depuit Forchheim-

er assumption, as explained in Fig A.1a. The flow within the saturated zone was described by Darcy's law as follows

$$
\begin{aligned}
& v_{x}=-K_{x} \frac{\partial \Phi}{\partial x} \\
& v_{y}=-K_{y} \frac{\partial \Phi}{\partial y}
\end{aligned}
$$

where $K_{x}$ and $K_{y}$ are coefficient of permeability in the $\mathrm{x}$ and $\mathrm{y}$ directions, respectively; $\Phi$ is the total potential expressed as

$$
\Phi=\left(h_{w}+H_{t}-H_{\rho}\right) \cos \alpha+y \sin \alpha+x \tan \gamma
$$

The geometric terms in Eq.A.3 are illustrated in Fig. A.1b. For isotropic permeability, continuity of flow yields

$$
C \frac{\partial h_{w}}{\partial t}=Q_{r} \cos \alpha-\frac{\partial}{\partial x}\left(v_{x} h_{w}\right)-\frac{\partial}{\partial y}\left(v_{y} h_{w}\right)
$$

where $\mathrm{C}=$ specific yield

The Kriging technique was used to generate the soil parameters for each element in the watershed using data collected at specific points. The recharge values, $Q_{r}$, were computed as a 
function of rainfall, $i$, according to the following regression relationship

$$
Q_{r}=-0.012+0.7 i
$$

This relation is based on the Goldschmidt and Thornthwaite theory of evapotranspiration suggested by sangrey et al. (1984). The regression coefficients were obtained from two cases studied by Johnson (1977). 


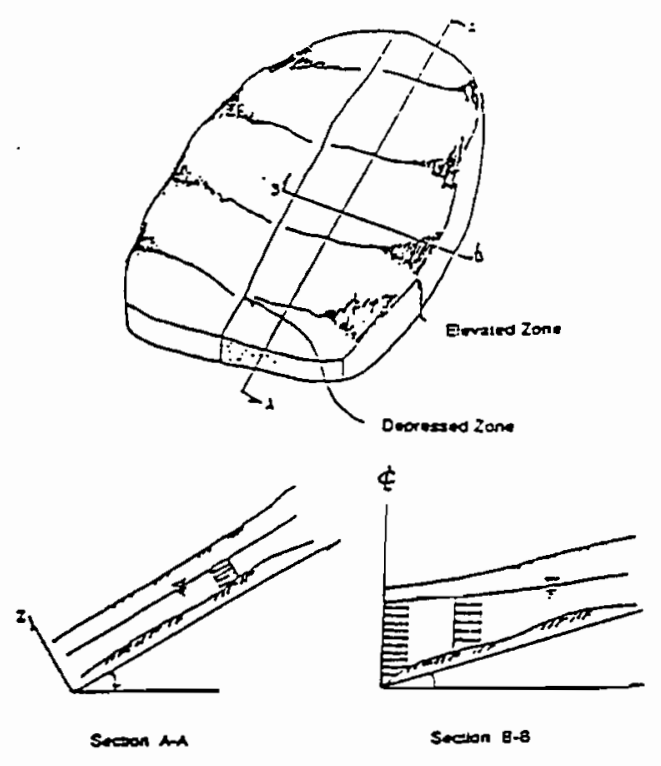

(a)

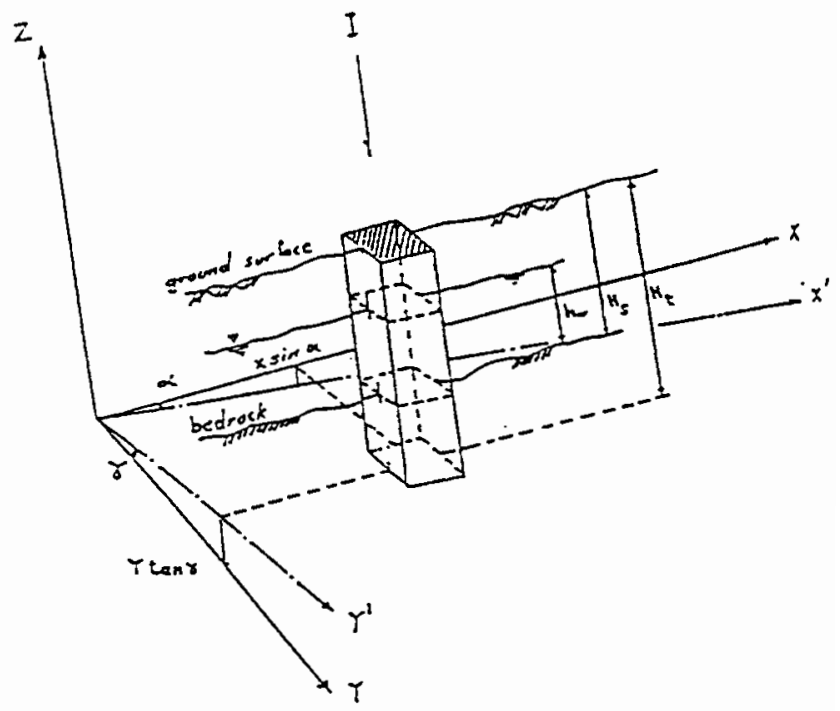

(b)

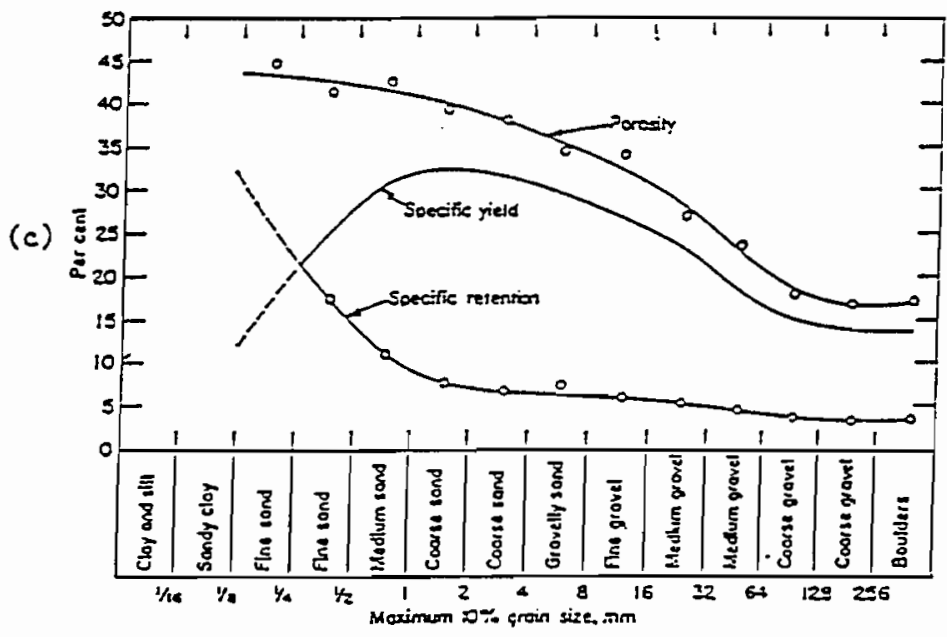

Figure A.1: (a) Flowlines in downhill and transverse directions, (b) geometric parameters of two dimensional model (Lee, 1986), (c) specific yield for different soils (Eckis, 1934). 


\section{Appendix B \\ ONE DIMENSIONAL MASS BALANCE MODEL}

This model, developed by Reddi and Wu (1991), treated the unsaturated flow and the saturated flow separately. Flow in the unsaturated zone was assumed to be vertically downward, and the entire hillslope segment was treated as a control volume to compute drainage by gravity. The unsaturated zone was subdivide into three zones as shown in Fig. B.1a. In the moisture zone, alternating wetting and drying of the soil surface during consecutive storm and interstorm periods are governed by capillarity and gravity. As the depth increases, the soil moisture gradient decreases until moisture movement becomes dominated by gravity; this is the percolation zone. Near the water table, capillary forces become dominant, which creates the capillary zone between the water table and percolation zone. The moisture content distribution was assumed to be linear in each zone, and the mass balance model (Eagleson, 1978) was used to predict the water content in the three zones as follows

$$
\begin{aligned}
& \theta_{j}^{(1)}\left(z_{j}\right)=\theta_{j}^{(0)}\left(z_{j}\right)+\left(v_{j-1}-v_{j}-E_{e j}\right) \Delta t \\
& E_{e}=\alpha_{e} E_{e q}
\end{aligned}
$$

where $\theta_{j}^{(1)}, \theta_{j}^{(0)}=$ mean water contents in the $f^{\text {th }}$ zone at times (1) and (0), respectively; $z_{j}=$ thickness of the $f^{\text {th }}$ zone; $E_{e j}=$ evapotranspiration rate in the $f^{\text {th }}$ zone; $E_{e q}=$ coefficient of evapotranspiration; $\alpha_{e}=$ equilibrium evapotranspiration; $v_{f-1}, v_{j}=$ downward moisture fluxes at the top and the bottom of the $f^{\text {th }}$ zone, respectively. The moisture flux in Eq. B.1 was calculated using Darcy's law, then 


$$
v_{j}=0.5 K(\theta)\left(\left(\frac{\psi_{j}-\Psi_{j-1}}{z_{j}}+1\right)+\left(\frac{\Psi_{j+1}-\Psi_{j}}{z_{j+1}}+1\right)\right)
$$

where $k(\theta)=$ hydraulic conductivity as a function of water content at the bottom of $f^{\text {th }}$ zone; $\Psi_{j-1}, \Psi_{j}=$ suction potentials at top and bottom of the $f^{\text {th }}$ zone, respectively. The moisture flux, $v_{o}$, at the top was assumed to be equal to rainfall intensity, $\mathrm{i}$, minus evapotranspiration, $\mathrm{E}$, which was computed using the equilibrium evapotranspiration approach (priestly and Taylor, 1972). According to Campbell (1974), the function of $\varphi(\theta)$ and $K(\theta)$ may be expressed as

$$
\begin{aligned}
& \Psi(\theta)=\Psi_{s} W^{-B} \\
& K(\theta)=K_{s} W^{2 B+3}
\end{aligned}
$$

in which $\mathrm{W}=$ degree of saturation $=\theta / \theta_{s}, \theta_{s}=$ saturated water content, $\Psi_{s}=$ suction pressure at saturation or air-entry pressure head, $\mathrm{B}=$ an unsaturated flow parameter, and $K_{s}=$ saturated permeability.

The kinematic storage model (Sloan et al., 1983) was chosen to represent flow in the saturated zone. The idealized plane hillslope has an impermeable bed of slope $\alpha$ and length $L$, and a soil profile of constant thickness, H, Fig. B.1b. The model assumed that the water table has a constant slope between the upslope and downslope boundaries of the sloping soil mass, at any given time. The hydraulic gradient was assumed to be constant, equal to $\alpha$, although the slope of the water table changes with time. The mass balance equation is expressed in mixed finite difference form as

$$
\frac{S_{d}^{(1)}-S_{d}^{(o)}}{t^{(1)}-t^{(o)}}=i_{s} L-\frac{q^{(1)}+q^{(o)}}{2}
$$

and $q$ is given by

$$
q=h_{o} K_{s} \sin \alpha
$$


where $i_{s}=$ rate of water input to the saturated zone from the unsaturated zone, and $S_{d}=$ drainable volume of water stored in the saturated zone of the hillslope. In case of plane slope, $S_{d}$ is given by

$$
S_{d}=\frac{h_{0} \theta d}{2}
$$

in case of converging slope with convergent angle, $\beta, S_{d}$ is given by

$$
S_{d}=\frac{\pi h_{o} \theta_{d} L^{2}}{2}\left(\frac{\beta}{360}\right)
$$

where $h_{o}=$ the groundwater level at exit. 
(a)

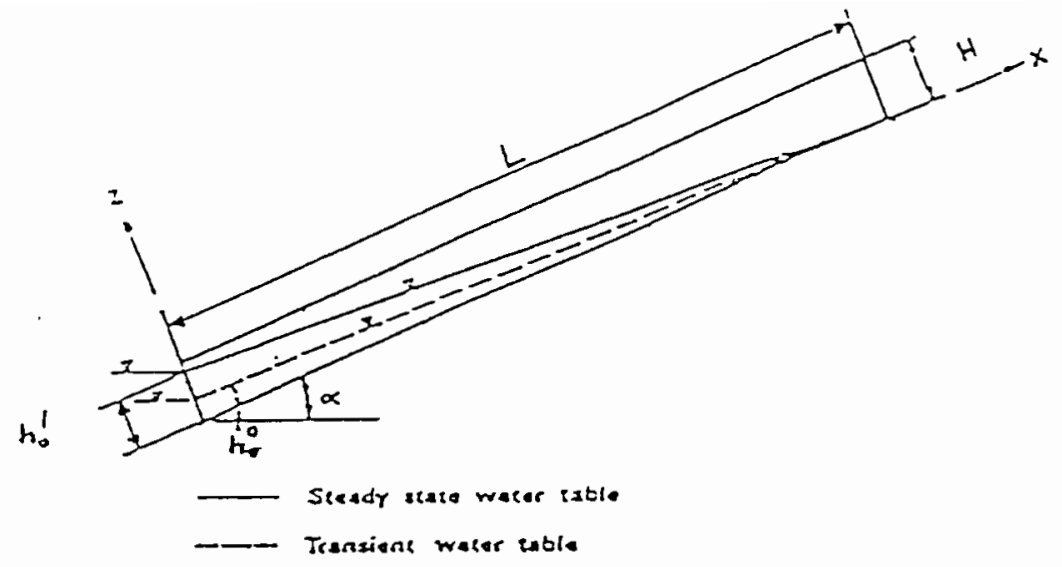

(b)

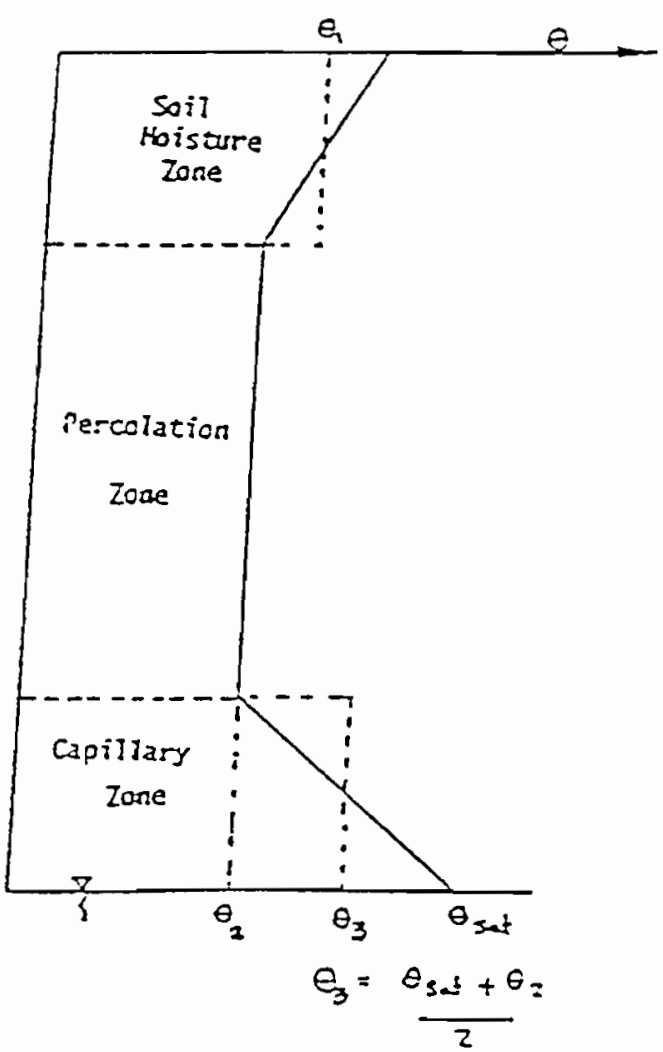

Figure B.I: (a) Idealization of moisture profile in the unsaturated zone, (b) the kinematic storage model (Reddi and $W u, 1991$ ) 


\section{Appendix C \\ DERIVATION OF THE FIRST ORDER SECOND MOMENT}

The Taylor expansion of the functional relationship, F, involves a vector of random variables, $u$, using Vetter's (1973) notation is

$$
F(u)=F\left(u_{0}\right) \frac{1}{K_{i}}\left[D^{X}{ }_{u^{I}} F\right]\left(u-u_{0}\right)^{* K}
$$

where $\mathrm{F}$ is a vector function of the vector $\mathrm{u}$, and $u_{0}$ is the mean value of $\mathrm{u}$ around which the function is expanded; [ $D^{K}{ }_{u^{r}} F$ ] is the $K^{\text {th }}$ derivative of $\mathrm{F}$ with respect to the transpose of $u$ evaluated at $u_{0} ;\left(u-u_{0}\right)^{*}{ }^{K}$ is the result of K Kronecker products of $\left(u-u_{0}\right)$ with itself. Neglecting higher order terms in Eq. C.1, the expected value F is

$$
\begin{aligned}
E(F) & =E\left[F\left(u_{0}\right)+\left(D_{u^{x}}\right)\left(u-u_{0}\right)\right] \\
& =E\left(F\left(u_{0}\right)\right)+D_{u^{u}} F E\left(u-u_{0}\right)=F\left(u_{0}\right)
\end{aligned}
$$

Similarly, the variance of $F$ can be approximated to first order by

$$
\Sigma_{F}=\left(D_{u^{T}} F\right) \bar{\Sigma}_{u}\left(D_{u^{T}} F\right)^{T}
$$

It can be seen from Eq. C. 3 that $\Sigma_{F}$ depends on the the variance of the input variables and the sensitivity of $\mathrm{F}$ to the variables in vector $\mathrm{u}$ in the neighborhood of $u_{\circ}$ Eq. C.3 may be expanded as (Ang and Tang, 1975)

$$
\Sigma_{F}=\sum_{i=1}^{n}\left(\frac{\partial F}{\partial X_{i}}\right)^{2} \operatorname{Var}\left(X_{i}\right)+\sum_{i \neq j}^{n} \Sigma\left(\frac{\partial F}{\partial X_{i}}\right)\left(\frac{\partial F}{\partial X_{i}}\right) \operatorname{Cov}\left(X_{i}, X_{j}\right)
$$


where $\mathrm{n}$ is the number of random variable in the function $\mathrm{F}$ and $\operatorname{Cov}\left(X_{i}, X_{j}\right)$ is the covariance between $X_{i}$ and $X_{j}$ 


\section{Appendix D}

\section{BINOMIAL DISTRIBUTION FOR A VARIABLE, P}

Define the "Bernoullii" random variable, $x$, to be either failure or success

$$
\begin{array}{ll}
X=1 & \text { if } \text { a failure is observed } \\
X=0 & \text { if } \text { a failure is not observed }
\end{array}
$$

Then the probability mass function of $\mathrm{X}$ is simply

$$
\begin{array}{ll}
P_{X}(x)=p & x=1 \\
P_{X}(x)=1-p & x=0
\end{array}
$$

where $p$ is the probability of failure. Define $Y=$ total number of failures in $n$ "Bernoulli" trials. For $p=$ constant then, from Binomial distribution (Benjamin and comell, 1970)

$$
\begin{aligned}
& E(Y)=n p \\
& \operatorname{Var}(Y)=n p(1-p)
\end{aligned}
$$

If $\mathrm{p}$ is random variable with a mean value $\bar{p}$, then $P(X=1 \Pi p)=p$. Then

$$
\begin{aligned}
E(Y) & =E\left(\sum_{i=1}^{n} X_{i}\right) \\
& =\sum_{i=1}^{n} E\left(X_{i}\right) \\
& =n E(p)=n \bar{p}
\end{aligned}
$$

and

$$
\begin{aligned}
\operatorname{Var}(Y) & =\operatorname{Var}\left(\sum_{i=1}^{n} X_{i}\right) \\
& =n \operatorname{Var}\left(X_{i}\right)=n E\left(\operatorname{Var}\left(X_{i} \Pi p\right)\right)+\operatorname{Var}\left(E\left(X_{i} \Pi p\right)\right)
\end{aligned}
$$




$$
\begin{aligned}
& =n E(p(1-p))+\operatorname{Var}(p) \\
& =n E\left(p-p^{2}\right)+E\left(p^{2}\right)-(E(p))^{2} \\
& =n E(p)-(E(p))^{2}+n \bar{p}(1-\bar{p}) \\
& =n \bar{p}(1-\bar{p})
\end{aligned}
$$

Define the random variable $Q=Y / n$, then

$$
\begin{aligned}
E(Q) & =E(Y / n) \\
& =\frac{1}{n} E(Y)=\frac{n \bar{p}}{n}=\bar{p} \\
\operatorname{Var}(Q) & =\operatorname{Var}(Y / n)==\frac{1}{n^{2}} \operatorname{Var}(Y) \\
& =\frac{n \bar{p}(1-\bar{p})}{n^{2}} \\
& =\frac{\bar{p}(1-\bar{p})}{n}
\end{aligned}
$$

Note that $Q=Y / n$ is the ratio between number of failures and $\mathrm{n}$. Then $Q=P_{f}$ defined by Eq. 8.28 . 
Appendix E

NOTATIONS

$$
\begin{aligned}
& \mathrm{a}, \mathrm{b}, \mathrm{c}=\text { dimensions } \\
& \mathrm{b}=\text { width of a catchment } \\
& \mathrm{B}=\text { unsaturated flow parameter } \\
& c_{i}=\text { certainty of slide } F_{i} \\
& \mathrm{C}=\text { specific yield } \\
& \mathrm{c.o.v} .=\text { coefficient of variation } \\
& c=\text { soil cohesion } \\
& c_{r}=\text { tree root strength expressed as cohesion } \\
& \mathrm{D}=\text { duration } \\
& \mathrm{DEM}=\text { Digital Elevation Model } \\
& D_{s}=\text { coefficient of diffusivity } \\
& \mathrm{E}(.)=\text { expected value }=\text { mean } \\
& E_{e q}=\text { equilibrium evapotranspiration } \\
& E_{e}=\text { evapotranspiration parameter } \\
& F_{s}=\text { landslide number } \mathrm{i} \\
& \mathrm{F}
\end{aligned}
$$


f = probability density function

g = gravitational acceleration

$\mathrm{H}=$ soil thickness

$H_{s}, H_{t}=$ soil thicknesses for the 2-D model, Fig. A.1b

$h_{c}=$ critical depth of groundwater

$h_{o}=$ depth of groundwater at exit

$h_{w}=$ depth of groundwater

$h_{w} / H=\mathrm{Z}=$ peak groundwater-depth ratio

$i=$ infiltration rate $(L / T)$

$i_{s}=$ rate of water input to saturated zone from unsaturated zone.

I = total amount of infiltration ( snowmelt + rain)

$I_{g}=$ hydraulic gradient

$J_{x}=$ sensitivity of $F_{s}$ to variable $\mathrm{x}=\frac{\partial F_{s}}{\partial x}$

$\mathrm{K}=$ coefficient of permeability

$K_{s}=$ coefficient of permeability at saturation.

$K_{i}=$ coefficient of permeability of porous inclusion

$K_{p}=$ equivalent coefficient of permeability of layered system.

$K_{f}=$ equivalent coefficient of permeability of fracture system

$K_{m}=$ coefficient of permeability of infilling material of infilled fissure system

$K_{r}=$ coefficient of permeability of intact rock

L = slope length

$M=$ snowmelt

$M_{r}=$ safety margin

$M_{T}=$ potential snowmelt 
$\mathrm{n}$ = number of pixel within a polygon

$\mathrm{N}=$ model error

$\mathbf{P}()=$. probability

$\mathrm{p}=$ probability mass function

$p_{f}=$ probability of failure

$q_{o}=$ tree surcharge

$\mathrm{q}$ = drainage in Reddi's model (1988)

$Q_{f}=$ recharge through fracture

$Q_{r}=$ rainfall recharge

$\bar{p}, \dot{p}=$ mean and variance of fraction of state 2 in a domain $l$

$R=$ rainfall $(L)$

S = snow-water equivalent (L)

$S_{d}=$ drainable volume of water in Reddi's model(1988) = storage capacity

$T_{a}=$ air temperature

$t_{\mathrm{o}}=$ return period

$x_{1} \& x_{2}=$ variables

$t$ = time

$u=$ augmented vector

$u_{o}=$ mean value of the augmented vector $\mathrm{u}$

$v_{i}=$ downward moisture flux at zone $\mathrm{i}$

$\operatorname{Var}(x)=$ variance of $x$

$\mathrm{W}=$ degree of saturation $=\theta / \theta$,

$\alpha=$ slope angle

$\alpha_{e}=$ evapotranspiration coefficient 
$\beta=$ catchment closing angle

$\beta_{r}=$ reliability index

$\eta=$ kinematic viscosity

$\eta_{i}=$ correction factor for groundwater zone, i, Table 5.1

$\gamma=$ transversal slope

$\gamma_{d}=$ dry soil unit weight

$\gamma_{\text {sat }}=$ saturated soil unit weight

$\gamma_{w}=$ water unit weight

$\gamma_{\text {wet }}=$ moist soil unit weight

$\Gamma^{2}(t)=$ variance function (Vanmarcke, 1983)

$v_{i}=$ activity type $\mathrm{i}$

$\theta=$ volumetric water content

$\theta_{d}=$ drainable porosity

$\theta_{s}=$ saturated water content

$\phi^{\prime}=$ effective angle of internal friction

$\rho(t)=$ correlation function, (Vanmarcke, 1983)

$\sigma=$ standard deviation

$\Sigma_{u}=$ variance matrix of the augmented vector $u$

$\Sigma_{u 1}=$ systematic variance matrix of the vector $u$

$\Sigma_{u 2}=$ random variation matrix of the vector $\mathrm{u}$

$\Sigma_{u 3}=$ occurrence variance matrix of the vector $u$

$\Sigma_{\phi c}=$ covariance between $\phi^{\prime}$ and $c^{\prime}$

$\Psi=$ suction

$\psi_{s}=$ suction at saturation 
$\Psi=$ prior variance matrix

$\Omega=$ observation uncertainty

$\Delta_{s}=$ systematic coefficient of variation

$\Delta=$ point coefficient of variation

$\Delta_{o}=$ occurrence coefficient of variation

$\Delta_{l}=$ total c.o.v. of spatial average over a domain $l$

$\delta=$ correlation distance, Vanmarcke (1983)

$\beta_{s}=\frac{\bar{x}_{1}}{\bar{x}_{2}}=$ ratio between the mean of property of soil 1 and soil 2, Tang et al. (1989)

$\alpha_{s}=\frac{\mu_{2}}{\mu_{1}}=$ ratio of the mean duration of state 1 and state 2 , Tang et al. (1989) 


\section{BIBLIOGRAPHY}

1. Abdul, A.S. and Gillham, R.W. (1984) "Laboratory studies of the effects of the capillary fringe on streamflow generation", Wat. Res. Res., Vol. 20, pp. 691-698.

2. Abramento, M. and Carvalho, C. S. (1989) "Geotechnical parameters for the study of natural slopes instabilization at 'Serra do Mar'", ICSMFE, 12, Rio de Janeiro, Proc.

3. Alger, C. S and Ellen, S. D. (1987) "Zero-order basins shaped by debris flows, Sunol, California, USA", IAHS Publ. No. 165, pp 111-119

4. Ali, E.M., Wu, T.H. and Chang, N-Y (1980) "Stochastic model of flow through stratified soils", J. of Geotechnical engineering division, ASCE, Vol. 106, No. Gt 6, pp. 593-610.

5. Ang, A.H. (1973) "Structural risk analysis and reliability-based design", ASCE, J.Struct. Div. 99(ST9), pp. 1891-1910.

6. Ang, A.H. and Cornell, C.A. (1974) "Reliability bases of structural safety and design", Journal of Structural Division, ASCE, Vol. 100, No. ST9, pp. 1755-1769.

7. Ang, A.H. and Tang, W.H. (1975) "Probability concepts in Engineering planning and design; Volume I: basic principles", John Wiley \& Sons Inc.

8. Ang, A.H. and Tang, W.H. (1984) "Probability concepts in Engineering planning and design; Volume II: Decision, risk, and, reliability", John Wiley \& Sons Inc.

9. Anagnosti, P. (1969) "Three-dimensional stability of fill dams", Proc. 7th Int. Conf. Soil and Foundation Engrg., Vol. 2, 275-280.

10. Ahnert, F. (1984) "Local Relief and the Height Limits of Mountain Ranges", American Journal of Science, Vol. 284, P. 1035-1055

11. Alonso, E.E. (1975) "Stochastic formulation of soil properties", Proc. 2nd Int. Conf. Application of Statistics and Probability in Soil and Structural Engineering, Aachen, 9-32.

12. Alonso, E.E. (1976) "Risk analysis of slopes and its application to slopes in Canadian sensitive clays", Geotechnique Vol. 26, No. 3, pp. 453-472.

13. Atkinson, T.C. (1978) "Techniques for measuring subsurface flow on hillslopes" in Kirkby, M. J. (ed.), Hillslope Hydrology, Chichester, Wiley, 73-120. 
14. Bakr, A. A., Gelhar, L.W., Gutjahr, A.L. and MacMillan, J.R. (1978) "Stochastic analysis of spatial variability in subsurface flows, 1 . comparison of one and three dimensional flows", Water Resources Research, Vol. 14, No. 2, pp. 263-271.

15. Baligh, M. M. and Azzouz, A. S. (1975) "End effects on stability of cohesive slopes", Journal of the geotechnical Engineering division, ASCE, Vol. 101, No. GT11, Proc. Paper, 11705, pp. 1105-1117.

16. Bear, J. (1972) "Dynamics of fluids in porous media", American Elsevier Environmental Science Series, N.Y.

17. Beneventi, S., Cecere, V., Fioresi, G., Ricciardi, C. and Sciotti, M. (1989) " Stability condition in the Larderello area (Italy)", ICSMFE, 12., Rio de Janeiro, Proc.

18. Benjamin, J. R. and Cornell, C. A. (1970) "Probability, Statistics, and Decision for Civil Engineers", McGraw-Hill Book Co., Inc., New York, N.Y.

19. Benosky, C.P. (1992) "Spatial analysis techniques for the automated extraction of watershed characteristics", MS Thesis, the Ohio State University, Columbus, $\mathrm{OH}$.

20. Beven, K. (1981) "Kinematic Subsurface Stormflow", WRR, Vol. 17, pp. 1419-1424.

21. Beven, K. and Germann, P. (1982) "Macropores and water flow in soils", WRR, Vol. 18, No. 5, pp 1311-1325.

22. Beven, K. (1982) "On Subsurface Storm Flow: Prediction with Simple a Kinematic Theory for Saturated and Unsaturated Flows", Water Res. Res., Vol. 18, No. 6, pp. 1627-1633.

23. Bergado, D.T. and Anderson, L.R. (1985) "Stochastic analysis of pore pressure uncertainty for the probabilistic assessment of safety of earth slopes", Soils and Foundations, Vol. 25,(2), pp. 87-105.

24. Binley, A., Elgy, J. and Beven, K (1989) "A physically based model of heterogeneous hillslopes, 1. Runoff production", Wat. Res. Res., Vol. 25, No. 6, pp. 1219-1226.

25. Bishop, A.W. and Henkel, D.J. (1962) "Measurement of soil properties in the triaxial test", Edward Arnold Ltd., London.

26. Bishop, A.W. and Morgenstern, N. (1960) "Stability coefficients for earth slopes", Geotechnique, Vol. 10, No. 4, pp 129-150.

27. Bjerrum, L. and Simons, N.E. (1960) "Comparison of shear strength characteristics of normally consolidated clays", In: Research conference on shear strength of cohesive soils: 1960 June 13-17; Boulder, Co. New York: ASCE: 711-726

28. Bjerrum, L. (1966) "Mechanism of progressive failure in slopes of overconsolidated plastic clays and clay shales", The Third Terzaghi Lecture, ASCE Structural Engineering Conference, Miami, Fla. 
29. Bouma, A.1., Monnies, T.h. and Vrouwenvelder, A. (1979) "Probabilistic reliability analysis", Proc. of Second Int. Conf. on Behavior of Offshore Structures, 521-542.

30. Bouma, J. and Anderson J. L. (1973) "Relationships between soil structure characteristics and hydraulic conductivity, Field Soil Water Regime", Spec. Publ. Soil Sci. Soc. Am., 5, 77-105,1973.

31. Bouma, J. (1981) "Soil morphology and preferential flow along macropores", Agric. Water Manage., Vol. 3, pp. 235-250.

32. Black, T.A. (1979) "Evapotranspiration from Douglas fir stands exposed to soil water deficits", Water Resources Research, 15, 164-170.

33. Brackley, I.J.A., Philotheou, P. and Terbrugge, P.J. (1989) "Assessment of risk for road widened over unstable mock slope", ICSMFE, 12, Rio de Janeiro, Proc.

34. Brand, E.W. (1981) "Some thoughts on rain-induced slope failures", ICSMFE, 10., Stockholm. Proc. 373-376.

35. Bresler, E., Bielorai, H., and Laufer, A. (1979) "Field test of solution flow models in heterogeneous irrigated cropped soil", WRR, 15(3) pp 645-652.

36. Braun, D. D., Gillmeister, N. M. and Inners, J. D. (1989) "Post-glacial to historic dipslope rock block slides in the valley and ridge province of northeastern Pennsylvania", The Geological Society of America, Special papers 236.

37. Brunengo, M.J. (1991) "Landslide inventory", Glenoma and Mineral quadrangle, Washington state.

38. Brunengo, M.J. (1989) "Output data on precipitation, snow and storm weather", west central Cascade Range, Washington.

39. Burrough, P.A. (1986) "Principles of geographical information systems for land resources assessment", Oxford; Clarendon Press; New York.

40. Caine, N. (1980) "The rainfall intensity-duration control of shallow landslides and debris flows", Geografiska annaler, 62A, P. 23-27.

41. Campbell, R. H. (1975) "Soil Slips, debris flows, and rainstorms in Santa Monica Mountains and vicinity, Southern California", U. S. Geological Survey Professional paper $851,51 \mathrm{p}$.

42. Campbell, R.H., Varnes, D.J., Fleming, R.W., Hampton, M.H., Prior, D.B., Sangrey, D.A. and Nichols, D.R. (1985) "Landslide classification for identification of mud flows and other landslides" in Campbell, R.H., ed., Feasibility of nationwide program for identification of hazards from mud flows and other landslides: U.S. Geological Survey Open-File report 85-276, p. A1-A24.

43. Cannon, S. H. and Ellen, S. (1985) "Rainfall conditions for abundant debris avalanches, San Francisco bay, California", California Geology, Vol. 38, no. 12, p. 267-272 
44. Casagrande, A. (1965) "Role of the calculated risk in earthwork and foundation engineering", journal of the soil mechanics and foundations division, ASCE, Vol. 91, No. SM4, pp. 1-40.

45. Cherubini, C., Cotechia, V., Renna, G. and Schiraldi, B (1983) "The use of bivariate probability density function in Monte Carlo simulation of slope stability in soils", In Proceedings, 4th international conference on applications of statistics and probability in soil and structural engineering; Pitagora, France: 1401-1411

46. Chen, R.H. and Chameau, J.L. (1982) "Three-dimensional limit equilibrium analysis of slopes" Geotechnique, Vol. 33(1), pp.31-40.

47. Chow, V.T. (1964) "Handbook of applied hydrology", Mcgraw-hill

48. Chowdhury, R.N. (1978) "Slope analysis", Elsevier Scientific Publication Company, Amsterdam-Oxford-New York.

49. Chowdhury, R. N. and Tang, W. H. and Sidi (1987) "Reliability model of progressive slope failure", Geotechnique, Vol., 37(4), pp. 467-481.

50. Chowdhury, R. N. and Tang, W. H. (1987) "Comparison of risk models for slopes", Proceedings of the 5th International conference on applications of statistics and probability to soil and structural engineering, Vancouver, pp. 863-869.

51. Childs, E. C. (1971) "Drainage of groundwater resting on a sloping bed", Water Resour. Res., Vol. 7, No. 5, pp. 1256-1263.

52. Clapp, R.B. and Horenberger, G. M. (1978) "Empirical equations for some soil hydraulic properties", Water Resources Research, 14(4), 601-604.

53. Clough, R. N. and Woodward, R. J. (1967), "Analysis of embankment stresses and deformation", journal of the soil mechanics and foundations division, ASCE, Vol. 93, No. SM4, pp. 529-549.

54. Corotis, R. B., Azzouz, A. S. and Krizek, R.J. (1975) "Statistical evaluation of soil index properties and constrained modulus", Proceedings of the 2 nd international conference on applications of statistics and probability to soil and structural engineering, Achen, pp. 273-293.

55. Cornell, C.A. (1971) "First-order uncertainty analysis of soil deformation and stability", Proc. Int. Conf. on application of statistics and probability to soil and structural engineering, Hong Kong.

56. Costa, A. J., Cout, A.M., Fernandes, C.E. and Craizer, W. (1989) "Intense rainstorms and ground slides", ICSMFE, 12., Rio de Janiero, Proc.

57. Cividini, A., Maier, G. and Nappi, A. (1983) "Parameter estimation of a static geotechnical model using a Bayes' approach", J. Rock Mech Sci. \& Geomech Abstr. Vol. 20 No. 5 pp. 215-226. 
58. Cramer, H. (1964) "Mathematical Methods of Statistics", Princeton Univ. Press, Princeton, $\mathrm{NJ}$.

59. Dagan, G. (1979) "Models of groundwater flow in statistically homogeneous porous formations", Water Res. Res., Vol. 15, No. 1, pp. 47-63.

60. Dakhly, A.H. (1989) "Reliability analysis of slopes subjected to progressive failure", thesis presented in the partial fulfillment for the degree of doctor of philosophy, Cairo University

61. David, M. (1977) "Geostatistical ore reserve estimation", In: Developments in Geomathematics, Vol. 2, Elsevier, Amsterdam.

62. Dietrich, W. E., Reneau, S. L. and Wilson, C. J. (1987) "Overview; "Zero-order basins" and problems of drainage density, sediment transport, and hillslope morphology; Erosion and sedimentation in the Pacific rim, Proceeding of the Corvallis Symposium", August 1987: Inter. Assoc. of Hydro. Sciences Pub. 165, p. 27-37.

63. Dunne, T. (1978) "Field studies of Hillslope flow processes", In: Hillslope Hydrology, edited by M. J. Kirkby, Wiley-interscience, New York, pp. 227-293.

64. Duncan, J.M. (1974) "Practical uses of the finite element method in geotechnical engineering", soil mechanics lecture series, Computer applications in foundation engineering and construction, Northwestern university, Evanston, Illinois, pp. 10-43.

65. Duncan, J.M. and Houston, W.N. (1983) "Estimating failure probabilities for California levees", Jour. of Geotech. Engrg., Vol. 109, No. 2, pp. 260-268.

66. Dunlop, P. and Duncan, J.M. (1970) "Development of failure around excavated slopes", Journal of the soil mechanics and foundation division, ASCE, Vol. 96, No. SM2, pp. 471-493.

67. Durgin, p. (1984) "Subsurface drainage erodes forested granitic terrene", Physical geography 4 (1), 24-39

68. Durlofsky, L.J. (1991) "Numerical calculation of equivalent grid block permeability tensors for heterogeneous porous media", Wat. Res. Res. Vol. 27, No. 5, pp. 699.

69. Dutton, G.H. (1981) "Fractal enhancement of cartographic line detail", Amer. Cartog., V. 8, p. 23-40.

70. Eagleson, P.S. (1978) "Climate, soil vegetation, parts 3 and 4", Water Resources Research, Vol. 14, pp.731-739 741-748.

71. Eckis, R. P. (1934) "South Coastal basin investigation, Geology and groundwater storage capacity of valley fill, California", Div., Wat. Res. Bull. 45.

72. Einstein, H. (1988) "Landslide risk assessment procedure", Fifth International Symposium on Landslide, Lausanne. 
73. Evans, I.S. (1980) "An integrated system of terrain analysis and slope mapping", Z. Geomorphol. Suppl., 36, 274-95.

74. Farmer, J.D. and Ott, E. (1983) "The dimension of Chaotic attractors", Physica D; Nonlinear Phenomena, Amesterdam, Netherlands, 7(3), 153-180.

75. Fellenius, W. (1936) "Calculation of the stability of earth dams", Transactions, 2nd Congress on Large Dams, Vol. 4, Washington, D.C.

76. Folayan, J.I. and Hoeg, K. and Benjamin, J.R. (1970) "Decision theory applied to settlement predictions", J. soil Mech. \& Found. Div., ASCE, Vol. 96, No. SM4.

77. Fredlund, D.G. Krahan, J. and Rufahl, D.E. (1981) "The relationship between limit equilibrium slope stability methods", Proceedings of the 10th international conference on soil mechanics and foundation engineering, Stockholm, pp. 409-416.

78. Fredlund, D. G. (1987) "Slope stability analysis incorporating the effect of soil suction", In: Anderson, M.G.; Richards, K.S., eds. Slope stability, New York: John Wiley and Sons:113-144.

79. Freeze, R. A. (1971) "Three-dimensional, transient saturated- unsaturated flow in groundwater basin", Water Resour. Res., 7(2), 347-366.

80. Freeze, R. A. (1975) "A Stochastic-Conceptual analysis of one-dimensional groundwater flow in nonuniform homogeneous media", Water Res. Res. Vol. 11, p. 725-741.

81. Freeze, R. A. (1977) "Probabilistic one-dimensional consolidation", Jour. of Geotech. Engrg., ASCE, Vol. 103, No. GT7, pp. 725-742.

82. Freeze, R. A. and Cherry D.A. (1979) "Groundwater", Prentic-Hall, Englewood Cliffs, New Jersey, 604 pp.

83. Freeze, R. A. (1980) "A Stochastic-Conceptual Analysis of Rainfall-Runoff Processes on a Hillslope", Water Res. Res., Vol. 16, No. 2, p. 391-408

84. Freudenthal, A.M., Garrelt, J.M. and Shinozuka, M. (1966) "The analysis of structural safety", Journal of structural division, ASCE, Vol. 92, No. st1.

85. Gelhar, L.W., Wilson, J.L. and Gutjahr, A.L. (1979) "Comment on simulation of groundwater flow and mass transport under uncertainty", Adv. Water Resour., Vol. 2

86. Goldsmith, P.R. and Smith, E.H. (1985) "Tunnelling soils in south Auckland", New zealand. Engineering Geology 22 (1), 1-11.

87. Goodchild, M.F. (1980) "Fractal and accuracy of geographical measures", Math. Geol. V. 12, p. 85-98.

88. Goodchild, M.F. (1982) "The fractional brownian process as a terrain simulation model", Proceeding Thirteenth Annual Pittsburg Conference on modelling and simulation, V. 13, p. 1133-1137. 
89. Goodchild, M.F. and Mark, D. M. (1987) "The Fractal Nature of Geographic Phenomena", The Association of American Geographers 77(2) pp. 265-278.

90. Goughnour, R.D. and Sallberg, J.R. (1964) "Evaluation of the laboratory vane shear test", Highway Research Record, No. 48, Highway Research Board, p. 27.

91. Gryta, J.J. and Bartholomew, M. J. (1989) "Factors influencing the distribution of debris avalanches associated with the 1969 hurricane Camille in Nelson County, Virginia", Geological Society of America, Special papers; 236.

92. Gray, D.H. and Leiser, A.T. (1982) "Biotechnical slope protection and erosion control", New York: Van Nostrand Reinhold. 279 p.

93. Gray, D.H. and Magahan, W. F. (1981) "Forest vegetation removal and slope stability in Idaho batholith", Res. Pap. INT-271. Ogden, UT:U.S. Department of Agricultural. Forest Service, International Forest and Range Experiment Station, 23 p.

94. Greenway, D.R. (1987) "Vegetation and slope stability", In: Anderson, M.G., and Richards, K.S., eds. Slope stability, New York: John Wiley and Sons: 187-230.

95. Gutjahr, A.L., Gelhar, L.W., Bakr, A.A. and MacMillan, J.R. (1978) "Stochastic analysis of spatial variability in subsurface flows, 2.Evaluation and application", Water Res. Res., Vol. 14(5), pp. 953-959.

96. Hammond, C., Hall, D., Miller, S. and Swetik, Pl (1991) "Level I Stability Analysis (LISA)", General Tech. Rep. INT-000 International research Sta., Forest Service, USDA, Moscow, ID

97. Hansen, J.B. (1967) "The philosophy of foundation design; design criteria, safety factors and settlement limits. Symp. Bearing Capacity and Settlement of Foundations", Duke University, North Carolina, 9-13.

98. Harr, M. E. (1977) "Mechanics of particulate media-a probabilistic approach", New York, McGraw-Hill

99. Harr, R. D. and Yee, C. S. (1975) "Soil and hydraulic factors affecting the stability of natural slopes in the Oregon Coast Range", Water Resources Research Institute, Oregon State University, WRRI-33, 204 p. 1975.

100. Hasofer, A.M. and Lind, N. (1974) "An exact and invariant first-order reliability format", J. Engrg. Mech., ASCE, Vol. 100(1), pp. 111-121.

101. Henderson, F.M. and Wooding, R.A. (1964) "Overland Flow and groundwater flow from a steady rainfall of finite duration", J. of Geophys. Res., Vol. 69, pp. 1531-1540.

102. Hewitt, A.E. and Van Wambeke A. (1985) "The error taxadjunct and its application in soil taxonomy assignment", Soil Science Society of America Journal, 49, pp 952-956.

103. Hillel, D. (1982) "Introduction to soil physics", Academic press, New York, 364 pp. 
104. Hovland, H. J. (1989) "The 1984 Caribou landslide", ICSMFE, 12., Rio de Janiero, Proc.

105. Hoeg, K. and Tang, W.T. (1977) "Probabilistic considerations in the foundation engineering for offshore structures", Proceedings, Second international conference on structural safety and reliability, Munich, pp. 267-296.

106. Hoek, E. and Bray, J.W. (1981) "Rock slope engineering", The institution of mining and metallurgy, London, England.

107. Holtan, H.N., England, C.B., Lawless, G.P. and Schumaker, G.A. (1968) "Moisture tension data for selected soils on experimental watersheds", ARS 41-144. 609 PP., Agr. Res. Serv., Beltsville, Md.

108. Holtz, W. G. and Gibbs, H. J. (1956) "Triaxial shear tests of pervious gravelly soils" ASCE, Jour. of Soil Mech. and Foundation Div. 82 (SM1): paper 867.

109. Horn, B.K P. (1981) "Hill shading and the reflectance map" Proc. IEEE 69(1), 14-47.

110. Horton, R.E. (1933) "The role of infiltration in the hydrologic cycle", Eos Trans. AGU, $14,446-460$.

111. Horton, R.E. (1945) "Erosional development of streams and their drainage basins; hydrophysical approach to quantitative morphology", Bulletin of the Geological Society of America 56:275-370

112. Huang, Y.H. (1975) "Stability charts for earth embankments, Transportation research record 548", Transportation research board, Washington, D.C., pp. 1-12.

113. Huitt, J.L. (1956) "Fluid flow in simulated fracture", Journal American Inst. Chemical Eng. Vol. 2, 1956, p. 259-264

114. Ice, G.G. (1985) "Catalog of landslide inventories for the northwest", National Council of the Paper Industry for air and Stream Improvement, Inc. (NCAST) Tec. Bulletin 456.

115. Iverson, G. (1984) "Bayesian statistical inference" Sage Publications.

116. Janbu, N. (1954) "application of composite slip surfaces for stability analysis", Proceeding of the European conference on stability of earth slopes, Stockholm, Vol. 3, pp. 43-49.

117. Janbu, N. (1973) "slope stability computation, Embankment-Dam engineering", Casagrande volume, edited by R. C. Hirschfeld, and S. J. Poulos, John Wiley \& Sons, In. New York, pp. 47-86.

118. Jenson, S.K. and Dominique, J.O. (1988) "Extracting Topographic Structure from Digital Elevation Model Data for geographic information system analysis", Photogrametric Engineering and Remote sensing, Vol. 54, pp. 1593-1600

119. Jacobson, R. B., Cron, E. D. and McGeehin, J. P. (1989) "Slope movements triggered by heavy rainfall, November 3-5, 1985, in Virginia and West Virginia, U.S.A.", The Geological Society of America, Special Papers; 236. 
120. Jibson, R. W. (1989) "Debris flows in southern Puerto Rico", The Geological Society of America, Special papers; 236.

121. Johnson, K. A. and Sitar, N. (1989) "Significance of transient pore pressures and local slope conditions in debris flow initiation", ICSMFE., 12., Rio de Janiero.

122. Johnson, K. A. and Sitar, N. (1987) "Debris flow initiation: an investigation of mechanisms", Report No. UCB/GT/87-02

123. Johnson, K. H. (1977) "A Predictive Method for Groundwater Levels", M.S. Thesis, Cornell University, Ithaca, New York.

124. Journel, A.G. and Huijbregts, Ch. J. (1978) "Mining Geostatistics", Academic Press, London.

125. Kaufmann, A. (1968) "The science of decision-making", Mcgraw-Hill, New York.

126. Khalil-Naghadeh, N. and Valliappan, S. (1991) "Flow through porous media with deformable matrix: implicit formulation", Wat. Res. Res. Vol. 27, No. 7, pp 1703-1709.

127. Khallel, R. (1992) "Equivalent porosity estimates for colonnade networks", Wat. Res. Res., Vol. 28, No. 10, pp. 2783.

128. Kirkby, M.J. and Chorley, R.J. (1967) "Throughflow, overland flow, and erosion", Int. Assoc. Scientific Hydro. Bull. 12, 5-21.

129. Kirkham, D. (1947) "Studies of hillslope seepage in the Iowan drift area", Proceedings of the soil science society of America, Vol. 12.

130. Kochel, R.C. (1987) "Holocene debris flows in central Verginia", in Costa, J.E. and Wieczorek, G. F., eds., Debris flows/avalanches; process, recognition, and mitigation: Geological Society of America reviews in Engineering geology, V. 7, p. 139-155.

131. Kochel. R.C., Johnson, R. A. and Wayland, R. J. (1981) "Geomorphic evidence for multiple episodes of debris avalanching in central Virginia", Virginia Journal of Science, v. 32, p. 127.

132. Krahn, J. and Fredlund, D. G. (1983) "Variability of engineering properties of natural deposits", In Proceedings, 4th international conference on applications of statistics and probability in soil and structural engineering, 1983 June 13-17; Universita di Firenze, Italy: 1017-1029

133. Kulatilake, P.H. and Miller, K.M. (1987) "A Scheme for estimating the spatial variation of soil properties in three dimensions", Proceedings of the 5th international conference on applications of statistics and probability to soil and structural engineering, Vancouver, pp. 669-677.

134. Lambe, T.W. (1967) "Stress path method", Journal of the Soil Mechanics and Foundations Division, ASCE, Vol. 93, No. SM6, p. 309-332. 
135. Lambe, P.C., Silva, F., Marr, W.A. and Lambe, T.W. (1989) "Instability of natural slopes in Puerto Rico", ICSMFE, 12., Rio de Janiero, Proc.

136. Lambe, T.W. and Whitman, R.V. (1969) "Soil Mechanics", John Wiley \& Sons, Inc., New York.

137. Lee, I.M. (1986) "A probabilistic prediction of porewater conditions for unsteady groundwater flow on sloping bed", Ph.D. dissertation, the Ohio State University, Columbus, $\mathrm{OH}$.

138. Lee, I.M. and Wu, T.H. (1987) "Groundwater fluctuations in hillside slopes", Proceedings of 5 th International Conference on Applications of statistics and probability in soil and structural engineering, Vol. 2, p. 694-701.

139. Leshchinsky, D., Baker, R. and Sliver, M.L. (1985) "Three-dimensional analysis of slope stability", Int. J. Num. and Anal. Meth. in Geomech., Vol. (14), pp. 429-439.

140. Li, K.S. and Lumb, P. (1987) "Probabilistic design of slopes", Canadian Geotech., Vol. 24(4), pp. 520-535.

141. Linsley, R.K., Kohler, M.A., and Paulhus, J.L.H., 1982. "Hydrology for Engineers", Third Edition, McGraw-Hill book

142. Louis, C. (1967) "A study of groundwater flow in jointed rock and its influence on the stability of rock masses", Doctorate Thesis, University of Karlsruhe, 1967, (in german). English translation Imperial college Rock Mech. Res.report No. 10, sept. 1969. 90 page.

143. Luxmoore, R.J. (1981) "Micro-, meso-, and macroporosity of soil", Sci. Soc. Am. J., $45,671,1981$.

144. Lumb, P. (1974) "Application of statistics in soil mechanics", Soil mechanics-New Horizons, Butterworth\&Co., London, England, pp. 44-111.

145. Lumb, P. (1975) "Spatial variability of soil properties", In Proceedings, 2nd international conference on applications of statistics and probability in soil and structural engineering: pp. 397-421.

146. Lumb, P. (1970) "Safety factors and the probability distribution of soil strength", Canadian Geotechnical Journal, 7(3), pp. 225-242.

147. Lumb, P. (1966) "The variability of natural soils", Canadian Geotechnical Journal, 3(2): pp. 74-97.

148. Lyytik Ainen, H.E. (1986) "Stereological criteria for primary topographic contour", Finnish Society for Surveying Sciences, Publication Nr. 2, 156.

149. Mark, D. M. and Aronson, P.B. (1985) "Scale dependent fractal dimensions of topographic surfaces: an empirical investigation, with applications in geomorphology and computer mapping", Mathematical Geology, 16(7), 671-683. 
150. Marks, D., Dozier, J. and Frew, J. (1984) "Automated Basin Delineation from Digital Elevation Data", Geo-Processing, Vol. 2, pp. 299-311.

151. Martz and Waller (1982) "Bayesian reliability analysis", John Wiley \& Sons.

152. Matsuo, M. and Kuroda, K. (1974) "Probabilistic approach to design of embankments, Soil and foundations", Transactions of JSCE, Vol. 14, No. 2, pp. 1-17.

153. McDonnell, J. J. (1989) "The age, origin and pathway of subsurface stormflow in a steep, humid headwater catchment", Ph.D. thesis, Univ. of Canterbury, Christchurch, N.Z., 270 p.

154. McDonnell, J. J. (1990) "The influence of macropores on debris flow initiation", Q. J. Eng. Geol.

155. McDonnell, J. J. (1990) "A Rationale for Old Water Discharge Through Macropore in a steep, Humid Catchment", Water Res. Res. Vol. 26, No. 11 pp 2821-2832.

156. Mandelbort, B.B. (1967) "How long is the coast of Britain? Statistical self-similarity and fractional dimension", Science, V. 156, P. 636-638.

157. Mandelbort, B.B. (1977) "Fractals: form, chance, and dimension", Freeman, San Francisco, 365p.

158. Mark, D.M. and Aronson, P.B. (1984) "Scale-Dependent Fractal Dimensions of Topographic Surface: An Empirical Investigation, with Application in Geomorphology and Computer Mapping", Mathematical Geology Vol. 16 No. 7, 1984

159. Mayerhof, G.G. (1970) "Safety factors and probability distributions of soil strengths", Canadian Geotechnical journal, Vol. 7, No. 3.

160. Morgenstern, N.R. (1963) "Stability charts for earth slopes during rapid drawdown", Geotechnique, Vol. 13, No. 2, pp. 121-131.

161. Morgenstern, N.R. and Price, V.E. (1965) "The analysis of the stability of general slip surfaces", Geotechnique, Vol. 15, No. 1, pp. 79-93.

162. Morse and Thornburn (1961) "Reliability of soil map unit", 5th I.C.S.M.\&F.E., pp. 259-262.

163. Musiake, K., Yasumiti, O. and Masahiro, K. (1988) "Unsaturated zone soil moisture behavior under temperature humid climatic conditions - tensiometric observations and numerical simulations", Journal of Hydrology, 102, pp. 179-200.

164. Nieber, J. L. (1982) "Hillslope Soil Moisture Flow: Approximation by a onedimensional formulation", Pap. Am. Soc. Agric. Eng., 82-2026, pp. 1-28.

165. Nieber, J. L., and Walter, M. F. (1981) "Two-dimensional Soil Moisture Flow in Sloping Rectangular Region: Experimental and Numerical Studies", Water Res. Res., Vol. 17 , pp. 1722-1730. 
166. Nitao, J.J. and Buscheck (1991) "Infiltration of liquid front in an unsaturated fractured porous medium", Wat. Res. Res., Vol, 27, No. 8, pp. 2099-2112.

167. O'Callaghan, J.F. and Mark D.M. (1984) "The extraction of drainage network from Digital Elevation data" Computer vision, Graphic and Image Processing, Vol. 28, pp. 323-344.

168. Oboni, F. and Bourdeau, P. L. (1983) "Determination of the critical slip surface in stability problem", In: Proceedings, 4th international conference on applications of statistics and probability in soil and structural engineering, 1983 June 13-17: Universita di Firenze, Italy.

169. Ogawa, S. and Kawamura, K. (1989) "Topographical consideration for landslide prediction", ICSMFE, 12., Rio de Janeiro. Proc.

170. O'Loughlin, C.L. and Ziemer, R.R. (1982) "The importance of root strength and deterioration rates upon edaphic stability in steepland forests", In: P.I. 07-00 Ecology of subalpine Zones. Proceedings of an IUFRO workshop, Corvallis, OR, Forest research laboratory, updaon State University: 70-78.

171. O'Loughlin, E.M. (1986) "Prediction of Surface Saturation Zones in Natural Catchments By Topographic Analysis", Water Res. Res., Vol. 22 No. 5, p. 794-804.

172. Oka, Y. and Wu, T.H. (1990) "System Reliability of slope stability", ASCE, Jour. of Geotech. Engrg., Vol. 116, No. 8.

173. Papantnopoulos, C.I. (1979) "An Information theory approach to slope stability", Proceedings of the 3rd International Conference on applications of Statistics and Probability to soil and structural engineering, Sydney, pp. 466-476.

174. Peck, R. B. (1967) "Stability of natural slopes", Journal of soil mechanics and foundation division, ASCE, Vol. 93, No. SM4, Proc. Paper 5323 pp. $403=417$.

175. Peatross, J. L. (1986) "A morphometric study of slope stability controls in central Virginia", M.S. thesis: Charlottesville, University of Virginia, 150 p.

176. Peucker, T.K., Little, J.J. and Mark, D.M. (1978) "The triangulated irregular network", In Proc. of the DTM Symp., American Society of Photogrammetry-American Congress on survey and mapping, St Louis, Missouri, pp. 24-31.

177. Peucker, T.K. and Douglas, D.H. (1975) "Detection of surface specific point by local parallel", processing of discrete terrain elevation data. Computer Graphic and Image Processing, Vol. 4, pp. 375-387.

178. Philip, J.R. (1957) "The theory of infiltration: 4. Sorptivity and algebraic infiltration equations", Soil Science, Vol. 84, pp. 257-264.

179. Prellwitz, R.W. (1981) "Forest Service Handbook 7709.11" In: Transportation Engineering Handbook, Region 1, supplement 11, Chapter 60, Foundation engineering, U.S. Department of Agriculture, Forest Service. 
180. Prellwitz, R.W., Howard, T.R. and Wilson, W.D. (1983) "Landslide analysis concepts for management of forest lands on residual and colluvial soils", Transportation Research Record 919, 27-36.

181. Rackwitz, R. (1976) "Practical probabilistic approach to design", Bulletin 112, Comite European du Beton, Paris, France.

182. Rasmussen, WR. (1991) "Steady fluid flow and travel times in partially saturated fractures using a discrete air-water interface", Wat. Res. Res., Vol. 27, No. 1, pp. 67.

183. Reddi, L.N. (1988) "Probabilistic analysis of groundwater levels in hillside slopes", Ph.D. dissertation, The Ohio State University Columbus, $\mathrm{OH}$.

184. Reddi, L.N. and Wu, T.H. (1991) "Probabilistic Analysis of Ground-Water Levels in Hillside Slopes", Journal of Geotechnical Engineering, ASCE, Vol. 117 pp. 872-890.

185. Reneau, S.L. and Dietrich, W.E. (1987) "Size and location of colluvial landslides in a steep forested landscape; Erosion and sedimentation in Pacific rim", Proceedings of the Corvallis Symposium, August 1987, Inter. Assoc. of Hydro. Science Pub. 165, p. 39-48.

186. Rethati, L. (1983) "Distribution function of soil physical properties" In: Proceedings, 8th European conference on soil mechanics and foundation engineering, 1983; Helsinki, Finland: $405-410$

187. Ronold, K.O. (1989) "Probabilistic consolidation analysis with model updating", Jour. of Geotech. Engrg., Vol. 115, No. 2, pp. 199-210.

188. Rubin, J. (1968) "Theoretical analysis of two- dimensional transient flow of water in unsaturated and partly unsaturated soils", Proc., Soil Society of America, 32, pp. 607-617.

189. Sagar, B. and Kisiel, C.C. (1972) "Limits of deterministic predictability of saturated flow equations", Joint symposium on fundamentals of transport phenomena in porous media, Univ. of Guelph, Guelph Ontario, Canada.

190. Sangrey, D. A., Harrop-Williams, K. O. and Klaiber, J. A. (1984) "Predicting Groundwater Response to precipitation", Journal of Geotechnical Engineering Division, ASCE 110 (7), p. 957-975

191. Sakar, P.K., Bidwell, O.W. and Marcus, L.F. (1966) "Selection of characteristics for numerical classification of soils", Soil Science of America Proceedings, 30, pp. 269-272.

192. Schroeder, W. L. (1983) "Geotechnical properties of southeast Alaskan forest soils", USDA, Forest Service Report, Civil Engineering Department, Oregon State University, Corvallis, Ore., Dec.

193. Schroeder, W. L. and Filz, G. (1981) "Engineering properties of southeast Alaskan forest soils", Research report to U.S. Department of agriculture, Forest Service, Civil Engineering Department, Oregon State University. 
194. Schroeder, W. L. and Swanston, D. N. (1987) "Application of geotechnical data to resource planning in southeast Alaska", General Technical Report PNW-198. Corvallis, OR: U.S. Department of agriculture, Forest Service, Pacific Northwest Forest and Range Experiment Station, 22 p.

195. Schroeder, W. L. and Alto, J. V. (1983) "Soil properties for slope stability analysis: Oregon and Washington coastal mountains", Forest Science, 29 (4): 823-833.

196. Schultz, A. P. and Southworth, C. S. (1989) "Large bedrock landslides of the appalachian valley and ridge province of eastern north America", The Geological Society of Ameri, Special papers; 236.

197. Schultz, E. (1971) "Frequency distributions and correlations of soil properties", In Lumb, Peter, ed Proceedings, 1st international conference on applications of statistics and probability in soil and structural engineering, 1971 September: Hong Kong: 371-387

198. Schweppe, F.C. (1973) "Uncertain Dynamic Systems", Prentice-Hall, Inc., Englewood Cliffs, NJ.

199. Sidi, I. (1985) "Probabilistic prediction of friction pile capacities", thesis presented to dept. of civ. engrg. Univ. of Illinois of Urbana, I11., in partial fulfillment of the requirements for the degree of Doctor of Philosophy.

200. Sidle, R.C., Pearce, A.J. and O'Loughlin, C.L. (1985) "Hillslope stability and land use", Water Resources Monograph series No. 11. American Geophysical Union, washington D.C. $140 \mathrm{p}$.

201. Singh, A. (1970) "Shear strength and stability of Man-Made slopes", Journal of the soil mechanics and foundations division, ASCE, Vol. 96.

202. Sklash, M.G. and Farvolden, R.N. (1979) "The role of groundwater in storm runoff", Journal of Hydrology, Vol. 43, pp. 45-65.

203. Sloan, P. G., Moore, I. D. and Eigel, J. D. (1983) "Modeling surface and subsurface storm flow on Steady-slopping Forested Watersheds", Rep. 142, 167 pp., Water Res. Ins., University of Kentucky, Lexington, Kentucky.

204. Sloan, P. G. and Moore, I. D. (1984) "Modeling Subsurface Stormflow on steeply sloping Forested Watersheds", Water Res. Res., Vol. 20, No. 12, pp. 1815-1822.

205. Snow, D.T. (1986) "Rock fracture spacing, openings and porosities", Journal Soil Mech. Foundation Div. Proc. ASCE Vol. 94, 1968, P 73-91

206. Smith, J. (1988) "Decision analysis: a Bayesian approach", Chapman and Hall.

207. Smith, L. and Freeze, R.A. (1979) "Stochastic analysis of steady State groundwater flow in a bounded domain, 1. One-dimensional simulations", Water Res. Res., Vol. 15, No. 3, pp. 521-528. 
208. Shearer, J.W. (1990) "The accuracy of digital terrain models", In: Terrain Modelling in Surveying and civil engineering, edited by G. Petrie and Kennie, Pub. Whittles Publishing Services.

209. Shelberg, M.C., Moellering, H. and Lam, N. (1982) "Calculating the fractal dimensions of empirical cartographic curves", In: proceedings, Fifth International Symposium on computer assisted cartography ( auto carto V), P. 481-490.

210. Shreve, R.L (1966) "Statistical low of stream numbers", Journal of Geology 74:17-37.

211. Soil Conservation Service (1987) "Soil survey of Lewis County area, Washington", U.S. Dept. of Agriculture.

212. Spangler, M.G. and Handy R.L. (1982) "Soil Engineering", 4th ed. Harper \& Row, publishers, New York.

213. Spencer, E. (1967) "A method of analysis of the stability of embankments assuming parallel interslice forces", Geotechnique, Vol. 17, No. 1, pp 11-26.

214. Spencer, E. (1973) "Thrust Line criterion in embankment stability analysis", Geotechnique, Vol. 23, No. 1, pp. 85-100.

215. Strahler, A. N. (1964) "Quantitative geomorphology of drainage basins and channel networks", in V. T. chow (ed.) Handbook of Applied Hydrology, New York, McGrawhill, section 4-II.

216. Sultan, H. A. and Seed, H.B. (1967) "Stability of sloping core earth dams", Journal of the soil mechanics and foundations division, ASCE, Vol. 93, No. SM4, pp. 45-68.

217. Suzuki, H. and Matsuo, M. (1988) "Procedure of slope failure prediction during rainfall based on the back analysis of actual case records", Soils and Foundations, Vol. 28, No. $3,51-63$.

218. Suzuki, R. (1977) "Slope profiles and classification of slope types", surveying No. 7, 43-50 (in japanese).

219. Swanston, D.N. (1967) "Debris Avalanching in thin soils derived from bedrock", U.S. Forest Service Research Note, PNW-64, 7 p.

220. Tang, W.H., Sidi, I. and Gilbert, R.B (1989) "Average property in a random two state medium", J. Eng. Mech., ASCE, pp. 131-144.

221. Tang, W.H. and Gilbert, R.B. (1989) "Statistics of spatial average in a random two-state medium", Structural Safety, 6, pp. 271-282.

222. Tang, W.H. and Gilbert, R.B. (1988) "Average property in a 2-dimensional two-state random field model", Proc., Symp. on Stochastic Dynamics, Univ. of Illinois at UrbanaChampaign.

223. Tang, W.H., Yucemen, M.S. and Ang, A.H-S. (1976) "Probability based short term stability of slopes", Canadian Geotechnical Journal, 13 (3): 201-215. 
224. Tang, W.H. (1984) "Principals of probabilistic characterization of soil properties", In: bridge between theory and practice, pp. 74-89. New York: American Society of Civil Engineers.

225. Tang, W.H., Chowdhury, R.N. and Sidi, I. (1985) "Progressive failure probability of soil slopes", Proc. Int. Conf. Structural Safety and Reliability, Kobe III, 363-372.

226. Tang, W.H. (1971) "A Bayesian evaluation of information for foundation design", Proceedings, 1 st inter. conf. on applic. of stat. and prob. for soil and struc. engin., Hong Kong, pp. 173-185.

227. Tang, W.H. and Ang, A.H. (1973) "Modeling, analysis and updating of uncertainties", Prepr. No. 2016, ASCE, Nat. Struct. Eng. Meet. San Francisco, Calif.

228. Tang, W.H. (1981) "Updating reliability of offshore structures", Proc. Symp. on Probabilistic methods in structural Engineering, ASCE Nat. Convention, St. Louis, Mo. October, 139-156.

229. Taylor, D.W. (1948) "Fundamentals of Soil Mechanics", John Wiley and Sons, New York.

230. Terzaghi, K. and Peck, R.B. (1967) "Soil mechanics in engineering practice", John Wiley \& Sons, Inc., New York.

231. Terranova, T.F. and Kochel, R.C. (1987) "Multivariate analysis of factors related to debris avalanching in Nelson County, central Virginia", Geological Society of America Abstracts with programs, v. 19, p. 866.

232. Tsukamoto, Y. and Kusakabe, O. (1984) "Vegetation influences on debris slide occurrences on steep slopes in Japan", In:Proceedings, Symposium on effects of forest land use on erosion and slope stability, 1984, May 7-11: Honolulu, Hawaii: 63-72.

233. Tsukamoto, Y. and Minematsu, H. (1987) "Hydrogeomorphological characteristics of a zero-order basin", IAHS Publ. No. 165,61-70.

234. U.S. Army Corps of Engineers (1956) "Snow Hydrology: Summary report of snow investigations", North Pacific Div. Corps of Engineers, Portland, OR, 437p.

235. United States Geological Survey (1990) "Digital Elevation Models", Data Users Guide 5.

236. Vanmarcke, E.H. (1983) "Random Fields", The MIT Press, 382 p.

237. Vanmarcke, E.H. (1974) "Decision analysis in dam safety monitoring", Proceedings, Engineering Foundation Conference on the Safety of Small Dams, Henniker, N.H., ASCE, pp. 127-148.

238. Vanmarcke, E.H. (1977) "Probabilistic modeling of soil profiles", Journal of the geotechnical engineering division, ASCE, Vol. 103, No. GT11, Proc. Paper 13364, pp. 1227-1246. 
239. Varnes, D.J. (1978) "Slope movement; types and process", In: Landslides analysis and control, Special Report 176, Transportation research board, Commission on sociotechnical systems, National research council, National Academy of science, Washington D.C., pp. 11-33.

240. Verduin, J. R. (1987, "PC STABLE5M Description of modifications" Internal report in ground Engineering No. 141, School of civil Engineering, Purdue University, West Lafayette, Indiana, August.

241. Vetter, W.J. (1973) "Matrix calculus operations and Tatlor expansions", SIAM Rev., 15(2), pp. 532-369.

242. Vieux, B.E. (1991) "Geographic information systems and non-point source water quality and quantity modelling", Int. J. Hydrological Process, 5(1), 101-113.

243. Vieux, B.E. (1993) "DEM aggregation and smoothing effects on surface runoff modeling", Journal of computing in civil engineering, Vol. 7, No. 3, pp. 310-338.

244. Warren, J.E. and Price, H.S. (1961) "Flow in Heterogeneous Porous Media", Soc. Pet. Eng. J., Vol. 1, pp. 153-169.

245. Whitman, R.V. (1984) "Evaluating calculated risk in geotechnical engineering", Journal of the geotechnical engineering division, ASCE, Vol. 110, No. GT2, pp. 145-188.

246. Wiberg, E.J. (1990) "The probability distribution of snowmelt in clearcuts from a rainon-snow event in the central cascades of washington", Master Thesis, The Ohio State University

247. Wieczorek, G. F. and Sarmiento, J. (1983) "Significance of storm intensity-duration for triggering of debris flows near La Honda, California", In: Geological Society of America, Abstracts with programs, v. 15, no. 5, p. 289.

248. Wieczorek, G. F. (1987) "Effect of rainfall intensity and duration on debris flows in central Santa Cruz Mountains, California", In: Costa, J. E., and Wieczorek, G. F., (eds.), Debris flows/avalanches; process, recognition, and mitigation: Reviews in Engineering Geology, Geological Society of America, v. 7, p. 93-104.

249. Williams, G. P. and Guy, H.P. (1973) "Erosional and depositional aspects of Hurricane Camille in Virginia, 1969", U.S. Geological survey professional paper 804, 80 p.

250. Wilson C. J. and Dietrich W. E. (1987) "The contribution of bedrock groundwater flow to storm runoff and high pore pressure development in hollows", IAHS Publ. No. 165,49-59.

251. Wilson, R.C. (1989) "Rainstorms, Pore pressures, and debris flows: a theoretical framework", Inland geological society, Vol. 2., pp. 101-117.

252. Wittke, W. (1973) "General report on the symposium: Percolation through fissured rock", Bull. Intern. Assoc. Eng. Geol., pp. 3-28. 
253. Wolfe, C.M. and Hachich, W. (1989) "Rain-induced landslides in southeastern Brazil", ICSMFE., 12., Rio de Janiero, Proc.

254. Wright, S.G. (1969) "A study of slope stability and undrained shear strength of clay shales", Thesis presented in partial fulfillment of the requirements of the degree of Doctor of philosophy to the University of California, Berkley, USA.

255. Wyllie, D.C., McCammon, N.R. and Brumund, W. (19 ) "Planning slope stabilization programs by using decision analysis", Transportation research records 749, p. 34-39.

256. Wu, T.H., Merry, C.J., Abdel-Latif, M.A. and Benosky, C.P. (1993) "Landslide hazard mapping, 1. prediction of piezometric levels", report submitted to Timber/Fish/Wildlife. Coop. Monitoring, Elevation, Research Committee (CMER).

257. Wu, T.H. (1976) "Investigation of landslides on Prince of Wales Island, Alaska", Geotechnical Engineering report No. 5, Dept. of Civil Engineering, Ohio State University, Columbus, Ohio, Feb.

258. Wu, T.H., and Kraft, L.M. (1967) "Probability of foundation Safety", Journal of the soil mechanics and foundations division, ASCE, Vol. 93, No. SM5, pp. 213-231.

259. Wu, T.H. and Kraft, L.M. (1970) "Safety analysis of slopes", Journal of the soil mechanics and foundation division, ASCE, Vol. 96 No. SM2, Proc. paper 7174, Mar., 1970, pp. 609-630.

260. Wu, T.H., Beal, P.E., and Lan, C. (1988a), "In situ shear test of soil-root systems", ASCE, Journal of Geotechnical Engineering, 114(12): 1376-1394.

261. Wu, T.H., McOmber, R.M., Erb, R.T., and Beal, P.E. (1988c) "Study of soil-root interaction", ASCE, Journal of Geotechnical Engineering, 114(12): 1351-1375.

262. Wu T.H., Martinez, R.E. and Kjekstad, O. (1984) "Stability of Ekofisk Tank: Reliability Analysis", Journal of Geotechnical Engineering, Vol. 110, No. 7, pp. 938-956.

263. Wu, T.H. (1984) "Effect of vegetation on slope stability", Transportation Research Records 965. Washington DC, Transportation Research Board: 37-46.

264. Wu, T.H., McKinnell, W.P., and Swanston, D.N. (1979) "Strength of tree roots and landslides of Prince of Wales Island", Alaska, Canadian Geotechnical Journal. 16(1): 19-33

265. Wu, T.H. and Baladi, G. Y. (1986) "The effect of grain characteristics on the limiting densities and angle of repose of cohesionless soils", Preprint, Transportation Research Board annual meeting; 1986 January; Washington DC.

266. Wu, T.H., Tang, W.H., Sangrey, D.A. and Beacher, G.B. (1989) "Reliability of offshore foundations-State of the art", Jour. of geotech. eng., Vol. 115, No. 2.

267. Wu, T.H., and Swanston, D.N. (1980) "Risk of landslide in shallow soils and its relation to clearcutting in Southeastern Alaska", Forest Science, 26:495-510. 
268. Wu, T.H. (1989) "Variability of geological materials", In: The Art and Science of Geotechnical Engineering, E.J. Cording, W.J. Hall, J.D. Haltiwanger, A.L. Hendron Jr., G. Mesri, ed. Prentice Hall, Englewood Cliffs, NJ. 221-239.

269. Wu, T.H., Lee, I.M., Potter, J.C. and Kjekstad, O. (1987) "Uncertainties in evaluation of strength of marine sand", Jour. of geotech. eng., Vol. 113, No. 7.

270. Wu, T.H., Potter, J.C. and Kjekstad, O. (1986) "Site exploration for offshore structures", J. Geotechnical Engineering, 112 (11) pp. 981-1000.

271. Wu, T.H. (1991) "Soil stabilization using vegetation", Proc. of workshop, Michigan university, Am Arbor

272. Yong, R.N. (1984) "Probabilistic nature of soil properties", In: bridge between theory and practice, pp. 19-73. New York: American Society of Civil Engineers.

273. Yucemen, M.S. and Tang, W.H. (1975) "Long term stability of soil-slopes: a reliability approach", Proc. of 2nd Int. Conf. on applications of statistics and probability in soil and structural engineering, 2, 215-229.

274. Yucemen, M. S., Tang, W.H. and Ang, A. H-S. (1973) "A probabilistic study of safety and design of earth slopes", Civil Engineering Studies, Structural research series No. 402, University of Illinois, Urbana, III., July, 1973.

275. Zaradany, H. (1978) "Boundary conditions in modelling water flow in unsaturated soils", Soil Sci. 125(2), 75.

276. Zaslavsky, D. and Sinai, G. (1981) "Surface Hydrology: I, II, III, IV, and V", Journal of the Hydraulics Division, ASCE, Vol. 107.

277. Ziemer, R.R. (1981a) "Roots and the stability of forested slopes", In: Erosion and sediment transport in Pacific rim steeplands: Proceedings of a symposium: 1981 January 25-31: Christchurch, New Zealand. Publication 132, London: International Association of Hydrological Sciences: 341-361.

278. Ziemer, R.R. (1981b) "The role of vegetation in the stability of forested slopes", In: Proceedings, International Union of Forestry Research Organizations XVII world conference; 1981 September; Kyoto, Japan: 1-15.

279. Ziemer, R.R. and Albright, J.S. (1987) "Subsurface pipeflow dynamics of north-coastal california swale systems", IAHS Publ. No. 165,71-80

280. Zing, Z. (1988) "Three-Dimensional Stability analysis of concave slope in plane view", Jour. of Geotech. Engrg., Vol. 114, No. 6, pp. 658-671. 